\title{
RMIT
}

UNIVERSITY

\section{Looking beyond traditional bibliotherapy: a new view}

A thesis submitted in fulfilment of the requirements for the degree of Doctor of Philosophy

Susan McLaine

Bachelor of Arts (Honours) (Victoria University, Melbourne)

School of Accounting, Information Systems \& Supply Chain

College of Business \& Law

RMIT University

March 2021 


\section{Declaration for candidates submitting a thesis}

I certify that except where due acknowledgement has been made, the work is that of the author alone; the work has not been submitted previously, in whole or in part, to qualify for any other academic award; the content of the thesis is the result of work which has been carried out since the official commencement date of the approved research program; any editorial work, paid or unpaid, carried out by a third party is acknowledged; and, ethics procedures and guidelines have been followed.

\section{Declaration statement for candidates who received Australian Government funding}

I acknowledge the support I have received for my research through the provision of an Australian Government Research Training Program Scholarship.

Susan McLaine

15 March 2021 


\section{Acknowledgements}

My strong passion and belief in the healing power of literature, otherwise known as bibliotherapy, has nourished and sustained me on this thesis journey.

I have held dear a sentence by poet Mary Oliver while writing this thesis. They are by poet Mary Oliver. 'There is nourishment in books... fires for the cold, ropes let down for the lost, something as necessary as bread in pockets of the hungry' (Oliver 1994, p. 122).

Throughout the writing of this thesis, there has been many times that people have 'let down ropes' when I have felt lost, and I thank:

For their words so eloquently written, writers of literary texts who give us a way to explore the feelings and thoughts sitting deep within us. These writers' words have inspired me to think deeply and offered comfort when I have used literature to get through challenging times.

The 17 research participants for sharing their experiences. The facilitators so generously gave much time, thought, emotion, and resources into Book Well. And their group participants found joy, stimulation, and comfort in taking part in these groups. I thank them for sharing their learnings with me to advocate for something we all together believe is so tremendously powerful and important to develop. Thank you for your trust, and I hope together we achieve this aim.

Supervisors: Dr Sue Reynolds and Dr June Allan for both generously staying with me through retirement; Dr Paul Mercieca for early supervision; Dr Huan Vo-Tran and Dr Elizabeth Tait for late supervision. However, special thanks need to go to Dr Sue Reynolds. This thesis journey has been challenging and, without Dr Reynolds' patience and support, one that may not have been completed.

To State Library Victoria, for providing the training and supporting my study in the area of bibliotherapy.

To all the people who have talked with me, helped me develop thinking and suggested books to read especially Andrew Hiskens and John Marsden.

And to friends who have heard more about bibliotherapy than they probably ever wanted to hear but listened, including but not limited to Alan White, Christine Andell, Elizabeth Mackenzie, Jane Tanner, Jaq Grantford, Jeannie Campbell, Manorani Guy, Matt Van Hasselt, Michael Chiller, Mike Shuttleworth, Pam Saunders and Robyn Ellard.

To the generous spirited people who helped me get over difficult times at different stages of this thesis journey including but not limited to Aneesa Iqbal, Brenda Harrison, Eadie Miller, Ehdena Khomami, Emma Last, Fiona Lee, Jacinta Halloran, Jim Henderson, Jo Crabbe, Margo Fields, Norma Jones, Paula Kelly-Paull, Sue Herringslake, Tasha Mannes, Ros Handley, Tony Camerilli, Winsome Caunce.

To the gals, Gaye, Hanan, Heather, Kim, Liliane, Lynne, Mary, Melissa, Natasha, Pamela, Sims, Sophie, Suzanne, Ursula.

My bibliotherapy soul mate, Jennie Bolitho, for her inspiration, guidance and wonderful bibliotherapy conversations!

Special thanks to Jeff Prentice and Peter Jeppesen, dear departed friends whose interest and 
support of my bibliotherapy work I will always hold dear.

And lastly, but most importantly, my family, for the years I have been working on this thesis instead of having family time. And most especially, my son Jasper, whose support over these years has never diminished, urging me on when I was disheartened and helping out to free my time to study. This thesis is dedicated to you, my amazing son.

I, Susan McLaine, want to make a positive change in the world. And to do this I want to revolutionize bibliotherapy-the thinking in this $\mathrm{PhD}$, is helping me to do it. 


\section{Contents}

Declaration $\quad$ ii

Acknowledgements iii

Abstract $\quad$ xii

Chapter One: Introduction 1

1.1 Introduction to bibliotherapy 1

1.2 A shift in health and wellbeing 2

1.3 Wellbeing 3

1.4 Background to the training 4

1.5 Research rationale $\quad 7$

$\begin{array}{lll}1.6 & \text { Research question, aims and objectives } & 7\end{array}$

$\begin{array}{ll}1.7 \text { Methodology overview } & 8\end{array}$

1.8 Thesis structure 9

1.9 Research contribution 9

$\begin{array}{ll}2.0 \text { Chapter One concluding comments } & 10\end{array}$

Chapter Two: Literature review 11

2.1 A brief history of therapeutic reading 12

$\begin{array}{ll}2.2 \text { Bibliotherapy definitions } & 14\end{array}$

$\begin{array}{ll}2.3 \text { Objectives of bibliotherapy } & 15\end{array}$

$\begin{array}{lll}2.4 \text { Multi-disciplinary views of bibliotherapy } & 19\end{array}$

$\begin{array}{ll}2.4 .1 & \text { Bibliotherapy in clinical areas } \\ & 19\end{array}$

2.4.1.1 Bibliotherapy and hospitals $\quad 19$

2.4.1.2 Bibliotherapy in psychiatric hospitals 20

2.4.1.3 Bibliotherapy in veterans' hospitals 22

2.4.1.4 Bibliotherapy and general practitioners 23

2.4.1.5 Bibliotherapy within counselling 25

2.4.1.6 Internet bibliotherapy 25

2.4.2 Bibliotherapy in non-clinical areas 28

2.4.2.1 Bibliotherapy in the education system 28

2.4.2.2 Bibliotherapy and the arts 30 
2.4.3 Creative bibliotherapy in community settings

2.4.3.1 Bibliotherapy in criminal justice 34

2.4.3.2 Bibliotherapy within aged care $\quad 35$

2.5 The effectiveness of bibliotherapy 35

2.5.1 Bibliotherapy used within clinical settings 36

2.5.2 The success of bibliotherapy to effect wellbeing 37

2.5.3 The success of creative bibliotherapy to effect wellbeing 38

2.6 Creative bibliotherapy training 41

2.7 Chapter Two concluding comments 44

Chapter Three: Methodology and methods $\quad 46$

3.1 Methodology 46

3.1.1 Interpretative phenomenological analysis (IPA) 46

3.1.2 Theoretical orientations of IPA 49

3.1.2.1 Phenomenology 49

3.1.2.2 Hermeneutics 49

3.1.2.3 Interpretation 51

3.1.3 Strengths and limitations of the IPA approach 52

3.1.3.1 Strengths of the IPA approach 52

3.1.3.2 Suitability of an IPA approach 53

3.1.3.3 Motivations for researchers to use an IPA approach 53

3.1.3.4 Limitations of IPA 55

3.1.3.5 Manual analysis $\quad 57$

3.1.4 How IPA is being used to answer the research question 58

3.1.4.1 Reflexivity 58

3.1.4.2 Rigor and validity $\quad 59$

$\begin{array}{ll}3.1 .4 .3 & \text { Idiographic approach }\end{array}$

$\begin{array}{ll}3.1 .5 & \text { Analytical approach } \\ \end{array}$

3.1.5.1 The hermeneutic circle 61

3.1.5.2 The double hermeneutic 61

$\begin{array}{ll}3.2 \text { Methods } & 62\end{array}$

3.2.1 Recruiting research participants 62

3.2.2 Ethics 62 
3.2.3 Interview question development 63

3.2.4 Data recording and storage 64

3.2.5 Identifying themes 64

3.2.5.1 Coding and theme development process 64

3.2.5.2 Themes 66

$\begin{array}{lll}3.3 & \text { Theoretical approach } & 67\end{array}$

$\begin{array}{ll}\text { 3.3.1 Grounded theory } & 67\end{array}$

$\begin{array}{ll}3.4 & \text { The research participants }\end{array}$

$\begin{array}{ll}3.5 \text { Chapter Three concluding comments } & 70\end{array}$

Chapter Four: Bibliotherapy training $\quad 72$

4.1 Research participant definitions of bibliotherapy 72

$\begin{array}{ll}4.2 \text { Therapy } & 74\end{array}$

4.2.1 Different concepts of therapy within bibliotherapy 74

4.3 Participants' expectations of bibliotherapy training $\quad 75$

4.3.1 Expectation/Reason 1: To learn new skills 75

4.3.2 Expectation/Reason 2: To increase vocational opportunities 76

4.3.3 Expectation/Reason 3: To develop a community program 76

4.3.4 Expectation/Reason 4: Reader development 77

4.3.5 Expectation/Reason 5: To support community mental health 78

4.3.6 Expectation/Reason 6: To increase understanding of bibliotherapy $\quad 79$

4.3.7 Expectation/Reason 7: Involuntary participation 79

4.4 Meeting expectations $\quad 80$

4.5 Expectations of partnership delivery 82

4.6 Agreement to run groups 83

4.7 UK and Australian program variations in expectations 84

$\begin{array}{lll}4.8 & \text { Chapter Four concluding comments } & 87\end{array}$

Chapter Five: 'Biblio' 89

5.1 Reading materials 89

5.1.1 Reading material provided by The Reader Organisation 90

5.1.2 Independently selecting reading materials 92

5.1.3 Process of selecting reading material texts 95 
5.1.4 Bias in independent reading material selection 96

5.1.5 Time required for reading material selection 97

$\begin{array}{lll}5.2 & \text { Reading aloud } & 99\end{array}$

$\begin{array}{ll}\text { 5.2.1 Reading aloud to adults } & 100\end{array}$

5.2.2 The experience of reading aloud 101

$\begin{array}{ll}\text { 5.2.3 Preparing to read aloud } & 101\end{array}$

5.3 Breaking the flow of reading aloud 103

$\begin{array}{ll}5.3 .1 \text { Pausing } & 103\end{array}$

$\begin{array}{ll}\text { 5.3.2 Shared reading } & 104\end{array}$

$\begin{array}{ll}\text { 5.3.3 Silence } & 106\end{array}$

$\begin{array}{ll}5.4 \text { Chapter Five concluding comments } & 108\end{array}$

Chapter Six: Therapy part A: Partnerships and delivery 110

6.1 Enabling community wellbeing $\quad 110$

6.1.1 Libraries as facilities for community wellbeing 110

6.1.2 Motivations to provide community wellbeing programs 113

$\begin{array}{ll}6.2 \text { Therapeutic alliances } & 115\end{array}$

6.2.1 Forming organisational alliances to run bibliotherapy groups 115

$\begin{array}{ll}\text { 6.2.2 Delivery partnerships } & 117\end{array}$

$\begin{array}{ll}6.3 \text { Group delivery } & 119\end{array}$

$\begin{array}{ll}\text { 6.3.1 Groupwork processes } & 120\end{array}$

6.3.1.1 The physical environment 120

6.3.1.2 Distractions 122

6.3.1.3 Group norms 123

6.3.1.4 The establishment of safety in a group 124

$\begin{array}{ll}\text { 6.3.1.5 Leading a group } & 125\end{array}$

$\begin{array}{ll}\text { 6.3.2 Non-verbal communication } & 128\end{array}$

6.4 Shared reading and listening $\quad 129$

$\begin{array}{ll}\text { 6.4.1 Shared listening } & 130\end{array}$

6.4.2 Creating a listening atmosphere 131

6.4.3 Silence and listening 132

6.4.4 Types of listening 132

$\begin{array}{lll}6.5 & \text { Group discussion } & 133\end{array}$ 
6.5.1 Enabling group discussion 134

$\begin{array}{ll}6.5 .2 \text { Integrating group discussion } & 135\end{array}$

6.5.3 Expanding group discussion 136

$\begin{array}{ll}\text { 6.5.4 Personal disclosure by facilitators } & 139\end{array}$

6.6 Chapter Six concluding comments 140

Chapter Seven: Therapy part B: Achieving therapeutic outcomes 141

7.1 Engaging in hermeneutic processes 142

$\begin{array}{ll}\text { 7.1.1 Hermeneutic circle } & 142\end{array}$

$\begin{array}{ll}\text { 7.1.2 Double hermeneutic } & 143\end{array}$

$\begin{array}{lll}7.2 & \text { Therapy considerations } & 144\end{array}$

7.2.1 What is therapy? 144

7.2.2 Therapy in clinical and non-clinical settings 144

$\begin{array}{lll}7.3 \text { Wellbeing considerations } & 145\end{array}$

$\begin{array}{ll}\text { 7.3.1 What is wellbeing? } & 145\end{array}$

7.3.2 Wellbeing and creative bibliotherapy 146

7.3.3 Wellbeing and a sense of belonging and social connectedness 148

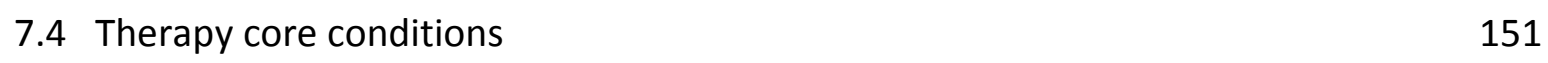

7.5 Therapy core conditions in creative bibliotherapy 153

7.5.1 Unconditional positive regard 153

$\begin{array}{ll}\text { 7.5.2 Empathy } & 155\end{array}$

7.5.2.1 Empathy development in group members 158

$\begin{array}{ll}\text { 7.5.3 Congruence } & 159\end{array}$

$\begin{array}{ll}7.6 \text { Therapeutic relationships } & 160\end{array}$

$\begin{array}{ll}\text { 7.6.1 Interpersonal relationships } & 160\end{array}$

$\begin{array}{ll}\text { 7.6.2 Connecting with self } & 161\end{array}$

7.7 The therapeutic concept of holding the 'space' 163

$\begin{array}{ll}\text { 7.7.1 Literary texts holding the 'space' } 163 & 163\end{array}$

7.8 The therapeutic outcome of 'biblio' and 'therapy' 164

$\begin{array}{ll}\text { 7.8.1 Emotions } & 165\end{array}$

7.8.2 Emotions and literary texts 168

$\begin{array}{ll}\text { 7.8.3 Emotions and meaning-making } & 170\end{array}$

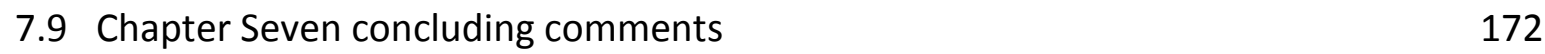


$\begin{array}{lll}8.1 \text { Broad research findings } & 174\end{array}$

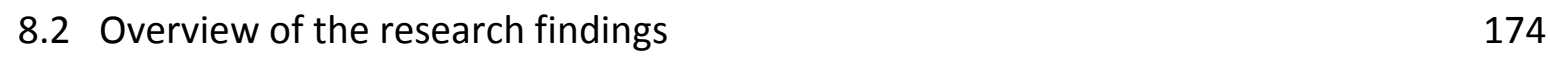

$\begin{array}{ll}\text { 8.3 Key findings in the Australian program } & 174\end{array}$

$\begin{array}{ll}\text { 8.3.1 Social connectedness } & 175\end{array}$

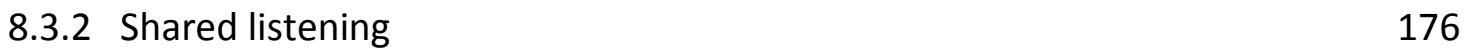

8.3.3 Literature as a therapeutic tool 176

8.3.4 Meeting requirements of public libraries into the future 176

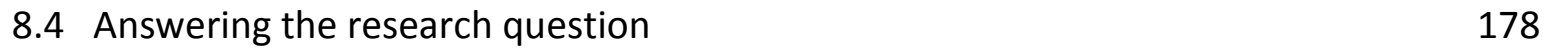

$\begin{array}{ll}8.5 \text { Limitations of the research } & 179\end{array}$

8.6 Recommendations for future creative bibliotherapy training 181

8.6.1 Bibliotherapy training - recommendations 183

8.6.1.1 Recommendation one (personal): Core conditions 183

8.6.1.2 Recommendation two (personal): Building on personal 184 attributes

8.6.1.3 Recommendation three (personal): Self-awareness 184

8.6.1.4 Recommendation four (personal): Pre-training therapeutic 184 transparency

8.6.1.5 Recommendation five (personal): Establishing 184 bibliotherapy as a therapeutic offering

8.6.1.6 Recommendation six (facilitation): Group therapeutic 185 transparency

8.6.1.7 Recommendation seven (facilitation): Groupwork 185 knowledge

8.6.1.8 Recommendation eight (facilitation): Listening awareness 185 and development

8.6.1.9 Recommendation nine (facilitation): Emotional 185 complexities

8.6.1.10 Recommendation ten (facilitation): Selecting literary texts $\quad 186$

8.6.1.11 Recommendation eleven (facilitation): Engaging with 186 literary texts

8.6.1.12 Recommendation twelve (facilitation): Audience 186 awareness

8.6.1.13 Recommendation thirteen (facilitation): Mental health 186 understanding

8.6.1.14 Recommendation fourteen (facilitation): Developing 
therapeutic alliances

8.7 Chapter Eight concluding comments

References

Appendix One: Ethics approval

Appendix Two: Interview questions

Appendix Three: Transcription sample

Appendix Four: Training manual contents

235

Appendix Five: Coding framework

236

\section{Diagrams}

Diagram 1: Wellbeing and resources and challenges

\section{Tables}

Table 1: United Kingdom and Australian nomenclature

Table 2: Addressing IPA limitations

Table 3: Contrasting IPA and grounded theory

Table 4: Individual research participant details

Table 5: Techniques for training in creative bibliotherapy 


\section{Abstract}

For the purposes of this research, bibliotherapy is defined as using books to help people deal with psychological, social and emotional challenges. Traditional bibliotherapy, as used with Cognitive Behavioural Therapy (CBT), is a well-established therapeutic intervention within clinical settings where health professionals prescribe reading non-fiction self-help books to help people deal with psychological, social and emotional issues. This research looks beyond the traditional use of nonfiction texts within CBT in clinical settings, to creative bibliotherapy, which is facilitated by nonclinical practitioners using literary texts in community-based group settings to promote wellbeing. An objective of this study was to gain a deeper understanding of the separate 'biblio' and 'therapy' elements to better understand how the relationship between them can be developed and applied by facilitators to support the wellbeing of people participating in creative bibliotherapy sessions. This study focuses on the perceptions of non-clinical facilitators who have undergone creative bibliotherapy training and subsequent program delivery. This study contributes to the body of knowledge of the importance of the role of the facilitator in bibliotherapy.

United Kingdom and Australian health guidelines, Better mental health for all: a public health approach to mental health improvement (Regan et al., 2016) and The Victorian public health and wellbeing plan 2019-2023 (Victoria Government, 2019), are positioning the promotion of wellbeing at the core of government health policies. In these policies, community-based programming is identified as a significant way to promote wellbeing, through services that focus on fostering community engagement within community settings. This current study suggests that suitably trained creative bibliotherapy facilitators may promote wellbeing by providing opportunities for people to make meaningful connections within communities and to engage with literature to support the development of a more positive state of mind.

Semi-structured interviews were conducted focusing on the experiences of facilitators who had undertaken creative bibliotherapy training, and an interpretative phenomenological analysis approach used to consider the effectiveness of the training in preparing them to deliver bibliotherapy. Analysis of the interview data has revealed the need to include 'biblio' and 'therapy' more equally than in past delivery of bibliotherapy - where books were the primary focus - in order to help maximise the wellbeing of people participating. 


\section{Chapter One: Introduction}

This thesis investigates the effectiveness of creative bibliotherapy training provided to nonclinical facilitators in Australia. It presents a qualitative analysis of the preparation of nonclinical facilitators to deliver bibliotherapy in community reading groups, using literary texts, as a technique to support promotion of the wellbeing of group participants. Throughout this thesis, these non-clinical facilitators are referred to as facilitators (as they were in the training) and research participants (as they were subsequently, for this research project) interchangeably. This brief introductory chapter summarises the context of the research project and provides an outline of the research question, aims and objectives, rationale and methodology.

\subsection{Introduction to bibliotherapy}

Bibliotherapy commonly refers to using literature, of any genre, to help people deal with psychological, social and emotional challenges. The word 'bibliotherapy' originates from the Greek words for book, 'biblion', and healing, 'therapeia.' An American, Samuel Crothers, combined the Greek words in 1916 to describe bibliotherapy as a process in which literature was prescribed as medicine for a variety of ailments.

Bibliotherapy is a therapeutic intervention used as an approach within clinical settings, where health professionals prescribe non-fiction self-help books to support people experiencing mental health issues (Monroy-Fraustro et al., 2021). Creative bibliotherapy is a form of bibliotherapy using imaginative literature in non-clinical settings to promote psychological and social wellbeing. In a clinical setting bibliotherapy is a form of cognitive behavioural therapy (CBT). In CBT, self-help books can provide a range of techniques for changing thoughts, feelings and behaviours (Neenan \& Palmer 2012, p. xvi). Books used within a CBT context are seen as an effective adjunct treatment for mental ill-health.

In its early forms bibliotherapy was used in psychiatric hospitals as a treatment for the mentally ill. By the mid-twentieth century libraries had become established in many European and American psychiatric hospitals and bibliotherapy had been mainly used with hospitalised adults to support mental health. Towards the end of World War I libraries had also become established in many veterans' hospitals, and bibliotherapy was administered to support an increase in demand to treat military veterans suffering emotional trauma. 
The deinstitutionalisation of mental health care in the 1970s further evolved bibliotherapy. Bibliotherapy began to move away from the hospital environment and into diverse areas of the community. As with Crothers' original description of bibliotherapy, many subsequent definitions are broad, allowing scope for the use of both fiction and non-fiction in a variety of applications for a range of purposes. The one thing in common in all manifestations of bibliotherapy is the use of literature to help people deal with psychological, emotional and social challenges.

Since the 1970s bibliotherapy has also come to include literary texts read aloud by a trained facilitator, followed by discussion to interpret and make meaning of the text. This form of bibliotherapy is known as creative bibliotherapy and is commonly delivered in group sessions (Gregory et al., 2004). In creative bibliotherapy a facilitator selects a text to provide the primary structure and focus for reading aloud and group discussion to encourage emotional engagement with the text (Shechtman \& Nir-Shfrir, 2008). The term creative bibliotherapy broadly refers to using imaginative literature as a pathway to personal perspectives of, and insight into, psychological, social and emotional challenges (Pettersson, 2018). This view of creative bibliotherapy is shared by the researcher.

Creative bibliotherapy programs were first delivered in the United Kingdom (UK) in community settings in 1972 and were prominent in the UK by the end of the first decade of the twenty-first century (Brewster 2011, p. iii). Creative bibliotherapy programs were first delivered in the United States in 1991 and in Australia in 2010.

\subsection{A shift in health and wellbeing}

In recent years, both in Australia and internationally, there has been a shift towards the delivery of community-based health services to support improving people's health and wellbeing in order to reduce dependence on traditional medical models (Baum, 2002; Garrubba \& Melder, 2019; England NHS, 2016; Woods et al., 2016). Research literature indicates that there is a contemporary change in the direction of health care from hospitalbased to community-based settings for health and wellbeing practice and programs in groups (Aveling et al., 2017; Bossers et al., 1997; Friedland et al., 2001; Lloyd et al., 2002; Mason, 1998). Garrubba and Melder (2019, p. 2) assert that healthcare in Australia is being pushed towards development of large- and small-scale innovative community-based models of community delivery. 
Empirical research is beginning to develop a compelling narrative for the use of creative bibliotherapy within a community setting as a person-centred, collaborative group model, providing a foundation to respond to people's wellbeing and social needs, and to support psychological and emotional challenges. Data has shown benefits of creative bibliotherapy practice and demonstrates that bibliotherapy programs delivered in community locations, such as libraries, are an effective way of promoting wellbeing in community settings (Brewster, 2014; Hicks, 2006; Tukhareli, 2014). Creative bibliotherapy programs provide an informal, accessible, and cost-effective way of filling a unique wellbeing niche within community-based services and programs, and strengthen relationships between practitioners within health care and social sectors (Tukhareli, 2014).

The terms 'role-established' (traditional) and 'role-emerging' (non-traditional or alternative) (Bossers et al., 1997; Mulholland \& Derdall, 2005; Overton et al., 2009; Wood, 2005) assist in associating therapy with not only trained therapists in a clinical setting, but also with a broader incorporation of suitably trained facilitators within community settings. Facilitating creative bibliotherapy in community settings could be considered an emerging role in therapy.

\subsection{Wellbeing}

As outlined below in Section 1.6: Research questions, aims and objectives, the aim of this study is to understand how bibliotherapy can support the promotion of wellbeing of individuals and groups in society. To better understand this some definitions of wellbeing, and an overview of government policies addressing wellbeing, are included for context.

The World Health Organisation's (WHO) Constitution implicitly links wellbeing and quality of life (World Health Organisation, 1946). The WHO defined health 'as a state of complete physical, mental, and social well-being rather than merely the absence of disease or infirmity'; encompassing mental and social elements and thus acknowledging the broader dimensions of health. The WHO also asserted that the 'enjoyment of the highest attainable standard of health is one of the fundamental rights of every human being' and argued that health is a precondition for wellbeing and quality of life (World Health Organisation, 2017).

Within Australia, wellbeing is considered from many perspectives, including levels of connection, disconnection and engagement with others, social acceptance, community support, and the degree of experiencing negative and positive feelings (Australian Bureau of 
Statistics, 2020; Organisation for Economic Co-operation and Development, 2020). Statements in both the UK and Australia provide evidence that global health guidelines are positioning the promotion of general wellbeing for individuals and groups in society as part of government thinking and health policies: in the UK Better mental health for all: a public health approach to mental health improvement (Regan et al., 2016), and The Victorian public health and wellbeing plan 2019-2023 (Victoria Government, 2019).

UK and Australian developments indicate the significance of community-based programs, which can impact wellbeing. 'Wellbeing' guidelines can be found in the UK National Institute for Health and Clinical Excellence (NICE) recommendations. The role of NICE is to guide 'NHS, local authorities, employers, voluntary groups and anyone else involved in delivering care or promoting wellbeing' (NICE n.d., para. 9). The NICE guidelines for the promotion of wellbeing include the use of literature as a practical strategy to support wellbeing. The NICE website advocates CBT and recommends using self-help books in areas of psychological wellbeing; that is, bibliotherapy.

Bibliotherapy, delivered by trained facilitators, can support individuals to take part in community activity and offers a way to feel a sense of belonging, especially for those experiencing social isolation. Creative bibliotherapy allows individuals to connect with other community members and develop a social network that can build a support system within the community.

'Wellbeing' means different things to different people; however, it is broadly considered to indicate quality of life and this can be promoted through meaningful interactions and connections. Wellbeing can be considered from many perspectives: a person, a family, a community, a population group, or a societal perspective (Organisation for Economic Cooperation and Development, 2015). Robinson and Billington (2013, p. 2) assert that creative bibliotherapy delivered in group sessions offers 'a practical way to improve wellbeing and foster social inclusion'.

\subsection{Background to the training}

The training for delivery of creative bibliotherapy in Australia was conducted in Melbourne in 2010 through a collaborative initiative of State Library Victoria (SLV), the Public Libraries Victoria Network (PLVN), and the Victorian Health Promotion Foundation, known as 
VicHealth. Support for the training came through VicHealth's (2010) Building health through arts and new media action plan which included in its objectives the aims of increasing social connection for participants, increasing involvement in community and group activities, and working in partnership across sectors.

A team of three trainers from The Reader Organisation (TRO) in the United Kingdom (UK), a charitable social enterprise, conducted the first course of its kind offered outside the UK. In the UK, TRO call their reading group program 'Get Into Reading' (GIR) and describe it 'as a form of creative bibliotherapy' using 'bibliotherapeutic principles' (Chamberlain \& McCullis 2013, p. 32).

The five-day intensive training was provided to 20 participants on the understanding that each newly trained facilitator would commit to the eventual implementation of a creative bibliotherapy program with a community partner, and would assist with evaluating delivery of the program established (State Library Victoria, 2010). No prior knowledge was required for the training and participants in the training were selected via an expression of interest (EOI) process from Victorian public library staff, and included one community partner.

Additionally, two other participants who worked with aged-care groups asked to attend and were allowed to do so.

Table 1: United Kingdom and Australian nomenclature

\begin{tabular}{|l|l|l|}
\hline Organisation name & United Kingdom & Australia \\
\hline $\begin{array}{l}\text { The Reader Organisation (TRO) } \\
\text { Now known as: The Reader } \\
\text { This study will refer to TRO }\end{array}$ & State Library Victoria (SLV) \\
\hline Training name & Read to Lead & Book Well \\
\hline Program name & $\begin{array}{l}\text { Get Into Reading (GIR) } \\
\text { Now known as: Shared Reading } \\
\text { This study will refer to GIR }\end{array}$ & Book Well \\
\hline
\end{tabular}

The 41-page training manual (2010, unpublished) for the 'Book Well' training in Melbourne comprised 11 pages addressing the practicalities of delivering the GIR program; the balance of the manual included photos, case studies, readings and information regarding the 
different settings in which it was delivered in the UK. The topics addressed were:

- $\quad$ Reading Aloud

- Choosing Materials

- What Makes a Get Into Reading Text?

- Facilitation Skills

- Preparing a Text

- $\quad$ Reading in Acute Mental Health Settings

- $\quad$ Reading with People with Dementia

- $\quad$ Reading with People from Racial Minority Backgrounds.

The full contents of the training manual are provided in Appendix Four.

The training was delivered over five days to the group as a whole and in smaller break-out groups. The larger group setting was used for broad discussion, watching videos of UK facilitators in action, and information delivery. The small break-out groups were used for practicing bibliotherapy sessions, with each trainee taking a turn as a facilitator while others played various roles in the group (e.g., a disruptive group participant), and provided feedback. Additionally, time was spent each day to develop a group performance of a Shakespearean play to be presented to the State Library Victoria leadership team and unrelated to bibliotherapy training.

My role in the training was as the coordinator of the 'Book Well' program in Australia. In January 2010 (two months prior to delivery of the 'Book Well' training), my employer, State Library Victoria, sent me to the UK to attend five days of intensive training in the 'Get Into Reading' program and build a relationship with TRO with the intention of three trainers from the TRO coming out to Australia in March 2010 to deliver the training in Melbourne. As 'Book Well' training coordinator, I was involved in organising all the trainers, trainees, and training requirements. After the training, my role extended to supporting the new bibliotherapy facilitators to develop programs and partnerships, sourcing and supplying suitable literary texts, and follow-up reporting. Before attending the UK training, I had delivered bibliotherapy groups and completed a Bachelor of Literary Studies Honours research study in bibliotherapy. 


\subsection{Research rationale}

It is important to understand more about the training necessary for delivering creative bibliotherapy so that it can support the wellbeing of individuals and groups in society. Creative bibliotherapy facilitates the links between 'biblio' and 'therapy' and it is important for non-clinical facilitators to understand this relationship for its successful delivery. In examining the relationship between 'biblio' and 'therapy' in bibliotherapy, the use of Aristotle's truism that 'the whole is greater than the sum of its parts' is very appropriate. It provides a valuable concept for considering bibliotherapy both as a whole and for its separate components. Deconstructing the separate components of bibliotherapy - 'biblio' and 'therapy' - allows for the possibility of a new understanding of the relationship between them, and therefore of possible outcomes of bibliotherapy. Understanding the interactive elements of the relationship between 'biblio' and 'therapy' provides an opportunity to look further at how their interaction can be developed to foster wellbeing.

\subsection{Research question, aims and objectives}

The focus of the thesis is the research participants' perspectives of the training they undertook in Melbourne, 2010 for facilitation of creative bibliotherapy, and particularly their understanding of the two elements of 'biblio' and 'therapy' in this practice. This context informed the research aim and objective, and the research question as given below.

The aim of this study is to analyse bibliotherapy group facilitators' perspectives of their creative bibliotherapy training to establish how the relationship between 'biblio' and 'therapy' can be developed and applied by non-clinical facilitators to support the promotion of the wellbeing of individuals and groups. To achieve this aim, the objective was established to investigate the experiences of facilitators from non-clinical backgrounds who had undertaken creative bibliotherapy training in Melbourne in 2010, and the effectiveness of the training in preparing them to deliver bibliotherapy in community settings in Australia.

Building on the aim and objective, the research question is:

How can the understanding of the relationship between 'biblio' and 'therapy' be developed in non-clinical facilitators and applied to support the promotion of the wellbeing of individuals and groups in society?

The research question was investigated by interviewing seventeen research participants to 
seek their recollections and opinions of how the training undertaken had prepared them to deliver creative bibliotherapy in community settings. The training experience of the research participants informed the researcher's central finding related to the relationship between 'biblio' and 'therapy' in creative bibliotherapy as it is currently understood by facilitators, and how that understanding could be developed in training for more effective delivery of creative bibliotherapy to support wellbeing (see 8.6: Recommendations for future bibliotherapy training).

\subsection{Methodology overview}

The research methodology employed interpretative phenomenological analysis (IPA) to examine the phenomenon of the lived experience of the research participants in their training for and delivery of creative bibliotherapy.

IPA fuses philosophies from phenomenology and hermeneutics (Smith, 1996a; 1996b), offering a method that is both descriptive (phenomenology) and interpretative (hermeneutics) in its approach (Pietkiewicz \& Smith, 2014). The use of IPA allows for comprehensive and thorough work focused on a small number of participants. IPA was used to analyse the data collected through semi-structured interviews of bibliotherapy facilitators. An in-depth study was conducted through the processes of the hermeneutic circle (Chapter 3.1.5.1) and the double hermeneutic (Chapter 3.1.5.2) which allow for more detailed examination of individual data within the total data collected.

Since IPA was developed in the mid-1990s (Smith, 1996a; 1996b) it has become an established, and significant, qualitative approach (Todorova, 2011). Although its foundations are in psychology, IPA has 'found a broad array of applications in healthcare contexts' (Ward \& Miller 2013, p. 14) and in a range of social science fields (Kirkham et al., 2015), including the arts (Southcott \& Joseph, 2014) and music therapy (Solli \& Rolvsjord, 2014). The broad recent uptake of IPA has been attributed to its strength in offering a structured approach with specific processes and guidelines for directing a study while maintaining a flexible and innovative position (Ward \& Miller, 2013). 


\subsection{Thesis structure}

This thesis is structured to support the objective of this study; that is, to gain a deeper understanding of the separate 'biblio' and 'therapy' elements in bibliotherapy and to better understand how the relationship between them can be developed and applied to support the wellbeing of people participating in bibliotherapy sessions.

The chapters to follow provide detailed discussion of these elements. Chapter Two presents a review of the literature relevant to this study. Chapter Three provides details on the chosen methodology and its application to answer the research question. Chapter Four looks at the participants' understanding of the relationship between 'biblio' and 'therapy' through analysis of the interview data collected. The themes of 'biblio' and 'therapy' are examined through an extended account of 'biblio' in Chapter Five and 'therapy' in Chapters Six and Seven. Chapter Eight provides concluding comments and offers limitations of this research study and recommendations for training inclusions to better prepare facilitators of creative bibliotherapy.

\subsection{Research contribution}

Previous studies of bibliotherapy have primarily used quantitative methods to examine traditional bibliotherapy application from the perspective of the service user. More recent qualitative studies of creative bibliotherapy acknowledge the importance of the role of the facilitator in delivering bibliotherapy, including: Billington et al. (2010); Brewster (2011); Centre for Research into Reading, Information and Linguistic Systems (CRILS) (2012); and two unpublished evaluations of the Book Well training at State Library Victoria in 2012, made available to the researcher in my role as the coordinator of the Book Well training to be considered in this research. The CRILS report findings note that facilitation is one of the most important components of bibliotherapy intervention (2012, p. 30). The report noted the importance of the role of the facilitator in choice and presentation of the reading material (pp. 8-9), the conduct of the session, including discussion (p. 9), and notes that training is necessary (p. 32). Billington et al., address the role of guiding emotional and intellectual responses to the literary stimuli $(2010$, p. 13), and the necessity for the facilitator to have expertise as an interpreter of narrative and poetry (p. 34). 
Despite the apparent crucial role of the facilitator in delivering creative bibliotherapy there are no known studies that address the experiences of those facilitating creative bibliotherapy sessions. The perspectives of facilitators themselves are missing from bibliotherapy research literature to this point in time. An important consideration for this study was that the findings are constructed from the experiences of the research participants who were all bibliotherapy facilitators. As briefly outlined above, IPA is both descriptive and interpretative, allowing the researcher to focus on an individual facilitator's understanding of their experience and consideration of similarities and differences between facilitators. Additionally, IPA encompasses experiences from the perspectives of the researcher, offering a deeper understanding and interpretation and a rich portrayal of overall experience. Through the use of IPA this research contributes original work to the body of knowledge about bibliotherapy, and in understanding the particular significance of the facilitator's role.

\subsection{Chapter One concluding comments}

The chapter has outlined the framework of this thesis and presented the research question, aims, rationale and methodological approach. It has also introduced the concept of wellbeing and it relevance to the research question and research aims.

The aims and objectives of this research study focussed on considering the effectiveness of the training from the perspective of the experiences of the facilitators who undertook the training rather than an evaluation of the training model itself. Using IPA as the methodological approach, the research adds to knowledge of the importance of the facilitator's role in delivering bibliotherapy, leading to recommendations for future training and research.

The next chapter will look at the methodology used to analyse the data; findings from the experiences of the facilitators who undertook the training and were participants in this research are discussed in Chapters Four to Seven. Chapter Eight proposes recommendations for future training and research in creative bibliotherapy. 


\section{Chapter Two: Literature review}

\section{Introduction}

Bibliotherapy has evolved in a variety of professions, and is interdisciplinary in nature. The multiple disciplines include the clinical areas of general medical practice, psychology, nursing, social work and counselling. The literature also reveals that the non-clinical areas of librarianship, education, criminal justice and occupational therapy utilise bibliotherapy. The people practicing, researching and writing about bibliotherapy include health professionals and people in other helping professions, for example, psychologists, physicians, general practitioners (GPs), therapists, counsellors, nurses, librarians and teachers. People who participate in bibliotherapy are described by a variety of terms including patient, client, participant, beneficiary, customer, patron, group member and reader.

Rubin (1979) reviewed the sources of bibliotherapy publications between 1970 and 1975 . Of the 131 articles included in the study, 35 percent appeared in librarianship journals and 65 percent in journals for other disciplines, including psychology, nursing and occupational therapy. Forrest (1998) reviewed the source of bibliotherapy publications between 1993 and 1997. Of the 111 articles included in this study, 20 percent appeared in librarianship journals and 80 percent in journals for other disciplines. These included 57 percent written by psychologists, 11 percent by nurses, 10 percent by social workers and two percent by other professional groups. Forrest determined that most of the research originated from the United States (US) (68 percent), followed by seven percent originating from the United Kingdom (UK). Within the Australian context, Forrest (1998, p. 161) comments on a 'lack of reading therapy [i.e., bibliotherapy] studies originating from Australia'.

More recent reviews conducted by Chamberlain et al. (2008), Fanner and Urquhart (2008), and Tukhareli (2014) similarly indicate an emphasis on bibliotherapy in the health sciences. Fanner and Urquhart (2008) identified 130 articles that were predominantly written by psychologists on clinical trials of bibliotherapy for depression, substance abuse and sexual dysfunction. Chamberlain et al. (2008) identified 57 relevant papers on clinical trials of bibliotherapy with people experiencing depression and anxiety. Tukhareli (2014) identified 93 studies published between 2007 and 2013 looking at bibliotherapy use for depression, anxiety, stress, hypochondria, obsessive-compulsive disorder, panic disorder, post-traumatic 
distress, borderline personality disorder, hoarding, social phobia, sexual disorders, insomnia, eating disorders, grief and bereavement, obesity, and alcohol-related disorders.

From the literature reviewed several key theorists have emerged as influential in the development of bibliotherapy: Dr. William Menninger in psychiatry, Louise Rosenblatt and reader-response, Alice Bryan in psychology/librarianship Caroline Shrodes in literature, Joyce Rhea Rubin and librarianship, and John Pardeck in social work. All have contributed to the field of bibliotherapy generally by relating it to their own specialty area. The work of these key theorists, along with other significant publications and landmark studies, will be discussed.

This literature review provides a detailed summary of existing literature addressing six aspects central to bibliotherapy: an overview of the history of bibliotherapy (2.1); an overview of the definitions of bibliotherapy (2.2); an overview of the objectives of bibliotherapy (2.3); an outline of the development of bibliotherapy in multiple disciplines (2.4); the effectiveness of bibliotherapy to support wellbeing (2.5); and bibliotherapy training, specifically training for creative bibliotherapy (2.6).

\subsection{A brief history of therapeutic reading}

Section 2.1 will provide a brief overview of the history of therapeutic reading, and how the growth of bibliotherapy led to the development of creative bibliotherapy. Sections 2.2 to 2.7 will offer additional information on the evolution of bibliotherapy.

The word bibliotherapy is relatively new terminology, coined in the early twentieth century (Chapter 1.1: Introduction to bibliotherapy). However, various authors writing about bibliotherapy have indicated the existence of ancient inscriptions suggesting that the idea of bibliotherapy - using literature to heal - goes back to ancient times. For example, in Thebes at the temple of Ramses II an inscription above the library entrance read 'Healing place of the soul', and in Alexandria the library inscription read 'Medicine for the mind' (Jack \& Ronan 2008, p. 162).

Therapeutic reading in medical facilities can be traced to the Middle Ages. William Shakespeare [159-?] refers to the use of literary texts to provide solace in this line from Titus Andronicus, Act 4, Scene 1, Rome. Titus's garden: 
'Come, and take choice of all my library,

And so beguile thy sorrow...'

The earliest record of prescribed reading in a hospital was 1272, where 'the Al-Mansur Hospital in Cairo provided readings from The Koran as part of their patients' treatment' (Jack \& Ronan 2008, p. 164). From the 1700s, libraries were starting to be established in some psychiatric hospitals, and the practice of therapeutic reading was often included in the treatment of mentally ill patients.

Two physicians, Dr Benjamin Rush and Dr John Minson Galt II, encouraged the use of books as part of treatments plans. In 1810, Rush was among the first to recommend reading as part of a medical patient's treatment. In 1853, Dr John Minson Galt II wrote the first article on the subject of therapeutic reading, discussing the use of books for treatment purposes for the insane.

The first professional librarian was appointed in a psychiatric hospital early in the twentieth century, and therapeutic reading became an acknowledged part of the work in many psychiatric hospital libraries. Towards the end of World War I, libraries also become established in many veteran's hospitals, and a short time later therapeutic reading was implemented. In the mid-twentieth century, the American Library Association (ALA) recognized, and gave its support to, the reading of books as a therapeutic tool, and thus recognized it as an accepted aspect of librarianship. In the 1960s two landmark bibliotherapy events took place: in 1962, a symposium organised by the journal Library Trends; and in 1964 an ALA workshop. Subsequently there came a gradual shift to using literary texts in community settings such as libraries, and this is now commonly known as creative bibliotherapy.

In the United Kingdom development of creative bibliotherapy began early in the twenty-first century in the form of two reading group models: the Get Into Reading program and the Reading and You Scheme (RAYS) (see Section 2.4.3: Creative bibliotherapy in community settings). Get Into Reading was subsequently introduced internationally, in Australia in 2010, and several other countries, including Denmark, Wales, Scotland and New Zealand. 


\subsection{Bibliotherapy definitions}

I have described the multiple disciplines, across clinical and non-clinical areas, that use literature in varied therapeutic applications depending on the field of practice. The wide application of the practice of bibliotherapy highlights the difficulty of defining bibliotherapy, or arriving at a consensus for a definition. An important milestone in developing an agreed definition of bibliotherapy took place in 1962. The Committee on Bibliotherapy (a division of the American Library Association) conducted a survey in an attempt to clarify the meaning of bibliotherapy in view of a lack of consensus for any one definition (Tews, 1962). The 1962 special issue of Library Trends, focusing on bibliotherapy, incorporated a questionnaire targeting respondents engaged in some way with bibliotherapy. The targeted respondents included physicians, psychologists, nurses, sociologists, school teachers, chaplains, occupational therapists, and educators in languages and adult education. A range of respondents working in libraries, including library educators, institution library consultants, general hospital librarians, state hospital librarians, nursing school librarians, volunteer library workers, library administrators and public librarians were also surveyed. The committee aimed to use the respondents' data as a basis for the formulation of a common definition but definitions from different disciplines illustrate the lack of consensus. In replying to the questionnaire a psychiatrist said:

Bibliotherapy is the conscious and deliberate use of reading materials and/or guidance of the patient's use of reading materials for the purpose of furthering or supporting the therapeutic program as a whole as it relates to a particular patient or, in some cases, to a more or less homogeneous group of patients.

(Tews 1962, p. 99).

However, a librarian considered it to be:

A planned program of reading or reading activity for an individual patient or group of patients with clearly defined purposes based upon medical diagnosis... it also provides for evaluation and follow-up of its effects upon the patient. This procedure would involve the cooperation of both the librarian and the appropriate medical staff in the planning and using of specialized knowledge and skill that each brings to the total activity.

(Tews 1962, p. 99).

The data from 58 respondents were considered to construct the final composite definition:

Bibliotherapy is a program of selected activity involving reading materials, planned, conducted, and controlled as treatment under the guidance of the physician for 
emotional and other problems. It must be administered by a skilled, professionally trained librarian within the prescribed purpose and goals. The important and dynamic factors are the relationships which are established, the patient's reactions and responses, and the reporting back to the physician for interpretation, evaluation, and directions in follow-up.

(Tews 1962, p. 99).

As the literature review has shown, there is no single, agreed definition of bibliotherapy. The lack of consensus of what bibliotherapy is, is demonstrated by the large number of opinions on the subject depending on its application across a wide range of disciplines using bibliotherapeutic principles. However carefully attempts are made to define the term, in practice and discussion bibliotherapy remains an elusive, intangible, highly complex activity.

\subsection{Objectives of bibliotherapy}

Key theorists within the field of bibliotherapy categorise "bibliotherapeutic goals according to diagnosis, treatment and prevention' (Sclabassi 1973, p. 71). Key ideas and opinions on bibliotherapy are considered below.

In the late 1930s, American Louise Rosenblatt developed and defined reader-response theory as a shift in the positioning of the reader of a text, from an absence to a central position through the engagement that happens when reading a text (Rosenblatt, 1938). Rosenblatt, a professor of English education at New York University, opposed the principal thinking of the time that assumed that the meaning of text resided solely in the author's narrative, disregarding the reader's role in determining meaning for each individual.

Rosenblatt explored the benefits of bibliotherapy through a reader-response perspective, asserting that the fictional characters in books may increase readers' understanding of themselves through identifying with characters' challenges, hopes and dreams. Rosenblatt asserts that reading literature is perhaps the only process by which the reader can discover that their own life 'reflects a common experience of others in his society' (Rosenblatt 1938, p. 243).

Dr Alice Bryan, a US psychologist and librarian, considered that in bibliotherapy 'the reader must be understood as a whole personality, and his reading planned in terms of his personal needs' (Bryan 1939a, p. 10). 
In an article entitled 'Can there be a science of bibliotherapy?', Bryan (1939b, p. 775) identified that for scientific recognition bibliotherapy needed an established body of experimental data from which to develop universal principles. She formulated six objectives of bibliotherapy:

1. To show the reader they are not the first to have a problem

2. To permit the reader to see that more than one solution is possible

3. To help the reader see the basic motivations of people (including themselves) involved in a particular situation

4. To help the reader see the values involved in the experience in human terms

5. To provide facts needed for the solution of the problem

6. To encourage readers to confront their problems.

The six objectives above, as suggested by Bryan, informed the work of Caroline Shrodes (1949) in the first academic thesis on the subject ten years later. Shrodes proposed that there were four phases that the reader needed to pass through for literature to have a therapeutic benefit:

1. Identification

2. Projection

3. Catharsis

4. Insight.

Caroline Shrodes, like Alice Bryan, had a background in psychology but was working outside of the area, in the Language Arts Division at San Francisco State University. Shrodes defined bibliotherapy 'as a process of dynamic interaction between the personality of the reader and literature' (Shrodes 1949, p. 33). Shrodes did not assume that the teacher utilising bibliotherapy must be a skilled therapist. Through appropriate text selection, the teacher could provide interaction between books and readers to offer the opportunity for 'personality assessment, adjustment, and growth' (Russell \& Shrodes 1950a, p. 335). Russell and Shrodes (1950b, p. 420) suggest that bibliotherapy may be considered a practice that unites education, clinical work, and mental health.

Shrodes (1949) identified two types of literature to consider for bibliotherapeutic use. The first was didactic literature, usually in the form of cognitive behavioural therapy books. A cognitive behavioural therapy book is often described as a self-help book and can provide a range of techniques for changing thoughts, feelings and behaviours (Neenan \& Palmer 2012, 
p. xvi). The second was imaginative literature, usually in the form of fiction, poetry, inspirational stories and biographies. Shrodes asserted that imaginative literature showed greater therapeutic potential due to the emotional engagement possibilities, which she maintained were necessary for effective bibliotherapy.

Similar to Bryan (1939a; 1939b) and Shrodes (1949), Elizabeth Schlenther (1999, p. 30), a paediatric ward librarian from Wales, identifies stages necessary for the reader to feel a therapeutic benefit from literature:

1. The identification with a character or situation and the projection of oneself into it.

2. Catharsis - the experiencing of an emotional release.

3. Insight and integration.

Schlenther's work with bibliotherapy became more directed to children and she compiled an online directory of books relating to health issues for children. The Healthy Books website is hosted by the Chartered Institute of Library and Information Professionals (CILIP) website for the Health Libraries Group. The bibliography lists over 2515 annotated books, organized into 106 different categories of emotional, physical, social and mental health (CILIP, 2020).

Sclabassi (1973), divided bibliotherapy practice into four types:

1. Intellectual

2. Social

3. Emotional

4. Behavioural.

Intellectual bibliotherapy relates to the goal of communicating facts and knowledge; social bibliotherapy focuses on developing a feeling of belonging; emotional bibliotherapy is concerned with universalisation, making meaning of feelings and offering opportunities to discuss thoughts and feelings; behavioural bibliotherapy is concerned with developing socially acceptable behaviour.

In 1978b Joyce Rhea Rubin (a library professional in the US) increased the range of therapeutic opportunities for bibliotherapy by outlining three distinct models:

1. Institutional bibliotherapy

Using primarily didactic non-fiction literature to support psychological problems of individuals in mental institutions. In this model doctors prescribe reading material and 
discuss with the patient what they have read. This model may include a librarian offering reading recommendations. The purpose of this model is to provide information, recreation and re-socialisation.

\section{Clinical bibliotherapy}

Using primarily imaginative literature in groups, either in an institution or the community. In this model clients discuss the readings with librarians working in partnership with a doctor or psychologist. The objective of this model is to encourage insight and behavioural change.

3. Developmental bibliotherapy

Using imaginative and didactic literature with people who do not have mental health problems to maintain mental health. This model is usually delivered by a librarian, teacher or facilitator who discusses the literature with individuals. This model intends to help in times of problems (non-clinical), and to maintain or promote good mental health (Rubin 1978b, pp. 4-5).

Rubin asserted that central to the success of all three types of bibliotherapy was the discussion of the text after reading. Similar to Rubin's models of bibliotherapy, Haynes and Haynes-Berry (1986) outlined two bibliotherapy practices: 'reading therapy,' which involves a health professional, or a librarian, recommending a book to read based on the text's therapeutic capability relative to individual psychological issues; and 'interactive bibliotherapy', which involves an interactive process where a facilitator guides a participant's involvement through group discussions. Morawski \& Gilbert (2000) assert that discussions about literature are an important part of the bibliotherapy process.

Cather (2007) conducted research into using imaginative literature for women, written by women, in a library-based bibliotherapy service. Cather suggests, like Rubin and others above, that the discussion of the reading materials with the aid of a facilitator led to reflection and provided opportunity for personal growth.

Brewster (2011, p. 216) proposes four emergent types of bibliotherapy: emotive, escapist, informational and social. Brewster suggests, similar to Rubin and Haynes and Haynes-Berry, that within emotive and social bibliotherapy dialogue with the reader and the relationship between group members and facilitators are important factors of success in the outcomes. The objectives of bibliotherapy presented in the literature are important in thinking about the question this research study is addressing: 'How can the understanding of the relationship between 'biblio' and 'therapy' be developed in non-clinical facilitators and applied to support the promotion of the wellbeing of individuals and groups in society?' 


\subsection{Multi-disciplinary views of bibliotherapy}

Bibliotherapy is used across many fields of practice and a variety of professions. Section 2.4 will initially look at bibliotherapy use in clinical areas (Section 2.4.1); this will be followed by a discussion of bibliotherapy use in non-clinical areas (Section 2.4.2).

\subsubsection{Bibliotherapy in clinical areas}

Sections 2.4.1.1 to 2.4.1.6 will look at literature that documents the evolution of bibliotherapy in clinical areas. Beginning with early bibliotherapeutic practice in hospitals, to more recent practices of psychologists, general practitioners and counsellors.

\subsubsection{Bibliotherapy and hospitals}

In this research the term 'hospital library' refers to a library providing reading materials or health information for patients of a hospital. In 1939, the Hospital Division of the American Library Association nominated its first bibliotherapy committee (Rubin, 1979). Bibliotherapy was becoming an acknowledged part of the work in many hospital libraries and librarians were beginning to assemble bibliographies to assist patients with their problems (Briggs \& Pehrsson, 2008). Margaret Kinney, who was the chief librarian at the Veterans Administration Hospital in New York, is acknowledged for producing a series of comprehensive bibliographies on bibliotherapy, furthering the notion that bibliotherapy was increasingly becoming an acknowledged part of the work in many hospital libraries. The International Federation of Library Associations and Institutions (IFLA) published four sets of recommendations for patients' libraries from 1960 through 1984. The IFLA recommendations were the first bibliotherapy standards written and issued by a professional library association for a hospital library. The first set of recommendations was published in 1960 in Libri (vol. 10, no. 2, pp. 141-146) as 'Mémoire indicateur sur les bibliothèques d'hôpitaux' (Memorandum on hospital libraries); a shorter version appeared in English in Hospital Abstracts, 1961/1963. A second set of recommendations, 'IFLA Standards for Libraries in Hospitals', was published in UNESCO's Bulletin for Libraries (vol. 23, no. 2, pp. 70-75). IFLA's third recommendations were published as paragraphs (pp. 5361) in IFLA's 'Public Library Section's Standards for Public Libraries' (IFLA 2000, pp. 9-10). Reflecting an expanded focus, these recommendations included not only hospital patients, but also housebound readers, the visually handicapped, day centres, clubs, residential 
homes for the elderly, and prisons, remand and detention centres. Finally, in 1984, IFLA published 'Guidelines for Libraries Serving Hospital Patients and Disabled People in the Community'. These guidelines covered services to a number of other groups, including aphasiacs/dyslexics, people with motor handicaps, the deaf, and people with psychiatric illness. Noting that it was impossible to draw up universally applicable standards, the 1984 document aimed, instead, to be a set of suggestive guidelines based on the experiences of librarians in the field, and work that had already been done by national library associations.

\subsubsection{Bibliotherapy in psychiatric hospitals}

During the nineteenth century, libraries became established in many psychiatric hospitals in Europe and the United States of America and bibliotherapy was incorporated into treatments used for the mentally ill (Salup \& Salup, 1981). Early examples include the pioneering work of William Tuke at The Retreat in England. The Retreat, founded by Tuke in 1796 , became a model for psychiatric hospitals around the world, inspiring the more progressive American facilities, such as the Brattleboro Retreat, Hartford Retreat and Friends Hospital, founded in the early nineteenth century (Books LLC, 2010), to use a form of bibliotherapy that became known as reactive bibliotherapy. In reactive bibliotherapy readers responded independently to the literature without any follow-up discussion or interaction with health professionals (Riordan et al., 1996).

American physicians Benjamin Rush and John Minson Galt Il are acknowledged for promoting bibliotherapeutic work in the mid-nineteenth century through the advocacy of reading therapy in asylums (Weimerskirch, 1965). Rush's reading recommendations included both fiction and non-fiction books for recreation (travel books, novels) and knowledge (philosophical, moral, religious subjects) (Tews, 1962). Galt recommended that every asylum have a library of well-chosen books, including fiction books, believing that reading occupies the mind, distracting from delusions and morbid feelings, and also serves the purpose of a pleasant way to pass the time, offering pleasure and comfort.

In 1904 Kathleen Jones became the first appointed professional librarian in a psychiatric hospital (McLean Hospital, Massachusetts). Jones produced a series of books entitled 'Hospital libraries' (1923, 1939 \& 1953), focusing on the value of library collections and material selection to support treatment for the mentally ill (Hendricks et al., 1999). 
Further promotion of library services to psychiatric hospitals was developed by Alice Tyler during her term as secretary to the lowa State Library Commission from 1900 to 1913 when she also established a travelling library service that visited lowa hospitals. The service delegated the selection of reading materials to a patient, who acted in the role of the librarian in a volunteer capacity (Panella, 1996). Pierre Jones (1944, p. 474) wrote an article in the Bulletin of the Medical Library Association encouraging the state mental hospital to 'do preventive work' with the 'use of selected reading as therapy'. He advocated that if research could be undertaken into the use of using selected inspirational reading the findings might show that 'something quite enlightening, and certainly most interesting, might emerge'.

In 1919 The Menninger Foundation in Kansas was founded by psychiatrists Charles William and Karl Menninger. In 1925 the foundation established a hospital for the mentally ill, and in 1926 the Southard School for children suffering mental illness. In 1930 Karl Menninger published a book entitled 'The human mind', which discussed the use of developmental bibliotherapy at the clinic as a way to help individuals with negative emotions and personal development. Karl Menninger stated that 'books may indeed minister to a mind diseased and come to the aid of the doctor' (Menninger K 1930, p. ix). The Menningers were the first physicians to conduct substantial research into the effectiveness of bibliotherapy, and in 1937 Dr William Menninger published an article entitled 'Bibliotherapy' (Menninger W, 1937), in which he defined the different responsibilities within the health professional and hospital librarian partnership.

The physician was responsible for:

- Direction of collection development, including the approval of book purchases

- Interviewing the patient

- Discussing with the librarian the patient's requirements

- Approving the reading materials selected by the librarian for individual patients

- Prescribing the book to the patient as part of their treatment

- Discussing with the patient the way in which the book offered support and its impact on their mental health

- Discussing individual patient issues and results with the librarian. 
The librarian was responsible for:

- Making purchases and maintaining the collection

- Book distribution and loan records

- Selecting reading material to suit an individual patient's needs

- Interviewing the patient about their reactions to the prescribed reading and submitting a written report to the physician.

(Menninger, W 1937, pp. 267-268).

Additionally, Dr William Menninger (1937, pp. 266-267) wrote of a 'general approbation of the use of bibliotherapy... [which additionally] helped the individual identify himself with a social group'. Menninger's writings suggest an example of very early creative group bibliotherapy.

\subsubsection{Bibliotherapy in veterans' hospitals}

After each World War, I and II, hospitals for veterans were founded. During these times the use of bibliotherapy broadened as a treatment for soldiers returning from wars. Towards the end of World War I, libraries become established in many convalescent hospitals (Ireland, 1934; Peterson-Delaney, 1938). The UK government appealed to the public to provide books for patient libraries before the wounded began to arrive. In the United States, at the end of World War I, a dynamic, cohesive drive called the 'patients' library movement' began and was sustained by librarians and physicians to promote placement of organized libraries for patients in hospitals' (Panella 1996, p. 52). Sadie Peterson-Delaney, the chief librarian at the Tuskegee Veteran's Administration Hospital in Alabama, began working with a more interactive type of bibliotherapy with returned soldiers from World War I. PatersonDelany, through discussion with the patient, would prescribe readings for both recreation and information relevant to their particular circumstance (Tews, 1970). Paterson-Delany (1938) documented the experience in an article entitled 'The place of bibliotherapy in a hospital', in which she concluded that reading materials prescribed to soldiers, by a librarian, assisted them in developing coping skills and improve feelings of wellbeing. The demand for psychiatrists to treat military veterans was the basis for a substantial research study of the effectiveness of bibliotherapy, conducted by Elizabeth Pomeroy in 1937. The study included 1,538 patients from 62 Veteran's Administration hospitals. 
The data showed increased benefits when texts were well chosen for individual patients (Pomeroy, 1937).

W.B. McDaniel II, Director of the Philadelphia College of Physicians, who had a broad interest in the classics, described bibliotherapy thus, '(f)or perhaps the first time since the days of ancient Thebes there was the realization on a very large scale of the fact that books may indeed be medicine for the soul-and, hence, the body' (McDaniel 1956, p. 586).

The Menninger Clinic (part of the Menninger Foundation) had begun to offer training programs for mental health professionals in the 1930s, establishing the Menninger School of Psychiatry, which was acknowledged as the country's largest psychological training organisation at that time. The Menninger School of Psychiatry supported the increase in demand for psychiatrists to treat military veterans in veterans' hospitals after World War II. Co-founder William Menninger had left the clinic and taken up the position of Director of Psychiatry in the US Army at the start of World War II. He led the committee responsible for directing changes in mental health reform in the US following World War II.

\subsubsection{Bibliotherapy and general practitioners}

Early in the twenty-first century, an interesting development linking health professionals and librarians transpired through the Books on Prescription (BoP) scheme in the UK. BoP schemes operate through partnerships between general practitioners and librarians where the former recommend or 'prescribe' a book to patients who then take the book prescription to a local library to source and borrow the book.

BoP schemes arose when a Cardiff doctor, Dr Neil Frude, developed a pilot partnership model working with Cardiff Libraries (Frude, 2004). A bursary from Wales Mental Health in Primary Care (WaMH in PC) provided funding for purchasing 35 recommended self-help titles identified from a survey of psychologists and counsellors. Frude created 'Prescriber Packs' issued to every GP and primary care counsellor in Cardiff (Frude, 2004). Data collected showed 1600 books were borrowed from 15 library authorities under the BoP scheme in the first 12 months and the scheme has developed to become a widely used method of treatment for some mental illnesses (Brewster et al., 2012). The pilot BoP model then expanded geographically nationwide across Wales (Frude, 2009), and then the United Kingdom. 
In 2006 The Reading Agency in the UK prepared an audit of BoP activity in English libraries for the Arts Council England and the Museums Libraries and Archives Council, United Kingdom. Of the 46 responses received, 21 public libraries were operating the BoP model (Hicks, 2006). Hicks (2006, p. 4) stated that the number of public libraries participating in the scheme indicated 'a recent upsurge in activity' as 'the majority of BoP schemes had been in operation for less than a year'. The BoP model has spread rapidly and has developed across the UK, in partnership, in many cases, with community and secondary health services within a primary care trust (PCT) agenda (Hicks 2006, pp. 8-10). A PCT was an administrative body that was part of the National Health Service in England from 2001 to 2013, responsible for commissioning primary, community and secondary health services from providers.

A systematic review of BoP projects in libraries conducted by Chamberlain et al. (2008) identifies evidence to suggest the BoP model is a cost-effective intervention. A more recent study has estimated that over 100 Books on Prescription-type schemes operate in the United Kingdom however, 'there are no national standards, and there is some disparity in service provision' (Brewster et al. 2013, p. 572). More recently, Rosie May Walworth, a public librarian in the UK, discusses adapting Reading Well Books on Prescription into separate programs for sufferers of dementia and young people. Walworth also discusses development of a school-based approach for young people (Walworth, 2018a; Walworth, 2018b).

In 2007, the 'North Inner City Partnership in Primary Care (Dublin), in collaboration with Dublin City Public Libraries, piloted the first book prescription scheme in Ireland' (Dublin City Council: Bibliotherapy, 2014). The success of the Dublin City Libraries book prescription scheme led to several other schemes being launched in Ireland.

In Australia, Central West Libraries in NSW partnered with the Centre for Rural and Remote Mental Health at the University of Newcastle (CRRMH) in 2015 to launch a BoP scheme in Orange, New South Wales. The various applications of the BoP model illustrate that the collaboration between health care professionals and librarians remains strong in the bibliotherapy area.

\subsubsection{Bibliotherapy within counselling}

Key practitioners in bibliotherapy have documented the use of creative bibliotherapy within 
counselling and family therapy (Pardeck, 2006, 1998, 1994, 1993, 1991a, 1991b, 1990a \& 1990b; Pardeck \& Markward, 1995; Pardeck \& Pardeck. 1998, 1986, 1985 \& 1984), writing about the use of literary texts to support children and young adults with problems. Gold (1990 \& 2001) discusses the use of literary texts to assist with marriage guidance counselling. Pehrsson and McMillen (2004, 2005 \& 2010), and McMillen (2006) discuss bibliotherapy using literary texts within the clinical practice of professional counsellors. In the late twentieth and early twenty-first centuries, counsellors have used traditional bibliotherapy focusing on specific problems being experienced by individual adults (Briggs \& Pehrsson, 2008). Examples include alcohol abuse (Bien et al., 1993; Miller et al., 1993; Rather, 1995; Vannicelli, 2001), career motivation (Eliasa \& Iswanti, 2014), chronic fatigue (Chalder et al., 1997), eating disorders (Berg \& Moore, 1996; Treasure et al., 1996), low selfesteem (Waite et al., 2012), obsessive compulsive disorder (Fritzler et al., 1997), panic attacks (Carlbring et al., 2005; Gould et al., 1993; Hecker et al., 1996; Hecker et al., 2004; Kiropoulos et al., 2008; Lidren et al., 1994; Newman et al., 1997; Sharp et al., 2000), smoking (Troop et al., 1995), and social phobia (Marks et al., 2004; Tillfors et al., 2008).

Alongside the practice in adult counselling, counselling with children also began to focus on using bibliotherapy for specific problems. Examples include children's anxieties associated with beginning school (Rich \& Bernstein, 1975), anxiety with specific curriculum areas (Furner \& Duffy, 2002), challenges of gifted children (Hebert \& Kent, 2000; Jeon, 1992), dealing with having alcoholic parents (Pardeck, 1990a), dealing with parents divorcing (Kramer \& Smith, 1998), fear of the dark (Barclay \& Whittington, 1992; Paparoussi et al., 2011), grief associated with death (Ayyash-Abdo, 2001), learning and social skills in disabled adolescents (Anderson, 2000), and social-emotional skills (Sullivan \& Strang, 2002/2003). Work with children was further developed by Pardeck (1990b, 1991a, 1991b, 1993 \& 1994) and Pardeck and Pardeck (1984, 1985, 1986 \& 1998) through using books within family therapy as a tool to help children deal with problems.

\subsubsection{Internet bibliotherapy}

Internet bibliotherapy is run by psychologists using a digital platform, rather than an office. An example is Griefnet in the United States, which provides a library of prose and poetry relating to grief and loss, and a related site for children. Other examples include the 
Australian National University's 'MoodGYM' and 'e-couch', both free online interactive programs. These programs provide self-education and support for psychological problems through internet-based cognitive behaviour therapy (IBCT). Bibliotherapy in this format follows clinical setting practice using a CBT or self-help book in HTML format. Delivery of the programs can employ both therapist-guided IBCT (Hedman et al., 2014) and self-guided IBCT (Wootton et al., 2013) models. Vernberg and Schuh (2002), in an analysis of internet bibliotherapy, found bibliotherapy offered in this mode had been a source of social support for participants and 'ICBT could be described as Internet-delivered bibliotherapy' (Hedman et al. 2014, p. 49).

Internet bibliotherapy has been developing since the early twenty-first century (Rothbaum, et al., 2001). An Australian CBT study with individuals with increased depressive symptoms in the Australian community of Canberra, showed evidence that the internet is 'a feasible and powerful tool in delivering community-based health interventions' using bibliotherapeutic principles (Christensen et al. (2004, p. 3). Other examples include its use for alcohol-related disorders (Kavanagh \& Procter, 2011), anxiety (Jorm et al., 2004), depression (Andersson \& Cuijpers, 2009; Carlbring et al., 2009; Schneider et al., 2005), chronic headache (Difede \& Blanchard, 2005), eating disorders (Riva et al., 2003), fear of public speaking (Anderson et al., 2005; Botella et al., 2010; Harris et al., 2002), obsessivecompulsive disorder (Tolin et al., 2007; Wootton et al., 2011 \& 2013), panic attacks (Carlbring et al., 2006; Richards \& Alvarenga, 2002), phobias (Carlbring et al., 2005), posttraumatic stress disorder (Difede et al., 2002; Rothbaum et al., 2001), sexual disorders (Optale et al., 2003), and stress management (Vallani et al., 2007).

In Australia, the National Health and Medical Research Council (NHMRC, n.d.), Australia's peak body for health and medical research, provides funding for mental health research through a competitive peer-review process. In 2013, Professor Helen Christensen from the University of New South Wales was granted $\$ 3,750,000$ to develop e-mental health resources in Australia. E-resources apply the self-help-based principles of cognitive behavioural therapy.

Noruzi (2007) has described the practice of 'webotherapy', the online equivalent of the more traditional practice of bibliotherapy. Webotherapy aims to empower clients to instigate positive change in their lives, through the reading of materials delivered online. 
Online bibliotherapy services could support deinstitutionalisation in areas where there are long waiting lists for services, or people wishing to avoid any possible stigma from accessing conventional mental health services. An online format could be a practical alternative for individuals in regional communities who cannot travel to services easily. The online format provides a practical way to share bibliotherapy information and resources primarily through the provision of lists of self-help books for people and practitioners looking for suitable books to support the treatment of mental health issues.

'The Future of Health' report produced by the Commonwealth Scientific and Industrial Research Organisation (CSIRO, 2018) provides a vision and a plan for how Australia can shift focus away from illness treatment and the management of health and well-being. The report states that digital technologies could assist many of the necessary changes, complementing the role of health and wellbeing professionals. However, the report asserts that the health and wellbeing sector needs to consider how to facilitate greater uptake of innovative and effective health and wellbeing solutions.

The 2020 COVID-19 health crisis presented the immediate need for creative bibliotherapy to develop into a digital format. With new rules about social distancing and lockdowns enforced across most of the planet, face-to-face creative bibliotherapy delivery was suspended along with most library and community events. Two rapid evolvements were The Reader Organisation in the UK providing bi-weekly Facebook live poetry readings (The Reader Organisation, 2020a), and State Library Victoria produced creative bibliotherapy podcasts (State Library Victoria, 2020a; 2020b). The unique creative bibliotherapy podcast produced by State Library Victoria is an excellent example of a novel wellbeing innovation, being the first podcast of its kind, offering creative bibliotherapy in a new facilitated selfreflective digital format, with a series for adults and children.

A discussion paper produced by Australian mental health and wellbeing support organisation Beyond Blue, entitled 'Victoria's next 10-year mental health strategy', recommended that the Victorian government adopt a strong focus on e-mental health technology, including bibliotherapy (Beyond Blue, 2015). The paper suggests e-mental health programs have been demonstrated to be as clinically effective as a face-to-face treatment for mild to moderate depression and anxiety, and up to 50 times more costeffective. During the coronavirus pandemic, which the Victorian government claims has 
resulted in a mental health crisis, alternate therapies such as a bibliotherapy podcast could offer a resource to support the emotional, social and psychological challenges of the pandemic.

\subsubsection{Bibliotherapy in non-clinical areas}

From the 1950s, the use of bibliotherapy began to move away from the hospital environment and into a wide variety of therapeutic, educational and community settings. An important factor in the evolution of bibliotherapy is the deinstitutionalisation of mental health care. From the 1950s to the 1970s reform of mental health services started in the United States and moved across many countries worldwide (Ramon et al., 2007). During this time patients were released from institutions to live in the community with mental health care provided 'under the banner of "community mental health"' (Bassuk \& Gerson 1978, p. 48). For example, when the Agnews State Hospital in California closed in 1972, the Patients Library moved its successful bibliotherapy hospital-based program into the community (Lack \& Bettencourt, 1971).

With the deinstitutionalisation of mental health care in the 1970s, the concept of recovery become part of the language used in community mental health care (Anthony et al., 2003; Le Boutillier et al., 2011; Slade, 2009 \& 2010,). Recovery includes a focus on fostering social inclusion (Ramon et al., 2007) which can be supported by the development of a strengthsbased approach based on listening to stories (Rappaport, 1995). This illustrates the changing nature of bibliotherapy and links it with the notion of 'therapy' in non-clinical settings through supporting psychological, social and emotional challenges, in line with changing attitudes and approaches to community mental health care. Sections 2.4.2.1 and 2.4.2.2 will look at literature that documents the evolution of bibliotherapy in non-clinical areas.

\subsubsection{Bibliotherapy in the education system}

In the early twentieth century there was a move towards including the use of bibliotherapy with children, Bradley and Bosquet (1936) recommended a list of suitable books for treatment of children with behavioural or personality disorders as part of four proposed therapeutic applications: attending school, development of interests outside school, informal learning, and supervised reading. A 1946 study conducted by Sister Mary Agnes, from St. Francis College in Indiana USA, is recognised as being influential in developing 
bibliotherapy usage with children. Sister Mary Agnes (1946) aimed to determine if reading without the support of a physician or psychiatrist could offer children an effective strategy to deal with school-related problems, such as low confidence in their academic abilities. The data collected indicated some improvement in the behaviour and attitudes of the children in the study after they read and discussed three to five prescribed fiction books. Sister Mary Agnes furthered her research in 1947 through conducting research into the effect of reading on behaviour and racial attitudes of adolescents. In this study, data was collected via a questionnaire from two groups. The first 'reader group' comprised 100 white girls who had borrowed at least two books from their Catholic school library within the past year, either written by an ethnic author or about ethnic characters. The second 'control group,' had no known history of borrowing books connected to ethnic issues. In comparing the two groups, Sister Mary Agnes found more acceptance of ethnicity within the 'reader group'.

Other early documented uses of bibliotherapy in the educational environment include for coping behaviour, alleviating fears, and personality development (Cimciolo, 1965; Hoagland, 1972; Nicholson et al., 2003), gifted students (Frasier \& McCannon, 1981), slow-learners (Witty, 1964), and for stuttering (Emerick, 1966).

Russell and Shrodes (1950a, p. 335) state that bibliotherapy is in the 'province of every teacher of literature' and that '(i)t does not assume that the teacher must be a skilled therapist'. Bibliotherapy use in the classroom is seen as 'compatible with certain educational purposes in a developmental or preventative rather than remedial sense: education for psychological maturity, life adjustment, and character development' (Salup \& Salup 1981, p. 5). Salup and Salup's notions resonate with Rosenblatt's earlier theories (Section 2.3: Objectives of bibliotherapy), in which Rosenblatt asserts that using literature therapeutically enriches students and prepares them to become active members in society. Further to this, Rosenblatt proposes two different purposes and experiences of reading a text: the 'efferent' and the 'aesthetic'. The 'efferent' reading stance is fact-oriented, where the reader focuses on the information in the text, and is commonly used by students as a reading method for information seeking. Whereas, 'aesthetic' reading is a more empathic style of reading that is connected to emotional engagement (see Chapter 7.8: The therapeutic outcomes of 'biblio' and the 'therapy').

A book entitled Facilitating human development through reading: the use of bibliotherapy in 
teaching and counseling (Zaccaria \& Moses, 1968) is another example of a shift towards applying bibliotherapy in the community to support psychological and emotional challenges. Zaccaria and Moses, both educational psychologists, considered that '(b)ibliotherapy is compatible with the goals of contemporary education which include fostering development of a whole, adjusted personality' (Zaccaria \& Moses 1968, p. 245).

More recently, English teachers are using fiction to demonstrate resiliency concepts through thinking about and discussing 'setbacks faced by characters' (Seligman et al. 2009, p. 305) in fictional narratives, and Seligman's model is used in several studies (Brunwasser et al., 2009; Cardemil et al., 2002; Cronlund, 2008; Kristjánnsson, 2012; McLoughlin, 2009; Rashid, 2009; Wilson \& Thornton, 2007/08; Wood \& Tarrier, 2010). Seligman et al. (2009, p. 305) also deliberate on how English teachers are using literature to facilitate discussion with students around 'signature strengths and... resiliency concepts to demonstrate... thinking about setbacks faced by characters'.

\subsubsection{Bibliotherapy and the arts}

Many forms of therapy use the 'healing power of art through its various forms' (Tukhareli 2011, p. 18), such as art therapy, music therapy and dance therapy. In many arts therapies the artistic endeavour is deliberately used for interpretation of thoughts and feeling and offers a conversation partner to assist with verbal processing (Ansdell, 1995; Thomashoff et al., 2009). Literary texts could be considered parallel to the creative practices of arts therapies that use emotive visuals, calming or motivating music, and dance movement.

A broad definition of arts therapies offered by The Australian, New Zealand and Asian Creative Arts Therapy Association (ANZACATA) incorporates the use of creative processes with individuals and groups through accessing imagination and creativity to improve and enhance mental and emotional wellbeing. ANZACATA (n.d.) describes arts therapies as producing 'reverie', defined 'as a state of mind that enables contemplation, imagination, and creativity'. 'Reverie' can have therapeutic and healing effects through connecting with our inner world in a way that enriches our relationship with others and ourselves, supporting wellbeing rather than illness (Smith, 2013; The Dax Centre, 2015). Farrington et al. $(2012$, p. 69) assert that similar to other mixes of arts and therapy, creative bibliotherapy uses the words in literary texts to produce 'reverie' that 'lifts people out of self-absorption 
and away from the self-conscious issues and problem-solving methods of therapy'.

Non-clinical, or complementary and alternative medicine (CAM) modalities, often use artsbased therapies. Many different practices are included in CAM, including art, dance, music and visualisation and guided imagery (John Hopkins Medicine, 2020; Patel, 1998). Engebretson and Wardell (1993) note an interesting distinction between the models of scientific and alternative medicine modalities, asserting that the scientific modality aims for "cure" and the CAM modality is created based a "healing" principle. Engebretson and Wardell (1993) define "cure" and "healing":

"Cure" basically reflects the physical reality; that is, the body is free from specific symptoms and one is returned to a familiar state of function. "Healing" occurs at different levels of human existence. One can be healed emotionally, psychologically, socially and spiritually without physically being cured of specific symptoms or disease. (Patel, 1998, p. 77)

\subsubsection{Creative bibliotherapy in community settings}

Creative bibliotherapy schemes using literary texts began in the UK in 2000 (Brewster, 2011). The main purpose of creative bibliotherapy is to encourage participants to apply creative thinking to personal problems through reading and discovering, such as how characters similar to themselves confronted problems and solved them within literary texts (Pardeck, 2006). Since 2000, two significant creative bibliotherapy models, delivered in community settings by non-health professionals, have emerged in the United Kingdom. In 2000, the Kirklees and Calderdale Library Services launched the Reading and You Scheme (RAYS), now called 'Well Into Words'. In 2001, The Reader Organisation (TRO), situated at the University of Liverpool, launched its flagship 'Get Into Reading' program (GIR). In Australia, the 'Book Well' program emerged in 2010, inspired by the GIR model.

Whilst most recent bibliotherapy activity is in the UK, in a variety of community settings, a recent book titled Bibliotherapy (McNichol \& Brewster, 2018) presents a series of global case studies illustrating how creative bibliotherapy approaches can be used across different settings and with a variety of user groups, including in public libraries, academic libraries and healthcare settings. These case studies reflect the international spread of creative bibliotherapy initiatives and include examples from the UK, North and South America and Australasia. In the book facilitators provide anecdotal evidence demonstrating how libraries 
and non-clinical facilitators can engage with more diverse audiences, such as homeless populations, psychiatric patients, speakers of other languages and people living with dementia.

A variety of authors contribute chapters to Bibliotherapy (McNichol \& Brewster, 2018) and include Cristina Deberti Martins, bibliotherapist-psychologist at the Portal Amarillo Library in Montevideo, Uruguay, who outlines her work with socially vulnerable patients, specifically with drug-use problems. Martins summarises a program of weekly sessions held inside the library which is lowering anxiety of group members through the use of poetry and literary texts read aloud and discussed (Martins, 2018). Kate Gielgud, Health Information Coordinator at Westminster Libraries, London, compares two bibliotherapy read-aloud groups to discuss texts and styles of reading groups for native and non-native English speakers (Gielgud, K, 2018). Elena Azadbakht, Health and Nursing Librarian, and Tracey Englert, Science \& Technology Librarian, at the University of Southern Mississippi in the USA, developed a bibliotherapy program from an existing university book club. The program is aimed at supporting students' wellbeing, and therefore better success in their studies (Azadbakht \& Englert, 2018). Natalia Tukhareli, Librarian at Scarborough and Rouge Hospital, Toronto, Canada, provides an overview of bibliotherapy programmes developed and successfully implemented in international library and community settings. Natalia's work includes communities of those living with HIV/AIDS in Johannesburg, South Africa, and in Toronto, Canada, and has led to the development of a program that uses fiction, nonfiction and poetry to decrease loneliness and promote wellbeing. An evaluation of the program demonstrates how creative bibliotherapy is supporting challenges and improving individual wellbeing (Tukhareli, 2018). Fiona Bailey, a bibliotherapist for Midlothian Libraries in Scotland, reflects on maintaining the group dynamic in a book group over a long term (Bailey, 2018). David Chamberlain, a librarian working for the National Health Service and delivering bibliotherapy in an older in-patient psychiatric ward, discusses the importance of partnerships with providers (Chamberlain, 2018).

In all the global bibliotherapy activities in community settings described in Brewster and McNichol 'collaboration is a key theme; engaging in bibliotherapy offers librarians opportunities to collaborate with partners such as healthcare providers and arts 
organisations' (Brewster \& McNichol, 2018, p. xv). Collaboration is discussed further in Section 6.2: Therapeutic alliances.

A second recent book titled Reading and mental health (Billington, 2019) similarly presents a series of global case studies, however, these explicitly focus on how the Get Into Reading (GIR) approach has been used across different settings, and with a variety of user groups. Again considered are a range of clinical and community settings, including general practice, mental health, dementia, prisons, and psychiatric practice. Case studies are prominently from the UK, with mentions of programs in Denmark, Canada, New Zealand and Australia. GIR is characterised by its emphasis on the importance of serious, 'classic' literature (as discussed in Section 5.1.1: Reading material provided by The Reader Organisation) and much of Reading and mental health (Billington, 2019) focuses on using serious, 'classic' literature. Another large section outlines quantitative and qualitative methodologies used in collecting data, including interpretative phenomenological analysis as used in this research. Also discussed are physical responses of people in GIR groups and neuroscientific studies of the reading brain coming out of the Centre for Research for Reading, Literature and Society (CRILS) at the University of Liverpool, and out of the University of Exeter.

There is limited reference to creative bibliotherapy use in public libraries in the literature. Hick's 2006 audit of bibliotherapy activity in public libraries in England established that there was a 'small amount of creative bibliotherapy activity conducted on the basis of local initiatives' (Hicks 2006, p. 6). Alternative settings to libraries include The School of Life, founded by Alain De Bottom in London, which employs bookstore owners, PhD candidates and literature lovers to provide 'literary prescriptions'. Despite use of the term 'prescription', this is not a clinical-based model or connected with Books on Prescription (as provided by doctors). A literary prescription, or fiction reading recommendation, is made (at a cost) after the School of Life bibliotherapist discusses a person's concerns and their reading histories (The School of Life, n.d.). The service, often provided online, is aimed at individuals, couples and families who may not be clinically depressed but who are experiencing stress due to life stages and life transitions such as work, divorce and mid-life crisis. In 2020 Gertrude and Alice's bookstore in Bondi, New South Wales and literary blogger Lucy Pearson, teamed up to provide 'literary prescriptions', similarly to The School of Life as described above (Kraner-tucci 2020), and also for a cost. 


\subsubsection{Creative bibliotherapy in criminal justice}

Coyle (1987) states that libraries arose in jails in Europe and America as early as the seventeenth century. By the mid-1830s prisons of similar design were being built across most of the north-eastern states of America, and they all included a library.

Prison libraries began to be established in some Australian penal settlements post-1830. The ships transporting convicts to Australia included books for these libraries as well as a librarian who had been appointed to care for the books on board the ship.

However, research indicates that the actual prison libraries were maintained predominately by the convicts themselves (Carroll \& Garner, 2017a). Library registers show that the collections included a large selection of poetry and some novels and, similar to creative bibliotherapy, '(r)eading aloud to the convict population was a common part of prison routine with regular readings', although predominantly from 'sacred texts and worthy books' (Carroll \& Garner, 2017b).

Sclabassi $(1973$, p. 75$)$ reports that researchers interested in the use of bibliotherapy within the broad field of corrections claim that it has resulted in a lower percentage of recidivism. A more recent study by Pardini et al. (2014) revealed that bibliotherapy using self-help books was successful in relieving depression and other psychological symptoms in prison inmates. Similarly, Garner (2020, p. 16) discovered that 'prisoners needed to be given opportunities to read, to find relief and escape from their situation' of anxiety and other psychological symptoms. In an earlier study, Garner (2017, p. 340), in examining the lived experiences of Australian prisoners, found that reading supports prisoners' mental state through 'a means of connecting with others'. Developing this idea of connecting with others within a recidivism-reduction focus, the University of Massachusetts developed a community-based bibliotherapy program entitled 'Changing Lives Through Literature' (CLTL), using literary texts within the criminal justice area as an alternative to jail. Since 1991, the CLTL program has grown to 20 community programs across the US and England (see Section 2.5.3: The success of creative bibliotherapy to effect wellbeing). In 1992, the Jail Library Group (JLG) began bibliotherapy work as a practical activity in the Graduate School of Library and Information Studies program at the University of Wisconsin-Madison. Their initiative was acknowledged by a 'Community-University Partnership Award' from over 3,000 nominations of community initiatives in the State of Wisconsin. Furthering the work in 
this area, TRO, using the Get Into Reading (GIR) model, began reading groups as a therapeutic intervention in men's and women's prisons in the UK (Billington 2011, p. 67).

\subsubsection{Creative bibliotherapy within aged care}

Aged care providers are keen to provide a facilitated cognitive stimulating activity for their residents to compliment other activities such as arts and craft activities and bingo. Reading aloud groups offer a cheap and accessible intervention within aged care facilities, offering regularity, continuity and structure for people whose lives may be empty (Orrell et al., 2017).

Book Well partner organisations specifically 'hoped for the reading groups to provide cognitive stimulation' in aged care settings (Clark et al. 2019, p. 102). Davis et al. (2019, pp. 293-295) undertook neuroscientific studies of the reading brain, including MRI brainimaging experiments, which made it possible to see the brain light up and make robust interconnections when poems or stories created a suddenly raised level of attention, having a positive effect on people with dementia.

The Alzheimer's Poetry Project (AAP), USA, is an example of a non-clinical intervention for groups of people with dementia utilising poetry to inspire creative self-expression, reduce social isolation, and provide social and intellectual stimulation. Since 2003, AAP has conducted poetry sessions in 32 states in the USA and seven countries in different cultures and languages, including English, German, Hmong, Polish, Korean, Japanese, Mandarin and Spanish. AAP's observations and research report positive impacts and improvements in aged care home participant mood, attention, engagement and communication (Australian Centre for Arts and Health, 2018).

\subsection{The effectiveness of bibliotherapy}

Throughout the evolution of bibliotherapy key theorists and other significant studies have demonstrated a growing interest in the effectiveness of bibliotherapy. Section 2.5 will look at the effectiveness of bibliotherapy across both clinical and non-clinical settings as an adjunct treatment to support psychological, emotional and social challenges. 


\subsubsection{Bibliotherapy used within clinical settings}

An important concept of bibliotherapy is a notion that its earliest purpose was to provide treatment for psychological problems. The goal of bibliotherapy within a clinical setting is to provide an adjunct treatment for treating mental health illnesses such as mild to moderate depression and anxiety (Glasziou et al., 2013). Cognitive behavioural therapy (CBT) is often used as a sole or adjunct treatment for psychological problems (Kenwright, 2010) and prescribing a self-help book that can provide the patient with a range of techniques for changing thoughts, feelings and behaviours (Neenan \& Palmer 2012, p. xi) is a form of CBT. Some level of interactive support from a health professional is generally offered to encourage the patient to read the text and to explain any parts of the text that may need further clarification. The professional can interact with the patient through face-to-face contact, by telephone, by email, or another online communication method, such as Skype or Zoom (Cuijpers et al., 2010a). The level of interaction is determined by whether the model used is guided or semi-guided, and whether the patient works through the book independently, or with the health professional providing instructions on how to apply the strategies. Guided self-help may take place over multiple face-to-face sessions while semiguided self-help bibliotherapy provides only minimal follow-up support from a health professional, usually through telephone or email communication.

From the mid-twentieth century, studies focusing on the use of self-help books progressed from qualitative accounts to quantitative clinical trials. The effectiveness of clinical bibliotherapy has been more recently established using psychological statistical testing criteria measuring improvements in mental health. Some examples of studies focusing on how the treatment of psychological problems using self-help bibliotherapy has shown effective outcomes include:

- Anxiety (Matcham et al., 2014).

- Bulimia (Beinter et al., 2014; Troop et al., 1995).

- Depression (Cuijpers, 1997 \& 1998; Floyd, 2003; Frazer et al., 2005; Jamison \& Scogin, 1995; Smith et al., 1997)

- Headaches (Difede \& Blanchard, 2005; Strőm et al., 2000).

- Insomnia (Mimeault \& Morin, 1999; Strőm et al., 2004). 
- Migraines (McGrath et al., 1992).

- Mindfulness (Cavanagh et al., 2014).

- Post-traumatic stress (Ehlers et al., 2005).

- Problem drinking (Apodaca \& Miller, 2003).

- Sexual issues (Mintz et al., 2012; Van Lankveld, 1998).

- Young adult depression (Moldovan et al., 2012).

In particular, Cuijpers et al. (2011) completed a meta-analyse of research which showed that guided self-help bibliotherapy treatment has significant effectiveness in the treatment of depression and anxiety. In 2013 Cuijpers et al. focused on self-help for depression and hopelessness in a meta-analysis of 13 studies and 616 respondents which showed that the effectiveness of self-help bibliotherapy treatment was significant. In this analysis, the randomised controlled trials included: Carrington, 2006; Collins, 1996; Duarte et al., 2009; Hepburn et al., 2009; Laidlaw et al., 2008; McKendree-Smith, 1998; Pecheur \& Edwards, 1984; and, Rohen, 2002. Bower et al. (2013) in a meta-analysis from 16 data sets of 2470 patients with depression found similar outcomes.

Other effective randomised control trials include Clarke (2005), de Graaf (2009), Meyer et al. (2009), Salkovskis et al. (2006). In Australia, self-help '(b)ibliotherapy has NHMRC Level 1 evidence of efficacy' (Glasziou et al. 2013, p. 200); that is, evidence obtained from a systematic review of all relevant randomised controlled trials.

\subsubsection{The success of bibliotherapy to effect wellbeing}

Most randomised controlled trials and meta-analyses have provided evidence that self-help bibliotherapy is an effective adjunct treatment for mental health, especially in cost-driven service provision. Providing self-help through schemes like Books on Prescription can have a cost-benefit through purchasing power, reducing costs when provided on a larger scale (Brewster 2008).

Individuals can feel 'stigmatized' by seeking treatment for mental health problems (Cuijpers 1997, p. 141) and some studies have shown a preference for bibliotherapy over face-to-face psychological intervention (Clarke et al., 2005; Floyd et al., 2004 \& 2006; Wollershiem \& Wilson, 1991). The research suggests that people with mental health challenges favour selfhelp strategies such as bibliotherapy to more traditionally prescribed treatments such as 
drugs. Priest et al. (1996) found a preference for non-drug approaches over prescribed medications.

Interestingly, studies have indicated that the success of bibliotherapy was not influenced by the level of therapist contact (Cuijpers et al., 2010b; Cuijpers \& Schuurmans, 2007). In most cases, an effective patient-therapist relationship was achieved with only minimal contact, with the therapist (Furmark et al., 2009), that is, semi-guided, and just providing access to self-help books can produce improvement for individuals (Williams et al., 2013).

The success of bibliotherapy as a therapeutic tool, within clinical settings, is linked to outcomes based on symptom reduction measurement but it is unclear if different studies include the same methods of outcome measurement, such as the type and length of treatment and initial symptom severity (Shadish \& Sweeney, 1991; Spielmans et al., 2007). Additionally, not all self-help models, or health professionals, recommend the same books so the results of different trials cannot be generalised (Richardson et al., 2008). Also of consideration is the fact these studies don't include details of how much of a book is actually read during treatment (Bowman et al., 1995), or include a measurement of the reading level of patients (Glasziou et al., 2013).

\subsubsection{The success of creative bibliotherapy to effect wellbeing}

A broad array of qualitative studies of creative bibliotherapy acknowledge the success of creative bibliotherapy to support psychological, social and emotional challenges (Matthijs Bal \& Veltkamp, 2013; Djikic et al., 2009; Dodell-Feder \& Tamir, 2018; Kid \& Castano, 2013; Koopman 2011, 2013 \& 2015; Longden et al., 2015; Mar et al., 2006; Oately \& Djikic, 2018; Pino \& Mazza, 2016).

Benefield et al. (2019) suggest that creative bibliotherapy offers opportunities to engage people through methods other than traditional therapy, through supporting people to change thinking around personal difficulties. Gray et al. (2019) describe creative bibliotherapy as providing a safe and intimate social space that provides and a meaningful activity in terms of both the immediate reading experience and the purpose it brought to people's lives.

In 2013, a quantitative study, and the first known independent randomised controlled trials, evaluating the 'Get Into Reading' model was conducted in Italy, with 41 hospitalised 
participants with psychosis. Even though the sample size was small, results showed significant improvement in the wellbeing and symptoms of the participants (Volpe et al., 2013).

Although there are limited studies to draw on, Glavin and Montgomery $(2017$, p. 103) explored the effectiveness of creative bibliotherapy in reducing symptoms in adults with post-traumatic stress disorder (PTSD) and found 'there is too little evidence regarding bibliotherapy to begin using it in practice with populations effected by PTSD although the absence of harm would suggest that in the context of studies it would be worth further exploration'.

Creative bibliotherapy work within the criminal justice area has shown positive results as a therapeutic tool. The University of Massachusetts developed the community-based The Changing Lives Through Literature (CLTL) bibliotherapy program in 1991 as an alternative to jail. A 1998 evaluation of the program indicated the program had a positive impact both on the individual group members and the communities in which they live. The evaluation noted a reconviction rate of only $18.75 \%$ from the CLTL group compared with $45 \%$ in the comparison group (Jarjoura \& Krumholz, 1998). A 2013 evaluation (Schutt et al.) replicated and extended the 1998 evaluation of CLTL impact on recidivism conducted by Jarjoura \& Krumholz. Schutt et al. used a larger sample, covered more jurisdictions and allowed a longer follow-up period. They looked at behaviour 18 months before CLTL and 18 months after CLTL. There were 600 participants in the study. There was a 60\% drop [in reoffending] for CLTL participants and $16 \%$ for others. This more recent evaluation also found 'the rate of recidivism and offense severity declined for program participants more than for those in the comparison group' (Schutt et al. 2013, p. 181). Both the number and severity of incidents were reduced (Stoehr, 2016). The evaluation proposed that the program has achieved remarkable results, holding a high-value proposition in the community (Andrews \& Bonta, 2010).

The Reader Organisation (TRO) has conducted research studies into the use of the Get Into Reading creative bibliotherapy model in a range of settings, and its ability to influence mental health and wellbeing in reading groups, particularly for depression and dementia: Billington et al. (2010) conducted a one-year research study into the therapeutic benefits of reading groups in relation to depression and wellbeing. The study looked at the data from 
two groups in Liverpool in the UK; one in in a GP surgery and the other in a health drop-in centre. The clinical data indicated that statistically significant improvements in the mental health of depressed patients had occurred during the 12-month period in which they had attended reading groups.

Longden et al. (2016) investigated the impact that engaging in a reading group activity held in Merseyside, UK had on participants with mild to moderate dementia. The data revealed that belonging to a reading group was strongly conducive to wellbeing.

Robinson \& Billington (2013) found significant improvement in wellbeing when investigating women in prison engaging in a reading group activity.

Billington et al. (2017, p. 155) compared standard therapy for chronic pain with reading group activity. The data provided evidence that group reading had the 'potential as an alternative or long-term follow-up or adjunct to CBT'.

In an unpublished evaluation of the Book Well program delivered at State Library Victoria feedback received from participants and partners was overwhelmingly positive, with 96 per cent of respondents recording positive wellbeing impacts. As most of the groups took place in the aged care sector, the feedback was predominately from residents and staff of aged care facilities. Thirty-six per cent of the respondents felt encouraged, 42 per cent felt uplifted and 18 per cent felt calm. A small number ( 4 per cent of the total) felt a negative response, however, comments by participants showed these negative responses were usually brought about by the story itself.

Research over a significant time period demonstrates the success of bibliotherapy generally as an adjunct treatment for supporting psychological, emotional and social challenges in a variety of environments. Creative bibliotherapy research, although in its early stages, indicates that it potentially offers opportunities as an effective adjunct therapy. Broadly, studies indicate that creative bibliotherapy delivered in community settings offers nonspecified but individual therapeutic benefits (Hodge et al., 2007), including reducing isolation and promoting a sense of wellbeing (Billington et al., 2010). Pettersson (2018, p. 127) asserts that creative bibliotherapy offers 'a pathway to new perspectives, [and]... has similar results to those sought in psychoanalytically influenced bibliotherapy: recognition and insight'. 


\subsection{Creative bibliotherapy training}

This section addresses the training offered for delivering creative bibliotherapy for participants in community groups. A chronological overview of developments in training for creative bibliotherapy will be provided.

In the 1962 special issue of Library Trends focusing on bibliotherapy (see Section 2.3: Objectives of bibliotherapy), Margaret Kinney considered the need for training in bibliotherapy, and training requirements. Following the 1962 special issue of Library Trends focusing on bibliotherapy, the American Library Association (ALA) held a three-day bibliotherapy workshop in 1964. The attendees were diverse and included physicians, occupational therapists, psychologists, librarians, educators and chaplains. The most important outcome of this workshop was the consensus that there were three fundamental requirements for bibliotherapy to develop as a field:

1. Bibliotherapy training courses

2. More conclusive research

3. A standard terminology

Subsequently, Arleen McCarty Hynes, librarian at St. Elizabeth's Hospital in Washington, D.C., founded the ALA Bibliotherapy Round Table in the early 1970s, which funded lectures and an annual conference to promote education for bibliotherapy.

Chadbourne (1976, p. 19) agreed with Kinney that a bibliotherapist 'should be a librarian trained in clinical methods, instead of a clinician trained in library methods'. Hendricks et al. (1999) discuss an early US attempt at bibliotherapy training when '(i)n 1970, Reverend Louis Rongione, of Villanova University Graduate School of Library Science, taught one of the first classes on the theory of bibliotherapy'. The idea of training was further pursued in 1973 when Arleen McCarty Hynes established a hospital-based training program in bibliotherapy (McCulliss \& Chamberlain, 2013). Hynes, a hospital librarian, began a training program in library studies at St. Elizabeth's Hospital in Washington, D.C. The training, which included bibliotherapy, had a minimum requirement of 448 hours of study over a two-year period (Rubin, 1979).

In 1980 Tietjen (1980) reported on a survey to determine levels of bibliotherapy training undertaken by sixty-nine library professionals. The survey indicated that only one college, 
the Catholic University of America, offered a formal bibliotherapy course. Eight others indicated bibliotherapy as a unit within a broader course, such as Librarianship; six noted that students could elect to pursue bibliotherapy through independent study or special projects; and three reported undertaking short courses or workshops involving bibliotherapy (Tietjen 1980). However, since this time, there has been very limited training in bibliotherapy reported worldwide. Training for creative bibliotherapy will be discussed in Section 2.6.

With regard to developing bibliotherapy Panella $(1996$, p. 52) describes the sustained efforts through the 20th century:

to establish organized libraries for hospitalized people but also to expand and systematically study bibliotherapy and to shape patients' librarianship as a professional specialty. The movement's achievements include the establishment of patients' library committees within national and international associations; impetus for development of academic programs to train patients' librarians; and publication, from 1944 through 1970 , of successive sets of standards for hospital patients' libraries.' However, despite these efforts 'patients' librarianship' has not been further developed.

At the end of the twentieth century, Schlenther (1999, p. 32) asked a question considering the multidisciplinary nature of bibliotherapy:

Why are there no training courses in reading therapy? One can study music therapy, art therapy and drama therapy... Why not reading therapy? I think the answers lie in the diversity of it. When searching the literature, one finds books and articles in medical journals, nursing journals, library journals, welfare and social service journals, education and play group journals, and in psychology and sociology journals. A great number of people are interested in it, each from his or her point of view.

More recent research shows a limited global offering of training but it is interesting that overall the term 'bibliotherapy' is rarely used in the limited global offerings reporting relevant programs.

The Changing Lives Through Literature program (CLTL) offered a one-day annual training program when the training was developing in the US in the 1990s, and the UK in 2000s. The training was delivered through three one and a half hour discussions: a short story discussion, a roundtable discussion, and a panel discussion. However, rather than actual training CLTL now encourages people who are wanting to start a CLTL program to make 
contact with them for support and to use the resources provided on their website. These resources include sample lesson plans and text suggestions. The resources offer book, or 'biblio', suggestions and ways to work with them are provided. The 'therapy' element is included in a general way through encouraging participants in bibliotherapy sessions to reflect on and consider their behaviour by looking at the behaviour of characters in stories (Changing Lives Through Literature, 2003).

The Reader Organisation (TRO) provides UK-based 'Read to Lead' face-to-face training for the Get Into Reading program (as discussed in Chapter 1.4: Background to the training). Originally a sequential five-day residential course, training is now offered over three days across several weeks. The training offers 'biblio' suggestions and ways to work with books, poems and stories are provided but there is no consideration of actual therapy.

In the UK, Kirklees Library and Information Centre runs creative bibliotherapy sessions, offers a short video about bibliotherapy, and provides 'Well Into Words' bibliotherapy training. Kirklees Council 'believe we were the first to begin using bibliotherapy in Britain in 2000' and claim that as leaders in the field they have developed many 'tools' of engagement and diverse techniques. Since that time they have 'delivered thousands of sessions in settings such as acute psychiatric admission wards, dementia care wards, day centres, dementia cafes, rehabilitation centres, stroke association meetings, alcohol and drug addiction centres and care homes... and have trained staff from health, social care, other library authorities, charities and community organisations and also deliver sessions to mental health degree nurses' (Kirklees Council, n.d.). 'Well Into Words' has an active Facebook page (Kirklees, 2019) that lists research on bibliotherapy and describes different approaches to conducting bibliotherapy. In 2020, author Anne Cleeves and previously a Kirklees Library bibliotherapist announced she is providing funding for the library to train more bibliotherapists to work for the Kirklees Library and Information Centre (Cleeves, 2020; Duffy, 2020).

In May 2015, in the Czech Republic, Masaryk University's Department of Psychology included an 'Introduction to Bibliotherapy' as part of the syllabus (Masaryk University, 2015). The instruction was delivered by the Institute of Library and Information Science from the University of Pécs, Hungary. One of the workshop aims was to provide an alternative tool for group therapy and it included instruction on selecting materials and 
creative writing as ways to develop problem-solving and a deeper understanding of oneself.

In October 2015, Lapidus Scotland, a community-based project focused on promoting health and wellbeing through creative words, workshops and events, (Lapidus Scotland, 2020), and the NHS Education for Scotland, developed 'Words Work Well Scotland Bibliotherapy Toolkit', to support facilitators when using stories and literary resources within a bibliotherapeutic framework (The Network, 2016). Lapidus Scotland uses a dedicated webpage to provide information on how to use the tool kit, and extensive bibliotherapy resources and guides for facilitating bibliotherapy in groups (The Words for Wellbeing Organisation, 2020a). Training originally offered in 2020 has been rescheduled for March 2021 as a result of COVID-19 (Cockburn, 2020).

A free six-week online course using bibliotherapeutic principles was offered in 2016 by Professor Jonathon Bate and Dr Paula Byrne from the University of Warwick, entitled 'Literature and mental health: reading for wellbeing' (FutureLearn, 2016). Bate and Byrne use poems, plays and novels to demonstrate how using classic literature and poetry can support people experiencing stress, heartbreak, bereavement, trauma, depression, bipolar, ageing and dementia. This course was open to anyone with an interest in literature or mental health. No previous experience or qualifications were required. A bibliotherapy related online course was offered in 2020 entitled 'Understanding anxiety, depression and CBT. Improve your understanding of depression and anxiety and find out more about an effective and evidence-based treatment: CBT' (FutureLearn, 2020).

\subsection{Chapter Two concluding comments}

The literature reviewed describes the concept of bibliotherapy as both old and new. It is old because the therapeutic value of reading has been recognized from ancient times. It is new in the sense that variant creative practices and innovative applications have recently been developed to use literary texts within diverse community therapeutic contexts. Rubin (1978a \& 1978b) described the benefits of bibliotherapy, using literary texts with people without diagnoses of mental illness, to help manage psychological, emotional and social challenges. In that sense, bibliotherapy can be seen as far broader than the traditional use of prescribing non-fiction cognitive behavioural therapy books as a clinical treatment. Several significant pieces of literature have advanced the development of creative 
bibliotherapy using literary texts. Shrodes (1949), in the first academic thesis on the subject, maintained that literary texts showed greater therapeutic potential due to the reader's emotional experience. Morrison (2008) asserted that bibliotherapy works best using literary texts to help people improve their mental health and wellbeing. A fundamentally important development is that the purpose of bibliotherapy has shifted from just helping individuals recover their mental health to facilitating the promotion of good mental health, and thus support wellbeing.

Davis et al. (2019, p. 304) write that readers themselves are not consciously aware of the dynamic cognitive and emotional interplay that determines their experiences. The effect of reading literature in this regard is likely to involve complex processes that take place "behind the scenes'. These processes are developed further through exploring the separate 'biblio' and 'therapy' elements in Chapter Five, Six and Seven. Providing greater understanding of the separate elements will increase the success of bibliotherapy to support wellbeing.

The more recent case studies presented in Section 2.4.3: Creative bibliotherapy in community settings, draw on a range of practical delivery approaches. These, establish how libraries in particular can be engaged in bibliotherapy delivery as well as discussing overcoming challenges to support growth in creative bibliotherapy as a field of study and practice.

Chapter Three, will provide a detailed outline of the theoretical orientations of interpretative phenomenological analysis (IPA); the methodology that has been selected to examine the data to answer the research question and describe the methods employed for collecting and analysing data. 


\section{Chapter Three: Methodology and methods}

\section{Introduction}

Chapter Three introduces the methodological framework for the study and a detailed overview of the theoretical orientations of interpretative phenomenological analysis (IPA), the analysis method used in this study. IPA draws on the theoretical orientations of phenomenology and hermeneutics. The research is an interpretivist, social constructivist approach to the research problem using the participants' and researcher's personal narratives. The study is dependent on the participants' views of the phenomenon being studied as they tell their experiences, while recognising the influence of the researcher's own background and experiences (Cresswell, 2018).

Chapter Three is split into two main sections. Initially, Section 3.1: methodology, examines both the phenomenology and hermeneutics approaches and outlines how, together, they are suited to effectively answer the research question. The second section, Section: 3.2, outlines the research design. The research methods employed for collecting and analysing data are described; information on recruiting research participants, ethics approval, interview question development, data recording and storage, identifying themes, coding and theme development are discussed. Section 3.3 briefly contrasts IPA to reader-response theory, narrative theory and grounded theory. Section 3.4 introduces the research participants.

\subsection{Methodology}

IPA is valuable for complex, ambiguous and emotionally laden topics such as that examined in this research into creative bibliotherapy (Smith \& Osborne, 2015). Interpretative phenomenological analysis (IPA) is a variant of phenomenology that draws on the theoretical orientations of phenomenology and hermeneutics. Sections 3.1.1 and 3.1.2 will discuss how phenomenology and hermeneutics together form the Interpretative phenomenological analysis approach.

\subsubsection{Interpretative phenomenological analysis (IPA)}

Johnathan Smith, Professor of Psychology, Birkbeck University of London, conceptualised IPA in the mid-1990s. Smith's 1996a article, entitled 'Beyond the divide between cognition 
and discourse: using interpretative phenomenological analysis in health psychology', published in Psychology \& Health by the American Psychological Association, argued 'for a qualitative approach central to psychology, rather than importing one from a different discipline'.

The IPA approach, as developed by Smith, draws on the work of key phenomenological and hermeneutic theorists including Gadamer, Husserl, Heidegger and Schleiermacher (Smith, 2007). IPA blends philosophies from phenomenology and hermeneutics, offering a method that is both descriptive (phenomenology) and interpretative (hermeneutics) in its approach (Pietkiewicz \& Smith, 2014).

Smith (2011a) articulated that when he first developed IPA in the mid-1990s his motivation was to be able to achieve a rich and detailed portrayal of personal experience that was not being captured by current psychological research. Smith (2011b, pp. 55-66) was concerned that he needed 'to make a robust, vigorous and uncompromising case for qualitative psychology centred on individual personal experience because this was so lacking at the time'. IPA has become an established and significant qualitative approach in psychology (Todorova, 2011). Although its foundations are in psychology it has assumed an increasingly used position in qualitative research more broadly, across many fields (Willig, 2001). Multiple social science disciplines and community therapy-related settings are increasingly choosing IPA as a research methodology, including the areas of coaching and mentoring (Fouracres \& Nieuerburgh, 2020), counselling (Harrison et al., 2020), family studies (Armitage et al., 2020), geriatrics (Mole et al., 2019), and occupational therapy (Newport \& Clarke, 2020) to name just a small selection.

The aim of analysis using IPA is to reveal key themes that capture the meaning of the specific experience of a phenomenon (Smith, 1996a; 2996b). The themes are given breadth and depth by the use of illustrative quotes 'to give some indication of convergence and divergence, representativeness and variability' (Smith 2011a, p. 24) 'to capture and explore the meanings that participants assign to their experiences' (Reid et al. 2005, p. 20). With regard to sample size, there is an agreement that there is no right answer for IPA studies, with no rules regarding how many participants should be included; numbers typically vary between two and 25 (Alase, 2017; Pietkiewicz \& Smith, 2014; Smith et al., 2009). However 'fewer participants examined at a greater depth is always preferable to a 
broader, shallow and simply descriptive analysis of many individuals' (Hefferon \& GilRodriguez 2011, p. 756). The most crucial factor is that 'the selection of participants should reflect and represent the homogeneity that exists among the participants' sample pool' (Alase 2017, p. 13) to allow in-depth development of analysis of rich data providing common themes from shared experiences (Sandelowski, 1995; Smith et al., 2009; Vasileiou et al., 2018).

The method is described as a process where 'the participants are trying to make sense of their world; the researcher is trying to make sense of the participants trying to make sense of their world' (Smith \& Osborn 2003, p. 51). The IPA researcher is considered inseparable from assumptions and preconceptions about the phenomenon. This calls for the IPA researcher to possess both a comprehensive knowledge of the phenomenon under examination, as well as an understanding of the culture underpinning the phenomenon.

'Lived experience' is a fundamental principle to IPA. The 'experience' within this research study refers to the research participants' relationship to bibliotherapy through undertaking creative bibliotherapy training and subsequent program delivery. The researcher shared this 'experience' through coordinating and evaluating the Melbourne bibliotherapy training and the subsequent report writing and acquittal of the VicHealth grant that contributed to funding the training.

Smith et al. (2009, p. 57) state that 'an IPA research study should conduct semi-structured and unstructured interviews with as many as 25 participants, as few as two'. The 20 people who shared the bibliotherapy training experience were invited to participate in this research, resulting in a sample size of 17 . Of the 17 participants, 15 were public librarians from a wide range of metropolitan, suburban and country public libraries, one was an English as Second Language teacher, and another, a counsellor.

As indicated above, IPA calls for the researcher to have both knowledge and cultural understanding of the phenomenon. Before coordinating the Melbourne bibliotherapy training, the researcher undertook bibliotherapy training in the UK. I subsequently delivered bibliotherapy to socially isolated and marginalised groups in Victoria, such as homeless people, prisoners, in a range of community settings to further understand community demographics and analyse community needs. This developed both a comprehensive knowledge of the phenomenon under examination, and an understanding of the culture 
underpinning the phenomenon.

In IPA, rather than setting aside the researcher's beliefs, values and experiences, the researcher is considered valuable to the examination and significant to making the investigation meaningful. This approach enables researchers to make interpretations according to their own theoretical experiences; thus, the researcher's experiences and perceptions are incorporated into the research discussion.

\subsubsection{Theoretical orientations of IPA}

\subsubsection{Phenomenology}

Originating in the early twentieth century as a psychological approach to examining a phenomenon, phenomenology is 'concerned with the way things appear to individuals' with the aim of 'identifying the essential components of... experiences' (Pietkiewicz \& Smith 2014 , p. 8). Phenomenology is influenced by the thinking of Edmund Husserl (1859-1938). Husserl's phenomenology involved his notion of the importance of the method for gaining knowledge when looking at the experiences of others. In his lectures on 'The idea of phenomenology' he discusses the perplexities of the possibility of knowledge, in that:

Natural thought in life and in science is untroubled by the difficulties concerning the possibility of knowledge, while philosophical thought is determined by the position taken with respect to the problems of the possibility of knowledge. (Husserl 1999, p. 61)

Husserl maintained that only a specific method could establish knowledge from 'feeling (or thinking) one's way into the first-person, or experimental life of another consciousness' (Moran \& Cohen 2012, p. 94). Roberts (2013) defines the methodology of phenomenology as focusing on participants' descriptions of lived experience. Macleod (2019) states that IPA's distinguishing feature is that it makes participants' interpretations the most prominent or important feature of the analysis. This feature is useful for gaining an insight into the lived experience of the facilitators of creative bibliotherapy who were participants in this study.

\subsubsection{Hermeneutics}

Husserl's process was further developed by his student Martin Heidegger (1889-1976) into hermeneutic phenomenology. Heidegger's (1971, p. 151) 'lived experience' is a fundamental 
principle of IPA and is based on the understanding that "knowledge is not something perceived as a spectator; rather it is something that the learner is a participant in effecting'. Smith (2007) describes Heidegger's phenomenology as concerned with examining something deeply. In this way, hermeneutic phenomenological studies could be defined as focusing on understanding participants' lived experience (Roberts, 2013), while acknowledging that interpretation may be required to help with developing an understanding of the phenomenon. Within hermeneutic phenomenological studies, the concepts of the hermeneutic circle and double hermeneutic are central to interpreting lived experience (Smith, 2007) and will be defined more fully later in this chapter.

Originally hermeneutics were used during the nineteenth and twentieth centuries to aid the interpretation of biblical texts. The approach was subsequently developed across the humanities disciplines of history, law, literature and the arts. More recently, disciplines of contemporary human sciences such as psychology, sociology, political science and cognitive sciences such as linguistics (Smith, 2007) have employed hermeneutics. The researcher invites the participant to talk about their experiences, and the recorded conversation is then transcribed and interpreted.

Hermeneutics is also influenced by the thinking of Friedrich Schleiermacher (1768-1834) and Hans-Georg Gadamer (1900-2002). Schleiermacher's method of interpretation could be considered a holistic analysis involving a range of skills. Psychological and linguistic elements are used to make sense of words, both written and spoken, as well as intuition and consideration of the author or speaker's feelings in an attempt to make sense of the person who said them (Smith, 2007). Gadamer's process of analysis gave more importance to the meaning of the text, otherwise referred to as the art of interpreting a text. Gadamer's hermeneutics originated in biblical and legal disciplines and was later extended to all texts. Gadamer sought 'primarily to understand the content of what is being said and only secondarily to isolate and understand another's meaning' (Gadamer 1990, p. 294). Heidegger (1962) however encouraged exploration of the reason behind the words, both written and spoken, through the process of the hermeneutic circle. The hermeneutic circle, conceptualised by Heidegger, is considered perhaps the most significant component of hermeneutic theory. Smith et al. $(2009$, p. 28$)$ describe the concept of the hermeneutic circle as 'the dynamic relationship between the part and the whole, at a series of levels'. The 
hermeneutic circle is a non-linear approach to thinking that supports the interpretative aspect of analysis integral to IPA (Smith, 2011c; Smith et al., 2009; Stanley \& Nayar, 2014). It is also particularly relevant to this research study which uses the dual foci of books and therapy to consider and interpret both the parts and the whole of bibliotherapy. The hermeneutic circle is discussed further in Section 3.1.5.1.

In addition, the hermeneutic orientations within IPA can be seen in the double interpretation phase in which the participant and researcher are both interpreting through a process Smith and Osborne (2003, p. 51) referred to as 'double hermeneutics'. 'The value of the double hermeneutic lies in acknowledging that the researcher and participants can look at the same phenomena from different angles' (Wagstaff et al. 2014, p. 6). In this stage, the researcher brings personal perspectives to the meaning-making (Bevan, 2014; Elliot et al., 2012; Finlay, 2011; Stanley \& Nayar, 2014). In this second level of interpretation, the researcher endeavours to not only respond directly to what the participants have said but also build on the phenomenon under investigation by using related reading and the researcher's perspective to assist in interpreting what the participant has described. Engaging in a double hermeneutic is central to IPA (Smith \& Osborn, 2003) and demonstrates 'the dual role of the researcher as both like and unlike the participant' (Smith et al. 2009, p. 35). A double hermeneutic was used to effectively answer the research question in this study. Firstly, through exploring research participants' own understandings of facilitating the bibliotherapeutic process; then, by applying my knowledge and experience of bibliotherapy to the participant's initial personal sense-making (Finlay \& Ballinger, 2006; Smith \& Osborn, 2003). This provided a deeper and more insightful analysis in Chapter Seven. The double hermeneutic is discussed further in Section 3.1.5.2.

\subsubsection{Interpretation}

The philosophical foundations of these two traditional research approaches (phenomenology and hermeneutics) are concerned centrally with lived experience. However, the focus of how the experience is explored is different from each tradition. Phenomenological research is a descriptive form of interpretation, focusing on the understanding of the experience that exists in the minds of people experiencing the phenomena (Goering \& Streiner, 1996). As such it runs the risk of being solely focused on 
understanding phenomena from the perspectives of the people who are being studied, rather than looking for the cause of particular phenomena (Patton, 1991). To fully consider the nature of a topic, there must be an interactive relationship between the observer and observed (Carr, 1994).

In hermeneutic research, interpretation is seen as fundamental to creating meaning and developing understanding. 'Interpretation in the sense relevant to hermeneutics, is an attempt to make clear, to make sense of an object of study' (Taylor 1971, p. 3). Although phenomenology supports rich descriptions of the participants' experiences, while simultaneously illuminating possibilities not evident previously, 'phenomenology does not categorise or explain behaviour nor does it generate theory' (Finlay 2011, p. 3). The absence of interpretation within phenomenology is balanced with hermeneutics, which is concerned with the theory and practice of interpretation.

Many theorists have expanded on and moved forward the phenomenology and hermeneutics theories (Giorgi, 1994; Moustakas, 1994; Polkinghorne, 1989; van Manen, 1990). Smith, Flowers and Larkin (2009) individually and collectively have conceptualised and developed the new phenomenological research of IPA. With phenomenology foundations in health psychology, and hermeneutics foundations in the arts, IPA is both a fitting and exciting methodological approach for this research study; the former related to the therapeutic aspect of bibliotherapy and the latter to the 'biblio' in bibliotherapy.

\subsubsection{Strengths and limitations of the IPA approach}

In providing an overview of IPA, consideration must be given to its strengths and limitations. This chapter will now explore both the strengths and limitations of IPA and how this study addressed the limitations.

\subsubsection{Strengths of the IPA approach}

The strengths of the IPA approach include the creation of rich data, opportunities for diverse applicability, incorporation of the perspective of both researcher and participant, solid philosophical and theoretical foundations, incorporation of explicit data collection guidelines, procedures for analysis, and flexibility. These strengths will be discussed in more detail. 


\subsubsection{Suitability of an IPA approach}

Since IPA's conception in the mid-1990s, it has experienced rapid growth in areas outside of psychology. Ward and Miller (2013) have found a growing body of research studies using IPA to analyse the experiences of healthcare professionals, and IPA has been applied in diverse clinical and non-clinical settings for its ability to provide 'a flexible framework that can be adapted by researchers in accordance with their research aims' (Frost 2011, p. 53).

There is now a large body of published IPA studies available to indicate the quality of research using an IPA approach. Smith (2011a), who conceptualised IPA, identified 294 articles on research studies employing an IPA methodology published between 1996 and 2008.

\subsubsection{Motivations for researchers to use an IPA approach}

Research overviews below provide examples of IPA capacity for research in therapy-related settings many of them innovative. Selected studies include coaching sports (Annerstedt \& Lindgren, 2014; Cronin \& Armour, 2013), lecturing/teaching (Knewstubb, 2016), musical shaping (Greasley \& Prior, 2013), music therapy (Solli \& Rolvsjord, 2014), nursing practice (Wilson, 2014), occupational therapy (Cronin-Davis et al., 2009), physiotherapy (Caeiro et al., 2014), and wellbeing, aging and arts (Southcott \& Joseph, 2014).

Therapy-based research studies using IPA:

- British Occupational therapist Jane Cronin-Davis described IPA as an appropriate methodology for occupational therapists as it enabled research participants to tell their stories while still acknowledging the researcher's influence within the research process, 'which has a similar philosophy to the person-centred nature of occupational therapy' (Cronin-Davis et al., 2009).

- In their research study entitled Singing in La Voce Della Luna Italian women's choir in Melbourne, Australia, Southcott and Joseph (2014) explored the use of IPA to analyse a single case study as part of a larger ongoing research project. Smith et al. (2009) maintain that the idiographic focus of IPA is particularly beneficial for case studies, enabling researchers to generate rich and detailed accounts on a particular phenomenon.

- Greasley and Prior (2013) used an IPA approach in a study with professional musicians. The idiographic focus within IPA appealed to Greasley and Prior because they could initially focus on a particular individual's understanding of their experience and then bring out similarities and differences between participants. 
- Solli and Rolvsjord (2014) recruited participants from Solli's music therapy practice at a secure intensive psychiatric unit at a hospital in Norway. Solli and Rolvsjord assert that maintaining a dual role as researcher and therapist was beneficial to the study, as it lowered the stress level of the participants. However, alongside having valuable experience of a phenomenon under investigation, IPA researchers are also required to sustain an attitude of reflexive self-awareness on meanings arising in the data and their role in interpreting those meanings (Bevan, 2014; Elliot et al., 2012; Finlay, 2011). Solli and Rolvsjord (2014, p. 6) found the IPA process of reflexive self-awareness allowed them to incorporate 'reflexivity notes... and regular conversations with the research supervisor'. Based on their findings, the authors indicated how research undertaken with an IPA approach could influence music therapy within clinical practice.

- Wilson (2014) used an IPA approach in a study investigating the experiences of nursing practitioners' working across a range of areas in the UK. She felt IPA provided 'a defendable framework in which to examine experiences of practice, from considerations of question formulation, ways of entering the hermeneutic circle, and sensitivity towards participants and their experiences, to reflexive engagement with the whole process' (pp. 32-33). She considered that the hermeneutic circle and the overlapping perspectives of the researchers' and the practitioners' experiences offered deeper understanding and interpretation and a rich portrayal of experience.

- Knewstubb (2016) undertook an investigation of student understandings of different lecturers' teachings within the same history course at a New Zealand university. Initially, data was collected separately from lecturers and students. An IPA idiographic focus supported the development of the individual experiences of each participant. A double hermeneutic IPA concept was then used to co-construct a narrative between students and lecturers to show patterns of similarity and difference within the history course.

- Caeiro et al. (2014) conducted a US study that aimed to explore 18 physiotherapists' experiences of undertaking a narrative reasoning course. The double hermeneutic IPA concept was used to interpret the students' and researchers' perspectives about the contribution of literature, arts and reflective writing in facilitating narrative reasoning competencies.

- Cronin and Armour (2013, p. 5) conducted a single case study investigation of a community coach who was employed to deliver sports coaching in schools and the wider community in the UK. They wanted to use IPA for its 'idiographic, flexible framework that embraces the researcher throughout the process'. Cronin and Armour felt IPA was particularly relevant in this study for its commitment to the in-depth analysis of individual cases. The idiographic perspective of IPA allowed for in-depth exploration of the coach, context and relevant environments that led to deepening understanding the complexities of lives in communities. 
- Swedish researchers, Annerstedt and Lindgren (2014) also conducted a single case study with a sporting coach. This study aimed to describe and analyse the experiences and strategies of a successful coach in high-performance sports. IPA suited the dual researchers in this project as they discussed their analysis with each other and reflectively analysed the data to promote their interpretations and perceptions.

These individual researchers' considerations of the elements of IPA collectively provide illumination of the overall assistance an IPA methodology can offer this current study. The researchers above acknowledged the value of the hermeneutic circle for its ability to offer deeper understanding and interpretation, through co-constructing a narrative between participants and the researcher as a way of showing patterns of similarity and difference. The significance of the hermeneutic circle within IPA is discussed in Section 3.1.5.1.

Reflexivity was also seen as important by the researchers as it calls for the researcher to have widespread knowledge of the phenomenon. The principles of reflexivity within an IPA study are deliberated in Section 3.1.4.1.

The selection of studies above, using IPA to research a spectrum of experiences ranging from traditional therapies to more contemporary applications, shows the potential for researchers to use IPA to evaluate innovative therapeutic programs (Dean et al., 2006; Gill, 2015; Laverty, 2003; Sandelowski, 2006), including a study evaluating an arts-based wellbeing program (Pienaar \& Reynolds, 2015). The discussion of IPA methodology below offers strong evidence that it is an appropriate methodology to explore and answer this study's research question.

\subsubsection{Limitations of IPA}

While there are strongly identifiable strengths linked to IPA, there must be an acknowledgment of several limitations. Wagstaff et al. (2014) consider IPA limitations based on the experiences of eight researchers using the approach. The research studies conducted in Australia, Ireland, Malaysia, New Zealand and the UK offer an intercultural perspective. Additionally, Smith's (2011a) guide for conducting effective IPA research, developed from reviewing 294 IPA papers, has provided further understanding of the limitations.

Furthermore, several other studies have been reviewed, including; Brocki and Wearden's (2006) critical evaluation of the use of IPA; Bevan (2014); Danaher and Briod (2005); Dean et al. (2006); Elliot et al. (2012); Finlay (2011); Larkin et al. (2011); Smith and Osborne (2007); 
and, Stanley and Nayar (2014). The discussion below addresses the main limitations of IPA as determined by the research undertaken by the above researchers. The table below acknowledges the impact of IPA limitations on this research project and proposes how this research study will address them.

Table 2: Addressing IPA limitations.

\begin{tabular}{|c|c|c|}
\hline & Limitation & How this study addressed the limitation \\
\hline 1 & $\begin{array}{l}\text { Incorrectly implementing the } \\
\text { double hermeneutic }\end{array}$ & $\begin{array}{l}\text { This study aimed for the analysis to be both } \\
\text { interpretative and descriptive. } \\
\text { Interpretative commentary follows extracts from } \\
\text { the interview transcripts to show specifically how } \\
\text { the data contributes to the development of the } \\
\text { themes. }\end{array}$ \\
\hline 2 & $\begin{array}{l}\text { Tension between participant and } \\
\text { researcher perspectives }\end{array}$ & $\begin{array}{l}\text { This study provides illustrations from several } \\
\text { participants per theme to determine the } \\
\text { commonality of a theme and provide interpretative } \\
\text { commentary on each of the extracts from the } \\
\text { transcripts presented to show how they contribute } \\
\text { to the developing theme. } \\
\text { This study aimed to understand how the IPA } \\
\text { approach recognises the role a researcher has in } \\
\text { bringing their perspectives to the analysis; a key } \\
\text { feature of IPA. The researcher built on the } \\
\text { phenomenon by incorporating the researcher's } \\
\text { perspective to assist with interpreting what the } \\
\text { participant described. I asserted my role, } \\
\text { acknowledged my perspectives, and integrated } \\
\text { pre-existing knowledge and experiences into the } \\
\text { interpretation (Chapter Seven). }\end{array}$ \\
\hline 3 & $\begin{array}{l}\text { Researchers feeling overwhelmed } \\
\text { by the amount of collected data }\end{array}$ & $\begin{array}{l}\text { This study aimed to select main themes rather than } \\
\text { developing too many emergent themes. }\end{array}$ \\
\hline 4 & $\begin{array}{l}\text { Classifying too many super- } \\
\text { ordinate themes }\end{array}$ & $\begin{array}{l}\text { This study aimed to give sufficient space to the } \\
\text { elaboration of each theme. } \\
\text { This study aimed to provide details of particular } \\
\text { aspects rather than a broad exploration; and to do } \\
\text { justice to each theme, rather than presenting many }\end{array}$ \\
\hline
\end{tabular}




\begin{tabular}{|l|l|l|}
\hline & & $\begin{array}{l}\text { themes superficially. This research aimed to } \\
\text { enhance the themes by having an extended and } \\
\text { elaborate account of the main themes of 'biblio' } \\
\text { and 'therapy'. }\end{array}$ \\
\hline 5 & $\begin{array}{l}\text { The opposition between } \\
\text { 'idiographic focus' }\end{array}$ & $\begin{array}{l}\text { The analysis followed an idiographic approach; that } \\
\text { is, consistently checking that themes were } \\
\text { grounded in the data and representative of the } \\
\text { participant's experience (Nowell et al., 2017). } \\
\text { This study aimed to point the analysis to both } \\
\text { convergence and divergence through both patterns } \\
\text { of similarity among participants as well as the } \\
\text { uniqueness of the individual experience. } \\
\text { The unfolding narrative aimed to provide a careful } \\
\text { interpretative analysis of how participants manifest } \\
\text { the same theme in specific and diverse ways. This } \\
\text { study aimed for a nuanced capturing of similarity } \\
\text { and difference, convergence and divergence. }\end{array}$ \\
\hline 6 & $\begin{array}{l}\text { Qualitative analysis software } \\
\text { works against IPA's idiographic } \\
\text { focus }\end{array}$ & $\begin{array}{l}\text { This study recognised the value of manual tools in } \\
\text { the analysis. } \\
\text { Using manual analysis tools meets the aim of IPA } \\
\text { analysis to show through depth, rather than } \\
\text { breadth, the participants' experiences, and the in- } \\
\text { depth idiographic perspective of IPA (see Section } \\
\text { 3.1.3.5: Manual analysis below). }\end{array}$ \\
\hline
\end{tabular}

\subsubsection{Manual analysis}

Zamawe, a research fellow at University College London (2015), asserts that coding based on software queries does not capture the nuances of meaning made possible by manually examining the transcripts in detail. IPA researchers Smith et al. (2009) and Wagstaff et al. (2014) also assert that IPA cannot be satisfactorily implemented with software. This study's researcher conducted a manual analysis of the research data, reading each transcript in detail and developed tables of themes, including transcript extracts.

Pietkiewicz and Smith (2014, p. 9) assert that IPA researchers aim to produce 'an in-depth examination of certain phenomena', rather than generalising; and to retain an individual focus as well as a focus across the group's experiences. Hefferon and Gil-Rodriguez (2011) advise IPA researchers to observe a simple guideline of having fewer themes in their 
research to achieve more depth in their IPA. Adequate room within this thesis has been given to explore and elaborate the two main themes of 'biblio' and 'therapy'. This allowed sufficient scope to demonstrate patterns of both similarity among participants, and the uniqueness of the individual experience. The themes were extended by developing the relationship of 'biblio' and 'therapy' to 'wellbeing'.

Superordinate themes are developed from emergent themes. However, in IPA, the superordinate themes provide an organising framework for the analysis; the emergent themes are discussed in detail in the write-up. The manual process supports the two levels of theme development in IPA; that is, 'emergent' and 'superordinate' (in IPA superordinate themes purely provide an organising framework for the analysis). Smith et al. (2009) state that during the analysis and writing up, some themes become illuminated, and others lose vigour, depending on the emergent data. In IPA, the superordinate themes act as the perimeters for patterns of convergence and divergence.

\subsubsection{How IPA is being used to answer the research question}

The specific characteristics of the IPA approach, including reflexivity, rigor, validity, and the analytical and idiographic focuses, will now be discussed.

\subsubsection{Reflexivity}

Within IPA the presence and subjectivity of the researcher are not hidden, rather, they are explained and incorporated into the research (Danaher \& Briod, 2005; Smith et al., 1999).

Thus, the researcher's input is considered as being integral and essential (Danaher \& Briod, 2005; Finlay, 2011) and 'acknowledging the researcher's interpretation is a key feature of IPA' (Dean et al. 2006, p. 151). However, The IPA approach allows that the participants' data is concurrently deepened and complicated by the researcher's experiences and opinions (Finlay, 2011; Smith et al., 2009). This study will ensure that the researcher's experiences respond directly to what the research participants have said to ensure that the researcher's experiences and opinions enrich, rather than contradict, the findings from data analysis. Fade (2004, p. 648) states that "researchers carrying out [descriptive] phenomenology studies have aimed to 'bracket out' their preconceptions". However, the IPA approach acknowledges the role a researcher has in interpretation and bracketing is not a feature of IPA research. 
Heidegger's phenomenology is useful in considering the role of the IPA researcher in that, through the process of moving around the hermeneutic circle, the interviewer, becomes a curious listener within the world of the participants. Heidegger promotes reflecting on the experience of both the participant and the self from a stance of curiosity and empathy (Ratcliffe, 2012). In IPA, the researcher supports this attitude through reflexive selfawareness when interpreting significant meanings emerging from the data (Bevan, 2014; Stanley \& Nayar, 2014). Finlay and Gough (2003, p. ix) define reflexivity as 'continuing selfawareness'. Reflexivity affects all qualitative research but the level of the effect depends on the degree the researcher is aware of the ways in which their own experiences influence the research process (Hennum, 2014; Jackson, 2003; Willig, 2001). The "knowledge produced by IPA is, [...] reflexive in so far as it acknowledges its dependence upon the researcher's own standpoint' (Willig 2001, p. 66).

\subsubsection{Rigor and validity}

As discussed above in sections 3.1.1: Interpretative phenomenological analysis (IPA) and 3.1.4.1: Reflexivity, the researcher's beliefs, values and experiences are considered valuable to the examination of data collected, and significant in adding depth to the research discussion. Brocki and Wearden (2006) note weakness in published IPA research, in that the interpretive role of the researcher is often not mentioned. To include a feature integral to IPA studies and avoid the weakness noted by Brocki and Wearden (2006), this research has provided room for the researcher's experience to be included in Chapter Seven: Therapy part B: Achieving therapeutic outcomes. Chapter Seven uses hermeneutic processes to add depth to the interpretations of the facilitators' experiences and explore 'therapy' more deeply. In acknowledging that the interpretation of data within IPA is impacted by the researcher's interpretations, to avoid bias, tension and complications between participant and researcher perspectives, this study will ensure the researchers' experiences will respond to what the research participants have said. The researcher will build on the phenomenon being considered by incorporating the researcher's perspective to assist with interpreting what the participants have described. To avoid tension between participant and researcher perspectives, when the researcher's perspective is different this study will ensure that the researcher's experiences respond directly to the participants' experiences being discussed in 
order to build on the phenomenon under investigation.

In IPA, rigor is demonstrated through ensuring data is well-represented in the analysis.

'Extracts should be selected to give some indication of convergence and divergence, representativeness and variability, ensuring the reader gets to see the breadth and depth of the theme' (Smith 2011a, p. 24; Smith \& Osborne 2003, p. 57). Sufficient attention must be paid to the elaboration of each theme through the use of illustrative quotes giving the themes breadth and depth (Smith et al., 2009; Sweeny \& O'Connell, 2015; Tomkins \& Eatough, 2010). However, Smith (2011b, p. 59) notes that within IPA not all extracts need to carry the same weight, and a single comment from a participant can have significant interpretative leverage for the overall body of the research. This principle has been applied in the data analysis.

\subsubsection{Idiographic approach}

Qualitative methodologies are suited to an idiographic approach. An idiographic approach is described as in-depth investigation of individual cases (Allport, 1962). Runyan (1983) states that an idiographic approach, however, does not apply just to individual issues, but rather to related issues such as the identification of central themes that are brought together by sensitivity to what is specific to the individual.

The IPA process supports the researcher to identify commonalities, differences and contradictions, not only for a single participant but across a number of participants, all describing the same phenomena. These individual views reveal the principal common themes that have emerged from the data, enabling the inclusion of thought-provoking individual experiences (Smith, 1996b). In this way, using an idiographic approach supports the analysis to be illustrative rather than just descriptive.

\subsubsection{Analytical approach}

A distinguishing aspect of IPA methodology is its dedication to examining the experiences of its research participants in greater depth (Hefferon \& Gil-Rodriguez, 2011; Smith, 2011a). Within IPA an analytical approach looks for interesting use of words and emotional responses as a creative approach to bringing into the open ideas that, without in-depth investigation, can remain concealed within participant's data. IPA encourages the detailed examination of particular extracts within an interview. The hermeneutic circle and double 
hermeneutic are IPA processes designed for more in-depth investigation.

\subsubsection{The hermeneutic circle}

Engaging in the hermeneutic circle involves taking single utterances and small passages from a participant's transcript that 'shine like gems' and offer 'potent analytical leverage to a study' (Smith, 2011c, p. 6). A 'gem', as described by Smith (2011c, p. 7), is 'the thing that stands out when you're reading a transcript, it's the extract that demands attention and prompts further analytical work'. Corbin and Straus (2014, p. 66) similarly considered data coding as 'mining of data for hidden treasures'. In this study, using the hermeneutic circle created the opportunity to develop concepts from the participants' utterances that focussed on the relationship between 'biblio' and 'therapy'.

\subsubsection{The double hermeneutic}

The double hermeneutic process is described as the researcher trying to make sense of the participant trying to make sense of their experience (Finlay \& Ballinger, 2006; Smith et al., 2009). Within IPA, similar to other qualitative methodologies, access to the participant's experiences is dependent on what the participant chooses to disclose (Smith, 2009). Smith et al. (2009) assert that engagement in the double hermeneutic assists the researcher to reach a deeper understanding of the phenomenon through what the researcher thinks the participant is thinking. That is, through 'abstract and more conceptual interpretations' (Eatough \& Smith 2008, p. 187), to capture both the broad experience and complexity of individual experience (Smith \& Osborn, 2003).

As outlined above in Section 3.1.1, the double hermeneutic process is a two-stage process. The first interpretation phase can be categorised as the phenomenology stage, in which the participants offer their interpretation of meaning through their use of language and description (Finlay, 2011). However, in the first stage, ideas may still be in an undeveloped state (Berndtsson et al., 2007). The second interpretation phase can be categorised as the hermeneutic stage, in which the researcher brings personal perspectives to the meaningmaking (Bevan, 2014; Elliot et al., 2012; Finlay, 2011; Stanley \& Nayar, 2014) to build on the phenomenon under investigation.

The double hermeneutic enables the researcher to look at the same phenomena from a different angle than that of the participant and demonstrates 'the dual role of the 
researcher as both like and unlike the participant' (Smith et al. 2009, p. 35). An IPA researcher, similar to the participant, is situated in the phenomena being explored.

\subsection{Methods}

Section 3.2: Methods, will provide details on the research design using IPA which aims for a homogeneous sample to collect data from. IPA studies primarily use interviews for data collection (Gill, 2015). Fourteen semi-structured interview questions were designed, and piloted, and received ethics approval.

Interviews were audio-recorded by the researcher and transcribed by a transcription company. The researcher conducted accuracy checks of the transcripts produced, and random member checks to ensure that the interview data had been meaningfully analysed to reveal the key themes.

The process of question development, data collection and super-ordinate theme development within this study will now be described in more detail.

\subsubsection{Recruiting research participants}

The participants in this research study are 17 Australians (out of 20) who undertook bibliotherapy training in 2010. The database of the participants in the 2010 Melbourne training was used to send invitations to participate in this study. Initially, participants were contacted by the State Library Victoria Manager of Public Library and Community Engagement via an email to ask if they would like to take part in the study. SLV passed a list of those who had agreed and declined to participate in the study onto the researcher. The researcher followed up by directly phoning all participants who had agreed to take part. This phone call was followed by an email attaching the participant's information letter and consent form, and a request for the participant to nominate a place and time for the interview. Interviews were conducted in 2013 (limitations regarding the gap between the training delivered to research participants and the interviews asking about their training have been added to 8.5: Limitations of the research).

\subsubsection{Ethics}

Confirmation of the researcher's PhD candidature was undertaken on 13 March 2013 and 
approved on 15 March 2013. The planned research gained approval from the Business College Human Ethics Advisory Network (BCHEAN) on 22 August 2013 (see Appendix One). Intended processes for recruiting participants and then communicating with them as part of the study were examined and approved. A participant and information consent form was distributed to all research participants. Full compliance with the BCHEAN approval guidelines has been maintained.

\subsubsection{Interview question development}

Initially, a document analysis of the training manual used in Melbourne in 2010 was undertaken. The training manual content guided the development of semi-structured interview questions to explore the experience of participating in the training. Further questions looked at the effectiveness of the training. Fourteen interview questions were divided up into four broad groups:

Group one: Background to the training

Group two: The training experience

Group three: Reading in different therapeutic settings

Group four: The effectiveness of the training

These groups assisted in clustering the questions systematically and thematically and provided focus for both interviewer and interviewees.

The interview questions followed IPA guidelines in that they were open and not closed, and concerned with constructing understanding through exploring peoples' experiences in a particular context (Hefferon \& Gil-Rodriguez, 2011; Smith, 2011a; Willig, 2001).

The questions were designed to be exploratory, not explanatory. Using exploratory semistructured questions provides the opportunity to probe more deeply when further investigation is required. Probe questions were used when the researcher felt participants needed further questioning to support them to provide more in-depth answers.

The questions explored the participants' experiences in the bibliotherapy training and delivery contexts to construct an understanding of the knowledge the facilitators gained from the training and what knowledge still needed to be developed from their perspective, in relation to both 'biblio' and 'therapy'. A full list of interview questions can be found in Appendix Two. 
The interview questions were piloted by two volunteers who had knowledge of bibliotherapy but were not part of the cohort who had undertaken bibliotherapy training and were subsequently participants in this research. The volunteers were known by the researcher through a shared interest in the healing power of literature, and the aim of piloting was to use their expertise to test the questions for comprehension and transparency, and to develop an understanding of the time it would take for the interviews. Both volunteers had prior involvement in using literature for wellbeing outcomes: one was a librarian with experience in both secondary schools and public libraries; the other had supported bibliotherapy program delivery as a community wellbeing coordinator. The two volunteers understood the questions, and no changes were made. It was anticipated the interviews would take approximately 60 to 90 minutes.

\subsubsection{Data recording and storage}

Data was collected through semi-structured, audio-recorded interviews. The interviews were conducted either face-to-face or over the phone, as requested by each participant. All interviews were, with permission, recorded on a Philips voice tracer device which allowed for hands-free note-taking. I noted down any keywords or phrases that stood out in the interview to help support possible major themes and issues revealed by participants during their interviews.

A sample of data transcription can be found in Appendix Three.

\subsubsection{Identifying themes}

The development of themes in this study involved both descriptive and analytical coding. IPA was used to interpret and analyse the coded data. IPA researchers in previous studies have stated that they had found qualitative analysis software worked against IPA's ideographic focus. A decision was made not to use analysis software, such as NVivo, but to conduct a manual analysis of the transcribed interviews more suited to generating the indepth idiographic perspective of IPA. The process of developing themes within this study will now be described in more detail.

\subsubsection{Coding and theme development process}

A framework for coding interview data was initially established by document analysis of the 
bibliotherapy manual used by the participants in their training. The primary focus of a document analysis is that the researcher produces a set of a priori codes expected to be relevant to the study, creating a 'template' to apply in the analysis of data collected via the interviews (Bi et al., 2019; King, 1998). Early classification of themes accelerates the initial coding phase of analysis (King, 2012). Section 3.2.5.1 provides more detail of the stages taken to develop a coding template and theme structure.

The training manual content related to the practicalities of delivering the Get Into Reading program and the different settings in which it was delivered in the UK; it provided the basis of the early a priori codes:

- Reading Aloud

- Choosing Materials

- What Makes a Get Into Reading Text?

- Facilitation Skills

- Preparing a Text

- Reading in Acute Mental Health Settings

- $\quad$ Reading with People with Dementia

- Reading with People from Racial Minority Backgrounds.

These areas of the training manual were divided into the relevant early a priori codes of 'biblio', 'therapy' and wellbeing (a full list of the training manual contents can be found in Appendix Four). Additional a priori codes were used to code research participants' motivations for taking part in the training, their experiences of the subsequent delivery, and their reflections on the training. With further consideration of the interview data, the a priori codes were modified and added to (King 1998, p. 118). The following steps outline the stages undertaken in coding and theme development.

\section{Stage 1: Developing early a priori codes}

The training manual content was used as a basis to develop early a priori codes to support the development of the semi-structured interview questions.

\section{Stage 2: Writing detailed reflections}

Interviews were conducted, and personal reflections of the researcher were recorded after each interview. In these field notes, I recorded keywords or phrases that stood out in the interview to help support the development of the major themes and issues revealed by participants during their interviews.

Stage 3: Listening to recorded interview data

The audio interview was replayed soon after recording to document keywords and phrases 
that encapsulated possible themes.

Stage 4: Initial reading of transcripts

Transcripts were read individually, and assigned a priori codes.

Stage 5: Modifying and adding to the a priori codes

The keywords and phrases list was compared to the set of a priori codes, and the early codes were modified and added to.

Stage 6: Development of a coding framework

Following template analysis strategies, three transcripts were selected for initial coding for testing the coding set. Additional codes were added for any data that was not able to be coded by the initial set of codes. A coding framework of 48 sub-themes was constructed. The coding framework can be found in Appendix Five.

\section{Stage 7: Coding application}

All transcripts, including the three previously coded, were closely read and coded using the final coding framework. Codes were permitted to overlap to link to multiple meanings and notions. Working within an IPA context, codes were applied to sizeable sections of the data, rather than single words, to ensure that the meaning was retained.

\section{Stage 8: Theme structure}

The codes were clustered into different constellations to form themes. Overarching themes emerged around the expectations, purpose and practice of bibliotherapy, and the relationship between 'biblio' and 'therapy'.

\section{Stage 9: Commonalities and differences}

The data relevant to each theme was read closely to consider commonalities and differences.

Stage 10: More in-depth analysis

Interesting use of words and emotional responses revealed within participant's data was considered in more depth.

\section{Stage 11: Interpretation}

An interpretive and descriptive account was produced, including the researcher's perspective in line with IPA practice.

\subsubsection{Themes}

The data collected through the semi-structured interviews with bibliotherapy facilitators included a strong focus on 'biblio' and 'therapy' as separate entities. Three main themes showed the expectations, purpose, and the practice and process of bibliotherapy, and included strong elements that addressed 'biblio' and 'therapy' separately:

1. The anticipation and expectations of bibliotherapy 
2. The process of biblio

3. The process of therapy.

\subsection{Theoretical approach}

IPA shares some similarities with other forms of qualitative inquiry, these being readerresponse theory, narrative theory and grounded theory.

Reader-response theory relates more to those attending groups than facilitators of groups, making it unsuitable for this research. Narrative theory focuses on the analysis of stories, relevant to bibliotherapy but not suited to interpreting experiences of facilitating a reading group.

Grounded theory was considered as a possible methodology and will now be compared to IPA for suitability. As IPA is a comparatively new methodology, there is little published regarding comparison of using IPA with other research methodologies (Cronin-Davis et al., 2009).

\subsubsection{Grounded theory}

Grounded theory is often compared to IPA, 'with some struggling to see any meaningful distinction between the two' (Brocki \& Wearden 2006, p. 100). While both require researchers to produce findings grounded in the data (Gill, 2015), the approaches differ. It is important to explain the differences between grounded theory and IPA to understand the suitability of IPA to address this study's research question rather than grounded theory. The table below demonstrates differences found between IPA and grounded theory, sourced from Brocki and Wearden (2006); Corbin and Strauss (1990); Gill (2015); Mason (2010); Pietkiewicz and Smith (2014); and, Suddaby (2006).

Table 3: Contrasting IPA and grounded theory.

\begin{tabular}{|l|l|l|}
\hline Sampling & IPA & Grounded theory \\
\hline & $\begin{array}{l}\text { Aims for a relatively homogeneous } \\
\text { sample to collect data that can be } \\
\text { used to develop a comprehensive } \\
\text { and thought-provoking } \\
\text { interpretation. }\end{array}$ & $\begin{array}{l}\text { Sampling for theory } \\
\text { construction to check and } \\
\text { refine categories, not for the } \\
\text { representation of a given } \\
\text { population. }\end{array}$ \\
\hline Sample size & From 2-25, however sample sizes & Larger sample sizes, guidelines \\
\hline
\end{tabular}




\begin{tabular}{|c|c|c|}
\hline & $\begin{array}{l}\text { are often small. In-depth } \\
\text { engagement with individual cases } \\
\text { allows for a detailed examination of } \\
\text { similarity and difference, } \\
\text { convergence and divergence. }\end{array}$ & suggest 30-50 participants. \\
\hline $\begin{array}{l}\text { Theoretical } \\
\text { saturation }\end{array}$ & $\begin{array}{l}\text { Commitment to understanding } \\
\text { individuals' experiences without } \\
\text { establishing causal relationships } \\
\text { requires a small sample without } \\
\text { theoretical saturation necessary as } \\
\text { for grounded theory (Brocki and } \\
\text { Wearden, 2006; Corbin \& Strauss, } \\
\text { 1990). }\end{array}$ & $\begin{array}{l}\text { Grounded theory generally uses } \\
\text { saturation as a guiding principle } \\
\text { for data collection. } \\
\text { Aims to continue data } \\
\text { collection until no new themes } \\
\text { emerge as a way of establishing } \\
\text { claims within a wider } \\
\text { population. }\end{array}$ \\
\hline $\begin{array}{l}\text { Researcher's } \\
\text { knowledge of } \\
\text { the } \\
\text { phenomenon }\end{array}$ & $\begin{array}{l}\text { The researcher's knowledge of the } \\
\text { experience, and literature inform } \\
\text { the experience; it acknowledges } \\
\text { that the researcher's knowledge is } \\
\text { required to interpret the } \\
\text { participants' experiences. }\end{array}$ & $\begin{array}{l}\text { Does not allow for the } \\
\text { researcher's knowledge of the } \\
\text { experience. }\end{array}$ \\
\hline Focus & Focus on personal experiences. & Focus on social processes. \\
\hline Literature & $\begin{array}{l}\text { Allows researchers to develop a } \\
\text { concept through the literature, } \\
\text { related to the experience of } \\
\text { participants. }\end{array}$ & $\begin{array}{l}\text { Avoids the use of previous } \\
\text { literature to guide the data } \\
\text { collection and analysis process. }\end{array}$ \\
\hline Writing up & $\begin{array}{l}\text { More room for creativity and } \\
\text { flexibility. Just as with every other } \\
\text { stage of IPA there is not a single } \\
\text { right way to write up an IPA } \\
\text { analysis. Writing in an IPA study is a } \\
\text { creative process. There is a } \\
\text { constant moving between the parts } \\
\text { and the whole with selected } \\
\text { extracts used to illustrate and add } \\
\text { depth. }\end{array}$ & $\begin{array}{l}\text { Engage in constant comparisons } \\
\text { and seek exceptions or odd } \\
\text { cases that support the } \\
\text { development of a multi- } \\
\text { dimensional dynamic theory of } \\
\text { how different factors affect } \\
\text { human behaviours. }\end{array}$ \\
\hline Conclusion & $\begin{array}{l}\text { Seeks to understand the experience } \\
\text { of specific individuals or groups and } \\
\text { does not seek to generalise. }\end{array}$ & $\begin{array}{l}\text { Produces theories that explain } \\
\text { social processes. }\end{array}$ \\
\hline
\end{tabular}


While grounded theory may appear similar to IPA, the objectives of the two approaches differ with the former focussed on producing a theory and the latter on understanding a phenomenon without seeking to generalise.

\subsection{The research participants}

Section 3.4 provides an introduction to the research participants whose data is in the chapters to follow.

The research participants are seventeen individuals in Australia who have participated in a five-day bibliotherapy training course and subsequent program delivery. I have replaced all individual names in the study with pseudonyms and organisational names have been omitted. In brief, the table below reveals that the research participants are primarily women working in professional roles in metropolitan and regional community-based organisations, with public libraries being the predominant professional field.

Table 4: Individual research participant details.

\begin{tabular}{|c|c|c|c|}
\hline Pseudonym & $\begin{array}{l}\text { Professional } \\
\text { field }\end{array}$ & Role & Location \\
\hline Cheryl & $\begin{array}{l}\text { Public } \\
\text { Libraries }\end{array}$ & Community Programs Librarian & Metropolitan \\
\hline Debra & $\begin{array}{l}\text { Public } \\
\text { Libraries }\end{array}$ & Access and Inclusion Librarian & $\begin{array}{l}\text { Outer } \\
\text { Metropolitan }\end{array}$ \\
\hline Helen & $\begin{array}{l}\text { Public } \\
\text { Libraries }\end{array}$ & Community Librarian & Metropolitan \\
\hline Jane & $\begin{array}{l}\text { Public } \\
\text { Libraries }\end{array}$ & Library Resources Coordinator & Metropolitan \\
\hline Jamie & $\begin{array}{l}\text { School } \\
\text { Libraries }\end{array}$ & Secondary School Librarian & Metropolitan \\
\hline Kim & $\begin{array}{l}\text { Public } \\
\text { Libraries }\end{array}$ & Principal Librarian & Regional \\
\hline Leeanne & $\begin{array}{l}\text { Public } \\
\text { Libraries }\end{array}$ & Library Officer & $\begin{array}{l}\text { Outer } \\
\text { Metropolitan }\end{array}$ \\
\hline Melanie & $\begin{array}{l}\text { Public } \\
\text { Libraries }\end{array}$ & Home Library Service & Regional \\
\hline
\end{tabular}




\begin{tabular}{|c|c|c|c|}
\hline Meredith & $\begin{array}{l}\text { Public } \\
\text { Libraries }\end{array}$ & $\begin{array}{l}\text { Community Liaison and } \\
\text { Marketing }\end{array}$ & Regional \\
\hline Natalie & $\begin{array}{l}\text { Mental } \\
\text { Health }\end{array}$ & Creative Writing Group Facilitator & Metropolitan \\
\hline Rachel & $\begin{array}{l}\text { Public } \\
\text { Libraries }\end{array}$ & Children's \& Teenage Librarian & Metropolitan \\
\hline Rhonda & $\begin{array}{l}\text { Public } \\
\text { Libraries }\end{array}$ & Library Branch Manager & $\begin{array}{l}\text { Outer } \\
\text { Metropolitan }\end{array}$ \\
\hline Sarah & $\begin{array}{l}\text { Public } \\
\text { Libraries }\end{array}$ & $\begin{array}{l}\text { Team Leader Reader } \\
\text { Development }\end{array}$ & Metropolitan \\
\hline Sophia & $\begin{array}{l}\text { Public } \\
\text { Libraries }\end{array}$ & Information Librarian & $\begin{array}{l}\text { Outer } \\
\text { Metropolitan }\end{array}$ \\
\hline Tanya & $\begin{array}{l}\text { Public } \\
\text { Libraries }\end{array}$ & Roster and Volunteer Officer & $\begin{array}{l}\text { Outer } \\
\text { Metropolitan }\end{array}$ \\
\hline Terry & $\begin{array}{l}\text { Health } \\
\text { related } \\
\text { counselling }\end{array}$ & Counsellor & Metropolitan \\
\hline Wilma & Aged Care & Aged Care Program Coordinator & Metropolitan \\
\hline
\end{tabular}

\subsection{Chapter Three concluding comments}

IPA is a contemporary qualitative approach that has been used across multiple social science disciplines evaluating therapeutic programs.

There were several strong motivations for selecting this approach:

1. Its capacity for research in therapy-related settings (Dean et al., 2006; Ward \& Miller, 2013).

2. Its acceptance of the researcher's knowledge and its flexible description and interpretation structure (Smith, 2011c).

3. The bonding relationship that the approach allows the researcher to develop with research participants (Alase 2017, p. 9).

Chapter Four begins to explore the expectations facilitators had for delivering bibliotherapy pre-training, related to the skills and tools they felt they needed to be equipped to work in group therapeutic environments. Chapters Five, Six and Seven explore and develop the central concept of this research study - the relationship between 'biblio' and 'therapy' - in 
terms of the separate components of bibliotherapy, and as a whole. Chapter Five considers the book, or 'biblio', component and Chapters Six and Seven consider the 'therapy' component.

The data Chapters 4-6 are essentially descriptive of the data collected rather than being "pure" data/interpretation chapters, and will include reference to, and juxtaposition with, the work of other researchers; Chapter 7 is interpretive and includes the hermeneutic element of IPA. There is no separate discussion chapter. 


\section{Chapter Four: Bibliotherapy training}

\section{Introduction}

Chapter Four explores the expectations facilitators held about delivering creative bibliotherapy prior to undertaking their training. The interview questions focused on the research participants' shared experience of the bibliotherapy training in 2010, and the effectiveness of the training to prepare them to deliver bibliotherapy. Details of the training program are provided earlier in Section 1.4 and in Appendix 4.

Chapter Four will begin the analysis and discussion of the central findings of this research study by exploring research participants' initial understanding of the relationship between 'biblio' and 'therapy' based on their definitions of bibliotherapy (4.1), and expectations of training in bibliotherapy (4.2). The chapter will then consider the extent to which the training fulfilled research participants' expectations of both the training and their delivery of creative bibliotherapy following training (Sections 4.3; 4.4; 4.5 and 4.6). Finally, the chapter will consider variations between UK and Australian bibliotherapy, and the relevance of this in supporting wellbeing using bibliotherapy (Section 4.7).

\subsection{Research participant definitions of bibliotherapy}

The interview data revealed a variety of understandings of bibliotherapy. During the interviews the majority of the participants provided variations of definitions that encompassed bibliotherapy as a clinically-based therapy; that is, following a medical model of treatment rather than using literature to promote wellbeing in a non-clinical community setting. Some participants were not sure what bibliotherapy was.

Helen admitted she 'didn't know what bibliotherapy was.' Other research participants, while acknowledging they had no prior knowledge, used the term to conjecture meaning. Melanie proposed that 'biblio would be books but I suppose therapy is getting therapy from books but nothing more.' Rachel said 'just going from the term I would think of it as a therapy session somehow associated with reading [or] books.' Rachel continued to say, 'I would think of it as a therapy, though, not something delivered by librarians.' Jane thought 'that bibliotherapy improved people's sense of wellbeing.' 
Most research participants had developed a sense of the meaning of bibliotherapy around the traditional form of bibliotherapy, where books, usually self-help books, are prescribed, or recommended by health professionals for the purpose of providing information to support an individual with psychological and emotional issues. An example is provided by Debra who said she had 'a different interpretation of bibliotherapy' from using literary texts for therapy. Debra explained, 'the way I view bibliotherapy is that you use subject appropriate literature... when people are struggling with a death in the family or something like that, you find appropriate resources to enable them to actually address that through literature.' Cheryl had used this form of bibliotherapy in her current librarian role by offering self-help books to the general public. She said she had 'made up a whole lot of lists of books that can be used... to help them deal with various developmental stages of life or particular issues that might come up, for example books about dealing with death and dying. The lists that I made were more directed at particular subjects and topics.'

When asked what they knew about bibliotherapy, several other research participants mentioned the Books on Prescription (BoP) schemes that operate through partnerships between general practitioners and public libraries in the UK. As outlined in the literature review, BOP schemes involve general practitioners recommending or 'prescribing' a book to a patient. The patient then takes the book prescription to a local library to source and borrow the book. Leeanne said, 'I know they're doing it in doctors' surgeries.' Wilma also referred to the BoP approach as her concept of bibliotherapy: 'books on prescription model... which is a sort of self-help model.' Meredith explained 'I'd had a previous idea about bibliotherapy... I'd been looking at more that prescription for a book type of view... but didn't have any true concept of bibliotherapy as opposed to that prescription book model [that is, the Books on Prescription scheme]'. Kim said, 'even though I thought I understood what it [i.e., bibliotherapy] was about I didn't really as it turned out.'

These research participants' definitions of bibliotherapy connect to therapeutic outcomes within a medical framework, which is the notion that bibliotherapy is a model delivered by a medical practitioner or health professional using self-help books to address a particular issue.

Three research participants did not align bibliotherapy with traditional clinically-based treatment. They perceived that the use of literary texts was different from using non-fiction 
self-help books but Sophia said that she 'wouldn't have thought of it [as bibliotherapy]... it's kind of moving away from that traditional approach.' Debra felt the point of difference was 'where you're not actually choosing literature specifically to address an issue.' Leeanne described it as 'literature that heals, but not in that medicinal way.' Sarah supposed bibliotherapy could be defined as 'the therapeutic effects of reading' but also felt it was 'much, much more than that, much more powerful' and felt the prescriptive bibliotherapy model was 'very shallow... that's not the way I see bibliotherapy at all.' For Leeanne, creative bibliotherapy held 'the deep meaningful stuff that... that has the ability to make changes quietly and gets overlooked.'

Overall, the definition of bibliotherapy most commonly shared by the larger group of research participants is that of a clinically based treatment. This shared meaning suggests that the majority of research participants do not expect bibliotherapy to be doing something that is therapeutic in its intention or outcome.

\subsection{Therapy}

Differences in thinking and experiences of bibliotherapy will be discussed in Section 4.2: Therapy. This next section will explore the different concepts of therapy.

\subsubsection{Different concepts of therapy within bibliotherapy}

As established in the literature review 'clinical-based therapy' is different from 'healing therapies'. The literature review provides evidence that clinical-based therapy is a wellestablished form of diagnosis and treatment of disease and illnesses using traditional forms of medicine, psychology and psychiatry. Whereas, healing therapies use a more holistic approach to symptoms, employing practices that utilise a range of modalities connecting the body, mind, and spirit.

Traditional bibliotherapy, often aligned with Cognitive Behavioural Therapy (CBT), is an example of a recognised clinical-based therapy. CBT, using the therapeutic agent of self-help books, is a popular and recognised medical-based treatment, commonly delivered by a psychologist to address a particular issue.

Healing therapies have been used since ancient times and include many forms such as: massage, aromatherapy, yoga, tai chi, and meditation and mindfulness; and creative healing 
therapies such as art and music (Elkins et al., 2010; Lichtenstein et al., 2017).

Both models of bibliotherapy - traditional and creative - are therapeutic and employ specific therapeutic elements. However, the difference between the therapeutic characteristics can be found within the intention and outcomes, and the role of the therapist. These differences are supported by the individual roles of 'biblio' and 'therapy' in each type and will be discussed further in Chapters Five, Six and Seven. What needs to be kept in mind, however, is the research participants' expectations, or not, of seeing themselves as people who would be doing something that is therapeutic in its intention or outcome.

\subsection{Participants' expectations of bibliotherapy training}

This section will explore the expectations the research participants had of the training they were undertaking. The 17 research participants were asked, 'What were you looking for when you decided to take part in the training?' Research participants' expectations/reasons for attending the training were categorised into seven main themes from the a priori codes. Some research participants offered multiple responses that fit under more than one theme, indicating that they had more than one expectation/reason for undertaking the training. Each theme as follows will be discussed in further detail:

1. To learn new skills

2. To increase vocational opportunities

3. To develop a community program

4. To provide an extension of reader development

5. To support community mental health

6. To increase understanding of bibliotherapy

7. Involuntary undertaking.

\subsubsection{Expectation/Reason 1: To learn new skills}

The most common reason the research participants cited for undertaking the training was to learn new skills offered by the course. Leeanne held a 'belief about literature and reading, a strong belief that those things change people' and she wanted, 'to learn new skills' in this area.

As she only had a minimal understanding of bibliotherapy, Jane wanted to "learn the practicalities of how to deliver'. Whereas Sarah specifically wanted to learn 'skills of reading 
aloud... in a group.' Sarah also wanted to learn 'skills around the group situation' and 'techniques around silences and getting people to start talking.'

Wilma wanted to 'extend her skills' in working with poetry. She stated that she had experienced 'anxiety about the poetry.' Several other research participants also spoke about being worried about working with poetry. Christine said, 'I don't do poetry... personally I had very little appreciation of understanding poetry... I was fearful in fact because of the poetry aspect.'

The skills the research participants were aiming to achieve from the training relate directly to both 'biblio' and 'therapy'. Firstly, 'biblio' skills, in regard to working with literary texts; secondly, 'therapy' skills concerned with managing the group environment and facilitating discussion.

\subsubsection{Expectation/Reason 2: To increase vocational opportunities}

Some of the research participants wanted to undertake the training to increase career progression opportunities. Melanie 'just felt that it sounded interesting, something different that the library hadn't done.' She felt that it may increase her opportunities in the public library although she 'wasn't sure if it was going to work.' Leanne stated she wanted to undertake the training, 'to extend my job, my vocation, into more of the book and reading area.' Despite the fact she worked in a library, Tanya disclosed she 'volunteered for this course. I had no library background and no library training.' She hoped that this training would connect her more to public libraries through developing a library-based program. Outside libraries, Terry, who worked in counselling, 'saw it as another avenue for use within the counselling field' that 'reduces social isolation.' Natalie worked in a community mental health service provider organisation and she 'just liked the idea that I was able to branch out a bit and work with others through developing a partnership with a library from the local council area.'

\subsubsection{Expectation/Reason 3: To develop a community program}

Another common reason was an interest in creative bibliotherapy for the purpose of developing programming both in and out of the library. Participants spoke about the desire to have a program that would improve the reach of the library. Sarah said 'it was related to 
things like our library service philosophies of inclusivity and also reaching hard to reach communities.' Debra held an access and inclusion and outreach role; she felt the training course fitted with her library's 'overall drive towards ensuring that we include members of our community and find some interesting models to deliver adult programs.' Meredith held a community liaison role and she thought it could be used 'to try and explore how we could make contact with people who we didn't consider generally to be regular [library] users.' Tanya considered 'this would be a program that I could use to connect with the community, as community work for the library is a great focus here.' She 'wanted to do something more to deliver programs... to develop a program that I could use to connect with the community.' Jane's and Melanie's reasons link to outreach programming as 'a conscious effort to bridge the split between the social worlds of the public library and the community' (Grace \& Sen, 2013, p. 531). Jane said that although bibliotherapy was 'not directly related [to her role in the library] at all... she linked it with our outreach programs.' Melanie was a home services librarian, and could 'see it working in with the home library service... and not just have it in the library itself.'

From a personal perspective, Sophia said the training 'had a very strong community focus - I wanted just to be able to make a contribution at that level... on a personal level'. Sophia's attitude aligns with research from Reynolds et al. (2012) that shows a career in information management or library information science (LIS) is often chosen for its focus on public service delivery. Sophia's motivation to undertake the training was for the opportunity it offered to deliver something that may make a meaningful difference in the lives of individuals and society.

\subsubsection{Expectation/Reason 4: Reader development}

Research participants made several comments that linked their reason for undertaking the training to reader development practice in Victorian public libraries. The term 'reader development' originated in 1995 (Branching Out, 2015). It is used to describe an approach based on literature promotion used in public libraries to engage library patrons. Reader development practice aims to increase an individual's confidence and enjoyment of reading; open up reading choices; offer opportunities for individuals to share their reading experience; and raise the status of reading as a creative activity (Opening the Book, 2009). 
In a report prepared for Arts Council England and the Museums Libraries and Archives Council, United Kingdom, reader development work is described as being at the beginning of the bibliotherapy practice continuum (Hicks 2006, p. 3). However, Sturm (2003) exposes a limitation of reader development within this context, asserting that a reader development librarian makes suggestions related to what the patrons say they want; a bibliotherapist, on the other hand, suggests what they think the patrons may need.

Debra was 'responsible for a range of reader development programs'; and she 'thinks there was some understanding that that was how it [i.e., bibliotherapy] would tie in.' Similarly, Rhonda 'had been doing reader development type programs like book chat'; she thought her 'organisation saw it as an extension of this.' Sarah said she was interested because 'it was related to what I was doing in the area of reader development' but she also she felt that bibliotherapy 'wasn't exactly reader development in the public library context.'

\subsubsection{Expectation/Reason 5: To support community mental health}

Natalie, a mental health service professional, had been 'running a three-hour creative writing workshop... and people with mental illness were coming along to that regularly and it was a very successful program.' She was interested in exploring creative bibliotherapy use for individuals experiencing mental ill health because 'it related in the way that I knew that texts were highly valuable, highly important to starting a conversation with someone about so many different options.'

From a library perspective, Sarah's library service wanted programs that 'targeted people with mental health issues... that her library service found difficult to reach.' Meredith, a Community Liaison librarian, was hoping 'to develop a community program offer for identified groups of people with mental health issues where we know that they come into the library space.' Meredith also believed the training offered 'the opportunity to be able to present a kind of package to the community mental health team.'

Some of the research participants who had delivered in both aged care and mental health settings spoke of how they enjoyed the challenge of facilitating bibliotherapy sessions within a mental health setting. Debra said, 'it's very personal for me. Nursing homes, I think you could deliver the program until the end of time, every day of the week in a nursing home and it would just be an absolute winner and there'd be an infinite vast chasm of need, but 
that's probably not where I'd get as much pleasure.' Leanne felt that bibliotherapy in aged care is 'not as interesting... I would like to do more mental health.' Jane commented that the 'group that she preferred less... is where they're elderly... they don't challenge themselves or the readings or each other in the same way. It becomes, to my mind, far more predictable. I like the unpredictability of the more emotionally engaged group.'

However, some research participants spoke about not feeling comfortable delivering to groups experiencing mental ill health. Sophia stated that 'we have people coming into the library with mental health issues and deal with them on a one-to-one basis, but that's different than dealing with the mental health focus in a reading group. It's something that I don't have experience in... certainly I'm still relating to people at that community level but it is different.' Helen felt similarly in that, 'she didn't get adequate training to be aware of when things were going wrong and what I would do... I would have to go and do some other training.'

\subsubsection{Expectation/Reason 6: To increase understanding of bibliotherapy}

Some of the research participants had an understanding that working in specific ways with books could be therapeutic and were looking to broaden their knowledge of this. Natalie, working within the mental health sector, said, 'it was of particular interest to me to actually see what bibliotherapy was all about,' because she had been successfully using creative writing with individuals experiencing mental ill-health. Jane, a reader development librarian, 'wanted a better understanding of what bibliotherapy was... I was looking for clarification on a broad basis first and then the practicalities of how to deliver that and what the benefits would be... what is the theory behind it, or why is it so?' Whereas, Jamie said one of the reasons she undertook the training was because within her library service 'there was no understanding of bibliotherapy... my manager was intrigued with the idea of bibliotherapy and we were getting in lots of texts to use for bibliotherapy in the sense of medical [i.e., books on prescription type model].'

\subsubsection{Expectation/Reason 7: Involuntary participation}

A small number of research participants told how they undertook the training because it suited the aims of their library service, but did so reluctantly. Rachel said that 'when it [the training] was presented to the team each and every single team member said, they didn't feel 
they could take it on... My manager at the time... said this is too good an opportunity to let go... I was just nominated as the person that would go... I felt pushed... I didn't feel I could say no... but I was scared as well... that's how I felt.' Cheryl confessed 'it wasn't something that I wanted to do. The library service suggested it... I was fairly reluctant, quite fearful in fact... so I argued with them and said I wasn't the right person to go. But they insisted.' Kim said, 'my manager showed me the initial information and I thought oh, I'm not sure if that's for me. The bit that concerned me was the idea of working with people with problems... I distinctly remember saying to my manager look, I'm not sure about this... I wasn't convinced I'd be suitable for it... my capacity to handle that sort of atmosphere.'

\subsection{Meeting expectations}

This section will provide a summary of the discussion of meeting the research participant's expectations of attending the training as described above.

Some participants wanted to learn something new, increase job opportunities and increase programming capacity. Their reasons for wanting to undertake the training were connected to both organisational and individual motivations. Research participants were asked at the end of the interviews for this study if the training was effective in preparing them to deliver bibliotherapy. Overall, participants said the training did not effectively prepare them; that is, it did not effectively meet their expectations.

However, Debra clearly stated 'I believe it did [meet expectations]'. This may be because Debra had had a positive experience co-facilitating a U3A (University of the Third Age) bibliotherapy group jointly with another facilitator, who also undertook the training with Debra. In Debra's group the group members were highly literate middle-aged women rather than the marginalised audience members that are typical of bibliotherapy groups. Debra therefore did not have the same challenges other facilitators had who ran groups by themselves and with group members who had dementia and/or poor mental ill health. Initially, Jane thought that her expectations were met: 'I came back from the training really thinking that I had a good handle on this and knew what I was going to do... The more that I... deliver, the more I realised that I actually knew very little when I began. So I think that... It prepared me in that it gave me credibility.' Jane elaborated that 'When I went to do the training, it emerged that mental health was quite obviously a large part of it. But I think in 
my innocence when I started, or my naivety, I was just thinking of general community and wellbeing. It [the training] gave me the awareness that there would be such groups, but I didn't come away with the tools or strategies to deal with it... I know that I didn't feel particularly well-prepared.' Cheryl and Jane's comments represent the experiences of many of the other research participants. Rhonda felt she was 'ill-prepared in some ways... perhaps some of the practicalities of actually setting up partnerships.' Rachel 'didn't feel prepared enough [and] expected more of how to deal with different situations in a group setting.' Jamie felt prepared, 'a little, but not enough.' Wilma reflected, 'I think I only remember the good bits actually, but by going back through that I remember thinking - it wasn't a bad experience but it felt like it just, it needed something more to make it work.'

It is worth noting expectations that directly relate to the research participants' work in public libraries. As Jane explained, 'it was a bit of a tenuous bow that I took, in that I linked it [training] with our outreach programs. Working in a public library that explores community involvement as much as possible and supports it, I promoted bibliotherapy as an adjunct to that. But it certainly wasn't part of my public library work per se.'

Debra noted that her library service had not been 'strategic enough' in thinking about who attended the training. Debra, who attended the training, was 'responsible for coordinating all the library's programs across a broad age spectrum including early literacy and preliteracy areas and also managed the home library service. I'm not supposed to be doing direct service provision.' Debra revealed that her library service 'ran into challenges [and] needed people on the ground to do the delivery at possibly a different level to the people who were trained. So maybe that was, in hindsight, a little bit of an error... because we needed people on the ground to do that delivery at a different level to the people who were trained.'

Similarly, other research participants commented along these lines: Sarah said, 'for it to be sustainable, you can't just train one person from each library service. I think you've got to have two so there's always a backup person.' Rhonda commented, 'I do think they [her library service management team] hoped we might come back and train other staff. I think that was their big disappointment, that we weren't able to train other staff... having a second intake or a third intake and kind of achieving a critical mass within, say, our Victorian libraries would have been really, really wonderful.' The training was not a train-the-trainer 
model and, to some extent, not understanding the type of training and ongoing delivery requirements possibly led to expectations of the employing library services, in regard to the training, not being met.

Three of the research participants were reluctant, scared and challenged. They did not want to learn something new; they just wanted to get through the week long training. Kim reflected that 'I just remember even the very first session on the Monday, the introductory session, thinking then, okay, well it's four days or five days, I just have to get through it. To be quite honest that's what I thought to start with. I was concerned that I was fraudulent by being there.' These three participants were not thinking about what would come after the training; they were thinking about getting through the training and expected that the training would be difficult rather than expecting any positive or useful outcome. For these participants, their negative expectations were positively replaced, as described by Cheryl, who had initially argued with her library service about not wanting to go to the training (Section 4.3.7: Expectation/reason 7: Involuntary participation):

It [the training] opened a whole new world to me, at the end of it, I just loved it... the feeling like I had things to contribute. This story actually related to me, or there were things in it that rung a chord with me. I was able to contribute, which surprised me greatly. I think it definitely changed me, absolutely. I remember thinking, this is just amazing, this is something you could do that's really valuable and that can really make a difference to people's lives. It was amazing. It's still amazing. I think it's incredible. It was very special. It's a bit hard to explain exactly how it was, but it was.

Overall, the data collected from the trainee facilitators exposed that their expectations were often not met and that they did not have the capacity to return to their organisations and immediately deliver this new program. Several factors contributed to this. The main factors were that the training did not prepare them to: be an authority on working within a therapeutic capacity; form alliances and partnerships to run groups; and build capacity to achieve therapeutic outcomes. These issues will be discussed further in Chapters Six and Seven.

\subsection{Expectations of partnership delivery}

All research participants from public libraries had been asked to develop a partnership with someone from a professional organisation in their local community with the aim of undertaking the training and subsequently delivering the program together. The reasons 
why research participants from public libraries did not (with one exception) develop a community partnership prior to the training are explored in Chapter Six: Therapy part A: Partnerships and delivery. Sarah was the only research participant who had managed to do that, and in this case, it was more down to luck. Her partner Natalie, from a community health care organisation, offered services to people experiencing mental illness and also undertook the training:

I have been working in the mental illness area for just over five years and I find it a very comfortable area to work within. I was running creative writing workshops and various people with mental illness were coming along to that regularly and it was a very successful program and so it related in the way that I knew that texts were highly valuable, highly important to starting a conversation with someone about so many different options. There was a lot of texts that we also managed to find and create as part of what we offered on those workshop times. So, with my background and degree in creative writing, it was of particular interest to me to actually see what bibliotherapy was all about so I was well and truly on-board when I got the phone call about it. Reception could have put that phone call anywhere in the organisation and it came to my phone and it was just totally random (Natalie).

The importance of building strong partnerships and alliances for new public library program delivery will be further discussed in Chapter Six: Therapy part A: Partnerships and delivery. Collaborations with other community agencies can offer skills that may be lacking in staff in public libraries and may develop networks public libraries traditionally don't have.

\subsection{Agreement to run groups}

In Australia, Victorian bibliotherapy pilot programs were conducted with community partners in 2010 and 2012, as agreed by training participants. Over half of the initial 2010 groups took place in aged-care facilities, two with mental health service providers and the remaining programs with veterans, members from the University of the Third Age, service users with English as a Second Language and a homeless group (McLaine, 2011). In the second iteration of the program, in 2012, the facilitators aimed to work with different groups to those in the initial program; however, most found it difficult to engage other sectors and reverted to aged care options. Most of the facilitators did not have the skills to promote the program and negotiate agreements to run groups, particularly beyond the aged care sector. This will be discussed further in Chapter Six: Therapy part A: Partnerships and delivery. 


\subsection{UK and Australian program variations in expectations}

This section will outline how the research participants felt creative bibliotherapy in Australia differs from the original program in the UK. As outlined in Chapter 1.4: Background to the training, the 2010 training in Australia, delivered by The Reader Organisation (TRO) from the UK (now called The Reader), was based on TRO's philosophy of the importance of getting people reading. Their program was known as Get Into Reading at the time of the training and has since been renamed 'Shared Reading'. The Reader Organisation stated that 'in Get Into Reading (GIR) we practice a form of creative bibliotherapy. Books aren't prescribed by condition... they are rather chosen for their literary depths' (TRO n.d.a, link no longer available).

Whilst TRO asserted that GIR was aligned with creative bibliotherapy ideologies, the primary purpose of GIR was the use of serious classics for the purpose of supporting literacy development (Dowrick et al., 2012). The genesis of GIR lies in the adult education sector where its original purpose was to deliver a reading program in deprived areas with the goal of teaching adults English. The read-aloud practice began when Jane Davis, TRO founder and director, as the facilitator of those first literacy-focused GIR sessions (held in community settings in Birkenhead and Liverpool, UK), wasn't sure if the fourteen people who signed up could read for themselves. In regard to this, research participant, Jane, felt that the purpose of GIR was different from the development of creative bibliotherapy in the Australian context:

I think one of the differences is that in England the basis of it was looking at it from literacy... I think here [i.e., Australia]... literacy is not a problem. It's not something that is going to be tackled in the bibliotherapy sessions. So these people do not feel the need to read a classic aloud in order to raise their literacy level.

Other research participants also saw that the literature used by TRO to support literacy development within an educational context was not suitable for the Australian context. Helen said, 'The Reader Organisation were coming out of illiteracy really and wanting people who had not really read, for whatever reason... and struggled with things like Shakespeare.' Jamie thought 'the texts were suitable for the studies they i.e., TRO] were interested in. So what they were developing out of the university was studies on how a certain quality of literature affects people, but I don't think it was actually applicable here [in Australia].' Jamie's comment relates to another aspect of the UK program that did not translate well 
into the Australian context - the use of serious classic literature. Helen noted within her Australian groups that 'the Shakespeare... It spoke to them but not in the same way as in the UKJ'. Similarly, Meredith commented that 'The Reader Organisation's focus was certainly different from what I have discovered is happening in the groups that I'm working with. We do a lot of modern and almost abstract texts as well... They're [i.e., TRO texts] just too, I'd almost say stuffy... So we've moved to more modern short stories and bits of nonfiction as well, rather than that you know, "worthy" literature. I say "worthy" in inverted commas.'

The Reader Organisation was started at the end of the 1990s but 10 years later it began promoting GIR as 'a practical way of improving wellbeing and building stronger communities' (TRO n.d.b, link no longer available). This was a move away from using literature to support literacy development within an educational context, to using literature to promote wellbeing within a community context. This move to wellbeing was prompted in 2008 when Blake Morrison, a UK poet, author and academic, and a long-time supporter of TRO, published an article entitled 'The Reading Cure' in which he privileged the health benefits promoted through the work of TRO over literacy. Brewster (2011, p. 132) asserts that ' $(\mathrm{t})$ he translation from literature-as-education-and-literacy to literature-promotingwellbeing' and ' $(\mathrm{t})$ he shift from a model promoting literature to one promoting health and well-being has complicated the teleological narrative of GIR' (Brewster 2011, p. 143). Research participant Jamie noted this issue with the GIR program:

A lot of their [i.e., TRO] research in the universities is still on the brain stimulation on being read highly literate pieces. It's the stimulation of Shakespeare or the stimulation of Wordsworth. It's not so much the healing or the social benefit that comes from having that read to them. That means their science is based on the effect of the literature, rather than the effect of the feedback, mental feedback or whatever. So I think perhaps they're [i.e., TRO] confused and they are not able to step away from that. Even though they can see that the benefits should be community and social development, they are caught on how the effects come immediately from the exposure to literature.

The unpublished manual created by TRO used for the training in Australia stated that the program 'looks after the mental health of the general population' with outcomes of 'improved mental health and wellbeing, promotion of recovery, and the prevention of mental health problems'. However, these general aims and outcomes of bibliotherapy were not addressed in the training, as highlighted by Jamie's comment above. The experience of 
the Australian facilitators delivering groups was different from that of the more literacyfocused position of getting people reading in the UK. Jamie felt that 'it's not a literary thing, it's an emotive outcome that we're after' and that 'they [i.e., group members] are definitely looking for an emotive outcome.' Jamie spoke about this in more detail, saying that it was:

quite hard to bring it [GIR] to an Australian context... I do believe culturally we're quite different... In Australia it is more about the healing than the literacy and that's certainly different to what Reader Org I think is focusing on... I think in Australia we are looking less at the literacy than they are with the UK Reader Organisation, definitely... it really is the healing that a group is looking for, the healing rather than the literacy. Certainly that's where the interest has come from; people that are interested are the ones that are looking at the healing aspect definitely.

Wilma, remarked that TRO, 'came from a different perspective. Somehow I think that's infused even through the training.'

Meredith's comment below brings to light important thinking about the 'therapy' component of bibliotherapy and delivering a 'wellbeing' focused program in alliance with a mental health provider:

So the whole thing about what was the therapeutic aspect of our bibliotherapy program, yes, it's certainly the social aspect within the group when they're there but actually getting them to the library or into a [community space] - it's something, which comes up quite frequently in the objectives of the mental health team's perspective. Totally different from what The Reader Organisation is looking at. Probably, and sometimes with the therapeutic aspect of it, too, what The Reader Organisation saw as being a therapeutic aspect and what the community mental health team I'm working with sees as a therapeutic aspect are two different things because The Reader [Organisation] aspect was seen to be going into the mental health environment and delivering, where we were using this as a tool to get people into a community space. Complete reversal. So what The Reader Organisation was looking at doing about going into a mental health environment and delivering was very different from what I've found successful from my end of things. When you look, if you actually read through and have a look and see what their objectives are, what are they trying to do, by selling it to them to say okay, this meets what you want to do, rather than the other way round? Much better chance of them [i.e., a community health service provider] picking it up.

The above comments, from the Australian facilitators' experiences and comments in Chapter 5.1.1: Reading material provided by TRO, highlight that the UK program is more 'biblio' focused than as delivered in Australia. The UK program predominantly focuses on literature, and the Australian form of creative bibliotherapy is more 'therapy' focused in that 
it supports the promotion of wellbeing as its desired primary outcome.

A further discovery within this variation between the UK and the Australian focus is that 'shared listening' rather than 'shared reading', is significant in the Australian creative bibliotherapy program delivery (further detailed in Chapter 6.4: Shared reading and listening). This discovery that in Australia therapy has more importance in creative bibliotherapy than in the UK suggests that different training requirements are required. Setting up a group where listening is the focus, rather than reading, requires different skills and attributes of the facilitator and a shift in intention, actions, the facilitator's role, and measurements of success. Additionally, as Jamie stressed, 'for bibliotherapy groups to work there needed to be more of a focus on [therapy] than the literature [i.e., biblio]. I think that's what will make it work here [i.e., in Australia]. I think that's how it is going to work best is if the facilitators are trained to - I don't even know what the training should be, but it needs to have more of a social work background... I know so many librarians that I don't think would suit this activity... the people that are successful facilitators are going to be not pure librarians and not pure psychologists. They are going to somehow be a junction of those two things and the course will have to address that.' Encouraging appropriate alliances with community partners could also work to achieve this aim.

\subsection{Chapter Four concluding comments}

Chapter Four discusses the research participants' individual understandings of bibliotherapy, personal reasons for undertaking the training, and their expectations of what they would gain from the training.

The data revealed a range of understandings of bibliotherapy, from no understanding at all to appreciating its capacity to affect people's wellbeing. Several research participants had a good understanding of the self-help Books On Prescription model.

The data showed that the research participants had a range of reasons for undertaking the training, with learning new skills cited as a main reason. Several research participants admitted not being a voluntary participant and were attending because of insistence from their workplace.

Expectations of the training as perceived by the research participants varied greatly and were fulfilled to a lesser or greater degree across the spectrum. They provided insights into 
how future training could be better delivered for success in the Australian environment, directly addressing the aim and objective of the research project, and the research question (see Chapter Eight: Conclusion, for recommendations).

Early expectations of a requirement for training participants to develop community partnerships for future delivery of creative bibliotherapy programs was discussed and will be discussed further in Chapter Six.

The data reviewed in Chapter Four establishes that due to a lack of understanding of bibliotherapy, the facilitators had not expected that the training would be linked to the therapeutic use of literature. Once facilitators realised that emotional responses were involved and might require managing, a collective loss of expectation around feeling prepared to deliver bibliotherapy following the training was exposed.

Chapter Four has explored the expectations facilitators had pre-training. This discussion will be further developed in Chapters Five, Six and Seven, exploring what facilitators felt about the skills and tools needed to facilitate group therapeutic environments. Chapter Five looks specifically at 'biblio' components, such as selecting reading material and reading it aloud; Chapters Six and Seven (Parts A and B) look specifically at 'therapy' components, including developing skills in 'shared listening' which appears significant in the Australian creative bibliotherapy context for promoting wellbeing through books and reading. 


\section{Chapter Five: 'Biblio'}

\section{Introduction}

The focus of the thesis is the research participants' perspectives of the training they undertook in Melbourne, 2010 for facilitation of creative bibliotherapy, and particularly their understanding of the two elements of 'biblio' and 'therapy' in this practice. This context informed the research aim and objective, and the research question: How can the understanding of the relationship between 'biblio' and 'therapy' be developed in non-clinical facilitators and applied to support the promotion of the wellbeing of individuals and groups in society?

Chapter Five begins the in-depth exploration and development of the central concept of this research study - the relationship between 'biblio' and 'therapy'. This research study aimed to analyse facilitators' perspectives of creative bibliotherapy to answer the question of how the relationship between 'biblio' and 'therapy' can be developed and applied by non-clinical facilitators to support the promotion of the wellbeing of individuals and groups in society. An understanding was sought through focusing on research participants' shared experience of undertaking bibliotherapy training in 2010 , and the effectiveness of the training to prepare them to deliver bibliotherapy groups. In examining the relationship between 'biblio' and 'therapy' in bibliotherapy the use of Aristotle's truism that 'the whole is greater than the sum of its parts' is very appropriate. The research approach of using the dual foci of 'biblio' (i.e., the use of books) and therapy provides a valuable concept for considering bibliotherapy both for its separate components and as a whole. The analysis of the data for this chapter considers the book, or 'biblio', component as a distinct entity. Themes emerging from the data showed that there are strong elements that addressed 'biblio'. Initially, this chapter will consider the selection of reading material to read aloud (5.1). Next, the chapter will look at how facilitators bring the reading material alive through reading aloud (5.2). Then, the chapter will consider how facilitators monitor what is happening to the individual group members during the reading - or 'biblio' - process (5.3).

\subsection{Reading materials}

The word bibliotherapy originates from the Greek word for a book - biblio - and the use of books in a therapeutic process. The 'biblio' component can be considered a constant factor 
in all forms of bibliotherapy. Books are used in all models of bibliotherapy, although the types of books and genres differ.

As discussed in Chapter Four: Bibliotherapy training, literature, specifically literary texts is used as a therapeutic agent in creative bibliotherapy groups. The different narratives and poems selected for use in bibliotherapy can each play a different role in the group. The right story can provide the vehicle for transporting group members into a more open and willing state for the discussion activity. Billington $(2019$, p. 6), Dowrick $(2019$, p. 17) and Ellis et al. $(2019$, p. 72$)$ all found that reading stories aloud in reading groups, 'produced relaxation and calm in participants'; whereas, 'poetry, on the other hand, produced alert concentration, renewed mental effort and intensity'.

Selecting the reading material is a fundamental part of 'biblio' and is essential in its relationship to 'therapy'. Not only is the reading material selected for its relevance to the type of group, it needs to link to the commonalities of the group, i.e.,, similar experiences or challenges. The reading material needs to also connect to the group in a way that encourages a more in-depth discussion of those commonalities, helping people self-discover what it means to be human (Kayser, 1990). In this context, Section 5.1 explores research participants' thoughts on using supplied reading materials, independently selecting reading materials, and the sustainability of ongoing independent reading material selection.

\subsubsection{Reading material provided by The Reader Organisation}

The Reader Organisation's (TRO) 'Get Into Reading' program is characterised by its emphasis on the importance of serious, 'classic' literature. Examples of reading materials used by TRO include sonnets, Elizabethan poetry and prose, and high literature by, for example, Anton Chekhov, Doris Lessing, George Eliot, George Orwell, Emily Brontë', Charles Dickens and William Shakespeare. The 'Book Well' program training in Melbourne provided a list of ten TRO recommended stories and poems for facilitators to use in program delivery subsequent to the training. Research participants were asked in their interviews for this study, 'Tell me how the training provided you with suitable reading material to use in bibliotherapy groups'.

Some facilitators felt that Australian group members did not relate to classic literature in the same way that the United Kingdom (UK) group members had. Helen 'felt the texts that they used - a lot of them I couldn't use. I wasn't comfortable using them. I think England is 
different to Australia. I think that's an important thing... we're upside down in the seasons... and all the words were snow and ferns compared to heat and gumtrees... They [i.e., group members] didn't seem to relate.'

Natalie stated that 'some of the texts that we used in training were going to be a bit too oldfashioned like [British] colonial time stories and things like that... and did not grip me in any way shape or form.' Meredith said they were too 'stuffy' for her group and Sophia 'didn't feel that there were suitable texts and used different texts.'

Other facilitators' comments highlighted the perceived cultural differences between Australia and the United Kingdom (UK). While white Australian culture to some extent is derived from Britain, Australia has developed its own unique culture. Jamie:

[I] was very surprised at the course how culturally different it felt, the Australian as opposed to the UK because I thought we were very similar. I think even though we do read classics, most people read classics at school, a lot of Australians want something they can connect to more. So, to be very colloquial, Banjo Paterson rather than say Shakespeare and I needed someone to discuss that with which obviously I didn't with trainers from the UK. Australians need different - I don't believe that quality literature affects our minds in the same way it does in England. We've had our own literature and we've had our own readings and our own culture [i.e., white] for 200 years. I think it [i.e., the training] didn't prepare me to know what to do for the people I'm with here. I don't believe the training provided me with suitable texts because we've created our own society very strongly - I didn't feel prepared.

Similarly, Helen felt:

England is different to Australia. What I found is on the whole, for this age group [i.e., aged care], it's the Australian material that they loved, like 'My Country'. They know it and they say it by heart. Somebody will sing those sorts of things. They'll sing. Whereas the Shakespeare, they can discuss it but it's in the way they learnt it at school. That's particular for this age group because, if you've got a mixture of young people who are learning Shakespeare in a different way now and it's being related to now, whereas I don't believe that these people [i.e., in aged care] were encouraged to look at Shakespeare and what its relevance is to now. They learnt it as a piece of English history. They got it. It spoke to them but not in the same way.

Melanie noted one group member saying, 'we would never have done that as children' when she read listened to something 'written in a European sense, I think, about young children living in the country [i.e., English countryside]. So maybe it was too far removed from here, there was something in that was a bit off.' 
Next will be explored how facilitators selected reading material to use in groups.

\subsubsection{Independently selecting reading materials}

After using the ten recommended stories and poems provided in the training, Jane followed the guidelines of TRO to continue using serious, 'classic' literature with a group:

I did a book - and I can't for the life of me think what it was called - and they started off enjoying it, but after about five chapters it was too much the same and we ditched it. We agreed it just wasn't going anywhere. I thought that was interesting too, because it really made me aware that it wasn't purely the reading that they were enjoying. They were not being engaged with this book, which was still going through all sorts of various human conditions and experiences and things, but with no room for emotion. However, in the second book I did, the emotion was there. The emotion, they could all relate to. It was very much an emotional experience and that continued right the way through the book, regardless of what the chapter was about. So there was emotional engagement throughout.

Research participants were asked a range of probe questions during the interview to develop thinking around the way in which they selected reading material to use in groups. The questions asked of research participants addressed: what they look for in reading material; what makes reading material good or bad to work with; and what determines which reading material they used with different groups in different settings.

The facilitators found it difficult to explain what it was they were looking for when making reading selections. Cheryl reflected on using a story she had selected for reading as being a 'good' story: she couldn't 'find that leg-in to really try and open up different avenues [of discussion],' commenting that 'it has to be more than just a good story.' Jane agreed 'there has to be more in the text than simply good language, beautiful scenery, lovely atmosphere.' Jane felt there is a 'sense of achievement when people listen to or read a good text and really work hard and get something out of it and respond to it. So, I think the text needs to be a little bit challenging.'

Helen tried to establish 'the core thing'; she said,

There has to be some satisfaction. It doesn't mean that it has to have a happy ending. I choose the texts often from ones written in their own time because I know that they will have an understanding. Also, I pop in modern ones. Their natural ear - the language is important because their ear feels comfortable in a certain style. I don't mean style as imaginative or descriptive. I mean, it's the way it's said. Modern writers can do it too, 
which allows for that comfort. That's what I started off with. I purposefully put in some jarring ones. They'll tell me they didn't like it. Once we've talked about it and engaged in it, that's when the issues - when they have engaged that they feel more comfortable with it. So, I can do both.

Helen also felt 'the construct of a short story is important, of what a short story essentially is. The ending can be left open. But you have to know that it's ending.' Sarah also identified the narrative structure as important in that 'it needed to have a strong enough plot line in it' and must have 'some kind of storyline in it.' Similarly, Leanne 'selected texts that had a beginning, middle and end.' However, for Kim 'it didn't have to have a neat resolution... because you have to think really hard about what is going on in the story. Then when you get to the end you have to say well, what do you think has just happened? Some people get it straight away and others interpret it differently.' Debra also likes to work with readings 'that were a little bit open to interpretation.' Wilma said, 'it's really about finding a text that has enough in it. I guess if we'd done more of that [at the training] we might have got just a slightly better feel for it.'

The facilitators considered that subject matter was a key element that made literature good to work with. Jane, Rhonda and Tanya all spoke of 'universal themes' that Jane described as 'relating to a wider audience, rather than just an individual.' Debra elucidated that these are 'the things that make us human, the things that we all share, the common experiences that draw us together, like births and deaths and love and joy. The things that don't vary from culture to culture. How we express it might vary dramatically, how we celebrate it or recognise it, but the emotions, that's what we share and how we connect.' These ideas are similar to guidelines for selecting literary texts for bibliotherapy identified by Tu (1999), who recommends using literature that not only maintains a reader's (or listener's) interest but also portrays real life in experiences, future possibilities, emotions, controversy and resolution. However, Melanie 'didn't choose anything that had death in it or too much sadness. I don't think I was quite prepared to go down that path and have that discussion.' Several facilitators expressed that characterisation was central to discussion supporting Shrodes' (1949) notion, in writing about bibliotherapy, that the therapeutic benefit came from the process of identifying with another character and so developing a greater awareness of one's own behaviour and motivations. Sarah chose stories with 'strong characters' and stories that helped to 'understand their [i.e., the characters'] motives behind 
something.' Rhonda looked for 'powerfully-drawn characters' and stories with 'a lot of detail about people's lives to build up a character and enough interrelations with characters.' Wilma believed 'the characters need to engage the listener in a way that you either definitely see them as an antagonist or a protagonist in the story so as to be able to talk about the pros and cons of the choices made by the main characters.' Helen said it needs 'enough action. I don't mean plot. I mean, it could be just between characters... building up of a character and enough interrelations with characters.'

Language and images were noted as focal components of stories and poetry. Rhonda, required 'strong imagery.' Similarly, for Rachel, 'something that is descriptive, that people can visualise' was essential, 'where you can actually see yourself and immerse yourself in the text.' 'Imaginative use of language' was important to Jane; Rhonda required 'powerful language'; for Leeanne, 'a bit of dialogue' was needed.

Many of the facilitators deliberated on ways to engage readers. Terry believed that:

If you keep using the same stories then you start thinking the same way. So I think it's good to have differences as well, from different eras, different generational - it could be really old stuff so that the words you're using are completely different again, rather than just hearing words that we normally are used to, or the way the phrases are used, or expressions used. So, they're different to what we would consider.

Wilma thought that 'for the short space of time that you have, the text needs to have momentum about it' and 'a great twist to intrigue people' to sustain reader interest. For Tanya, 'some sort of challenge, or rite of passage' was necessary; Rachel looked for 'a sense of struggle'; Jane, 'a theme or an issue or a conundrum with a depth to it that will spark an emotional response to it.' Leanne looked for a story that provided 'a hook into it'; Natalie felt that 'leaving the listeners with a small amount of hope' was vital and Helen similarly said she 'stays clear of texts where there's no hope.'

Several facilitators stated the importance of selecting reading material that resonated with their individual groups. Tanya reflected that:

One of the most important things is finding text that suits the group that you're working with... when there wasn't anything that they couldn't identify with in any way, shape or form... if it was too unfamiliar or the language was not familiar, then I noticed that they found it harder to contribute [to the discussion].

Helen, considers 'the story needs to ring true in humanity. Therefore, the texts have to be 
different for different groups, I believe.' Relatedly, Debra considered that 'it's all very dependent on your group. You really have to 'read' the group and understand their needs.' Sophia thought that 'it's not just a concrete sort of text that would work with one particular group. It's a little bit more difficult than that... I guess it's just knowing your group and perhaps finding a familiarity within a group.' Natalie, considered that 'elderly people required a totally different focus yet again in terms of the texts and the poetry' compared to the demographics of other groups. Exploring the theme of childhood was recognised as significant; Rachel, Rhonda and Kim stated they often used 'stories of childhood.' Wilma elaborated this idea further, saying that using stories told:

Through the eyes of a child... had common ground which were about... children and children's experiences... [W]ith all this diversity of different people and their different experiences, childhood is a great way, even if they're completely diverse... of uniting the group in a conversation because everyone's got a childhood experience and everyone was born from someone even if they died or they were cruel or whatever.

\subsubsection{Process of selecting reading materials}

In discussing the expectations of training Cheryl confessed that the training 'wasn't something that she wanted to do. The library service suggested it... I argued with them... but they insisted' (Chapter 4.3.7: Expectation/reason 7: involuntary participation); but it emerged that her underlying reason for not wanting to take part in the training was connected to selecting stories and poems, particularly poems. Cheryl said that she didn't feel confident about selecting, 'poetry and short stories which she felt she had very little appreciation of or understanding of.' Cheryl spoke about how she remembered reading her first poem in the training, 'they [i.e., the trainers] must have thought I was awful, but I can remember saying, I don't do poetry!' Cheryl's confession was not the only one. Many of the research participants confided that they felt worried about a lack of knowledge of classic literature, short stories and poetry. Some felt that having the title of librarian meant added pressure because it implied that they should have knowledge of literature. Kim explained this feeling by commenting that 'even though I work surrounded by literature all day really, your day to day library work - you're not necessarily involved with it, you're recommending it or you're shelving it or whatever. You're not necessarily deeply involved with the content.' Helen said that facilitators need to 'carefully work out the stories to awaken that curiosity... I think it's something that has to be consciously looked at in a course. How do we want 
awakens those people [i.e., group members]?'

Most facilitators commented they would have liked more training in selecting literary texts. Wilma 'remembers there was an anxiety throughout the whole group of the participants [i.e., in the training] about the material and accessing the sort of material that would lend itself to group discussions.' The notion of using reading material as a catalyst for discussion will be developed in Chapter Six: Therapy part A: Partnerships and delivery.

\subsubsection{Bias in independent reading materials selection}

Section 5.1.1 and 5.1.2 have discussed research participants' thoughts on using supplied reading materials compared with independently selecting literary texts for use in bibliotherapy. However, consideration needs to be given to bias when making independent selections. While some of the research participants spoke about the importance of selecting the reading material to suit the people receiving it, and the aims of the bibliotherapy session, most of the research participants showed varying levels of bias in selecting texts. Many of the facilitators expressed that the text needed to resonate with them as central to how they select texts. Wilma stated that 'as the facilitator you have to like it.' Similarly, Helen, said you need to 'make certain you choose a story that you like.' Kim believed she 'couldn't carry it off if it didn't speak to me' but explained that at times she had 'possibly invested a bit too much in a text because she had personally loved it.' She remembered a group member 'couldn't stand it, [saying] "I hate it, hated it." So it pays not to get too precious about any of them I think.' Rhonda said, 'I think that I have to be emotionally involved in the story myself to be able to make it work for everyone else.'

Rachel identified that when selecting texts, 'first of all it's something that has to resonate with me. I did pick things that were important to me because that was kind of, I guess, my repertoire... Because that delivers a more authentic session... otherwise, in my opinion, you're a fraud.' Related to this, Natalie 'thinks it has to [resonate with you] because otherwise you're just committing a lie. I think you're just an actor on stage otherwise... if it doesn't speak to me how am I meant to elicit the audience?' Debra likes to use texts she is 'familiar with... or use her favourite poems, or favourite poets.' Melanie selected 'something that wasn't going to be too out there, that would take too much thought.' The fact that many of the facilitators expressed that the text resonating with them was central to how 
they select texts illustrates that facilitators can have bias towards their own interests when independently selecting texts. Selecting literary texts that resonate with group members as well as with the facilitator can increase social connection for participants, through supporting group members to get to know each other, and relate to each other, in a different way (McLaine, 2019). This in turn can provide benefits for community and social development, help to meet key outcomes for alliance partners, and contribute to the requirements of community programming in public libraries.

\subsubsection{Time required for reading material selection}

In answering the interview question, 'Tell me how the training provided you with suitable texts to use in bibliotherapy groups,' research participants were all concerned about the time required to source appropriate weekly literary texts if they were not provided. Debra described that 'it's the kind of thing you can do full time'; Sophie remembers 'spending a lot of time searching for material... I spent a lot of time selecting stuff... I spend all my time preparing text.' Rhonda and Terry both said 'it's time consuming'; and Helen said, 'it takes a long time to build-up adequate texts.' Rachel, said she 'did lots of trawling, and lots of reading short story anthologies, that's all I did for two years, to get material.' Natalie said 'it wasn't just a case of stumbling across them in 20 minutes. There was a fair bit of research that went in and traipsing through library shelves and things.' Jane said she did 'more discarding than choosing; whilst Wilma said 'wading through all the material can be enjoyable but it starts to be less enjoyable when you're running out of time for next week's session.' Meredith said that 'the library cannot commit time for us to source materials'; as did Rhonda, who sourced literary texts in her own time, saying 'I don't begrudge doing that, but it is a factor.' Debra felt that 'it was a challenge'; and so did Cheryl, who said 'the thing that overwhelms me, is finding stuff... I do find finding material an ongoing struggle but she 'stuck to her guns very strongly that she needed preparation time.'

Rhonda said 'you need a lot of material, and it can take some time to source it for yourself, and if your time is limited that can become an issue. If you're trying to do it within an organisation who allows you so much time and no more, there's a lot of time that you put in yourself doing it.' Rhonda said that although:

They are happy for me to continue I'm not sure how deep an understanding they have of what is involved, and I was reflecting on this the other day and thought well, perhaps the 
people who are making the decisions, I haven't actually run a session for them, which was something you [i.e., in the training] advised us to do. So that could be why they don't although they're committed to it, they perhaps don't understand how involved it is and how much time it can take to prepare and set up and deliver.

Similarly, Meredith commented:

When we [i.e., herself and the community partner] had a reflection on the group, they [i.e., community partner] feel it would be really good if you could spend more time sourcing material. Then I've got to turn around to the logistics side of that and say look, this is a group - I mean across the three [library] branches we're looking at perhaps 35 to 40 people participating. I can't spend - the library cannot commit four or five hours' worth of staff time to sit in on all these programs plus more time for us to source material for 35 clients.

Meredith also spoke about an unsuccessful endeavour to alleviate the time-consuming task of selecting reading material: 'we [i.e., other facilitators] thought at the end of the training that we could collectively start a Wiki... and it was a crashing failure... oxygen thieves who use material but never put anything in... it sort of just falls over on itself in the long run.'

However, working in partnership helped to share the load of selecting weekly literary texts for Natalie and Sarah, who discuss their process of sharing reading material selection:

Natalie: We divided the weekly readings as to whether Sarah was going to come up with the short story or the poem for that week... we gave each other enough notice so that the person that had to select the poem was given enough warning so that there was some sort of a combined theme running through both short story and poem which is how the whole bibliotherapy notion ran. We didn't just choose a random poem, just for the sake of it. I suppose if you're doing it in terms of a partnership both people need to be investing the same amount of energy and effort for it to work. We spent quite a lot of time getting that sorted and we spent - I suppose we were on top of things in terms of we knew it was going to take a long time to source the materials we were after, it wasn't just a case of stumbling across them in 20 minutes. There was a fair bit of research that went in and traipsing through library shelves and things.

Sarah: I found it much easier to find poems and Natalie found it much easier to find prose. I don't know why, maybe I read more poetry than she does perhaps... It does take a lot of time to do... there was all the preparation beforehand... It's the finding of the texts and then practising and preparation. So, it's a very time intensive thing... sharing resources is useful, but you have to find the things that suit your group as well.

Sarah: the reason I haven't done any more of these programs is that it was the time factor... it does take a lot of time to run a program like this. Because the session itself, I 
mean that was basically two hours out of my day every week just to do the session and then there was all the preparation beforehand. For the amount of time and effort, it didn't benefit a lot of people.

Sophie also commented on why she hasn't continued running groups:

I remembered spending a lot of time searching for material... I spent a lot of time on selecting stuff... I spend all my time preparing texts... I think that it would have been helpful if there was a bit more guidance in text selection... the one thing that would hold me back from it [i.e., running groups again] is the time it took in selecting texts.

The Reader Organisation often recommends books for serial reading which alleviates the need for weekly text sourcing. However, this was a particular issue in Australia (as discussed in Chapter 4.6: Agreement to run groups) where many of the groups took place in aged care and therefore group participants were often not able to recall what had happened in the previous reading when the book was taken up again from where it was left off. In aged care it is fundamental that each session has its own focus to assist group members to not feel any loss of continuity due to memory issues. Facilitators of groups with participants experiencing psychological and emotional challenges found similar issues. Meredith spoke of:

The idea of reading a chapter of a book, over a period of weeks. That has been a resounding failure because the clients forget. So while it might be something that a professional can remember and is interested in, saying we're up to here and we'll keep reading, doesn't work. It's a nice idea but it doesn't work and we've tried it with a couple of different sorts of texts as well.

Participants highlight an ongoing issue of the time-consuming task of reading material selection. Interview data indicates that the high level of time required to select literary texts is a central concerning issue to the facilitators but that having pre-selected reading materials, as in The Reader Organisation model, did not solve the problem.

\subsection{Reading aloud}

This section will discuss the experience of reading aloud from the point of view of the facilitator and their observations of how the way something is read aloud relates to the adult group participants listening. 


\subsubsection{Reading aloud to adults}

For adults reading is typically a solitary activity, often insular in experience with the words heard internally rather than out loud. The creative bibliotherapy practice of reading aloud in a group offers a different experience: an invitation to dwell more deeply on what is emerging from the words, within each individual and in the group as a whole. What distinguishes the practice of creative bibliotherapy from other forms of bibliotherapy, for example, an individual reading a self-help books is the reading aloud to a group. Benefield et al. (2019, p. 423) declare that 'to be read to is to be given a reading plus experience'. After the reading material has been selected, the facilitator needs to bring the literature to life. Billington et al. (2010) describes this as reading aloud expressively in a way that makes the literature alive in the room and creates an atmosphere of attentiveness. Fearnley and Farrington (2019, p. 326-327) similarly assert that 'each reading [is] a fresh starting point and a dynamic presence for what follows. The literature is now re-experienced as a live happening in which the reader is invited to participate, by attending not only to the words on the page but to the human voice in which those words are being made present'. Steenberg et al. (2019, p. 275) suggest it is this "liveliness" of the reading process which further allows the processes of reflexivity, inter-subjectivity and growth which are productive of well-being'.

Cheryl deliberated on ways to bring the literature to life. Rachel said she wanted to try to bring the text alive for them. Cheryl said she 'tried to read very expressively and certainly to phrase things so that it's easier to understand what's happening.' Related to this, Rachel 'thinks you do need to have some emotion behind your reading. I guess to bring a story to life I think it does need to have different tones at different places and sometimes, it does need to have emotion behind what you're reading.'

Bringing the literature to life is particularly important in the context of reading aloud to adults, many of whom may not have been read aloud to since hearing childhood stories. The facilitator needs to create in the adult participants a 'willingness to receive the words read aloud' (McLaine \& McKenzie, 2018); that is, a willingness to accept an invitation to dwell more deeply with what is emerging from the words. When this is achieved 'there is something remarkable about how these words from another person, living in another time and place, are sensed by 'group members' as almost physical events' (McCown \& Billington 
2017, p. 175).

\subsubsection{The experience of reading aloud}

Research participants were asked in their interview for this study, 'What was your experience of reading aloud before starting to facilitate sessions?' Wilma was the only facilitator with previous experience in reading aloud to adults, through reading poetry to people living with dementia. However, six of the facilitators had been involved with reading aloud to children during library 'story time' sessions, or could draw on a teaching background. Jamie, as a school librarian 'had done quite a bit' and didn't think 'it was something she needed to practise'; but, except for Wilma, reading aloud to adults was a new concept for the all of the facilitators interviewed.

Several facilitators conveyed that slowing down their reading was central to how they read aloud when they conducted sessions after the training. Meredith, was 'very conscious about slowing my delivery down... I've got to make sure when I'm reading something that I read it more slowly.' Wilma said what 'struck me is how you have to slow down and... you know it's unusual to read as slowly, but you do have to do that and it makes a huge difference.' Tanya considered:

The hardest part for me was learning to read slowly, jolly hard, I struggle with it. It's also that learning to breathe and pause at the right place to get your breath, because when you're reading silently to yourself you can skim through a sentence, but when you have to say it out loud and slow it down, you've got to find the right place to breathe and break it. Cheryl 'believed that you really need to read the text well, especially in this particular setting - they [i.e., group members experiencing psychological, social and emotional challenges] are people who really struggle with concentration. It's very easy for them to lose the thread and just not bother.' Tanya 'felt very self-conscious towards the end with some pieces. I'd start off okay and then at the end I think my tone started to falter because I could see the look of almost non-comprehension or boredom sometimes, they lost interest.'

\subsubsection{Preparing to read aloud}

Using the key elements of intonation, volume and temporal occurrences such as rhythm, tempo, placement of stresses in a sentence, and pauses, helps group members to recognise the intention of the writer (as interpreted by the group facilitator) and to feel intimate with 
the distant voice of the writer (Hughes \& Szczepek Reed, 2006). Some facilitators recognised the value of preparing the literary texts to read aloud and then practicing.

Sarah found for her 'it is a nerve-wracking thing reading aloud in public,' and thought that ' $a$ lot of the group members [i.e., facilitators during training] were quite nervous.' Rhonda said she, 'was terrified... Getting over the hurdle of actually reading aloud if you've never read aloud is pretty scary.' To get over this fear, many facilitators talked about practising reading aloud before delivering to groups. Tanya 'read it aloud once the night before.' Sarah said she 'practised - but I only really read it out loud once. I didn't do any more than that'; but Jane said that she 'reads aloud many times in practice... I still practise reading aloud before every session and sometimes I'll do it many, many times at home before I get there.' Tanya 'always practiced reading it aloud, because it's amazing the little traps that lurk in there in terms of the rhythms and the pacing and the odd word that you think you know how to pronounce and then when you get to it you stumble.' Both Terry, Rachel and Natalie also practiced: Terry 'read it out loud so I got a sense of how it flowed and how my voice sounded'; Rachel felt 'that's integral in a preparation... practicing reading aloud beforehand, to get my timing, to see that if the story that was going to fit into the timeframe that I had. But also to practice where I'd put emotion in particular lines or where I'd pause at particular points as well'; Natalie would 'rehearse reading aloud in the week beforehand so that I wouldn't stumble on any words and things like that.'

Jane, Kim, Sophia, Melanie, Cheryl, Meredith and Kim all spoke of importance of preparation, including practising reading aloud. Jane explained that she 'makes little annotations on my copy. So that when I'm reading, I might pause in places that I think are going to have more effect, or where I want to slow down so that the meaning comes through.' Kim uses 'little things written in the margins. I mark it up and then I go back to where the previous mark was and in between there's usually some reminders that I've scribbled.' Sophia believed 'you need to sit down with that particular text and work it for your group. I read it through a few times.' Whereas, Melanie thought the best approach was to 'wing it.'

Cheryl felt 'the preparation makes sure I am very familiar with the text and read it quite fluently, to help them along' and elaborated further:

I find preparation really, really important. In fact, I stick to my guns very strongly that I 
need preparation time. I read it and I usually read it out loud and often re-read it. It's just in reading and thinking about it, I guess, that I think of the questions. Often do a bit of research, find out a little bit about the background of the story or the poem. But all that stuff is not necessarily the stuff - like the background stuff and the research, it's not necessarily the stuff that you then take to the group, but it just helps me feel more confident, I guess, with the text. Yeah, but I find you need to read it through several times to really think thought what it is that - or where you might go with it, what you could explore.

The preparation of the reading material to read aloud was fundamental to building the confidence and capacity of the facilitators. Reading aloud to adults initially made the facilitators uneasy; and this in turn created unease in the listening group members. However, it usually does not take long for both the readers and the listeners to enjoy and appreciate the experience of giving and receiving the words aloud.

Several facilitators commented on the need for more training in reading aloud. Rachel said:

It would be useful to have more training, just talking about the voice and how that can add to the experience... I try to bring the text alive for them. I relied on my outside experience more than what the training presented... I've heard others say that, it'd be good to have some more skill development.

\subsection{Breaking the flow of reading aloud}

The Reader Organisation's Get Into Reading program is characterised by a read-aloud style emphasising pauses for discussion during the reading of the story, and group members sharing the reading. The Australian training included the pausing and sharing techniques; however, it is worth mentioning that the Australian facilitators found both these techniques broke the flow of the text being read aloud or, as described by facilitators, broke the rhythm and melody of reading. This concept is discussed further in Chapter Six: Therapy part A: Partnerships and delivery and Chapter Seven: Therapy part B: Achieving therapeutic outcomes.

\subsubsection{Pausing}

Only one facilitator used pausing in the reading as an ongoing approach. Sophia paused for discussion through the story and she felt that it worked in her group 'because of their English as a second language and because it was part of their ESL classes and they were coming to learn as well... there was a bit of talking about the concept but they'd also be 
talking about words. They'd be, oh, so this is what this means... Can I use these words in this context? Can I say this?'

Other facilitators had attempted to use pauses but hadn't continued with the practice for a variety of reasons. Melanie 'tried with the pauses... I felt that they wanted me to continue [with the reading aloud],' and Rachel similarly reflected that 'when I was trying pauses I remember one participant going, yeah, come on, let's get on with it.' Leeanne's group members as a whole 'didn't want to stop - they'd keep saying "no"'; and Tanya's group was the same, saying 'don't stop now.' Helen said, 'there's a preference definitely to reading it right through... they said, can we just keep going?' and 'can we get on with the story now?' From the facilitators' point of view, Terry thought that pausing 'breaks the atmosphere, breaks the continuity.' Helen also observed that pausing 'would break it [i.e., the session] up too much,' and Cheryl noted that 'sometimes it's hard to get them back on track.' Wilma felt that when pausing 'you've lost the thread of the story; people would say oh where were we? What were we doing and we've have to re-read bits and stuff.' Meredith said 'people don't like you to stop.'

\subsubsection{Shared reading}

The bibliotherapy method taught at the training was a shared reading model. In this approach group members take turns reading a section of the text, rather than the facilitator reading the text. It is common that copies of the story are offered to the participants to follow along, and as an invitation to read aloud. Rachel still remembers the response she received from her group members when 'I offered [to share the reading] and it was a big no. I've got memories of that.' But sometimes group members did want to contribute by reading and this created some issues. Wilma initially used the shared reading model but found, 'that it then actually became another little task for me to deal with because one woman wanted to read all the time and another person corrected everybody all the time which was a bit annoying.' Helen felt frustrated by a group member who would tell other group members, 'you don't read like that. You didn't read that very well, did you? You don't rhyme it like that, with the poetry. You continue the line on.' Jane 'doesn't think of her groups as being shared reading groups... I have tried and if somebody does read; other members of the group tend to get a bit twitchy and fidgety and want to say the word for the person when they fall over it. They get annoyed.' 
Many facilitators identified that shared reading hadn't worked in their individual groups. Cheryl said she didn't offer it to her group with intellectual disabilities and mental health issues because she was 'not confident that they can read. I think their level of literacy is fairly low.' Meredith said her group of 'mental health clients liked a stable environment. They don't really like surprises... So, consistency is really important when it comes to the reading of the text.' Jamie said when she tried 'it didn't work... in one group people wanted to, but it was more about practising their English... It wasn't related to what I had the group wanting to function for.'

Rachel, who spoke above of receiving a resounding no to sharing the reading, provides further useful elucidation as to why members of her group, and herself as a facilitator did not like this model:

I do remember one participant from the group going, come on, let's get on with it, yes I do remember that particular member saying that, yeah. Going into another group, I wouldn't offer it. If it was something that the group members wanted to do then I'd allow for that but it wouldn't be something I'd push for. Because I think that really mimics what happens in a classroom. That's not what I would want it to be. I would want it to stand alone and not be something that they could say, well that's exactly what we do in class. They did say they found being read to relaxing and hadn't experienced this since primary school.

Many of the Australian facilitators' comments reflect the facilitators' intent to effect therapeutic benefit. With this aim, it is essential that group members emotionally engage and connect with the reading material as reflected in Jane's comment that 'if somebody else [in the group] reads I think you'd lose the group and that emotional impact would be diluted.'

Terry considered that when listening to the reading material, group members 'can focus on what is being read and allow yourself to sort of sink into the description or the narrative of the story... that allows any thoughts or feelings or emotions to surface while you're being read to.'

Facilitators all spoke of endeavouring to use the model taught, however, they admitted that it had not worked in most groups. Jane felt that the 'emotional impact was diluted' by the shared reading model and 'didn't deliver the emotional impact that I think is what sets bibliotherapy apart, or in a world of its own. It's - I don't know how you say that.' 
[Researcher: It makes it therapeutic?;] Jane, laughs and answers, 'there we go. In a nutshell, yeah.'

The facilitators spoke emphatically about the shared model not being successful in their groups. This notion is discussed further in Chapter Eight: Conclusion.

\subsubsection{Silence}

Understanding the use of silence is an important skill for facilitation. Rather than breaking the flow of reading as discussed above in Sections 5.3.1: Pausing and 5.3.2: Shared reading, silence is a tool which, when used correctly, supports and enhances the reading aloud experience. Silence offers time for participants to be more comfortable and willing to accept the invitation to dwell more deeply with what is emerging from the words, as discussed in Section 5.2.1: Reading aloud to adults.

Poet, philosopher and Ted Talker, David Whyte (2014 \& 2017), talks about how stories and poems urge us to think about our particular journey in life with enough courage to face the challenges and the thresholds that confront us along the way. As listeners to stories and poems read aloud, group members get time - through silences - to soak up the images evoked by the words of writers and to think about them. When we meet emotions and images concealed in the potency of poetry or narrative, quietness helps us to take it in. Isaac $(2016$, p. 2) talks about the importance of facilitators of group sessions 'sitting' with both the words and the silences between the words. The concept of silence is an essential notion of developing group discussion. Kim has a good understanding of this concept as demonstrated in how she spoke about silence. She noted that she does not mind if no-one answers a question during a reading, indicating a willingness to just sit with both the words and the silence between the words. She also said:

The other thing that I always do which works is explain that there's nothing wrong with a bit of silence because it's a pretty noisy world and there's the compulsion to fill it all up with chatter. I just explain that it's okay to be quiet here... I had a lot of feedback... about the quietness of it... someone said adults don't get much quiet and once they got used to it, it really appealed to them.

Many of the facilitators did not understand the concept and importance of silence. Sarah, 'wanted to learn techniques by which you could get people to start talking if there were any silences so you could encourage people to talk, or is it okay they don't want to talk?' If 
facilitators feel discomfort in sitting in silence, they need to be careful not to develop approaches such as filling the gap with talk, and to practise being silent. Helen spoke about 'sometimes it's hard not to [fill gaps with talk] because there's gaps... I've learnt now just to be silent.'

Preston-Shoot (2007) suggests that silence indicates that a change has taken place and that facilitators need to learn to tune into what the silence may be communicating. Silence can reveal many things; for example, disinterest, resistance, boredom and indifference which may indicate that the facilitator has misjudged the group and selected inappropriate reading material that the group members cannot relate to or find accessible. However, silence can also mean group members are thinking deeply and need time to process their thoughts and feelings; as further outlined below.

Bibliotherapy reading groups have two distinct activities: listening and discussion. In the first activity of listening, the selected reading material is read aloud to group members. In the second activity, the discussion provides time where humans meet to engage in exploring their experiences and reflecting on their reality. Silence at the end of reading aloud can help to establish the important boundary marker between the different activities of listening and discussion and provide a space to offer an invitation to engage in conversation. A moment of silence can help facilitators be aware of the body language of the group members; this has been described as simultaneously reading both the text and the group members. When group members are given a clear cue that the listening to the story part of the session has finished, they often let facilitators know they are engaged and want to speak through nonverbal indications such as shifting in their seat or lifting their head.

It is important for facilitators to understand that silence 'allows':

- A sense of expectation and intimacy as a community of people, mostly unknown to each other and the facilitator, prepare themselves to receive something and to feel part of this temporary community.

- Time for thoughts to develop, rather than forcing them, and prepares the group for something new: a new perspective from which to consider something, or an absorbing insight when it arrives.

- A pause at a moment of depth, such as the sharing of a group member's profound experience or thought.

- Group members to be in the moment. The wisdom that has been revealed in all sorts of 
ways during the reading to reverberate.

Silence is discussed further in Chapter Seven: Therapy part B: Achieving therapeutic outcomes.

\subsection{Chapter Five concluding comments}

The data showed there were three significant skill areas involving books - or 'biblio' - that bibliotherapy facilitators believe are essential for delivering bibliotherapy sessions:

1. Knowledge of literary texts to provide a diverse, creative and productive range of reading materials to read aloud, to fit a session timeframe, and to facilitate discussion. Such knowledge would reduce the time intensive task of selecting literary texts for bibliotherapy sessions.

2. An ability to read aloud in an adult group context to make the literature alive in the room and create the atmosphere of attentiveness.

3. An ability to monitor how individual group members are processing the literature.

Reading material selection was the most discussed issue, highlighting both time and session outcome issues. The data indicates that the time needed for facilitators to source literary texts was inhibiting and contributed to bibliotherapy groups being unstainable for ongoing delivery for many of the facilitators. The time taken to select reading material could sometimes be reduced if facilitators know what they are looking for through proper session planning, or working with a partner. Also evidenced by the research participants was the need for selection based on a genuine outcome-focused framework. Facilitators were often not approaching sessions with an outcome in mind; instead just finding a text that would fill the dedicated session time reflecting their own text biases.

Facilitator bias is an interesting factor which significantly influences the choice of a text for a group. The fact that many of the facilitators expressed the need for the text to resonate with them, rather than the group, was central to how they select literary texts. In creative bibliotherapy it is critical that literary texts be selected to suit the people in the group (McLaine, 2019).

Participants revealed a lack of confidence in selecting literary texts for creative bibliotherapy sessions, especially poetry. Selecting literary texts to support a planned outcome is a critical aspect of 'biblio' in relation to 'therapy'. The 'biblio' stage acts as a catalyst for the 'therapy' stage, which will be discussed in Chapters Six and Seven as a distinct entity. Chapter Six: 
Therapy part A, deliberates on the practical aspects of delivery and partnership, considering the group practices and alliances needed in bibliotherapy groups to assist in realising the wellbeing, or 'therapy', component of bibliotherapy. Chapter Seven: Therapy part B, will more deeply examine the theory underpinning 'therapy'. 


\section{Chapter Six:}

\section{Therapy part A: Partnerships and delivery}

\section{Introduction}

Chapter Five discussed the 'biblio' component of bibliotherapy in detail. Chapter Six continues exploring and developing this research's central concept - the relationship between 'biblio' and 'therapy' in creative bibliotherapy - and considers the practical necessities for therapy to occur. Chapter Seven will discuss achieving therapeutic outcomes through creative bibliotherapy. While books are a constant component of all forms of bibliotherapy, 'therapy' could be described as a variable factor depending on the approach chosen for engaging with the literature, and the setting in which bibliotherapy is delivered.

The research participants were trained in a form of bibliotherapy known as creative bibliotherapy; that is, to engage with the literature, the 'biblio' component, as 'therapy' when facilitating bibliotherapy sessions. Initially, this chapter considers the idea of community and the library's role in enabling community wellbeing (6.1). The importance of forming a delivery alliance between a library service and local community service providers with therapeutic experience is discussed (6.2). Next, the chapter looks at the development of groups, considering aspects of groupwork processes and non-verbal communication (6.3). Then, the chapter will consider the importance of 'listening' as part of the 'therapy' aspect. (6.4). Finally, the chapter looks at how to facilitate group discussion (6.5).

\subsection{Enabling community wellbeing}

This thesis investigates the effectiveness of creative bibliotherapy training provided to nonclinical facilitators in Australia in order for them to deliver reading groups in community locations such as libraries or mental health services. Of the 17 research participants, 14 participants worked in libraries, and three research participants worked in mental health.

\subsubsection{Libraries as facilities for community wellbeing}

The Australian Government's vision of a socially inclusive society is one that is:

ensuring that everyone is able to participate fully in Australian society. It is about people having the necessary opportunities, capabilities and resources to enable them both to contribute to and share in the benefits of Australia's success as a nation 
(Australian Government 2010, p. 1)

For Australians to participate fully in society includes providing opportunities for connecting with other people. Engaging with local community resources is a way to support this connection and wellbeing. In this regard, public libraries and public library staff could be considered wellbeing resources: the public library provides both a safe, inclusive, community setting to hold community-based wellbeing programs, and staff to deliver the programs. Additionally, local libraries provide an effective communication channel which links people socially to groups, activities and service in their communities to improve their health and wellbeing (Norris, 2020). A community setting provides local opportunities to attend a program, build familiarity with new people and places, and supports individuals experiencing isolation to bond and develop rapport with others.

The role of modern public libraries in the western world has evolved over the years from providing the community with access to a repository of books for information and leisure reading, to providing a much broader range of services and activities, enabled by technology (American Library Association, 2017; Morris, 2016). Libraries are also now often community hubs that offer a range of community services, such as access to computers, free wifi, and a range of learning-based activities and community events and spaces. Some libraries provide a greater range of services, such as access to other professionals, including social workers and use of equipment, such as recording studios and 3D printers in maker spaces.

Additionally, 'library staff are tasked with dealing with the full gamut of humanity. Every issue that people can face (homelessness, mental health issues, addiction, domestic violence, etc.) gets manifested in the library', and people 'are increasingly turning to libraries as a source of shelter, compassion and assistance' (Rockne Corrigan, 2020). As community hubs and connectors, the role of libraries has changed, requiring library staff to increase their capacity and skills as they adapt to an evolving job (Hindustan Times, 2020; Lippincott et al., 2014). The whole person librarianship movement has encouraged social work collaborations and shared workload between social workers and library staff in community engagement since 2012 (Zettervall, n.d.). In the United Statesmore than 30 library services now have social workers to serve and support their vulnerable patrons together with library staff. Recently, City of Melbourne Libraries has hired a social worker to provide support services to the homeless seeking refuge in the library (Topsfield, 2019). 
Even though libraries are now often involved in providing services and programs for people experiencing mental health issues, the research interviews indicated that the facilitators had concerns about working with people with mental health issues. Debra said, 'I've run a few library services now. It's [i.e., providing mental health services and programs] not something we do strategically enough.' Although public library staff work with diverse communities in all kinds of ways, delivering 'therapy', or wellbeing, is not something generally considered part of the job. Jane said that she 'didn't fully appreciate it [i.e., working with groups experiencing mental health issues] was going to be a large part of the bibliotherapy when I started [the training]; [It] gave me the awareness that there would be such groups... but I didn't come away with the tools or strategies to deal with it... I'm not recalling any specific strategies that I was given in the training in order to deal with it.' Helen said, 'I feel that I haven't got that adequate training to be aware of when things were going wrong, what would I do and to the boundaries... I would have to go and do some other training.' Rachel felt that she had not been 'prepared enough to deal with some of the situations that I was presented with... because I have no background in that industry.'

Meredith said, 'if you're a nice little librarian from a nice comfortable town where the worst thing that's ever happened is a couple of screaming babies at story time, you should never imagine that that kind of training would prepare you to be in those environments [i.e., where there are mental health issues]... it [i.e., training] is doing people a disservice, that it [i.e., therapy] is not something that somebody who has had a minimal amount of training should expect or should consider themselves to be equipped to do. Definitely not.'

Terry, a counsellor who already worked within a therapeutic environment, observed that some of the other librarian research participants, 'became a bit concerned that the book reading might turn into a therapy session... If they don't have the skills then they might, I would think, consciously push it or drive it in a certain way so that stuff doesn't happen.' Rhonda didn't feel confident: 'I certainly would have felt that that would be a challenge, given the training that we had. I'm not sure how confident I would feel with people who are dealing with levels of mental illness within the community, people who are suffering from depression and anxiety... that sort of training, for that particular setting, would be invaluable.' Sophia, who delivered a reading group to a group of English as a second language students, felt that 'there was perhaps a gap between the training and actually 
running the program... I would have found that challenging... a lot more challenging... I would have needed more of an awareness of how that particular environment... operates.' Kim said she felt, 'fraudulent... about my capacity to handle that sort of atmosphere.' Debra said, 'I would have been fairly anxious' and was also concerned in that, 'if that [i.e., training] is the only training or exposure that somebody has to people with mental health problems, they would be absolutely stupid to walk into a group and try and start that delivery. Yeah, because that's not all of our areas of expertise.' Rhonda wanted 'units within the training, so that's very specific to that particular setting.' Leanne said, 'they [i.e., TRO] could've done a bit more about mental health.'

As discussed above in 6.1.1, the role of library staff can involve regularly assisting patrons experiencing mental health issues or homelessness as part of their job. Natalie thought it unrealistic that library staff facilitators didn't expect to be working in a 'therapeutic' context when many people in society, and patrons of public libraries, have issues such as mental illness. She said, 'if people [i.e., facilitators] say they don't have that experience of working with or engaging with people with mental illness I find that quite incredible to think of as well, when in one in five people experience some form of mental illness. So really people in your workplace, your neighbours, family members, there would be someone. You can't say that you only know four people in the world and so that's why you've missed out on that fifth person with mental illness.'

The facilitators' concerns suggest the possibility of developing alliances and partnerships so that facilitators can work with a partner from an appropriate mental health service (See 6.2: Therapeutic alliances), call on a backup service provider, or refer a group member to a service provider when deemed necessary.

\subsubsection{Motivations to provide community wellbeing programs}

As shown in Chapter 3.4: The research participants, most of the research participants were located in public libraries. Public libraries sit within the governance of local municipal councils and the Victorian Public Health and Wellbeing Act 2008 requires municipal public health and wellbeing planning (MPHWP) 'to identify strategies for creating a local community in which people can achieve maximum wellbeing' (City of Moonee Valley 2013, p. 3). Such planning for health and wellbeing needs to consider the key priorities for 
supporting people to enjoy a greater sense of wellbeing as addressed within all of the Victorian Public Health and Wellbeing Plans to this point in time (VPHWP 2011-2015, VPHWP 2015-2019, VPHWP 2019-2023). A major focus for action over the life of each of the three plans is based on local communities:

building on the strong tradition of community participation in Victoria, with a major focus on the role of local councils in municipal public health and wellbeing planning, as well as the Prevention Community Model developed under the Council of Australian Governments (COAG) National Partnership Agreement on Preventive Health (NPAPH).

(Victorian Government 2015, p. 3).

From the commencement of the Victorian Public Health and Wellbeing Plans, the Australian National Partnership Agreement on Preventive Health advocates that 'public wellbeing can be enhanced through collaboration between all levels of government and industry, business, communities and individuals... with a major focus on the role of local councils in municipal public health and wellbeing planning' (VPHWP 2011-2015, p. 13).

Sarah said that at her library service several of the staff in the management team wanted to have staff trained in bibliotherapy because it met their 'philosophies of inclusivity and also reaching hard to reach communities.' Sarah's library service 'targeted people with mental health issues... who are difficult to reach... so they could see from that that the library was a place for them.' Meredith said 'one of the things that we'd identified with the organisation... is we don't do enough programming that involves our marginalised clients.' Meredith shared her organisation's goal 'to make contact with or offer something to people who we didn't consider generally to be regular [library] users... people with mental health issues was one of those identified groups.' Meredith was keen to explore using literature as a tool to connect with individuals who were experiencing mental ill health. She said, 'we know that they come into the library space and use a variety of different services there on occasions... but as far as looking at it from a literature point of view, [that] wasn't something that we'd ever been able to manage to do.' Similarly, Debra questioned a library's ability to work with, and provide programs for, marginalised groups of the community. She commented, 'I think it's not necessarily something that, in my experience, libraries tend to do particularly well. That might be a little bit controversial, but where do we see ourselves fitting with this sort of stuff? Is it what a library really does? Now, I'd like to argue yes, it is, but where do you start? 
It really should come as an overall strategic direction or push from the organisation, but it rarely does.'

The motives of many libraries to participate in the training were underpinned by the aspiration to promote wellbeing in their municipality community. However, as Hallam (2014) discusses, to work in the wellbeing, or therapeutic, area requires library services to build strong partnerships and alliances with other agencies who already work within this context.

\subsection{Therapeutic alliances}

In this section, consideration is given to the issues faced by facilitators from non-clinical backgrounds delivering a program that provides therapeutic benefits to support the wellbeing of communities. As the literature review established, bibliotherapy is delivered by people from both clinical and non-clinical backgrounds, the former most often delivering the traditional form of bibliotherapy using cognitive behavioural therapy books and the latter most often using literary texts. Chapter Four: Bibliotherapy training, determined that the motives of some of the participating libraries for taking part in the bibliotherapy training and subsequent program delivery was underpinned by the hope to promote wellbeing in their local community. Chapter Four also revealed that the facilitators from non-clinical backgrounds found it challenging to engage community sectors and get agreement to run bibliotherapy groups in the community. To work in the wellbeing, or therapeutic, area requires library services to build alliances with other organisations who already work within the therapeutic setting (Hallam, 2014).

\subsubsection{Forming organisational alliances to run bibliotherapy groups}

As discussed in Chapter Four: Bibliotherapy training, for over half of the research participants the required program delivery following the training took place in aged-care facilities. Following the second iteration of training the facilitators aimed to work with different types of groups but most of them found it difficult to engage community sectors other than aged-care and returned to the aged-care option. Additionally, it was an easy sell to aged-care service providers who were keen to provide a facilitated activity for their residents to complement other activities such as arts and crafts. The aged-care service providers looked to the reading groups to provide cognitive stimulation. Aged-care facility 
managers generally believe the 'literature used, and the relevance of the topics selected for the lives of persons with dementia made these materials a natural for eliciting engagement and a great way to communicate with them' (McLaine 2012, p. 4).

Natalie, a mental health service professional, posed another possible reason why the facilitators returned to the aged-care option:

I got a sense that librarians didn't have networks and links to organisations that might be able to provide the sort of audience from a mental-health setting and it was maybe a bit all too hard. So many of the others [i.e., library professionals] were going into aged care because it was just convenience. The elderly people were there on the premises, they could just walk in, do their thing, head out the door, where I was gathering the troops from far and wide and having to do a big ring around and hope that on the day someone turned up.

Rachel, a library professional, validates Natalie's opinion: 'We didn't really have much of a network with mental illness in the community... in terms of organising it, it [i.e., aged-care facilities] was the easier option... But it didn't matter to be honest, they were just happy to have something to fill the gap.' Similarly, Helen commented that her library service 'didn't have much of a network with mental illness in the community.' Research participants' comments highlight that libraries do not have strong mental-health networks, and some comments below suggest that research participants may not know how to talk about the program to mental-health service providers. Jane said she needed words to 'sell the program', which Leanne described as 'this big treasure [that] no one wants.' Debra spoke of the need to be able to articulate the program to potential community partners clearly:

If you could talk about its benefits, where they [i.e., mental-health service providers] would understand what you were saying - where you could clearly, concisely explain the therapeutic benefits. Which you do, but it kind of comes out all mushy... Deep, resonating, awakening, you can't say all those things because they just think you're some freak. Not saying what it actually is, more fluffing around.

In Cheryl's interview as part of this research, she spoke emotionally about returning to her employing library after the training and running a session with the senior library staff:

One of the first things I did afterwards was take it [i.e., a bibliotherapy session] to our senior staff meeting. My boss was quite adamant that this was not the role of a librarian to be involved in stuff like this and that we were getting into stuff that we're just simply not qualified to handle. He was very dead against it. So we're opening a can of worms that we really have no expertise in. 
As a result of Cheryl's boss's reaction, Cheryl formed a collaboration with a local government community mental-health service provider and went on to deliver a successful program with 'the support of people who work in that area, [who] really get it, really understand what we're trying to do here. I think they are so valuable. I find that some of the texts really allow the space for some of the important but harder discussions and it's almost, if the partner's not willing to go there, they don't happen.'

\subsubsection{Delivery partnerships}

As part of applying to undertake the training, all research participants from public libraries had been asked to develop a partnership with an individual from a local government community service provider in their local community with the aim of, together, undertaking the training and subsequently facilitating bibliotherapy sessions together (Chapter 4.5: Expectations of partnership delivery). Sarah was the only research participant who formed an alliance and attended the training with her partner, Natalie, from a local government service provider. Natalie said of her public library partner Sarah (Chapter 4.5) 'it was more a case of she was going into the unknown. So just trying to put her at ease and word her up that things were going to go well come the time that we had to run a group.' Natalie felt that 'Sarah had to be brave initially to face a group that she knew nothing of that particular type of cohort [i.e., in mental health].' After the training Natalie, 'found the clientele... I heavily advertised it and did a lot of ringing around to try and get the right candidates for the program.' Sarah said she benefited from her partnership with Natalie:

I appreciated sharing the facilitation with someone who had the knowledge about the group I was working with. I was able to work well with the people with mental health problems because of Natalie and because of her expertise. Because I was supported, I never felt too worried about the situation getting out of control, yes, I felt more comfortable. I got more insight from her [Natalie] than from the training itself. It is beneficial to have two people with different strengths, skills or knowledge sharing the facilitation. In the partnership described above, one of the partners was skilled in literature and the other with working with people experiencing psychological and emotional challenges. Shared delivery also means sharing the workload of all the tasks required for the successful delivery of both the 'biblio' and 'therapy' aspects of bibliotherapy (see Chapter Five, Six and Seven). 
Similarly, although they did not co-facilitate groups, Jane and Helen worked for the same library service and Helen spoke about how 'having a co-partner working in the same library service has been wonderful. It's given me courage, knowledge, sharing, new input, new observations, sharing the comments which allows you to look for different things. I'm so fortunate. I would have to acknowledge that, without her, I don't know quite if I'd be still doing it, not that I don't like doing it. It's just you need something. It's a very lonely thing.'

\section{Concluding statement on therapeutic delivery alliances}

Chamberlain $(2018$, p. 118) asserts that partnership work is vital for library services to deliver programs such as bibliotherapy within community spaces. Similarly, Brewster et al. (2013, p. 577), assert that the notion of libraries and the health sector working in partnership 'was seen as the key' to establishing successful bibliotherapy programs. Comments from Meredith, who set up a formal partnership with a health service to deliver bibliotherapy in the library, provide useful insights into how to achieve success. Meredith feels that the "legalities and logistics of it [i.e., setting up an alliance] require really careful planning and that's how you build those sort of relationships and how you formalise them and support them.' Meredith believes it is important to 'start by reading through what are their [i.e., the partner's] aims, and what are they trying to do with their clients?' Meredith emphasises the need to:

make sure that what you're offering in the partnership sits well with what that other organisation wants to do... you have to speak their speak... this is what you're trying to do with clients, this is the way that we can help you do it rather than looking at it being a library program where we are trying to increase people's view of literature. You've got to find out where it [i.e., bibliotherapy] already matches with what they're trying to do. One of the things that they're trying to do is increase normalised behaviour, which means coming into public spaces. They're trying to get them out of their homes, into their cars or into buses or taxis and into a public space. That was the therapeutic aspect of it from the mental health team. The literature was a tool to use once they were there.

Meredith's comments about the 'therapy' component of bibliotherapy, as expressed below, further endorse the partnership aspect as being important to delivering a community-based alternate form of therapy:

So the whole thing about what was the therapeutic aspect of our bibliotherapy program, yes, it's certainly the social aspect within the group when they're there but actually getting them to the library or into a [community space] - it's something, which comes up 
quite frequently in the objectives of the mental health team's perspective.

Meredith's comments are insightful in offering recommendations for how non-clinical facilitators best deliver bibliotherapy in community environments through building strong collaborations and determining appropriate goals, particularly concerning the therapeutic goals and outcomes the partner organisation is wanting to achieve. For some partner organisations, the social element may be the outcome they want to achieve in a supportive environment for group members (Lipsey \& Cullen, 2007; Priestley \& Vanstone, 2010). For other organisations, a group that promotes an opportunity for building positive relationships may be what the partner organisation wants to achieve (Kramer, 1999; Steenberg et al., 2019).

Many community health providers have clients who utilise libraries because they feel that libraries offer a socially and emotionally safe place. Building library staff capacity in developing partnerships would help libraries find passionate and active partners in the health sector who can bring experience in working with community groups. Rachel, one of the research participants, asked for training to include information on developing partnerships, such as 'a kit on how to set up a contract between yourself and the organisation, and what things you want to put in place to help you as a facilitator.'

\subsection{Group delivery}

Groups are a collection of people that share some common purpose and social interaction (Brown, 1986; Coulshed \& Orme, 2006; Levine \& Moreland, 2006; Manor, 2000), and Toseland et al. (2004, p. 13) suggest that the dynamics created within groups are composed of 'elements of interaction'. In bibliotherapy groups the interaction develops from three specific elements. The first is the group members themselves, through both face-to-face interactions and what they bring to the group from the larger social environment. The second element is what the text brings to the group, through words written by an absent group member - the author. The third element is the facilitator, and how they influence and affect interaction. Hidden elements can also contribute to interaction, including non-verbal communication, physical factors, such as the size and set up of the room, the lighting, group norms, and the level of feeling safe. Interaction is also developed by facilitating connectedness and reflection (Abels \& Abels, 2002; Corey et al., 2009; Jacobs et al., 2012). 
Howie (1983, p. 287) describes bibliotherapy 'as a technique whereby the facilitator seeks to utilise interactive processes therapeutically... that can be used at a group level'. Section 6.3 looks at data collected from facilitators relevant to groupwork, including consideration of the critical influences of the practices of group work. Explored are processes and concepts such as planning and preparation for group sessions, use of self, leadership, power and authority, the establishment of safety, including the development of group norms, and dealing with challenging situations. However, factors affecting each process are not discrete, and many vital factors sit within multiple processes.

\subsubsection{Groupwork processes}

Groupwork processes address development of a comfortable and safe physical environment in which to hold the group, and the tasks involved in leading the group held within this environment (Benne \& Sheats, 1948; Burlingame et al., 2018; Gordon \& Kenny, 2018; Kukenberger \& D'Innocenzo, 2019; Lynch et al., 2018; Naveenan \& Kumar, 2018).

\subsubsection{The physical environment}

Feeling at ease in the physical environment is central to the success of groupwork when working with group members who can feel vulnerable due to their personal situation. Stevens et al. (2006) emphasise that meeting locally produces the most feelings of ease for a marginalised population. A library serves this purpose.

Kim's comments showed her group felt at ease in the library: 'a number of them in my group mentioned on their evaluations that having it in the library they liked because they said it felt like home which was nice... we've got some rooms - they're not completely separate from the rest of the library but you can be in there quite comfortably without other people wandering through. A number of them said it just felt like being home.' Natalie observed that 'there was certainly that sense of it being a private space and a space where people's ideas or thoughts or what they've come up with is respected and not mocked or ridiculed in any way shape or form.'

Rhonda spoke about group members' feelings of privacy, 'they felt that they didn't want to reveal things because they didn't feel that it was private... enclosed space was really important... It's challenging to find a space.' Leeanne described a group she held in a hospital, 'they have kind of a mental section there. It was that very clinical atmosphere - and 
then you have this kind of kitchen around the corner and you'd just have different people wandering in and making their cups of teas and they'd be staring at you reading this text. Yeah, it wasn't good.'

Meredith describes an environment that feels cold 'the only space that we had, this room at the back of the library, which is an old hall with an old stage. We'd cleaned it up as best we could but it was fairly grim. Anyway, the health team [i.e., mental health community partner] came down and said look, how do you feel, can we use this? I went oh well, I suppose it should be all right but it wasn't a nice room. It was cold and we tried hard with heaters to heat it up but - I suppose if you've ever been back stage in a theatre where the only heat's coming out of a small heater... it's awful.'

McLaine and Mackenzie (2018) assert that the physical environment needs to be set up to provide a sense of the session being a private place in which people's ideas or thoughts are valued, as is each participant's presence. Facilitators were also often faced with the challenge of competing with paying community members for meeting rooms within their library; many libraries would take a paying customer first due to budget necessity. Finding a good area to use at the same time each week was also a challenge for many of the facilitators.

Preparing the physical environment, wherever it is, also has a substantial impact on the group (Phillips, 2001). Leeanne who ran groups for people experiencing mental ill health stressed that 'you've got to have a good environment, like a relaxed environment where there's a feeling of safety and a cup of tea.' Natalie (a mental health professional) spoke about how she and Sarah (a library professional) set up the physical environment.

We were always there at least half an hour ahead of schedule to set things up and to make the room feel comfortable and prepare the tables and chairs... so when people walked into the room, the room was already set up... and done in a way where when people entered it was a seamless movement from the tea, coffee, biscuits, to sitting down and there were all the sheets of paper laid out.

Natalie commented on the importance of putting people at ease with a warm drink, which helped to create:

A genuine sense of warmth and welcoming as soon as people arrive to the group. Sarah and I always made sure that... coffee, tea, biscuits were always there and people would actually enjoy that part of it as much as everything else and they'd make their cups of tea 
and the biscuits were all shared around. So, again, it was food and drink as being part of the whole process. I think it might have been totally different if those comforting features weren't set up for the group members. People are rushing on trains and things and racing in with a minute to spare and when they walk in and you say just grab yourself a cup of tea and grab a biscuit and just relax and take your time and it gave everyone a sense of relief.

Research indicates that providing a warm drink supports socialisation and relaxation (Baumhover \& McNicoll, 2007; Waxman et al., 2007). Zhong and Leonardelli (2008) found that people who felt excluded in groups reported lower estimates of room temperature and a greater desire for warm drinks than did participants who felt included. The bibliotherapy facilitators with mental health backgrounds who were participants in this research seemed more aware of the importance of the physical environment in creating an environment conducive to groupwork. Natalie, with her background as a mental health service provider, recognised the importance of preparing the physical environment in particular. Providing the familiar and comforting features of morning tea is an expression of care which facilitators create for the group, and which develops a sense of feeling valued for participants. Doel (2006, pp. 129-130) asserts that 'a group is a place where people can feel they belong and achieve a sense of meaning. At the heart of this belonging is the feeling of being cared for and valued for who you are'.

\subsubsection{Distractions}

Some of the facilitators had an awareness of distractions that can interfere with groups. Distractions in the physical environment include noise and temperature (Schlenther, 1999; Toseland \& Rivas, 2005). Meredith commented on noise, 'I think the space is quite important. I tried running one of my groups in a completely different space, and it was interesting how little things like the level of noise next door - there was a café next door [affected the group]'. Meredith also commented on the temperature: when a room is 'on the chilly side they just want to go back to the other room.'

Some distractions could be more psychological based, such as medications or health issues affecting group members. Jane noted this in her comment about participants, 'if you want to fall asleep, I'm not going to judge you for falling asleep... some of them are in early stage Alzheimer's... so the behavioural -I wouldn't call them problems, their behaviour is different from the other group.' 
There are other distractions that also need to be considered. One can be difficulties with understanding the words used in the readings or conversation. Facilitators can unknowingly contribute to this by assuming that group members know the meaning of words read aloud and assume mutual understanding. This can happen if facilitators do not fully understand their audience, select literary texts that are not accessible to them, or fail to read non-verbal signs that the text may not be engaging group members.

\subsubsection{Group norms}

Norms are ways of behaving that are considered usual in a society or a group and which support group members' opportunities to build positive relations with others. Facilitators can provide positive behavioural guidelines to expected norms that influence how group members interact and behave in group activities.

Terry, an experienced counsellor, describes this as creating 'boundaries... it's very important... some simple rules and guidelines so everyone knows what the boundaries are.' Group norms provide guidelines for group members and are especially crucial to group members with mental health issues who may not understand appropriate ways to act in a social situation such as a group (Nowak et al., 2003).

Some group norms can be inherent in the physical space set-up, such as spacing seats so that group members are not invading each other's personal space. Mobile phone usage is an excellent example of where group norms can be set up at the start of each group, through a reminder to turn phones off or to silent.

Some group norms can be demonstrated, such as verbal communications: saying hello and goodbye to everyone, and please and thank you when appropriate. Other group norms can be modelled non-verbally, such as making eye contact with the person you speak with; or, at the commencement of the group, facilitators can open the door for group members, especially the elderly or incapacitated.

Group norms need to be clearly outlined as expectations at group commencement and enforced when needed. These include expectations of arriving on time, not using inappropriate language, not interrupting someone when speaking, and waiting to take your turn. Group norms can be particularly compromised by dominant group members, resulting in other members contributing little to the group or being talked over if they hesitate in 
their speech; this can be particularly challenging. Equally, dominating group members can divert the focus away from the session's theme or focus (Doel, 2006; Lindsay \& Orton, 2014).

Establishing positive group norms builds trust and supports the aims of bibliotherapy groups, including fostering group members to feel safe to verbalise their feelings in an atmosphere of trust. The feelings of being safe in a group will be discussed below.

\subsubsection{The establishment of safety in a group}

Creating a safe environment is crucial to the success of the reading group. 'Facilitators' social awareness and communicative skills are critical in creating individual confidence and group trust' (Billington et al. 2010, p. 6). McLaine and Mackenzie (2018) assert that the start and end of sessions provide an opportunity for personal interactions that help form the basis of safe relationships where trust is built. Natalie commented on how she starts to build trust through offering ' $a$ warm greeting for people that walk through the door and a smile on one's face and appreciating that someone's made the effort to come to your group and then the farewells at the end as well I think are just as important. Even just little messages like, I look forward to seeing you here again next week, it'll be great and people would say, yeah I'm really looking forward to it.'

Helen describes her process to build trust as:

playing it safe because what I'm really doing in those first six weeks is setting the scene, getting the safety, getting the trust. The trust is something that they come away having enjoyed or got something out of. I'm not there to push it at this stage. I'm there to bond, to build up trust. If it means taking gentler stories, stories that we know have got a common thread, that are a bit lighter, that give them a feeling of, I want to come back again.

Facilitators Kim and Jane provide examples of how they set the scene and establish a feeling of safety. Kim stated that 'the first thing you'd do is clarify with them that it doesn't matter if you don't understand it straight away, we're going to work it out together... there's still a sort of a hangover with adults that I have to understand this, I have to be seen to know what this is all about. Once you chip that away you can start to get somewhere. Just remind them that they don't have to understand it.' Kim also noted that in regard to questions, 'I always make it clear that I don't mind if no one answers... I just ask.' Kim found this helped ease 
group members' discomfort around the uncertainty of how much they are expected to disclose. Jane establishes her group similarly, stating, 'if there's a new person in my group when I'm describing what's going on I will always say, there's no right or wrong. You don't have to contribute if you don't want to. However you feel comfortable in this group is fine.' Jane continued, 'I think that must be a skill that I've learnt or brought to the group, because I don't see that that was something that we were trained to do.'

\subsubsection{Leading a group}

Maier (1967, pp. 239-249) states that a facilitator of any group is 'a leader who plays a role quite different from that of the members... A facilitated approach places the leader in a particular role in which he must cease to contribute... Instead he must concentrate on the group process... assume responsibility for communication between members... be sensitive to unexpressed feelings... protect minority points of view... keep the discussion moving, and develop skills in summarizing'. The behaviours and skills of the facilitator are critical for developing and maintaining group cohesion (Barney et al., 2006; Carron \& Spink, 1993; Estabrooks, et al., 2012). Facilitators' leadership styles will have an impact on group cohesion: 'Too passive an approach may undermine cohesion. Too authoritarian an approach may result in over-reliance... It may push the group too far or fail to begin where the members are... both approaches reduce the learning opportunities available to members' (Preston-Shoot 2007, p. 136-138).

Jane said, 'each time I've started a group they've understood that this is something different... they've looked to me for direction from the start.' Helen commented that she also felt that 'they expect you to lead.' Leading groups was new for many of the research participant facilitators, involving unfamiliar challenges that produced different leadership points of view from them. Jamie said, "I absolutely think the facilitator is responsible for what goes on in that room... it's something I'm nervous about.' However, Rachel felt 'I couldn't do that [i.e., lead].' Sarah had wanted to learn to 'lead the group at the same time [i.e., as reading aloud etc.].'

Meredith describes the facilitator's role in leading a reading group as 'you're bringing along the ingredients and you let them [i.e., group members] select how they want to put things together.' Meredith was one of two facilitators who successfully set up a formal partnership 
with a mental health service provider and who collected data from their clients who attended the group. Meredith received feedback from her service partner that 'one of the things that's come out of our clients' appraisals, with this particular program is that they like the feeling that when they're in the room... the clients have said that they really like is they don't feel like anyone's in charge.' This feedback validates that the group members responded well to a participative, rather than directive leadership style. Sophia commented 'it's a different sort of leadership role again because you're not directing your group. You're allowing the group to [direct themselves].' Another two significant factors in leading a reading group are self-awareness and the ability to challenge themselves to lead effectively (Melecio, 2014). Jane provides a good example of a facilitator demonstrating selfawareness: 'I play down the fact that I'm a librarian when I'm in this bibliotherapy group. I'm the facilitator of their group. I could say that the skill of being a librarian and having access to literature could be skills brought to the group, but I don't see it like that at all. Because I sometimes think that the less formality or - what's the word I want - I don't want to only bring texts and skills that are seen as professional, right, worthy, because I think that takes all of us into the realm of more head than heart.'

Some of the ingredients considered necessary for leading groups as revealed in the data collected from the research participants included: understanding group dynamics, establishing a feeling of safety in a group by exercising control on behalf of the group; and dealing with challenging situations in groups, such as people dominating or being disruptive; and making judgments of the suitability of reading material (Chapter 5.1: Reading materials) to engage the group. Helen and Meredith provide opinions that demonstrate the importance of leadership concepts. Helen says that 'the group dynamics is really important, not just knowing a bit of background to the individual but also the group dynamics. There's a pecking order usually.' Meredith says about dealing with group dominators that 'the one thing that you do need to be fairly firm on is not letting one person dictate conversations and to make sure that if somebody wants to have a say they get the opportunity to do that.' Meredith also talked about the importance of observing behaviour in order to engage the group and shape constructive group norms. 'If there is restlessness and irritability through a story; if it's one person, you're sort of going okay, well we'll just keep going. If it's two you tend to say all right, obviously this isn't going down so well and getting to a point where you 
need to intervene. You can't allow behaviour by one person in the group to disrupt the session for the others as well.'

Cheryl found that in engaging group members experiencing psychological and emotional challenges, 'the tricky parts is these are people who actually find it really hard to sit down and listen to a story for an hour. Part of that [i.e., managing such behaviour] is finding the material that'll hook them, but it's also finding ways to relate that story to them and once you can get them to link into it in some way then you're kind of onto something.'

Wilma was clear about her role in leading the group and found it an enjoyable experience, 'my own personal way of operating and my belief system is you're not setting up a power structure. In traditional therapies in a way the patient/therapist has the power structure... it's a different kind of dichotomy... I actually enjoyed it and I think if you were to continue doing it I think you have to enjoy it. I think you do.' Natalie, who had a background as a mental health service provider, felt in bibliotherapy 'it's more organisational power is what the facilitator has,' recognising there are different types of power.

Kim shows self-awareness of when not to use power: 'There was one night that I thought thing were getting to get a little bit out of hand. One of the participants looked at me as if well, you need to do something about this. I thought no bugger it, I don't need to do something about this. It will sort itself out. You can't manage everything. I guess it very much depends on your group and perhaps the setting... You cannot manage every little aspect of it or control every interaction in the group.'

Jane also shows great self-awareness of power: 'I didn't want to lead the discussion. I want to lead the group.' Leading groups and leading the discussion are interlinked, and this is discussed in Section 6.5: Group discussion.

Some facilitators did not seem confident with managing groups. Jamie said 'would love to be part of a group as a participant... I would prefer it as a participant because that power position of the facilitator doesn't feel right. I do wonder if I run more groups whether I would perhaps be not strong enough.' Rachel said in Chapter 4.4: Meeting expectations, that she 'didn't feel prepared enough [and] expected more of how to deal with different situations in a group setting.' Rachel speaks of a time she did not feel the confident with managing groups, 'where I felt threatened [by a group member]... I felt myself losing it during the 
session... it was almost like a black cloud had just come over the top. I didn't know how to deal with the situation. The people sitting in the group didn't know how to deal with the situation and at that point I just read the text. I read the text and I didn't stop until the session was finished, because that was almost my escape from that confronting situation.' Sarah believed it was 'more around the group situation that I was looking for training in... leading the group at the same time.' Rhonda felt that 'the most challenging part of it, was monitoring what's going on with everyone within the group. I would have appreciated... a little more training about that whole managing group dynamics and facilitation.' Jane went on to say that after the training she 'didn't feel I was any more proficient at running or at facilitating bibliotherapy sessions as I had been running book clubs with middle-aged ladies in the library... I didn't feel there was anything else more [i.e., from the training] - I wasn't given anything more specialised to deal with. I didn't feel that I was given any more skills than I already had.'

\subsubsection{Non-verbal communication}

Communication occurs both verbally and non-verbally. When asking the facilitators about non-verbal communication, most responses disclosed that facilitators felt that they did not develop an understanding of non-verbal communication from the training.

Rhonda claimed that non-verbal communication 'is actually useful' in running bibliotherapy groups. She explained that 'sometimes it's very obvious if someone's not engaged with the story. I did have one gentleman who had a hearing issue. His body language was quite clear that he didn't feel that it was for him. But yes, more on body language and those non-verbal signals would be useful within that whole context of managing your group.' Terry felt that when 'you're dealing with people with mental health issues, those body signs can be different again because it may be affected by medications or other things going on as well.' Many of the facilitators talked about non-verbal communication in the training. Four felt there was enough but their responses show that this was due to their feeling of personal competency in this area: Meredith said she understood non-verbal communication, 'because I've also studied psych'; Leeanne said 'I feel I read that pretty well'; Tanya asserted that it's 'something that I'm always fairly confident in'; and for Melanie it 'was sort of a second nature type of thing.' 
Nine of the facilitators, however, felt there was not enough about non-verbal communication in the training. Jane said, 'no, it obviously didn't make much of an impression on me, I'm afraid'; similarly Helen said 'no, it wasn't enough.' Rachel said, 'It's not something that resonates with me from the training'; Sarah 'didn't remember that being covered,' and Rhonda also said '[I] can't remember covering it.' Jamie said, 'we touched on that, but not in-depth at all.'

As well as reading non-verbal body language, facilitators also need to read the group as a whole. This could be described as 'reading the air', that is sensing the atmosphere; or 'reading the room', that is understanding the thoughts, mood and emotions of the group. Reader response theorist Rosenblatt $(1969,1978,1985)$ maintains that reading must be understood as a transaction between the reader and the text, in that it is a unique comingtogether of an individual personality and a specific text at a certain time and place under particular circumstances. In this regard, a facilitator needs to provide the literary text and the circumstances and 'read' the group member's emotional engagement as closely as the text itself. To do this facilitators need to encourage the sharing of personal experiences and interpretations or reflections, and fostering a feeling of enjoying being involved in a pleasurable activity together.

\section{Concluding comments on group development}

The data shows that not all the research participants felt confident about facilitating groups. A lack of capacity to work with groups diminishes the ability of the facilitator to help group members achieve increased wellbeing outcomes (Toseland et al., 2004).

\subsection{Shared reading and listening}

The Australian training program included developing facilitators' skills in the reading methods of Get Into Reading (GIR), otherwise known as 'shared reading', where the facilitator and group members each do some of the reading aloud. Chapter Five: 'Biblio', revealed that when facilitators used the 'shared reading' methods they had been trained in, their group members requested the facilitator read the story without changing readers. Facilitators stated that 'they [i.e., group members] said, can we just keep going?... I still ask... they still say, could we just go to the end? Don't stop. Let's go to the end.' Significantly, when using the 'shared reading' model, facilitators stated they felt that it 'breaks the emotion and 
feelings that are coming up... stops that internalisation... breaks the atmosphere, and emotional impact is diluted.' Jane said, 'I don't think of my groups as being shared reading aloud groups.' She spoke about group members reading small amounts of 'four lines, so even if they do stammer and start, people are forgiving of that. But any more than that [and I couldn't] deliver the emotional impact that I think is what sets bibliotherapy apart, or in a world of its own.'

After commencing group delivery, facilitators tried to be 'true to the teachings' of the shared reading model, but mostly, intuitively and independently, they adapted their delivery method to the facilitator reading the story in its entirety. The Australian facilitators observed and described the experiences of group members which revealed that it is 'shared listening' rather than 'shared reading' that achieved therapeutic outcomes. This is an important concept for this study (discussed further with respect to therapy in Chapter Seven), requiring that the facilitator has particular skills to manage groups with this focus. This research study did not collect data from participants who took part in reading groups, however, our capacity for listening receptiveness is connected to the way we connect to ourselves and others (Senge et al., 2004). Listening can be taught as a skill but it is also fundamentally a choice to give full attention to someone or something; facilitators can influence the level of therapeutic benefit experienced through the capacity of group members to listen. Setting up a group where listening is the focus, rather than group members reading, requires different skills and attributes in the facilitator, and a shift in intention, actions, and measurements of success in that role. Characteristics that are key to listening will be discussed next.

\subsubsection{Shared listening}

In developing the notion of 'shared listening' as significant in creative bibliotherapy, and ways of reading aloud, or prosody, will be considered. For the purposes of this research, prosody is used to describe a variety of read aloud styles, including intonation, rhythm, loudness, pitch, voice quality, silence and stress on words. Although there are several different types of prosody, emotional prosody is responsible for creating emotional tone and more subtle grades of meaning in the literary material being read aloud. This requires facilitators to decide how much stress to put on individual words to develop meaning and 
emotional significance (Ellis et al., 2019; McLaine \& Mackenzie, 2018).

Kim found that people in both the groups she had worked with 'said it's [i.e., listening to someone reading] calming and relaxing... that was mentioned more than once.' Tanya commented that 'they [i.e., group members] really liked listening to me read to them... I think they really enjoyed that aspect, they just closed their eyes, sat back and listened... you could see them sitting back and enjoying it and listening to it. They took it all in, they didn't miss a thing.' Jane said' I've been told that they like listening to my voice. I said, well, what do you mean? They said, the tone, the modulation. So the voice is part of the package.'

Wilma observed that "people respond to the rhythm... it takes people to a sort of more lyrical place.' Meredith felt that 'it's obvious that people are just enjoying the flow of language rather than wanting to comment on it... people don't like you to stop because it has its own rhythm and tempo that goes through it... a kind of melody, lyrical side of the text and the way that it flows.' Herman (2006) and Wennerstrom (2001) describe this as the music of speech, aligning the rise and fall of spoken pitch to the pitch in singing or playing an instrument. Oliver (1994, p. 42) claims that 'rhythm is one of the most powerful of pleasures, and when we feel a pleasurable rhythm we hope it will continue. When it does... we are in a kind of body-heaven'. This could be why the group members preferred facilitators to 'not stop' and to read 'until the end' without interrupting the rhythm.

In the role of reading aloud, prosody also plays a part in letting group members know when the facilitator is ceasing to reading aloud from a text and moving to starting discussion about the literary text (Hughes \& Szczepek Reed, 2006).

\subsubsection{Creating a listening atmosphere}

To enable attentive listening, setting up the environment to listen, both physically and psychologically, is crucial. The environment is more than physical space; there needs to be an intention to listen created. An essential part of the work of a facilitator is to create a space in which listening can occur and to get people in the 'mood to listen' through creating an atmosphere of attention, which Kuiken $(2019$, p. 346) describes as 'the kind of attention that facilitates responsive 'listening'. While reading is a taught skill, listening is not taught in the same way as reading so facilitators need to support group members by creating an atmosphere fostering listening. 
As well as a focus on developing the listening abilities of group participants, facilitators also need to develop their own listening skills. Facilitators may prepare to speak by practicing reading aloud, (Chapter 5.2.3: Preparing to read aloud), but they do not necessarily prepare themselves to listen. Isaacs (2016) describes listening ability as developing an inner silence, which is not a familiar feeling for most facilitators. To develop this requires some deliberate work by facilitators.

\subsubsection{Silence and listening}

Chapter 5.3.3: Silence, revealed that facilitators wanted to develop skills in filling the spaces of silence in a group situation. However, Isaacs $(1999$, p. 86$)$ asserts that 'to listen well, we must attend both to the words and the silence between the words'. He suggests that 'perhaps the simplest and most potent practice for listening is simply to be still' (Issacs 1999, p. 101). We can learn to listen through developing an inner silence and learning to just be present. Brady (2018) says of facilitating therapy in groups, that resisting the urge to speak, together with giving the group your full attention, provides the possibility for others to enter a reflective state. Creating ways for groups to sit in silence amid feelings of companionship is important to the group's social aspect and supports reflection (Billington, 2019; Fearnley \& Farrington 2019; Kuiken, 2019; Pettersson, 2018). Jane explained how one time she could feel the silence wasn't companionable:

If there are gaps [i.e., silence], I'll sit with the gap... I got to the end of it and there was silence, but it wasn't a nice silence. It wasn't - it didn't feel a silence brimming, about to happen. It was just a dead silence.

\subsubsection{Types of listening}

Chapter 2.4.2.1: Bibliotherapy in the education system, describes Rosenblatt's two different purposes and experiences of reading a text-the 'efferent' and the 'aesthetic'. The 'efferent' reading stance is fact-oriented, where the reader focuses on the information in the text. In an 'aesthetic' reading stance, the reader immerses themselves in the written word, sometimes referred to as 'getting lost in a book,' or more scientifically referred to as 'transportation' (DiGiulio, 2018).

Rosenblatt $(1978,1981)$ describes the 'aesthetic' experience of listening to a text read aloud as a warm, organic process where the primary motive is engagement. Rosenblatt states that 
when the listeners become more aware of the reading process, they can change to a more critical listening style concerned with comprehension (or efferent style as discussed in Chapter 2.4.2.1: bibliotherapy in the education system). Like skills for managing groups, facilitators need skills in developing the circumstances in which group members listen to provide an aesthetic experience to support emotional engagement with the literary texts. When emotionally engaged with listening to a literary text the 'aesthetic' experience of we use our emotions to enjoy the pleasure that comes from the beauty of language and sounds, referred to above as prosody. 'Aesthetic' listening can be regarded as a social process and is of significance to literary texts read aloud and can explain why so many Australian group members requested facilitators to 'don't stop' and 'go to the end'. Deeper listening can help group members slow down, feel quieter within, and feel more present and connected to something larger than themselves (Scharmer, 2009), supporting therapeutic benefits and wellbeing. Aesthetic listening is feelings-based, focusing on emotions and imagination, which are associated with therapeutic benefits. The notion of the 'aesthetic' experience of listening is further discussed in Chapter 7.8.3: emotions and meaning-making.

\subsection{Group discussion}

There is often a compulsion for people to share experiences, and when something is shared others may want to join the conversation and be part of the journey. Empathy and curiosity deepen understanding of the experiences that are being uncovered. Jane spoke about how she facilitates this:

from time to time I throw in a question, but I phrase it in a very vague way, or I use a very vague tone of voice, so that the impression I'm trying to give is that, I don't know either. I'm in here with you. What do you think? What's happening here? How do you feel? That kind of vagueness, because I don't want to give the answer. I don't want to lead them into the answer.

Jane's 'vague' approach aligns with Steenberg et al. (2019, p. 275) who suggest that with regard to 'the ambiguity of texts: the emphasis was upon affording open-ended reflective processes rather than providing definitions or solutions and strategies for how to deal with defined problems.'

Effective discussion enables the group members to engage with the literary texts as a 
therapeutic tool, through which they connect to both the text, and each other. The 'therapy' occurs 'through group discussion about the characters, common concerns and worries provoked by the reading ('biblio'), and by talking about ideas that may not be in the book at all, but which the story has dredged up from the [individual's] mental state' (Schlenther 1999, p. 31).

The separate activities of listening to both the literary texts read aloud and the group discussion, require group participants to employ different ways of listening. Up until the discussion the group has been listening passively to the text read aloud; in the group discussion stage the group members need to move into a state of active listening to participate. Moving group members from passive listening to active listening requires leadership from facilitators. Listening, 'properly understood and developed' (Isaac 2016, p. 2), offers an immediate gateway that can connect group members to the text, and to each other through discussing the text. This in turn can support group members' participation and, through this, their wellbeing. Aligned with skills for managing groups, facilitators need

skills in developing group discussion. Doel (2006) and Ward and Mullender (1991) talk about the central skills of developing group discussion as enabling, building, integrating and expanding. These key skills are discussed below.

\subsubsection{Enabling group discussion}

Doel and Kelly (2014) describes group facilitation as a process to enable the group to contribute to discussions. Justice and Jamieson (1999), Sibbet (2002) and Straus (2002) assert that the key role of facilitation in groups is to support group members to participate. Enabling the discussion in a reading group is a significant aspect of working with groups, whereby the facilitator provides the group members with the opportunity to take part in social interactions and then leaves it up to the individuals if they want to respond to the offer.

Wilma's comment demonstrates her understanding of this:

If you're making sure that everybody gets space [to be heard] and you try to create that space for people whether they take it up or not, that I think people really respond to being heard... and in fact I think that's really essential coming back to the actual part of the facilitation - that's your responsibility as the facilitator, to create that space, and I think that space can be very therapeutic... because you're the one guiding... you need to hold it 
together. You actually hold it [together]... I mean you're the one creating the space for people. You are directing the show... it requires enough confidence to do it.

Helen described one of the techniques for facilitating discussion as 'respect[ing] each individual rather than just, for example, allowing one person to dominate, how to respectfully be able to move it to somebody else, so that everybody felt a part of it but they also felt safe enough that they didn't have to say anything and really secure in that.'

Helen's comment highlights a key aspect of bibliotherapy groups where no group member is specifically asked to comment in the group discussion; it is up to each individual if they want to comment or not.

Doel and Kelly (2014) describes good facilitation as a process to support the group to build its own discussion, including being neutral about how the discussion develops, and having no stake in discussion outcomes. Jane said she has learnt to:

direct and shape more subtly, by letting it range, by allowing it to go sometimes in completely different directions from what I thought it was going to do. Allowing that to happen. In the back of my head I have where I thought the discussion would go, but if it's going somewhere else and it's all still coming from the text, then I'm happy.

Sophia felt 'it's a different sort of leadership' and she 'draws on previous experience, if you can relate to what they're saying, then you can add something that will be relevant or somehow related to what they're saying, not by telling your own story but just something that can make them feel comfortable to say more.' However, care must be taken with this approach as Helen noted you can, 'realise you've just talked too much.' Helen said she felt an expectation 'that means more talking. I find that it's a trap almost, that they allow you to get into. You have to be strong to say, this isn't about that. So there's discipline of yourself in it too and knowing why you're there... it's not about listening to me.'

\subsubsection{Integrating group discussion}

Early definitions of group 'integration' by Park and Burgess (1929) describe it as a process of fusion in which group members acquire the feelings and viewpoint of other group members and, by sharing and incorporating their experience and history, develop a common culture. This enduring explanation of integration in group discussion highlights the importance of the role of the facilitator to develop positive discussion. The facilitator needs to encourage group members to be open and willing to listen to the affective experiences of other group 
members (Porges, 2009). Kim provides a refreshing comment demonstrating her process of supporting individual identities.

I don't mind a little bit of argy bargy. We don't have to agree. It's not all about someone being right... it doesn't matter... It's conversation. It's going to be tense at times. People will be really passionate on some topics and I don't mind. It's not a true process if we're all just going to be to be nice all the time... it's a waste of time. To be honest I find it refreshing. I think you probably do [have to] be confident that you can carry it off. But it's just that the whole concept is refreshing because the modern world is just all about what sounds good, how we phrase things, marketing speak and all that sort of thing. This is not any of those things, that's why I like it.

Integrating group discussion, involves not only facilitating listening to each other but also assimilating the sentiments and attitudes of characters in the literary texts with those of the group members. Cheryl's process was:

to not just read the literature but to open it up and to say, well what do you think about that and how does that relate to you? What was it like for you when you were a child? What were your parents like? So you find out things, you gradually get to know about people. They get to know about each other. They're things - they're conversations - I'm saying this partly from what [the mental health community service provider partner] people have said to me, but they're conversations that people would not normally have in a place like that.

However, Cheryl explains that skill is needed when integrating the sentiments and attitudes of characters with the group members' experiences:

There's a fine line between encouraging someone to participate and overstepping the mark. There was one day where I felt like I'd gone over that line with [a group member] and I really regretted it. He actually didn't come for a week or two and I thought I'd blown it with him. But he has since come back to the group. I definitely think I muffed it that day... I was just so disappointed that day. I knew it as soon as I-you could just tell, he just withdrew and shut down and that was it. He didn't want to be pushed any further... I had pushed him too far, which was a shame.

\subsubsection{Expanding group discussion}

McNay et al. (2019) suggest that reading groups offer opportunity for reflection. To expand group discussion facilitators need to use strategies for interweaving discussion with reflective techniques (Porges, 2009).

Facilitators were asked in this research about how they develop discussions using 
reminiscing and reflection. Facilitators spoke about finding it hard to develop reflective discussion. However three facilitators, Jane, Natalie and Wilma, clearly understood the role in developing reflective discussion. Wilma commented that 'the reflection came... in the questioning... that could actually open that up, that kind of stimulates reflection.

Jane explains how she develops reflective discussion:

I tend to try to move away from reminiscing into reflection. It's very easy for them to go down the path of, I remember. Then it becomes just a memory thing. I remember. Yes, I also remember, and da-da-da. If they're just going to reminisce, it becomes very onesided. It's not necessarily anything that other people can relate to, or if they do relate to it, it's along the lines of, yes, I also did, or my life wasn't like that. So it becomes either the same or a bit of a-almost a competition. That just gets too far away from what I'm there for, or what the text represents, or what I'm trying to get out of the group.

I bring it back to reflection with more of the questions like, well, how did you feel about that? Or, what was your place in that? Or, does your sister have the same memories you do? So by bringing it more into how do you feel, or those sorts of emotional responses, I think there's a very big difference between reminiscing and reflection. If they are reminiscing I won't let them stay there. I'll allow - allow sounds awful - but I will allow it, because the reminiscing I see as a jump start to how they felt about the experience. In describing something that they're remembering it's giving them confidence in the group and then they open up and others open up. It's in the opening up that the reflection comes through.

Jane understood that reminiscing means that group members are not interacting and some members may be left uninvolved, or under-involved, which may prevent individuals and groups from achieving the aim of reflection.

Natalie felt that quality reflection, where group members interacted, came about:

when people were brave enough in the group to reflect back on a time from their past and kind of reveal that in retrospect now they might not have done things as $X, Y$ and $Z$ the way that it did happen at the time and they might have had more a situation where they would have taken the path of a particular character in the story... they're exposing themselves in a sense... there's no force there for anyone to have to reveal more than they have to but I think they just often feel compelled that they would like to share and we're all along there for the journey. Because it's all reflected back in the text or the line of the poem it kind of gives everyone that sense of like a security blanket so they're not just telling you some personal details or anecdote that's just random but it always did reflect back on the text.

Asking questions to encourage interaction between group members is another strategy to 
expand group discussion. McNichol $(2018$, p. 33) posits that of a number of potential advantages of bibliotherapy conducted in a group, 'the most significant is that important experiences or insights may be possible through interaction not just with the facilitator, but with the group members too'. Facilitators can assist this reflective process through asking open-ended questions that lead group members to think more deeply about the text and then find relevant examples within the literary texts to clarify a particular aspect of the text for them. Asking questions plays a vital role in developing group discussion.

Different strategies for asking questions of a group emerged from the facilitators. Leeanne 'thinks the text gives you that safety, where that person can reflect on something traumatic but within the safety of the text. But I think it wouldn't be forthcoming unless you asked.' Natalie 'thinks the open-ended questions certainly get people motivated to really delve deep into their brains trust.' She felt that the questions 'had to be very simple... Nothing too complex. The complexity came from when people were really thinking about the very simple question and then they would find great examples within the texts that would then clarify a particular aspect of the text for them.' Sophia has noticed 'the very open-ended or active listening and probing further, picking up on, I guess, the key part of what they're saying, asking questions that will make them think a little bit deeper... perhaps also having people prepared to go there and knowing that someone's prepared to share a little bit more... it is just knowing when someone's said enough and when someone's prepared to say more.' Guiding participants in a discussion by capturing the broad concepts of participants' contributions, and using carefully constructed comments and questions to pursue key perceptions of the text, are essential skills that provide a 'forum for discussing personal concerns without having to recount personal experiences' (Jarjoura \& Krumholz 1998, p. 130). Most of the facilitators prepared questions to ask the group when preparing the text. Sophia 'thinks that preparing questions helped a lot... I think with the group I had, if I hadn't have done that I think I might have lost them.' Cheryl agrees: 'one of the important things to facilitate conversation is the questioning. I do find thinking about the questions before I go in makes a difference. It doesn't necessarily mean that I'll ask them all, or I might think of something completely different on the spot. But I find that having thought it through myself first and thought about where we might go with some of this stuff does help.' Tanya said she 'jots down some open-ended questions in the margins so that I could jolt my memory.' 
Rachel 'would have a group of open-ended questions that I would write down on a little post it note next to my story.' Kim 'usually have a couple written questions prepared', and Rhonda said she 'prepared questions before the session.' However, Sarah said 'I sort of know what question would be right for that moment'; similarly, Leeanne 'asked questions intuitively.'

Some facilitators didn't ask questions at all, rather they just let the discussion develop between the group members. Meredith 'strongly tries to avoid asking questions as a way to get people to participate in something.' She 'just let things develop [because] trying to drive discussions is an artificial situation [and] if you're dropping a leading question, there is either this expectation that people will respond or that it's almost rude for someone not to say something and I don't like that.' Similarly Jane said, 'I don't start the discussion because I don't want to lead them into the answer... I read the text and I stop and I wait and wait for somebody to say something, anything that will open the discussion. If there are gaps, I'll sit with the gap... from time to time throw in an open-ended questions, but they're in my head. I don't write them down, they're just wandering around in there.' Similarly, Tanya revealed that 'if it was developing all by itself, I didn't bother to intervene. I tended to use the openended question when things fell silent for too long, like when it got to be uncomfortable.' Likewise Helen said. 'if somebody doesn't come forth with anything, that's when I'll ask the question.'

\subsubsection{Personal disclosure by facilitators}

Despite concerns about talking too much (as indicated in 6.5.1: Enabling group discussion), Kim felt that you 'need to be prepared to cough up as well... to provide a little something myself if I'm going to be asking them fairly direct questions.' Related to this, Natalie spoke of her feelings that 'you need to give something of yourself... for us just to sit back and just hear other people's stories without giving anything of ourselves I don't think is very fair.' Similarly, Rachel reflected that 'sometimes it took myself to open up before that kind of allowed participants to open up... I think if you are asking participants to give little jewels about their past or tell stories about themselves... if you're asking someone to do that I think you need to.'

Terry specifically used personal sharing to develop discussion, saying after reading 'this is 
what it feels like for me or this is what I think about the character, or this reminds me when I did a similar thing' as a way to 'encourage others to speak up.' Tanya also disclosed that, with regard to personal sharing, 'as a last desperate resort I would tell people how I felt and that would give them license to perhaps say something.' Some facilitators used personal disclosure as a strategy to develop discussion. However, facilitators need to be aware of not relying on using self-disclosure as a way to start group discussions.

\section{Concluding comments on group discussion}

Research has shown that in creative bibliotherapy, following the reading aloud of the literary texts with discussion can increase self-awareness, empathy and willingness to discuss feelings, thoughts, and behaviours that in turn improve coping abilities (McCoy \& McKay, 2006; Pehrrson \& McMillen, 2010). Facilitators need skills to lead and develop making meaning, or the art of interpreting the words read aloud, through discussion.

\subsection{Chapter Six concluding comments}

Chapter Six has discussed the importance of skills for managing groups and skills in developing group discussion. Also discussed was that when facilitators from non-clinical backgrounds want to effectively deliver creative bibliotherapy to support the general wellbeing of individuals and groups in society, it appears beneficial for them to work with a partner who can help them achieve this outcome. This appears to be especially relevant when delivering bibliotherapy to group participants experiencing mental health challenges, with research participants revealing that they had particular concerns about working with people with mental health issues. Working with community mental health service provider partners is important for library services to deliver bibliotherapy within community spaces to diverse participants. Staff in public libraries need the skills necessary to build strong partnerships and alliances with other agencies; this has not been addressed in training courses for facilitators of bibliotherapy to date.

The next chapter, Chapter Seven: Therapy part B: Achieving therapeutic outcomes, will explore therapeutic outcomes and discuss the fundamental facilitator attributes, rather than skills and tasks, that contribute to delivering something therapeutic, and explore another layer of the relationship between 'biblio' and 'therapy.' 


\section{Chapter Seven:}

\section{Therapy part B: Achieving therapeutic outcomes}

\section{Introduction}

Chapter Six: Therapy part A, considered the practical aspects of 'therapy' including the partnerships necessary to deliver creative bibliotherapy in community settings, and delivery practices. Chapter Seven continues the exploration and development of 'therapy'.

The research data showed that facilitators did not feel confident in delivering programs within a therapeutic context, and there was a high level of requests for more 'therapy' knowledge. This is directly related to the aim of the research to understand more about the relationship between 'biblio' and 'therapy' and how this understanding can be developed and applied by creative bibliotherapy facilitators to support wellbeing. The facilitators' interview data also indicated that group members found the groups therapeutic and the reasons for this are discussed below in the sections on therapeutic relationships and the therapeutic core conditions.

As outlined in Chapter Three, the chosen methodology, interpretative phenomenological analysis (IPA), is both descriptive (phenomenology) and interpretative (hermeneutics) in its approach (Pietkiewicz \& Smith, 2014). Chapter Seven uses the interpretative hermeneutics processes, the 'hermeneutic circle' and the 'double hermeneutic', to enable a more in-depth exploration of the relationship between 'biblio' and 'therapy'. Chapter Seven incorporates the researcher's own experiences and perspectives, another feature of IPA, to add depth to the facilitators' experiences and explore 'therapy' more deeply. As discussed in Chapter 3.1.4.2: Rigor and validity, the researcher's perspective, as applied in this chapter to assist with interpreting what participants have described, will respond directly to the experiences reported by the research participants.

This chapter initially outlines the hermeneutics processes (7.1). The chapter will broadly consider therapy (7.2) and wellbeing (7.3). Then the chapter will discuss universal therapeutic core conditions (7.4) and provide examples of the facilitator's role in providing these core conditions, that demonstrate the universal elements of traditional therapeutic 
culture and function within creative bibliotherapy (7.5). The chapter will then look at therapeutic relationships (7.6) and the therapeutic concept of holding the 'space' (7.7). Finally, the chapter will look at the therapeutic outcomes of 'biblio' and 'therapy' (7.8).

\subsection{Engaging in hermeneutic processes}

In Chapter Seven, hermeneutic processes will enable a more in-depth exploration of the relationship between 'biblio' and 'therapy'. The 'hermeneutic circle', outlined in Section 7.1.1, examines extracts that demand attention and analysis. The 'double hermeneutic', outlined in Section 7.1.2, enables the researcher to look at creative bibliotherapy from their own perspective, in conjunction with that of the research participant. More information about these processes can be found in Chapter Three: Methodology.

The hermeneutic focus in this chapter has made use of the metaphor of an onion, used in IPA to conceptualize unpacking the layers of understanding around a phenomenon (Miles et al., 2015). In this chapter, the phenomenon is 'therapy', specifically its relationship with 'biblio' and they way that when combined as 'bibliotherapy' provide 'wellbeing'. Each layer in the relationship between 'biblio' and 'therapy 'is vital to achieving therapeutic outcomes and represents a different lens through which to view 'wellbeing' (Kristensen, 2018).

\subsubsection{Hermeneutic circle}

The hermeneutic circle comprises taking single words and sentences from a research participant's transcript for further investigation. Smith (2011c, p. 6), the original IPA theorist, describes engaging the hermeneutic circle as taking single utterances and small passages that 'shine like gems' to offer 'potent analytical leverage to a study'. As described by Smith (2011c, p. 7), a gem is 'the thing that stands out when you're reading a transcript, it's the extract that demands attention and prompts further analytical work'. The extract below from Helen's interview contains words and utterances that 'shone like gems' and pulled me back to re-read several times during the analysis process, and now provide a way of entering the hermeneutic circle:

We just need to keep exploring this therapy and we would have a greater understanding of what it means for us... you have to look at what the traditional thing of therapy is and look at that and where people are really scared about it... you have to break down your preconceived ideas. 
The words that 'shine like gems' from Helen are 'exploring this therapy', 'greater understanding of what it means for us' and 'where people [i.e., facilitators] are scared about it.' The concepts [in italics] as opened up by Helen are discussed in Sections 7.2: Therapy; 7.3: Wellbeing; 7.4: Therapeutic core conditions; 7.5: Therapeutic core conditions in creative bibliotherapy; 7.6: Therapeutic relationships; and, 7.8: therapeutic outcomes of 'biblio' and 'therapy'.

\subsubsection{Double hermeneutic}

The double hermeneutic is an IPA process that helps researchers reach a more in-depth understanding by incorporating the researcher's perspective. Finlay and Ballinger (2006) and Smith and Osborn (2003) describe engaging in the double hermeneutic as bringing the researcher's perspectives to the meaning-making of data collected from research participants to build on the phenomenon under investigation. The double hermeneutic assists in interpreting what the participants have described, uncovering any hidden meanings.

In IPA the first interpretation stage is categorised as the phenomenology stage in which the participants offer their interpretation of meaning (Finlay, 2011). However, in the first stage, ideas may still be undeveloped (Berndtsson et al., 2007). The double hermeneutic is used as the second interpretation stage, in which the researcher brings personal perspectives to the meaning-making (Bevan, 2014; Elliot et al., 2012; Finlay, 2011; Stanley \& Nayar, 2014). In this second level of interpretation the researcher endeavours to not only respond directly to the experiences reported by the research participants but to also build on the phenomenon under investigation. This is done by using the researcher's experience and perspective to assist in interpreting what the participants have described. In this research, the double hermeneutic process will construct a narrative combining the overlapping perspectives of the researcher and the participants as a way to offer a deeper understanding and interpretation of the relationship between 'biblio' and 'therapy'. Publications by the researcher have also been incorporated throughout the discussions of the research data as part of the double hermeneutic process (see Reference list).

The double hermeneutic process will be used in four sections of this chapter. Firstly, in Section 7.5.2: Empathy; the second in Section 7.6.2: Connecting with self; Section 7.8.1: 
Emotions and, in Section 7.8.2: Emotions and literary texts. In each section, the researcher's perspective will be included to build on the research participants' experiences by interpreting the experiences described.

\subsection{Therapy considerations}

The discussion of therapy in Section 7.2 will link to a broad consideration of wellbeing offered in Section 7.3, with both sections building on how therapy is achieved through creative bibliotherapy supporting the promotion of wellbeing.

\subsubsection{What is therapy?}

Therapy is broadly considered as the process of resolving problematic behaviours, beliefs, feelings and, at times, related physical symptoms to help develop an individual's selfunderstanding of an issue and support them to make changes in their life (Psychotherapy and Counselling Federation of Australia (PACFA), n.d.). In clinical therapy, a clinically trained professional (i.e., counsellor or psychologist) will help develop the client's selfunderstanding of an issue and support them to make changes in their life (PACFA, n.d.). In non-clinical therapy, a suitably trained facilitator (i.e., an art, music or dance therapist) offers a participant a way to reconnect with themselves, developing an individual's selfunderstanding of themselves and offering new perspectives on issues and challenges (Acata, 2013) towards improving personal wellbeing. This is also possible through creative bibliotherapy delivered by non-clinical facilitators in community settings.

\subsubsection{Therapy in clinical and non-clinical settings}

Within therapy, there are many types of therapists delivering many different types of therapy to meet the needs of diverse clients. While both clinical and non-clinical forms of therapy are concerned with fostering a person's wellbeing there are differences between them.

Clinical forms of therapy:

- commonly takes place on a one-to-one basis

- $\quad$ involve a trained clinical professional, such as counsellor or psychotherapist

- the client can choose a therapist and therapy style best suited to their particular situation

- $\quad$ usually take place in a professional setting, such as a community mental health service provider or private psychologist or counselling practice 
- $\quad$ are more likely to be focussed on specific problems

- generally involve a therapist and client discussing the issues which are presented by the client prior to commencing therapy

- $\quad$ are often related to physical symptoms which a clinical professional will treat systematically e.g. lack of appetite from depression; diarrhoea from anxiety and headaches from insomnia.

- $\quad$ are concerned with the restructuring of the personality.

Non-clinical forms of therapy:

- $\quad$ often take place in a group setting

- mostly take place in a community-setting, such as a public library, prison or aged-care residence

- $\quad$ are not delivered by trained clinician in the therapy relationship

- take a more holistic approach to therapy, and wellbeing, rather than focusing on single issues

- focus on psychological, social and emotional challenges without attempting to physically cure specific symptoms or disease

- $\quad$ frequently use creative and artistic processes through various art forms, such as art therapy, music therapy, dance therapy and creative bibliotherapy (Chapter 2.4.2.2: Bibliotherapy and the arts).

Creative bibliotherapy is situated within non-clinical forms of therapy and provides a community therapy resource for people dealing with psychological, social and emotional challenges. Therapy, and wellbeing, are achieved through using a creative process, involving literary texts and discussion, as the vehicle for therapeutic change, thus enabling a change in thinking about and perspective of psychological, social and emotional challenges.

\subsection{Wellbeing considerations}

This section build on how therapy is achieved through creative bibliotherapy, supporting the promotion of wellbeing.

\subsubsection{What is wellbeing?}

As outlined in Section 7.2.2, both clinical and non-clinical forms of therapy aim to positively affect an individual's wellbeing. Chapter 1.3: Wellbeing, broadly defined wellbeing as promoting life quality through meaningful interactions and connections. However, the concept of wellbeing is complex and 'the question of how it should be defined remains unanswered' Dodge et al. (2012, p. 222). This study will consider wellbeing and creative 
bibliotherapy, and in this context wellbeing can be thought of as a changeable state that requires re-balancing each time an individual feels challenged psychologically, socially, or emotionally (Dodge et al., 2012; Headey \& Wearing, 1991; Kloep et al., 2009).

\subsubsection{Wellbeing and creative bibliotherapy}

Chapter One defined bibliotherapy as using literary texts to help people deal with psychological, social and emotional challenges. Creative bibliotherapy can promote and result in wellbeing through offering literary texts as a psychological, social and emotional resource to support people challenged in the same dimensions, as represented in a diagram below.

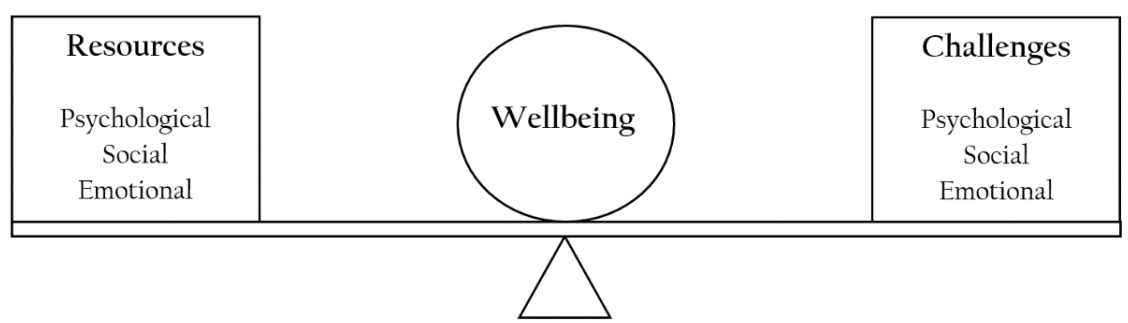

Diagram 1: Wellbeing and resources and challenges

Adapted from a visual representation of wellbeing offered by Dodge et al. (2012, p. 230).

The above diagram represents wellbeing at the centre of a seesaw with, on one end, the resources needed to meet challenges and, on the other end, possible challenges. The central resource is the literary text, supporting psychological challenges through helping develop insight and new perspectives; supporting social challenges through giving group members a way to be with others, and a different way to get to know and understand others; and supporting emotional challenges through enabling group members to recognize and experience emotions vicariously in a fictional world to improve understanding of personal emotions (Oately, 2009)

In this system of challenges and resources, each time we meet a challenge we need appropriate resources to steady the imbalance the challenge has created in our wellbeing equilibrium. When an individual has more challenges than resources the see-saw negatively declines. Alternatively, if the individual has the resources required, their wellbeing is maintained, or positive feelings of wellbeing may even increase. Therefore, literary texts, selected to focus on and support these challenges through reading aloud, and associated 
discussion, can be considered a wellbeing resource and can offer therapeutic and wellbeing benefits (Ford et al., 2000; McCoy \& McKay, 2006). The reading aloud aspect has been discussed in Chapter 5.2: Reading aloud. The group discussion aspect has been discussed in Chapter 6.5: Group discussion; this chapter discusses the therapy aspect and consequent wellbeing.

Using literary texts as a therapeutic resource, offers some unique therapeutic qualities. Some literary texts can provide words to describe emotions when individuals cannot find the words to express how they are feeling. A sentence in a story or the lines in a poem can be remembered and recalled when a person is challenged to find a way out of negativity as often experienced with psychological, social and emotional challenges. The bibliotherapeutic process essentially works by group members engaging the imagination to creatively make meaning of, and benefit from, the literary text relevant to themselves (Lewis et al., 2009; Oately, 1998), without having to recount personal experiences (Jarjoura \& Krumholz, 1998) of a psychological, social or emotional challenge. Natalie identified that her group members, 'feel compelled to share because it's all reflected back in the text or the line of the poem; it kind of gives everyone that sense of like a security blanket so they're not just telling you some personal details or anecdote that's just random but it always did reflect back on the text.' Cheryl provides an example of a positive result from a creative bibliotherapy session:

I remember one day in our group... we always have some of the Community Health staff... involved in the group. I remember one day them sitting there with their mouths open and their jaws on the floor because this person [i.e., group member], who is close to nonverbal, he says very little, shared about his family. We discovered that he actually has six children... they've known him, they've worked with him for a long, long time and this information came out of him. It's amazing to get information out of him for a start... but secondly, they just had no idea of this background that he had... It was amazing. It's still amazing. I think it's incredible.

Kim provides another example:

Then what's happened in both groups is that because they feel comfortable enough people will have said things that they've never told anyone else. There was a lady in the first group who mentioned having a child before she was married and had another family and no one knew about this other child. She told our group about that. She was confident to say it. Even just recently with this most recent group people were divulging things. Like it's not about getting the salacious details, it's prompted by whatever is in the story. 
In the creative bibliotherapy activity, neither the facilitators nor the participants explicitly deliver or receive therapy. Nonetheless, the activity can support people with psychological, social, and emotional challenges through developing a willingness to think about feelings, thoughts and emotions while increasing self-awareness and self-esteem, empathy and confidence, that in turn improve the ability to cope with challenges, and general wellbeing (Langum, 2004; McCoy \& McKay, 2006; Pehrrson \& McMillen, 2010; Pierce, 2016). These outcomes suggest that 'therapy' is an implicit result of reading group activity; and that creative bibliotherapy, as a non-traditional approach to therapy, directly and positively impacts wellbeing, sometimes long after the therapeutic relationship in the reading group has finished (Crenshaw \& Cannelli, 2020; McCoy \& McKay, 2006).

\subsubsection{Wellbeing and sense of belonging and social connectedness}

Creative bibliotherapy can positively effect wellbeing through providing a sense of belonging and social connectedness. Wainer and Chesters (2000, p. 146) assert that '(s)ocial connectedness describes a subset of the most important determinants of wellbeing'. 'Belonging and connection to place' (Wainer \& Chesters 2000, p. 141) are important aspects of wellbeing. A lack of lack of social contact negatively impacts on mental health and wellbeing (TRO, 2020b). Reading groups can provide a process for 'social integration (a sense of belonging within a social group)' Davis et al. (2016, p. 60).

An unpublished evaluation of the 2010 Book Well program was produced for State Library Victoria in 2012 by Smith \& Keating, Melbourne-based consultants, providing professional research, evaluation and planning services to the public and community sectors. The report asserts that reading groups 'made a positive difference for participants by offering a different kind of social activity: not only a new opportunity to connect, but also an opportunity that fostered new ways for participants to connect with one another'.

For someone experiencing social isolation, there is not a choice about being withdrawn; this is why facilitation is necessary in offering the experience to participate in something' (McLaine \& Mackenzie 2013, p. 9). 'The act of reading together a literary text not only harnesses the power of reading as a cognitive process, but also acts as a powerful socially coalescing presence, allowing readers a sense of subjective and shared experience at the same time' (Hodge et al. 2007, p. 102). The notion of shared experience using an arts-based 
program is supported by Daniels (2006), who claims that using the arts in therapeutic group work can support group communication to develop both a depth of meaning and a social element that allows closeness with that audience to develop.

Creative bibliotherapy, through facilitated reading groups, provides safe social interaction. 'There's something beautifully soothing about being read to' (Freeman-Greene, 2011) that creates the space that can offer the sense of safety necessary for isolated people to take part in a group. Often, if one feels lonely and isolated, listening to literary texts read out loud can help to provide both an inner and outer companionship with the words, the images and then with others. McLaine and Mackenzie (2013) assert that it is easy to underestimate the wellbeing to be found in face-to-face company and conversation, although this has been made more obvious during the COVID19 restrictions on interactions with others and the consequent impact on mental health. The facilitated discussion in creative bibliotherapy, following reading aloud, is a key factor in positively influencing wellbeing. Jane said of group of socially isolated women that 'sometimes you get the feeling that for those ladies, it's the first time they've heard their own voice.' Wilma recounted a powerful example of the importance of facilitated discussion:

Well one of the things that really struck me was that some of these people sort of came alive through the process and they would talk about feeling stimulated; that they hadn't had a conversation like that in a long time. The conversation wasn't about their aches and pains or all their troubles, although it may have touched on that through shared experiences, but that it was stimulating this conversation around the text. It was interesting who was attracted to the group, because this was completely in the community and it wasn't in a facility... they actually came voluntarily. It seemed to me that these were people who were desperate - and again see they're not in a therapeutic session - setting. They don't come together - a lot of these people never came together in a setting where they shared anything on a weekly basis. So I think they were desperate to, you know in a way it showed they are desperate to talk, to be seen, to be heard.

However, inclusion involves more than providing community support structures and services; participation that involves a sense of belonging is also needed to feel included (Irwin et al., 2006). Research participants commented on the ability of groups to develop connections. Terry felt that participation in the groups 'gets them [i.e., group members] out of themselves to a point where they can feel like they're engaging with others.' Wilma described a general feeling of wellbeing in that 'people kept turning up. You see I think that's 
actually a sign of them getting out, getting something out of it and looking forward to it and there are certainly a couple who came and said oh we really don't want it to end. That in itself I think is an indication that there has been a benefit of wellbeing if nothing else, sort of the generic wellbeing feeling.' Meredith also noted that 'people kept turning up to groups over a period of time' and felt that 'not many programs were able to achieve that sort of sustainability.' For Cheryl, 'the thing that I saw happen with this group was connections... they formed real connections.' Kim felt similarly that 'within these groups there is a great sense that you've communicated with people on deeper level than you would normally. Sometimes it's people that you wouldn't generally communicate with. They've communicated with each other.' Debra noted a group session that was special 'because they connected so deeply with the text and they connected with each other as well, the support that the group gave was amazing. It really was a beautiful thing. They made those connections.'

Fearnley and Farrington (2019, p. 326) propose that in ordinary public experience, the achievement of a sense of community and commonality between people is often dependent upon an agreement or acceptance of certain shared norms for a particular purpose. This may limit both the depth and the reach of such community as well as the place that the individual is able to occupy within it'. Coming together in a safe environment to listen to stories and poems read aloud, within a defined group model, extends the depth and breadth of a group through a common sense of purpose and belonging. When a successful response to literary texts happens with other people, a feeling of connection and synchrony emerges; a mutual sense of being together in a unique state and increased feelings of wellbeing through the 'unifying power of a reading group discussion' (Tukhareli 2018, p. 87). In a blog post for Changing Lives Through Literature (CLTL), a community-based creative bibliotherapy program as an alternative to jail, Tam Neville (2012) reports the words of Professor Robert Waxler, the program co-founder, at a CLTL meeting:

We collectively make a community. The activity is primarily verbal. Reading brings engagement with narrative - you see that you are connected to other people. The story that I just read is my story too. Then discussion with everyone sitting around a table, there's an open relationship between our experience and narrative. Story gives us meaning and helps us put ourselves in someone else's shoes. 
Waxler's address relates to Wainer and Chester's (2000) categorisation of social connectedness as one of the most important determinants of wellbeing. Research in Western medicine and neuroscience provides evidence through hundreds of case studies to establish that humans need to have a feeling of belonging to a social network, a sense of acceptance, and a way to come together as a community to increase wellbeing (McCarthy \& Thomas, 2004).

Libraries have the resources and infrastructure to provide effective community settings for accessing health information and health promotion programs (Leung et al., 2016). Libraries can offer creative bibliotherapy as a health promotion program to support individuals with psychological and emotional challenges and develop connections between individuals and the wider community.

Traditional bibliotherapy is a solitary self-focused activity involving reading prescribed texts, whereas creative bibliotherapy is a shared experience of texts where there is often a willingness to give time and attention to others. Natalie observed that it was a shared experience in which group members felt 'compelled to share an experience, something that they're giving of themselves allows us to all be part of that journey for them.' Subsequently, group members feel valued because they feel that others want to listen to them. Reading aloud, followed by discussion, encourages those who may not usually join in conversations to communicate in a different way. Appropriately selected literary texts create opportunities for group members to think about being part of a community (including the opportunity to be with people without the pressure of the expectation of having to interact unless group members desire to do so).

Stories offer opportunities for conversations around behaviour, trust, sharing, and our capacity for love, kindness, empathy and caring for others. These concepts are discussed further in Sections 7.4, 7.5, 7.6, 7.7 and 7.8 below.

\subsection{Therapy core conditions}

To more deeply explore the concept of therapy, this study turns to pioneering psychologist Carl Rogers (1951, 1961 \& 1980). Rogers is well-known for his revolutionary interpersonal relationship approach for effectively achieving therapy; that is, therapy outcomes are achieved by providing the three core-conditions of unconditional positive regard, empathy, 
and congruence, which together create Roger's person-centred approach. Unconditional positive regard requires facilitators to be accepting and non-judgemental. Empathy involves facilitators understanding the reality of group members, and congruence necessitates facilitators to be at one with the feelings the group members are experiencing and able to communicate these genuinely to the group members. These core conditions are described further in Section 7.4.

Rogers's core conditions are still highly regarded; more therapists cite Rogers as their primary influence than any other psychologist (Baldwin, 1987; Cherry, 2019), making him one of the most influential psychologists of the twentieth century and many evaluations of his work comment on the effectiveness of his approach (Brunero, 2008; Greene, 1994; Miller \& Moyers, 2017).

The conditions are seen as 'core' because they are the 'vehicle' which enables change and are very important in facilitation (Gillon 2007, p. 44). Bibliotherapy facilitators need to understand that creative bibliotherapy occurs due to creating the right conditions in which therapy can happen, as indicated by Rogers.

Gillon (2007, p. 45) says Rogers' success with therapeutic outcomes is 'wholly dependent on the therapist's capacity'. Rogers (1980) describes this capacity as a 'way of being', suggesting that the very 'presence' of another person offering these qualities [i.e., the core conditions] is sufficient for psychological change to occur (Rogers, 1987). Rogers' 1957 article The necessary and sufficient conditions of therapeutic personality change, emphasised that the core conditions were necessary to produce change-'no other conditions are needed' (Bozarth 2013, p. 180) and '(n)othing else was needed' (Gillon 2007, p. 43).

Through employing Rogers' person-centred approach of unconditional positive regard, empathy and congruence, creative bibliotherapy can implicitly deliver something therapeutic through focusing on promoting positive conditions for change rather than focusing on how to create change (Crenshaw \& Cannelli, 2020).

These core conditions will be further defined in Sections 7.4.1: Unconditional positive regard, 7.4.2: Empathy and 7.4.3: Congruence. In each of these sections, attention is paid to what is involved, within the context of creative bibliotherapy, and the facilitators' attributes in providing these core-conditions. 


\subsection{Therapy core conditions in creative bibliotherapy}

In Section 7.4, three core-conditions were cited as necessary to create the right conditions in which therapy, that is, psychological change or a change in perspective, can happen and thus improve an individual's wellbeing. The core conditions are of unconditional positive regard, empathy and congruence (Rogers 1951, 1961 \& 1980).

Understanding the core conditions leads to a fuller understanding of 'therapy', and consequently wellbeing (Wilkins, p. 26). Gillon (2007, p. 44) asserts that the core conditions 'present a considerable challenge to the person-centred practitioner, for they are not formulated skills to be acquired, but rather are held as personal attitudes or attributes of the therapist', or facilitator. The techniques used to provide the core conditions include caring, accepting, listening and understanding, which are more attitude-orientated than skills-orientated. The three attitudinal elements fit together, and in fact overlap, to form what Rogers calls a person-centred philosophical approach.

Although all three core conditions are of equal importance, unconditional positive regard is perhaps the hardest of the three to define and explain (Purton, 1998) and, therefore, it takes up the most significant part of this section.

\subsubsection{Unconditional positive regard}

Rogers (1959, p. 209) defines unconditional positive regard as 'warm acceptance of each aspect of the client's experience'. Hendricks (2001) explains further that unconditional positive regard involves facilitators staying with an interaction, even if it becomes a negative experience, for example, a group member suffering anxiety.

One major difference between therapists and facilitators is that facilitators refer to the participants as 'group members', not 'clients' or 'patients'. A therapist who diagnoses a client's psychological state as experiencing grief, depression, anger or some psychological issue may relate to the diagnosis more than the person, and may therefore be unable to provide unconditional positive regard. A facilitator, who is not in the role of providing psychological assessment or support, is more likely to see the group members as equal partners, rather than themselves as an expert treating a patient and they therefore remain available to offer unconditional positive regard. 
Unconditional positive regard is not something a facilitator can decide to provide or not; it only comes from holding an attitude of deeply valuing humanity and 'manifests itself in the counsellor's [or facilitator's] consistent acceptance of and enduring warmth towards her client' (Wilkins 2000, p. 24). This means caring for group members, even though facilitators do not know them, without forming evaluations, judgments or negative emotions.

To provide unconditional positive regard therapists and facilitators need to have an attitude that emotions come and go as part of the interaction. In this regard, a facilitator needs to be genuinely welcoming to the individual and see them as perfect the way they are without feeling the need to change them, and when a facilitator truly feels that, that is a moment of unconditional positive regard. Acceptance can be communicated indirectly through the facilitator's impartial expressions (Brodley \& Schneider, 2001), and verbally through choice of words, interpretations of statements and tone of voice. When group members feel the facilitator accepts 'all' aspects of them, it supports them to accept themselves with unconditional positive self-regard (Rogers, 1957).

Jane said of her group members:

They feel comfortable with me and I think because I'm sure they feel that I respect them and their views, whatever it is they say, and that there's no judgment-it's based on mutual respect, theirs and mine. I will always say, there's no right or wrong. I think that must be a skill that I've learnt or brought to the group, because I don't see that that was something that we were trained to do.

Referring back to the importance of Rogers' core condition of 'unconditional positive regard', humans have a need to be properly listened to, which can only be achieved when people are genuinely present in the listening experience. When a person truly experiences being listened to with attention and respect there is therapeutic benefit, or benefit to our wellbeing. Facilitators' attitudes of warmth have been discussed in Therapy part A.

Cheryl provides an example of having an attitude of deeply valuing humanity that manifests itself in the facilitator's acceptance of their group members:

You have to value people and their experiences. People of all sorts. Sometimes I feel really sad about the people in my group because they are people that our society doesn't value. Part of what I do is to say that we value you, that you're important enough for us to be interested in, to want to get to know, to share some stories with you. 
Rogers says of facilitating (1971, p. 276):

I wish to make the climate psychologically safe for the individual. I want him to feel from the very first that if he risks saying something highly personal, or absurd, or hostile, or cynical, that at least one person in the circle respects him enough to hear him clearly and listen to that statement as his authentic expression... I listen. I want to make the individual who speaks feel that what he has said is, to me, worthwhile, worth understanding, and that consequently he is worthwhile for having said it.

Jane provides an example of what Roger's is speaking about above, in regard to providing unconditional positive self-regard:

it's to give people kind of a sense of worth, in that they are valued, they are worthy of sharing their feelings and thoughts with others, with me. That's in their minds and their hearts, because it's exposing them, but it's in a safe, trustworthy place. Just to give them a sense of worth, because one of the loveliest things that they have said is they acknowledge that I have spent time with them and listened to them. I think that for - like I say, they almost have a sense of being privileged that somebody wants to spend time with them and listen to them. It's more than being listened to in any old discussion group or whatever. It's actually listening to how they feel and allowing them to express whatever it is they want in that safe environment. It makes them feel good. It makes them feel happy.

Kim provides an example of group members feeling accepted:

They mentioned the sharing, just general sharing and the support. They felt it was a supportive group. A couple of them were talking about they didn't feel that - they might say something wrong, they didn't think it would matter.

At its simplest, unconditional positive regard can be described as being warm and caring (McGregor, 2020). Feeling valued and cared about supports social and emotional development and is a determinant of wellbeing (Shahzad et al., 2014).

\subsubsection{Empathy}

Many definitions have been given of empathy. I refer to Rogers (1959, pp. 210-211) definition:

The state of empathy, or being empathic, is to perceive the internal frame of reference of another with accuracy and with the emotional components and meanings which pertain thereto as if one were the person, but without ever losing the 'as if' condition. Thus it means to sense the hurt or the pleasure of another as he senses it and to perceive the causes thereof as he perceives them, but without ever losing the recognition that it is if I were hurt or pleased and so forth. 
Tudor (2011) suggests that providing empathy is a process rather than a state, which means that a facilitator needs to send clear messages to group members that they are there to help them explore how they are thinking and feeling.

Empathy, like unconditional positive regard, requires laying aside the views and values you hold for yourself, and enter another's world without judgment, defining a psychological state, or wanting to change them. In being non-judgemental, it is important to not interpret observations; for example, commenting to a group member that they look sad, based on a look on their face and the content and tone of what the person is saying. It is important that group members feel that you are responding to them without judgment but with empathy for what they are experiencing.

A facilitator, who is not in the role of providing psychological assessment or support, is less likely to be trapped in defining the group member and trying to make the group member aware of their mental state. Equal to providing unconditional positive regard, empathy requires group members to feel valued, cared about and accepted for the person they are. However, empathy differs from unconditional positive regard in that being empathetic involves firstly listening: not just to the words being spoken, but listening for what the reality is behind the words, what the other person's understanding is of the reality. In its simplest form, empathy could be described as sensitive listening to understand without judgment. Being listened to by someone who cares, supports the feeling of being valued and can help a person to be more empathic towards themselves, which supports group members to develop new perceptions and think about challenges more positively. Empathy requires facilitators to recognise that group members have different emotions and experiences to their own (Batson et al., 2015; Davis 1980 \& 1983; Galinsky et al., 2008; Maibom, 2009; Pierce, 2016). Stern (1994) reminds us that empathy is not our interpretation of what we think others are feeling, and trying to make sense of it. An example could be a group member's lack of engagement, where facilitators would need to make sure that they do not interpret the reason without asking questions. Empathy is explained by Stern (1994, p. 441) as 'an attitude one takes toward making observations'. Cheryl provides an example of having this attitude:

You have to be willing to listen and you have to be tolerant because there's all sorts of - 
people - they don't necessarily behave in the way that you might think is most appropriate.

When empathy exists, group members are more likely to open up and share their thoughts, feelings, and pain, which can support group members to not feel alone, and enable them to feel social connectedness. Cheryl provides an example:

A group member, a Bosnian man, sat for a long time saying very, very little before he shared some of his story with us about the war and what he'd been through in Bosnia and about losing brothers in the war and the sadness that he feels even now at those losses. I think for him, he sat for a long time without sharing any of it. I think it took a while for him to trust us that we would listen and treat the information with respect. That's big stuff that he was telling us about that still clearly has a huge impact on his life, even though it's years ago now.

When developing a new facilitated self-reflective bibliotherapy podcast series (discussed in Chapter 2.4.1.6: Internet bibliotherapy), I had to think deeply about how to covey empathy in the context of listening to a podcast that allowed individual listeners to have their own experience during a time when everybody is reacting and responding to the covid situation differently. Understanding the inner world of another is a demanding process at the best of times; however, I needed to think about empathy on a new and different level in creating the podcasts to ensure that all listeners could have the opportunity to connect within their own range of reactions and unique experiences. It involved not just emotional presence but holding the emotional intention through the script writing and recording stages. Exploring empathy from this perspective certainly brought about change and learning for myself in thinking about the experience of core conditions and holding the 'space' (see below 7.7). Providing empathy requires your full attention and emotional presence. Jane says, 'I come out feeling a mixture of being elated and sometimes drained. It's both. The drained isn't a negative drain.' Cheryl said, 'I feel like I've made it sound like it's all wonderful and it's actually really hard. It's hard work.' Kim felt that 'at the end of it you need a bit of a wind down. You can't just go straight back out on the desk.'

Rogers (1987, p. 181) states, 'empathy is in itself a healing agent. It is one of the most potent aspects of therapy because it releases, it confirms, it brings even the most frightened client into the human race. If a person is understood, he or she belongs'. A sense of belonging, or social connectedness, is a determinant of wellbeing (ACT Wellbeing 
Framework, n.d.; Allen, 2019).

\subsubsection{Empathy development in group members}

Empathy is not something that can simply be given; it also needs to be received (Hargaden \& Sills, 2002). Section 7.5.2 discussed empathy from a facilitator's point of view. However it needs to also be mentioned that empathy can be developed in group members, which in turn supports group members' wellbeing. Cheryl provides an example to demonstrate when group members began to empathise with the characters of a story:

We read from Silas Marner... he's accused of a crime that he didn't do and moves away and he's bitter and twisted and then this little girl comes into his life and he looks after her and loves her. At one stage, the little girl who he calls Eppie, wanders off and he goes looking for her. The way that they [i.e., group members] sat with baited breath, it was just magic. The fear was that he was going to find-because he finds her down near the dam - there was an audible sigh when he found Eppie alive and well.

Mar et al. (2006) assert that within the practice of reading fiction, imagination may play a unique role in empathy according to the way readers process and understand stories. In this way, reading literary texts can influence empathy via what researchers in the field of psychology call 'experience-taking' or 'emotional transportation', when readers are emotionally affected by the story (Chow et al., 2013; Mar, 2011; Mar \& Oatley, 2008). Matthijis Bal and Veltkamp (2013, p. 8) propose that 'emotional transportation makes it possible for readers to change as a consequence of reading fiction, because it elicits various processes, including emotional involvement in the story and development of empathy that ultimately can result in emotional growth'. Matthijis Bal and Veltkamp $(2013$, p. 8$)$ found that an 'increase of emotional transportation enhances empathy for fiction readers while it does not for nonfiction readers'.

Fiction reading may have profound effects on empathic skills through readers empathising with the characters in the text, detecting subtle emotional expressions more effectively, and engaging in pro-social behaviour; that is, starting to identify with and consider another person (Anderson, 2012; Anderson \& Keltner, 2002; Bakhtin, 1984; Caplan, 2004; Gumbrecht, 1992 \& 2006; Hohne \& Wussow, 1994; Kramer, 1999; Kretzmann \& McKnight, 1993; Mar et al., 2006 \& 2009; McKnight, 2010; Winnicott, 2005).

For 'experience-taking' to happen, the reader must be fully engaged in the story and 
focused on the events occurring in the narrative, emphasising the need for facilitators' skills in selecting literary texts, reading aloud in an expressive way and developing the attentive and aesthetic listening skills of the group members (as discussed in Section 7.8.3: Emotions and meaning-making). Wilma, who ran a group with some fairly aggressive group members, describes a time when group members displayed some empathy towards each other.

Interesting that in this group of people, some of whom had short fuses, they gave each other the space to [make comments in discussion] and it was good to see that people can actually give each other the space to do that. This bloke who I think was the person who was homeless talked about his childhood growing up which was pretty tough. Everybody really silently came around him and it felt really supportive because it was a really tough childhood - he shared details about how tough it was. People just seemed to respond to that with a kind of quiet tenderness... you could really feel everyone being around him in a way, supporting him.

\subsubsection{Congruence}

Congruence has two aspects. The first is that the facilitator is congruent with the group members; Rogers (1961) defines this as the therapist is at one with the feelings they are experiencing and able to communicate these genuinely to the client if appropriate. Facilitating within a congruent stance means not standing behind a professional facade or mask, or appearing superior in any professional capacity (Ramsey, 2019; Rogers, 1957). Corey (1986) describes this as a facilitator's internal and external presentation being the same. Cheryl provides an example of a group member's feelings through experiencing a facilitator being congruent:

[a group member] said to me, which for me, I - was a huge compliment, I thought. He said that he thinks that I see the person and not the disability. So to really value them as people and to value them as people who've got something to contribute and... be willing to listen to them and hear them, I guess. It all sounds so wonderful, and it's not always, believe me. It's very up and down.

The second aspect is the group members become more congruent with themselves, through 'self-actualization [that] occurs when a person's "ideal self" [i.e., who they would like to be] is congruent with their actual behavior [i.e., self-awareness]' (McLeod, 2014).

When the first two core-conditions of unconditional positive regard and empathy are provided, group members are already possibly moving towards valuing and caring about themselves a little more. They may be starting to listen to themselves with more empathy. 
The first two core conditions support the group member to become more congruent with themselves. Also essential is for the facilitator to be consistently reading verbal behaviours, such as self-disclosure, and nonverbal gestures, which could include group members leaning forward or making eye contact. Cheryl provides an example of how a group member felt through the congruence of the facilitator:

It's little things, like I was in the supermarket on Saturday and one of my Book Well people was there with his mum. He was just so happy to see me, it was really funny, and he came up and gave me a big hug and wanted to introduce me to his mum. It's kind of like you're shared a bit of them or - I don't know. He was - I was really impressed because we'd read the first chapter of a book that Friday and he was telling her all about it, about the convict and all that happened.

As with both unconditional positive regard and empathy, a facilitator, who is not in the role of providing psychological assessment or support, is more likely to listen and encourage the group member on an equal level. The importance of the facilitator not feeling that the person needs diagnosing and fixing is significant again in this core-condition. Facilitators can provide the core condition of congruence by being transparent and just being themselves.

\subsection{Therapeutic relationships}

Creative bibliotherapy facilitators deliver a non-clinical form of therapy that can enrich an individual's sense of self and relationships with others resulting in wellbeing. This next section will discuss improving feelings of wellbeing through connecting with others and reconnecting with self.

\subsubsection{Interpersonal relationships}

Rogers asserts that the quality of interpersonal relationships matter the most and is the most significant element in determining effectiveness in therapy. He believes that the quality of an encounter between therapists and individuals is more critical than scholarly knowledge, professional training, and counselling orientation and techniques. Rogers explains that professions can get caught up with 'labels,' whereas a more 'naive' participant - in this research the facilitator - relates to the troubled person as a person, which he feels is far more therapeutic.

Rogers' (1971) emphasis on the quality of the relationship over professional competence is relevant to creative bibliotherapy. Rogers $(1971$, p. 279$)$ says that he has learned 'to rely on 
the members of the group to be as therapeutic or more therapeutic' than a facilitator; he believes a group will discover its potential and its members' potential themselves if the core conditions are present.

Community-based, non-clinical creative bibliotherapy 'somehow puts facilitators on equal standing with participants... when you facilitate a reading session, you do it as human being' (Ellis et al. 2019, p. 88). As Corcoran and Oatley (2019, p. 338) say, your 'mind bounces off and relays to other minds in the room', in line with Rogers' concept of person-to-person relatability. In a community setting, creative bibliotherapy facilitates exploring, sharing and comparing experiences of others, bounded by the carefully chosen literary material, and it is in such contexts that we might begin to understand the practice as a form of 'implicit therapy' (Corcoran \& Oatley 2019, p. 338). The unpublished 2012 evaluation of the Book Well program produced for State Library Victoria by consultants Smith \& Keating, found that reading groups have the ability to develop 'a therapeutic relationship in the sense of people being able to understand each other, and listen to each other, and understand their griefs and their stresses and their joys'.

\subsubsection{Connecting with self}

Further to the wellbeing discussion (being able to be derived from social connectedness as discussed above (in 7.3.3), group members reconnecting with themselves can also positively affect individual wellbeing. Creative bibliotherapy enables slowing down and being more present (discussed in Chapter 6.4: Shared reading and listening) and this supports group members to pay attention in a more focused way. This in turn helps them to be more present with themselves, notice the stirring of emotions, become more curious and develop awareness of other perspectives, which supports thinking about challenges and increases wellbeing.

The poem 'Witness', by Denise Levertov (Levertov, 2003), used in one of my group bibliotherapy sessions (as a facilitator) provides an example of reminding group members to listen with attention:

Sometimes the mountain

is hidden from me in veils

of cloud, sometimes

I am hidden from the mountain 
in veils of inattention, apathy, fatigue,

when I forget or refuse to go

down to the shore or a few yards

up the road, on a clear day,

to reconfirm

that witnessing presence.

My group discussed Levertov's comparison of how a mountain becomes invisible to her when veiled by cloud or when she forgets to pay attention to it. After a lively discussion, there was a pause. Two group members sat nodding off; other group members gently acknowledged the sleepers. Moments later, the group found new a new state of alertness, and I asked, 'What is present here just now?' One of the group members said in reply, 'It's attention'. I was mindful, when reading aloud to this highly medicated group, of the importance of using eye contact and my voice to weave an invisible net of support, and as a gentle prompt to assist the group members to be present and attentive and connect to self as described above (McLaine, 2019).

Facilitators found challenges with keeping group members' attention. Jane said 'the attention span is not that long' for her older group members. Tanya said her group members 'might have been a little tired,' as did Helen who said that 'sometimes they're tired... they're elderly people.' In groups delivered within the mental health sector, Cheryl said, 'it is so hard to keep their attention' and Wilma found her group members, 'were a bit tired... because a lot of them are so heavily medicated.' The facilitator's alert presence to the physical environment, the literary text, the individuals attending, and the dynamics of the group are complex and crucial elements of assisting the group members to be present and attentive to themselves and others as well as to the reading (McLaine, 2019).

Jane commented about the feeling of group members being present in an emotional way:

When I compare the groups that I've got, the one that makes me believe that I am doing therapeutic work, is the group of people who all live independently, but they are socially isolated. Their behaviour is different from the other group. It has an openness, an honesty, a trust, where sometimes it feels like there's going to be a loose cannon in the room and I don't know where it's going to go. I really like that, because I think then the work is doing its work. 


\subsection{The therapeutic concept of holding the 'space'}

The term holding the 'space' is a commonly used therapeutic term to broadly define a therapist's act of 'being there' for another (Brady, 2018; Pearl, 2017; Plett, 2015; Walter, 2016). This research will use this broad definition of holding the 'space' to describe the conscious act required of facilitators, similar to therapists, to be caring, present and open to group members (Brady, 2018).

Holding the 'space' occurs through a caring, non-judgmental, and empathetic process enabling facilitators to emotionally and invisibly support group members to feel part of the group (Bird, 2020). It is something only they are aware of doing. Kim spoke of this:

You have to really be able to take several deep breaths when you start and concentrate and be there. You've got to be there. It's not something you can just tick off your list. It's a bit yoga-ish in a way. You have to just sit - at the start of the group or as they're all starting to come in - well this might be just me.

\subsubsection{Literary texts holding the 'space'}

David Fearnley, a forensic psychiatrist at Ashworth Hospital in the UK, Medical Director of Mersey Care NHS Mental Health Trust and Associate National Clinical Director for Secure Mental Health, England, co-facilitated a reading group for several years in a secure psychiatric ward. Fearnley, along with co-facilitator Grace Farrington, explain the capacity of literary texts to hold the 'space':

There is always the sense that the book or poem deserves respect, that it deserves time. Everyone involved - both group leader and participants - is primed by the very presence of the book for "this is something significant". When a psychiatrist sits down with patients on a one-to-one basis, or in group psychotherapy, they are paid to have all the answers, or at least to be able to suggest a path towards the answers. In a reading group, the book, not the professional, becomes the expert.

(Fearnley \& Farrington 2019, p. 325).

Meredith provides a comment relating to literary texts in the capacity of a holding the 'space':

Using literature in a group environment is almost like a vehicle to keep the group together where the literature becomes a reason for actually meeting but the dynamics of the group sit on top of that. So the bibliotherapy, it almost becomes like a room where you meet. It's an environment where you meet and then whatever your mental health aspect, whatever plan the health professionals are taking towards the group, whether it is as a group 
therapy group, whether it is just as an almost social gathering, that sits on top of that again.

Natalie spoke of this as well, in that, 'at its most basic level, the texts and the poetry provided that vehicle in order to have that shared moment.' The facilitator plays a significant role in selecting the literary texts that will engage group members emotionally. The texts selected then act as a tool for holding the 'space' through reading them aloud, interpreting them through group discussion, providing reflection time, and maintaining the emotional experience for as long as possible. I provide here an example of the emotional experience lingering after delivering bibliotherapy to a group in an Australian aged-care facility:

I was in on a Friday, and they [i.e., residents who are in the reading group] were going in for dinner. People were passing me and still discussing the group, which was on Tuesday morning. They were talking about the literature as they passed me, saying, 'I think in that poem... .' That was quite surprising to me, to notice that they were still talking about the material.

(McLaine 2012, p. 5).

The notion of holding the 'space' is important and could be considered an additional core condition, in that it is necessary to allow space for group members to feel emotion, which is an important part of the therapeutic outcomes of 'biblio' and 'therapy' and is discussed below in Section 7.8.

\subsection{The therapeutic outcome of 'biblio' and 'therapy'}

Section 7.2.1: What is therapy, broadly outlined therapy as the process of resolving problematic behaviours, beliefs and feelings. Thinking and talking about feelings is key to the therapeutic process because these actions bring out emotions. Trevarthen (2009, p. 55) asserts 'emotions have healing power because they are... the primary mediators of social life... most importantly, human emotions link persons in the life of community; they communicate the well-being, cooperation, and conflict of our engaged lives'. Emotions motivate human behaviour and play an essential role in therapy. Those delivering therapy, both clinical and non-clinical, need to understand emotions. Emotions are crucial to therapy and will be discussed below in more depth with respect to creative bibliotherapy. 


\subsubsection{Emotions}

The research participants started to realise the potential of literary texts to awaken emotions during the training. Jane said (as also noted earlier in 6.1.1: Libraries as facilities for community wellbeing) that she 'didn't fully appreciate it [i.e., emotions] was going to be a large part of bibliotherapy when I started but it emerged that that was quite obviously a large part of it.' Jane observed that the other trainee facilitators had similar feelings:

It started to emerge in the training and other trainees were asking questions... The questions were asked in the discussions where we were talking about people's emotional responses to the texts, trainees were asking for more guidance to deal with potential emotional outpourings. It left a big question mark... It wasn't conclusively answered... I really don't recall any facilitation skills in assessing whether people were emotionally upset or extraordinarily touched by the text or by the discussion, or what to do about it if they were. Even theoretical sessions or time spent on those topics would have been helpful... It was a curious feeling. I just think - after that, just saying, were we confident to deliver groups like that? I remember feeling sort of a mixed feeling of, oh my goodness, I hope nobody in my group is like that, followed immediately by, I hope somebody in my group is like that, because that's really what this is all about.

Rhonda's comment shows insight into the potential of therapy through bibliotherapy: 'if we're [i.e., facilitators] evoking these powerful emotions it's important to be able to handle that skilfully if we're going to actually be helping people.'

Although Cheryl's quote (below) has been used before in Chapter Six in relation to forming alliances with community service providers, it has been used here for a different purpose.

One of the first things I did was take it [i.e., bibliotherapy session] to our senior staff meeting. I just did a poem, a very small poem, and I had my boss in tears. It shows the power of this. Also, for me, that I was able to bring this to this group of people and move them.

The above comment about how a poem affected Cheryl's manager demonstrates that literary texts can elicit emotional responses through words and emotional use of voice. The risk is that a group member may feel something they had not planned to feel (de Gelder et al., 2005). This possibility may make some people 'fear' being emotionally vulnerable in public (Burkeman, 2015). This possibility could also make facilitators fearful of 'dealing with potential emotional outpourings' as mentioned above by Jane. The possibility is that emotions may move someone to get upset, cry, or have a painful memory triggered and the facilitator needs to know how to deal with this. Debra described a time when this happened 
in her group:

We had two in tears once... Standing on the steps of the Library holding these crying women. It was a poem... it had a death in it and it brought back a lot of sad feelings for her, and then it set off another lady, so the two of them... Hannah stayed inside with one lady and I went outside with the other. So very powerful.

In my role as a bibliotherapist, like the research participants, I didn't initially fully appreciate the level of emotions that could be felt in bibliotherapy. And similar to Cheryl's manager's experience, during my own training (in the UK), I experienced, entirely unexpectedly, intense feelings of grief when the words of a poem triggered a painful memory and placed me in an uncomfortable situation when the training facilitator insisted that I took part in a discussion and kept asking me questions, which caused me to start crying. I personally experienced the importance of allowing a group member to decide whether to participate in the discussions or not.

Rogers (1971, p. 279) describes ways of facilitating groups and states that he 'does not like the facilitator who withholds himself from personal emotional participation in the groupwho holds himself aloof as the expert... To me, [i.e., Rogers], this shows defensiveness in himself and a deep lack of respect for the participants. Such a person denies his own spontaneous feelings and provides a model for the group, which is the complete antithesis of what I believe in'. Rogers' account of what he considers non-facilitative behaviour and he proposes instead that showing emotion as a facilitator is a strength rather than a weakness, builds respect and trust with groups, and models positively engaging with emotions. As a facilitator, I have also sometimes experienced having emotional reactions when reading a text aloud to a group. For example, when I read some of Nelson Mandela's autobiography Long Walk to Freedom to my reading group in the psychosocial rehabilitation unit in Victoria's largest men's prison. Mandela describes how he feels after hearing about a series of adverse events affecting his family and I cried after reading aloud how Mandela's friend sat beside him in the cell and held his hand. I had recently started this group and did not yet understand the individual group members or group dynamics. I had chosen this text because I had thought the group members might be able to relate to it as prisoners themselves and may also have felt similar moments of despair. Reading it aloud to them seemed to act as an emotional amplifier, to both myself and the group members, which took me by surprise and reminds me again of Cheryl's comment above, 'It shows the power 
of this [for me], that I was able to bring this to this group of people and move them.'

Helen also spoke of a similar experience, which links directly to Rogers' thoughts of showing emotions in groups.

I cried at The Snow Goose. The others [i.e., the group members] just - they were so gentle. They really cared for me. They mirrored back to me the safeness, the safety that I'd hopefully built up in them that trust that you could cry in front of these people and not - they would understand and have empathy. There was that respect being developed. That was proof of it, I think, not that I wanted it to happen that way but it did. Helen said 'she wanted to develop some awareness of my own vulnerability so that, if somebody raised an issue, I was aware enough of my own issues, that I didn't get hooked into that because I'm no point [i.e., no good] to anybody if I get hooked in their emotions in a way.' By noticing what is going on in our body, we can influence how we behave when we have an emotional reaction (Smith et al., 2017). Helen's comment creates awareness that we are not always able to control our emotional responses, and for some facilitators this may be scary, as it can be for group members. As well as observing themselves, facilitators also need to read non-verbal body language and tone of speaking that can provide cues for group members feeling emotions. Indications of feeling emotional can include a hot flush to cheeks or neck, touching the face, facial expressions, body posture, hand movements, eye movements, and changes in breathing and loud or mumbled comments (Kuiken, 2019; Rogers \& Farson, 1987). McDonnell and Cook (2019) comment that discussion within creative bibliotherapy is very different from having a normal chat and describe it more like a collaboration of thoughts as the group members allow themselves to open up, with each other and the facilitator. Usually 'the only people you do that with are very close friends, partners and therapists but there is always a comeback to whatever you say: in this there isn't. There is never any judgment. When you read something or say something there's no return to the therapist' (McDonnell \& Cook 2019, p. 149); that is, no one is considered the expert and there is a sense of working it out together. However, working with emotions is not for everyone. The possibility that listening to literary texts read aloud will trigger an emotional response is real, as indicated by the research participants and my own experiences. Facilitators need to remember that group members can have emotions triggered, which will have nothing to do with the skills of a facilitator. However, 'as a counter to those who'd consider this [i.e., people being moved by literature] a risk, l'd be 
more worried about the consequences if no-one is willing to take it' (Davis, 2012).

\subsubsection{Emotions and literary texts}

Pehrsson and McMillen (2005, p. 6), in their article titled 'Grounding counselors in the therapeutic use of literature', assert that literary texts 'can serve as a vehicle for expressing emotions'. In creative bibliotherapy, facilitators have to connect with literature differently from just making recommendations of a good read; this is particularly true for librarians who have become facilitators. Kim, a librarian, describes the necessary change in thinking:

I began to think well, I do know this stuff. I know this is writing and this is literature, this is my thing. So what I'm saying is - once I was comfortable again with the fact that yes, that's my area, this is my zone, moving across to using that area of comfort with other people, the transition was easier if that makes any sense.

Not all facilitators were able to make that transition so smoothly. Cheryl admitted she was scared of 'poetry and short stories.' Many of the research participants had previously confided to me (in my capacity as the Book Well training program coordinator) that they felt worried about a lack of knowledge of classic literature, short stories and poetry. I (as a bibliotherapist) could understand the research participants' angst, as I similarly did not have a great deal of knowledge of short stories or poetry early on. What I did learn quickly was to recognise the power of these forms of literary texts. Short stories and poems have high visibility of words that can provide particular focuses on feelings and experiences. I discovered that I had to approach short stories and poetry from an emotional point of view and discover in them the words which were useful to explore from a therapeutic point of view and linking to common to psychological, social and emotional challenges. Additionally, the format of 'short' pieces of literary texts can help people be open to listening to them. What I have found is that when the right words are read aloud they can engage an 'individual's imagination, whether reading is enjoyed or not' (McLaine, 2012, p. 7). I have come to appreciate short stories and poetry as art forms, and longer forms often do not capture my imagination or move me in the same way. Helen, one of the research participants, puts my feelings into words, describing working with poetry as 'what they're [i.e., the poems] doing is emotions, emotions, emotions, images, images, vivid images... it's like almost an arrow.' In creative bibliotherapy groups, a short story is often read first, and discussed, followed by the reading of the poem. Helen felt that 'the story [i.e., 
the stories used in creative bibliotherapy] just sets a scene for the poems.'

Jane felt, 'the poem does it all. The poem brings everybody back into the same space again and then completes the cycle and they [i.e., group members] always find there is a calmness at the end.' Poetry never fails to assist in finding thoughts and feelings and involves new perspectives on ideas, representations, images and words (Lewis et al., 2000; Martins, 2018; Phillips \& Davis, 2019). Jane provides an example of understanding when her group members have emotionally engaged with a literary text: 'you could hear this collective sort of sighs around the room. It was a feeling that was being expressed in a sound, a sigh. You only do that if you're engaging emotionally... a good text is going to hit them in the guts.' Jane's comment indicates that emotions are part of creative bibliotherapy and facilitators need an understanding of emotions within the therapeutic process. They may not need to do anything in particular but understanding emotions within the therapeutic process supports the facilitator in working with groups. The facilitator's primary role is to offer group members access to literary texts and to provide guidance to key concepts to be discussed (Jarjoura et al., 1998). Facilitators need to remember that it is the group member's choice to respond to the concepts presented in the literary texts, through choosing to take part in the discussion or not. Facilitators also need to remember that literary texts can help people realise emotions, and the result can be that emotions deep inside are then able to be expressed and shared. However, facilitators are not there to do the 'follow up therapy', only to help group members engage with literary texts, and it is up to group members who find their emotions through the literature engagement to act on them or not, not facilitators. What might be reasonable for facilitators is to develop an understanding of the emotional role within the therapeutic process and to work within a 'safe context'; that is, have the ability to call on a backup service provider for both themselves (to ask for guidance) and group members (for mental health support).

An experience from Cheryl illustrates the importance of understanding emotions within the therapeutic process. Cheryl spoke of her manager unexpectedly experiencing an emotional response when Cheryl ran a bibliotherapy session for her colleagues after returning from the training (as described earlier). Cheryl spoke of him being 'adamant that this was not the role of a librarian to be involved in stuff like this... He was dead against it'. As discussed in Chapter 6.2.1: Forming organisational alliances to run bibliotherapy groups, as a result of 
Cheryl's boss' reaction Cheryl went on to set up a very supportive alliance that was a pivotal factor to the success her program achieved.

Another important aspect of emotions is that facilitators need self-awareness of their own emotions and emotional triggers. To support group members' engagement with literary texts, facilitators need to suspend their emotional reactions, judgments, biases, solutionseeking and hypothesising. Isaacs (1999) refer to this as 'suspension' from inner dialogue. Coburn and Edge (2007, p. 20) describe this as 'taking leave', as a way to express standing your own emotions aside and making room for the emotions of others. Facilitators need to make their emotions, habits of thinking, prejudices, and biases transparent to themselves so that their listening and behaviour in conducting the group will be as free of judgment and emotional reaction as possible. Equally, also need to note that at times their own emotions, habitual thinking and judgments will automatically direct their thinking and behaviour, and that when this happens, recognise it and return to a less personal way of leading the group.

\subsubsection{Emotions and meaning-making}

Rubin (1978a \& 1978b) maintains that central to using imaginative literature to affect wellbeing is to discuss the text after reading. Dr Kathryn Naylor who facilitates a shared reading group at Ashworth Hospital, a high-security psychiatric institution in Liverpool, UK, describes how she supports the group members to realise emotions is by asking her group members to 'imagine' what the narrative being read aloud is 'like'; that is 'the things that are not in the words' (Benefield et al. 2019, p. 428). Panksepp (2008) suggests using a playful, curious, lightness in exploration, not-knowing stance when exploring emotions in a literary text. Jane spoke about the way she does this in Chapter 6.5: Group discussion:

I use a very vague tone of voice, so that the impression I'm trying to give is that, I don't know either. I'm in here with you. What do you think? What's happening here? How do you feel?

Creative bibliotherapy provides group members with a safe space which allows them to consider their issues or challenges with an emotional buffer through discussion of the key concepts presented in the literary text and allowing time for reflection (Carlson, 2001). Moments for reflection help group members to reconnect with themselves and increase self-awareness. In this way, creative bibliotherapy can facilitate new emotional experiences and emotional development (Gold, 2001). 
As group members get to know each other in a more deep and profound way, it can have therapeutic benefits. This joint emotional experience supports acceptance, curiosity and empathy, enabling the group members to become more accepting, non-judgemental, empathic and playful in getting to know each other even more. The process at the most fundamental level is reciprocal. Meaning-making in this way 'produces a new kind of emotional atmosphere' (Farrington et al., 2019, p. 56), which adds to the therapeutic benefit.

This emerging intimacy of the group may have an impact on the facilitator, as well as the group members. Hughes (2009) says that when a facilitator experiences moments of connection with group participants through the shared experience of texts being read aloud and discussed they are transformed by the experience themselves. Facilitators describe magic moments of being touched by what they bring to the group, and what the group members give back to them, as an earlier example from Cheryl demonstrates:

One of my magic moments was when we read from Silas Marner... The way that they [i.e., group members] sat with baited breath, it was just magic.

Cheryl spoke about this being a 'magic moment' for her in that she was also transformed by the experience. Cheryl said she, 'would never in a million years have thought that you could go and read to these people [i.e., people with intellectual, emotional and psychological challenges] and that they would be able to relate to in any way, let alone be able to open up and express, even in small ways, deeper emotions.' Natalie also commented on the capacity of 'the texts and poetry as the vehicle to have that shared moment.

Fosha et al. (2009) assert that emotions play a central role in psychological healing and Gold (2001) maintains that literary texts support emotional development through facilitating new perspectives of challenges. The emotions need to be involved for insight to develop. Group members listen to a text read aloud from a particular 'distance' which affects the involvement of emotion (Berns et al., 2013; Gholamain \& Oatley, 1997; Oately, 2009; Oatley \& Kerr, 1999; Rosenblatt, 1995).

'Over-distance', could be considered an intellectual reading of a story without the engagement of the emotions or connection to one's own life experiences. Over-distance is an avoidant reading style, distancing oneself from involvement and, therefore, emotions. 
'Under-distance', is still in a raw emotional state and unanalysed. At this distance, the reading is all emotion and no reflection. Readers either get the better of the emotion through making sense of them or become overwhelmed in the uprush of emotions.

'Optimal-distance', integrates thought and emotion in a meaningful way. The reader can connect the remembered memory to the self and incorporate it into current life.

Oatley and Kerr (1999) emphasise that optimal distance supports making sense of emotions, allowing readers to relive their personal experiences, but under gentler conditions.

Understanding how the reading process supports wellbeing validates the value of creative bibliotherapy.

Research (Davis, 2016; Eagleton, 2003; Longden, 2015) indicates that actively involving readers in responding to what they have read, through interpreting the literary texts to make meaning, brings more emotional significance to the lines of a poem or story. Iser $(1974$, p. 294) describes this as a process that 'brings to the fore an element of our being of which we are not directly conscious... and so [we] discover what had previously seemed to elude our consciousness'. Emotional connection with the text and other group members is at the core of wellbeing. A significant difference to traditional therapy that may influence the effectiveness of creative bibliotherapy is that in the latter form, participants 'choose whether or not and to what extent [they] wish to engage with the emotional content of the literature' (Jones et al. 2019, p. 439).

When connecting emotionally is met with an attitude of acceptance, curiosity and empathy, the experience of deep engagement is rich and is transforming for both group members and facilitators. Natalie described feeling this:

We were all there floating around in a bubble all together as a group and there was just this unspoken camaraderie between all of us. It was this real sense of calm and this real sense of, I don't know, you felt we'd all been uplifted in the room upon exit out the doors. And that every single member of that group, including the facilitators, had created that atmosphere. It wasn't just left up to the one person.

\subsection{Chapter Seven concluding comments}

Using IPA hermeneutic processes of the double hermeneutic and hermeneutic circle further meaningful consideration of the relationship between 'biblio' and 'therapy' was revealed.

Chapter Five discussed the 'biblio' component being considered a constant factor in creative 
bibliotherapy. Chapters Six and Seven discussed 'therapy' as the variable factor in creative bibliotherapy. The research has revealed that the critical variable is not what the facilitator says or does, but of utmost importance is the quality of the relationship between the facilitator and group members.

Hermeneutics has allowed for further richness around understanding 'therapy' in critical bibliotherapy, and that the critical factor is not the skills of a facilitator; it is the attributes and attitudes they bring to the process that positively affect wellbeing. This knowledge opens up a far broader understanding of therapeutic processes and the opportunity for therapy to be delivered by non-clinically trained facilitators. The wellbeing result of creative bibliotherapy can be strengthened through greater understanding of the core conditions that can improve the outcome of achieving therapy, and therefore wellbeing.

Chapter Seven directly addresses the aim of the research study to analyse bibliotherapy group facilitators' perspectives of their creative bibliotherapy training in relation to the 'biblio' and 'therapy' elements, and how they can be developed and applied to support the promotion of the wellbeing of individuals and groups. The participants' interview data enabled a deeper exploration of the understanding of the relationship between 'biblio' and 'therapy', and of the universal elements of traditional therapy.

Chapter Eight, the final, conclusive chapter, will provide an overview of the research; summarise this study's contribution to current knowledge; outline limitations of this research, provide recommendations for future bibliotherapy training, and suggestions for future research. 


\section{Chapter Eight: Conclusion}

Chapter Eight brings together the main findings from the research. Culminating experiences from seventeen research participants from across Victoria will be presented in a summary of the research findings in relation to the research question: How can the understanding of the relationship between 'biblio' and 'therapy' be developed in non-clinical facilitators and applied to support the promotion of the wellbeing of individuals and groups in society?

\subsection{Broad research findings}

Traditional bibliotherapy (that is, self-help bibliotherapy) has been researched comprehensively internationally to create an evidence base to support the use of bibliotherapy as a useful treatment for psychological illness. Creative bibliotherapy is a more recent innovative iteration of bibliotherapy using literary texts. Comparable to previous studies, this study found evidence to support creative bibliotherapy as a positive intervention to promote good mental, social and emotional health and wellbeing. Although creative bibliotherapy is developing a reasonable evidence base, previous research has focused on the different disciplines that offer various forms of bibliotherapy, and those who take part in these various forms of bibliotherapy, rather than those who deliver it.

\subsection{Overview of the research findings}

The data revealed two main elements affecting the delivery of creative bibliotherapy in Australia:

- The preferred form of creative bibliotherapy in Australia differs from the Get Into Reading program model taught in the training and as delivered in the UK. In Australia, the desired outcomes are different, requiring unique training in order for facilitators to successfully deliver both the 'biblio' and 'therapy' elements as a unified whole.

- There is a therapeutic element present in creative bibliotherapy that can be delivered by non-clinical facilitators and influence the wellbeing of group participants.

The above key findings will be discussed in more detail below.

\subsection{Key findings in the Australian program}

This section will look at the key findings of the research to better understand the 'biblio' and 'therapy' elements of creative bibliotherapy and how to develop it further within an 
Australian context.

\subsubsection{Social connectedness}

Like previous studies, this study found that creative bibliotherapy supports psychological and emotional challenges to promote positive social change. 'Sociologists define social change as changes in human interactions and relationships that transform cultural and social institutions' (Spanos Dunfey, 2019). Gray et al. (2019, p. 382) establish that 'reading groups have demonstrated an ability to build community and promote social interaction and social inclusion'. Delivered by appropriately trained facilitators, creative bibliotherapy can support individuals in community interactions and offers a way to feel a sense of belonging, especially for those experiencing social isolation. Creative bibliotherapy allows individuals to connect with other community members and develop a social network. Abels and Abels (2002) assert that bibliotherapy is not therapy in the sense of treatment but therapy in the sense of social change as defined above in relation to human interactions. Within a social change context, creative bibliotherapy could be seen as aiming to improve the quality of lives of vulnerable people fundamentally.

Rosenblatt (1938) describes how creative bibliotherapy participants take on an active cocreator role through discussion, by helping one another to hear words and see images. Ellis et al. $(2019$, p. 75$)$, bring light to this process of social change within a reading group, and the importance of the role of the facilitator in the process:

It is often the case that puzzlement or difficulty itself initiates group meaning-making... my function as group leader is not so much to direct, as to hold, or hold open, thoughts and ideas. Sometimes I capture aspects of participant contributions which help whole group understanding or which return us to a tiny detail-a word, phrase. Just as critical, however, is that the mode and quality of human attention to the participants is analogous to the attention given to the book or poem. The group leader must be an alert witnessing presence in relation both to the literature and the individuals.

Research participants' interview data demonstrated that creative bibliotherapy supports social wellbeing through reducing social isolation and increasing social interaction opportunities. 


\subsubsection{Shared listening}

An important finding from the data collected was that 'shared listening' was more important for the promotion of wellbeing in the Australian context than the UK standpoint of 'shared reading' (Chapter Four). Chapter Six discussed listening skills required for facilitators to deliver bibliotherapy in Australia and assist in developing group members' capacity to listen in reading groups for wellbeing outcomes. This is a new aspect for bibliotherapy and requires new skill development.

\subsubsection{Literature as a therapeutic tool}

The UK Get Into Reading groups found the significant main action was providing '(a) rich, varied, non-prescriptive diet of serious literature' (Billington et al. 2010, p. 6). However, Brewster, a UK bibliotherapy researcher, (2011) points out that several of her informants reported that the act of reading and discussing the text was more important than the specific works read in helping them deal with their psychological problems. Oately \& Kerr (1999, pp. 663-665) state that the task of all fiction writers is to create a literary text 'that has a certain kind of effect on the reader... and to suggest thoughts that might make sense of emotions in terms of goals of oneself and others'. Oately \& Kerr, like Brewster above, do not see this process as only possible using serious classic literature but the possibility lies in the realm of all literary texts. Mar \& Oately (2008, p. 178-187) similarly state it is the actual content of the material that affected readers' responses, not expectations derived from the genre of text they read. Stories that are engaging, well-written, and artfully constructed... [with] characters that possess a recognizable psychology... A science-fiction novel that takes place on a distant space station may have greater psychological realism' than more classic stories. What seems important is providing a meaningful way to connect to the story. This study, from the point of view of Australian facilitators, also found no emphasis on the importance of serious, 'classic' literature, and determined that stories selected to engage specific groups were most successful.

\subsubsection{Meeting requirements of public libraries into the future}

Public libraries, as part of local municipalities, are required to think strategically to support the promotion of the wellbeing of individuals and groups in society as indicated in Chapter 6.1.2: Motivations to provide community wellbeing programs. As a way of supporting and 
developing public library strategic thinking, regular research is undertaken by State Library Victoria (SLV) and the Public Libraries Victoria Network (PLVN) to consider how they can best prepare individual library services and, more broadly, the Victorian public library network, for the future. The key outcome of research conducted in 2013 was the development of a plan entitled 'Victorian Public Libraries 2030 Strategic Framework' (State Library Victoria et al., 2013) which presented two scenarios of the future of Victorian public library spaces: a 'creative' scenario and a 'community' scenario. The 'creative' scenario suggests programs that meet the community's wants and needs for creative development and expression. Whereas the 'community' scenario is about offering programs that provide social connection and the opportunity to participate in something in a safe and facilitated way. The idea of using library collections and spaces - both core library investments - for creative bibliotherapy to support the promotion of the wellbeing of individuals and groups in society is a good fit with both the creative and community future library scenarios.

It is important to consider the skills that 'creative' and 'community' librarians in the future will need. In 2014, the report 'Victorian Public Libraries: Our Future, Our Skills' (Hallam, 2014) was produced for SLV and the PLVN. This report incorporated a skills audit of Victorian public library staff to collect evidence of current skills and to anticipate future skills requirements. The data was interpreted through the lenses of the 'creative' and the 'community' library scenarios and used to develop a framework to articulate the core competencies required by the public library workforce for the remainder of 21st century.

The staff who deliver programs and services in the future will continue to draw on some of their more traditional skill sets (for example, information seeking, resource management, people management, project management, and marketing and promotion) however, the report asserts that 'both future scenarios will depend on the ability to build strong partnerships and alliances with other agencies' (Hallam 2014, p. 4). The report showed that only $9.6 \%$ of Victorian public librarians rated themselves as very confident in their skill level for building partnerships (on a Likert scale), despite managers ranking the importance of this skill at $82.1 \%$. The most critical skills noted are those relating to community development, especially related to issues of social inclusion in two capacities: firstly, establishing productive relationships with other community groups; secondly, public library staff must also understand the role of programs that will foster social inclusion and support 
community engagement.

In considering the skills that future library staff will need, David Lankes, a passionate advocate for librarians and their essential role in today's society, believes that public library staff must adapt to their community needs, social drivers and political philosophies instead of adopting those of others, or assuming that communities need and will respond to the same things. He states that the continued evolution of librarianship toward a proactive force for good in a community will change the necessary skills of librarians, the responsibilities of the community, how we assess success, and how we determine common services while focusing on local realities' (Lankes, 2019).

\subsection{Answering the research question}

How can the understanding of the relationship between 'biblio' and 'therapy' be developed in non-clinical facilitators and applied to support the promotion of the wellbeing of individuals and groups in society?

The thesis is focussed on the research participants' perspectives of the training they undertook in Melbourne, 2010 for facilitation of creative bibliotherapy. This context underpinned the research aim and objective, and the research question (as given above). The research participants' training experiences informed the researcher's understanding of the relationship between 'biblio' and 'therapy' in creative bibliotherapy as it is currently understood by facilitators; and how that understanding could be developed in training for more effective delivery of creative bibliotherapy to support wellbeing (see 8.6 Recommendations for future bibliotherapy training).

The data from this research suggest that a bibliotherapy facilitator's individual attributes and therapeutic techniques, based on Rogers's core conditions of unconditional positive regard, empathy, and congruence, positively influence wellbeing. This study found six significant techniques that non-clinical facilitators can apply to support the promotion of wellbeing:

1. Providing the therapeutic core conditions of positive regard, empathy and congruence

2. Developing knowledge of working with emotions

3. Developing skills in listening

4. Developing knowledge of working with groups and facilitating group discussion

5. Selecting literary texts to engage specific groups 
6. The use of prosody of reading the literary texts out loud.

Current creative bibliotherapy practice is more heavily biased towards 'biblio' elements but the research shows that more knowledge and understanding of 'therapy' within creative bibliotherapy is necessary to achieve the desired wellbeing outcomes. Analysis of the data has revealed the need to include 'biblio' and 'therapy' more equally and that the research participants wanted more 'therapy' training.

This is new knowledge in the field of creative bibliotherapy and future training should incorporate these techniques (see Section 8.7.1: Bibliotherapy training - recommendations, below).

\subsection{Limitations of the research}

1. A limitation of the research is that data was not collected from participants in reading groups for this study; the perspectives reported and analysed are from the facilitators' point of view only. Future research examining the perspectives of those participating in a group would complement the findings related to wellbeing outcomes.

2. A transcription service was used for all the recorded interviews. Any limitations in regard to this were minimised by the use of my own field notes to support the transcription.

3. Participant's recollections of the training may have been compromised due to the gap between undertaking the training in 2010 and the research interviews in 2013.

4. In Section 3.1.4.1 I discussed reflexivity and the importance of self-reflection for the researcher within an IPA study. This is because of the dual role a researcher holds in the IPA process, in which the researcher's beliefs, values and experiences are considered valuable to the analysis of data collected and significant in adding depth to the research discussion.

Probst and Berenson's (2014) work on the use of reflexivity was influential in developing my awareness that I needed to reflect on how my own experience could influence the research process and consider biases that had the potential to affect the research study.

Through self-examination, I recognised the impact of biases within my own research process. The first bias was regarding the stake I had in positioning myself as a bibliotherapy 'expert. This realisation grew after several interviews when I realised that being open to considering the participants' own encounters and experiences in bibliotherapy exposed me 
to things I had not experienced myself. This deepened my understanding of bibliotherapy, growing my knowledge and developing my level of expertise, and opening up meaning that otherwise might have remained invisible. This freed me of my notion of being 'the expert' and enabled me to be a more objective and engaged researcher.

The second bias was that my role as Coordinator of the Australian training being examined in this research made me feel some responsibility for the research participants' experience of the training. This realisation required me be aware that the research participants' experiences were not my responsibility. I became cognizant of the need to allow others to have their own experience and not place expectations on them.

I believe I counteracted possible biases by taking a stance of remaining engaged in an action of introspective reflection to foster reflexivity. I believe introspective reflection has made me a more self-aware researcher.

5. A counterpoint to my personal consideration of the relationship between myself and the research participants is that the research participants may have felt constrained in their responses to some questions by being interviewed by the person responsible for the training. Their feelings in regard to this are unknown.

In future IPA research, I would again choose to conduct a manual analysis as recommended by leading IPA researchers. It allowed me to stay close to the data, particularly the emotional aspects, and find the 'gems' as described by Smith in the Hermeneutic circle (Chapters 3.1.5.1 and 7.1.1). It would be harder to find the 'single utterances and small passages from a participant's transcript [that added] potent analytical leverage' (Smith, 2011c, p. 6) to this study without manually analysing the transcripts using dual-level IPA coding (Chapter 3.1.3.5: Manual analysis).

Also in relation to future research, I found the data from the three research participants who had been reluctant to undertake the training extremely revealing. These three research participants would make a fascinating study in themselves, exploring how their negative expectations were positively replaced. 


\subsection{Recommendations for future creative bibliotherapy training}

The research data suggests that rather than needing a clinical background to deliver bibliotherapy effectively, facilitators need a variety of skills and knowledge: an awareness of the therapeutic core-conditions of unconditional positive regard, empathy and congruence, and the ability to provide them, and knowledge of working with emotions; skills in listening; working with groups and facilitating group discussion; and skills in literary text selection and using prosody reading it aloud.

The research participants revealed in their interviews that while they enjoyed the training and found aspects of the training useful and relevant the separate elements of 'biblio' and 'therapy' were only addressed very broadly within the training manual and delivery.

This study revealed that there were creative bibliotherapy techniques, vital to the success of the Australian groups (above in Section 8.5: Answering the research question), which were only very broadly addressed in the unpublished manual created by TRO and the training in Australia, as summarised below:

Table 5: Techniques for training in creative bibliotherapy

\begin{tabular}{|c|c|}
\hline $\begin{array}{l}\text { Required Australian creative bibliotherapy } \\
\text { techniques }\end{array}$ & $\begin{array}{l}\text { Required techniques as addressed in GIR } \\
\text { training and training manual }\end{array}$ \\
\hline $\begin{array}{l}\text { 1. Providing the therapeutic core conditions } \\
\text { of positive regard, empathy and } \\
\text { congruence }\end{array}$ & $\begin{array}{l}\text { - Group members are all individuals - don't } \\
\text { generalise } \\
\text { - Mental health symptoms and medication } \\
\text { can affect group members' participation } \\
\text { - Group members may be socially difficult } \\
\text { - Group members may not attend regularly }\end{array}$ \\
\hline $\begin{array}{l}\text { 2. Developing knowledge of working with } \\
\text { emotions }\end{array}$ & $\begin{array}{l}\text { - Be aware of group members' emotions } \\
\text { - Accommodate or resolve group } \\
\text { members' emotions to avoid discomfort } \\
\text { and distraction }\end{array}$ \\
\hline 3. Developing skills in listening & No specific instruction provided \\
\hline $\begin{array}{l}\text { 4. Developing knowledge of working with } \\
\text { groups and facilitating group discussion }\end{array}$ & $\begin{array}{l}\text { - Read people as well as the literature } \\
\text { - Offer a friendly, democratic social } \\
\text { environment while still maintaining a }\end{array}$ \\
\hline
\end{tabular}




\begin{tabular}{|c|c|}
\hline & $\begin{array}{l}\text { facilitator role } \\
\text { - Set tone for interaction and guide group } \\
\text { discussion, especially with regard to } \\
\text { emotions and personal revelations } \\
\text { - Develop group on a social and personal } \\
\text { level } \\
\text { - Build a relationship with the reading } \\
\text { resources } \\
\text { - Develop understanding of literature } \\
\text { - Prepare texts for delivery and discussion } \\
\text { O Understand the ideas and thoughts } \\
\text { O Be flexible } \\
\text { - Accept not knowing or understanding } \\
\text { something } \\
\text { discussion }\end{array}$ \\
\hline $\begin{array}{l}\text { 5. Selecting literary texts to engage specific } \\
\text { groups }\end{array}$ & $\begin{array}{l}\text { - Texts should be accessible, without being } \\
\text { - } \text { - Choitronising, and rewarding } \\
\text { emotions } \\
\text { - Texts should be engaging } \\
\text { - Facilitators should relate to the literature } \\
\text { - Texts should go beyond story to reveal a } \\
\text { 'universal human core' } \\
\text { - Focus on 'reading for serious pleasure' }\end{array}$ \\
\hline $\begin{array}{l}\text { 6. The use of prosody of reading the literary } \\
\text { texts out loud }\end{array}$ & $\begin{array}{l}\text { - Allow time for group members respond } \\
\text { - Don't feel you have to fill silences } \\
\text { - Demonstrate that you are listening to } \\
\text { what people say with eye contact, } \\
\text { responding, and allowing people to finish } \\
\text { what they are saying } \\
\text { - Slow down } \\
\text { - Demonstrate emotional sincerity } \\
\text { - Assign group members to read aloud } \\
\text { (Note that GIR promotes group members } \\
\text { reading). }\end{array}$ \\
\hline
\end{tabular}


The research data analysis chapters identify and describe in detail the following critical components of training to guide future delivery of creative bibliotherapy in Australia:

1. Strong knowledge of literature and the ability to select accessible literary texts focused on improving people's wellbeing (Chapter Five).

2. An improved understanding of 'therapy' within bibliotherapy, increasing personal and professional confidence (Chapter Seven).

3. Skills in building program alliances and partnerships that interface with other community health service providers in the areas of health and wellbeing (Chapter Four and Six).

4. Good leadership qualities and a comprehensive understanding of group work (Chapter Six).

Fourteen key recommendations for inclusion in future creative bibliotherapy training from the analysis chapters are provided below.

\subsubsection{Bibliotherapy training - recommendations}

The recommendations are for inclusions in training for creative bibliotherapy for its successful delivery. They are labelled as personal skills and facilitation skills to be developed during training. The recommendations have been derived from analysis of the research participants' interview data, collected to address the aim and objective of the research project to consider the participants' perspectives of the creative bibliotherapy training they undertook in 2010, and its ability to prepare them as bibliotherapy facilitators promoting wellbeing in individuals and groups. The recommendations directly address the research question 'How can the understanding of the relationship between 'biblio' and 'therapy' be developed in non-clinical facilitators and applied to support the promotion of the wellbeing of individuals and groups in society?'

\subsubsection{Recommendation one (personal): Core conditions}

A new finding from the data is that providing the therapeutic core conditions of unconditional positive regard, empathy and congruence are necessary to produce positive change and successfully achieve wellbeing outcomes. Developing an understanding of the core conditions is essential for facilitators to comprehend how to achieve therapeutic results. 


\subsubsection{Recommendation two (personal): Building on personal attributes}

Facilitators already working in community helping professions may already have some or all of the attributes and ethics that support providing the therapeutic core conditions of positive regard, empathy and congruence. Enabling insight into, and evaluation of, personal attributes, and encouraging their development in relation to delivering creative bibliotherapy should be included in training.

\subsubsection{Recommendation three (personal): Self-awareness}

Providing the core conditions depends on individual facilitators understanding their own thoughts and feelings during a creative bibliotherapy session. To make conscious choices about our behaviour, we need to become aware of our intentions and the impact of our actions on others. Reflective practice in relation to delivering creative bibliotherapy is an important skill to develop.

\subsubsection{Recommendation four (personal): Pre-training therapeutic transparency}

A self-rating scale of the applicable skills and attributes required for creative bibliotherapy facilitation, particularly in relation to the therapy aspect, needs to be constructed so that potential facilitators can have a better expectation of the role requirements before making a choice to undertake training, and a better understanding of their individual needs from the training.

\subsubsection{Recommendation five (personal): Establishing bibliotherapy as a therapeutic offering}

Those delivering bibliotherapy need to understand clearly what they are attempting to do, and to think of themselves as 'bibliotherapy advocates' for the practice and its therapeutic benefits. A clear understanding of 'bibliotherapy' as a technique that helps support people through emotional, social and psychological challenges via literature, to assist them to make a change in outlook or perception, may be a factor in removing the fear of delivering 'therapy.' Additionally, skills in advocating for creative bibliotherapy as a method for supporting community wellbeing may assist in obtaining an investment in time and funding by employing or partner organisations. 


\subsubsection{Recommendation six (facilitation): Group therapeutic transparency}

Facilitators should open sessions stating a clear purpose, including the wellbeing or 'therapy' context of the group, to help the group members understand why belonging and contributing to the group are worthwhile. Group members may have no idea they are undertaking a therapy-based program with the possibility of consequent emotions. Even though participating in a reading group is not therapy, it has therapeutic results, and group members need to be prepared for emotions arising as a result. As part of their training facilitators should develop a script for introducing their sessions.

\subsubsection{Recommendation seven (facilitation): Groupwork knowledge} More knowledge of groupwork, and skill development for managing groups would further enhance the success of creative bibliotherapy delivery.

\subsubsection{Recommendation eight (facilitation): Listening awareness and development}

Research findings highlighted the Australian experience of the importance of shared listening versus shared reading towards developing a wellbeing outcome. Facilitators need to develop deeper listening skills for themselves, including greater attentiveness to nonverbal emotional cues such as facial expressions, body language, gestures and silence, and guide group members in developing their own listening skills. Facilitators should also prepare themselves for listening carefully prior to delivering a creative bibliotherapy session.

\subsubsection{Recommendation nine (facilitation): Emotional complexities}

Creative bibliotherapy facilitators from non-clinical backgrounds need to feel better prepared to deal with any emotional reactions that may arise within groups, to recognise the challenging and uncertain nature of emotions, and therefore increase their confidence to offer bibliotherapy despite the uncertainty of emotions. Additionally, facilitators need to understand that group members may be triggered emotionally by the text being read and discussed and this may have nothing to do with their facilitation.

Facilitators must become good at paying attention to signs, including reading non-verbal body language, that show whether group members feel at ease or not, or are emotionally 
affected.

\subsubsection{Recommendation ten (facilitation): Selecting literary texts}

Facilitators should work with delivery partners to develop an outcome-focused framework that defines the aims of a program and individual sessions, including the therapeutic outcomes desired by the partner organisation. These aims and outcomes will in turn influence the selection of literary texts. Texts selected should be directly related to each program or session and training in selection is required.

\subsubsection{Recommendation eleven (facilitation): Engaging with literary texts}

A facilitator's role is to offer access to suitable literary texts and provide support for and guidance on ways to listen and take part in discussions about the literature for a therapeutic outcome. Knowledge and skills of the reading process and meaning-making are vital.

\subsubsection{Recommendation twelve (facilitation): Audience awareness}

Having prior knowledge and information about the setting for a program, and of the demographics of group members, is essential for facilitators. For example, if facilitators are going into a community adult mental health environment, they need to ensure they are provided with an understanding of some of the issues and experiences affecting these group members. Facilitators need to work with professionals from the service provider to ensure that the program design satisfies the aims in regard to what they are trying to achieve with their marginalised clients.

Another vital aspect is thinking about the needs of the types of people who may take part in a creative bibliotherapy program or session. For example, people lacking connection with other people are likely to come into creative bibliotherapy groups and may find it hard to develop relationships. Often, due to their vulnerabilities, group members are withdrawn, highlighting a need to increase the knowledge and skills required to interact with these people.

\subsubsection{Recommendation thirteen (facilitation): Mental health understanding}

Including potential group participants in facilitator training can support a greater understanding of different settings and issues. 
- People experiencing mental illness could advise. A user of the mental health system could come in and talk about their experiences or sit in on a program to offer feedback.

- A professional mental health worker can help prepare facilitators to know what is happening in those environments and provide some insight into group members' possible responses.

- Facilitators experienced in delivering to groups with mental health challenges could be invited to present to trainees.

\subsubsection{Recommendation fourteen (facilitation): Developing therapeutic alliances}

Facilitators should be prepared for having a 'pre-delivery conversation' to support them in developing alliances with an organisation. Development of a 'kit' to inform setting up a contract between a facilitator's employing organisation, such as a library, and the partner organisation, for example a community mental health service, would support alliances.

\subsection{Chapter Eight concluding comments}

The facilitators' comments presented in the analysis chapters support the notion that creative bibliotherapy facilitation requires particular knowledge and skills. Understanding that the core conditions of unconditional positive regard, empathy and congruence are necessary to produce positive change and successfully achieve therapeutic outcomes is essential not just for future training and delivery of creative bibliotherapy in Australia but also internationally. This understanding clarifies the necessary inclusion of 'therapy' aspects required in future training of creative bibliotherapy facilitators. Understanding the importance of personal attributes and ethics will also support developing the capacity and confidence of facilitators of creative bibliotherapy and may support the development of the practice worldwide, giving it more credibility, acknowledgment and recognition.

I conclude with the words spoken by Cheryl who so strongly did not want to attend the training and was forced to do so:

I just loved it. I'm just so grateful that I had the opportunity to be involved. I'm fortunate that the library service insisted that I go, because I wouldn't have gone, I didn't want to go. So I'm really glad I did because it's opened up a whole new world. I would never in a million years, prior to this training, have thought that you could go and read to these people [i.e., people with intellectual, emotional and psychological challenges] and that they would be able to relate to in any way, let alone be able to open up and express, even 
in small ways, deeper emotions... I love that, I love that part of it. I love the part of it that it - that we take it to people who would otherwise not - I like the fact that - I don't know what I'm trying to say here - I do know what I'm trying to say; I like the fact that we take it to people who are disadvantaged in some way and that we share this stuff with people who we probably - I would never have imagined could benefit from this material. It's yeah, it's just that was revolutionary to me, I guess... I often wish more people would do it. Even with my family sometimes, I wish we could sit down together and read something and talk about it. It's such a great way to open up thoughts and feelings. We could all benefit from it, every single person, I'm quite convinced.

In Cheryl's quote, this experience of facilitating such therapeutic moments was revolutionary, or transformational, to her. In reading groups, facilitators are continuously involved in the act of discovery with group members. When they discover something or see a group member be positively impacted by a moment they have facilitated, it is likely to impact the facilitator as well. Cheryl refers to 'magic moments and Natalie says that the end of a bibliotherapy group 'We just felt like something quite magical had happened.' In examining the relationship between 'biblio' and 'therapy' in bibliotherapy, the use of Aristotle's truism that 'the whole is greater than the sum of its parts' was appropriate. It provided a valuable concept for considering bibliotherapy both for its separate components and in terms of its possibilities as a whole when the elements are effectively combined. 'Biblio' by itself can offer comfort and distraction; however, 'biblio' by itself does not always offer a new perspective or insight into a psychological, emotional or social challenge. 'Therapy' by itself can offer strategies to address emotional or physiological challenges; however, 'therapy' by itself does not always offer new perspectives from listening to literary texts read aloud and then discussed in a group, which can provide a different way to look at a challenge and develop social connection.

As stated, the facilitators at times used the word 'magic' to describe what it felt like was happening in their bibliotherapy groups. The magic of engaging the imagination, safe shared discovery, connection and a sense of belonging, mixed with unconditional positive regard, empathy, and congruence, enables creative bibliotherapy to impact an individual's wellbeing positively. In the hands of a facilitator who understands that they are giving a gift, creative bibliotherapy is indeed magical.

I, like Cheryl, wish more people would take the opportunity to experience and benefit from creative bibliotherapy, both delivering the program and participating in the program. It is a 
way to open up thoughts and feelings and reconnect with yourself and others. The last word in this research study is a call to action: for future training of facilitators of creative bibliotherapy to develop the necessary knowledge and skills to facilitate group members to experience this subtle but powerful form of improving wellbeing of individuals and groups in society. 


\section{References}

Abels, P \& Abels, S 2002, 'Narrative social work with groups: just in time', in S Henry, J East \& C Schmitz (eds), Social work with groups: mining the gold, The Haworth Press, New York, USA, pp. 57-74.

ACT Government n.d., Wellbeing framework: identity and belonging, ACT Government, viewed 14 July 2020, <https://www.act.gov.au/wellbeing/domains-andindicators/identity-and-belonging>.

Agnes, S 1946, 'Bibliotherapy for socially maladjusted children', Catholic Educational Review, vol. 44, pp. 8-16.

Alase, A 2017, 'The interpretative phenomenological analysis (IPA): a guide to a good qualitative research approach', International Journal of Education \& Literacy Studies, vol. 5, no. 2, pp. 9-19.

Allen, KA 2019, 'Making sense of belonging', InPsych, vol. 41, no. 3, viewed 15 September 2020, <https://www.psychology.org.au/for-

members/publications/inpsych/2019/june/Making-sense-of-belonging>.

Allport, GW 1962, 'The general and the unique in psychological science', Journal of Personality, vol. 30, no. 3, pp. 405-422.

American Library Association 2017, Public libraries play vital role in advancing health literacy, American Library Association, viewed 28 July 2020, <http://www.ala.org/news/membernews/2017/04/public-libraries-play-vital-role-advancing-health-literacy>.

Anderson, C \& Keltner, D 2002, 'The role of empathy in the formation and maintenance of social bonds', Behavioral and Brain Sciences, vol. 25. No. 1, pp. 21-22.

Anderson, H 2012, 'Peggy Penn in memoriam: 1931-2012', Journal of Family and Marital Therapy, vol. 38, no. 4, pp. 571-572.

Anderson, P 2000, 'Using literature to teach social skills to adolescents with LD', Intervention in School and Clinic, vol. 35, no. 5, pp. 271-279.

Anderson, P, Zimand, P, Hodges, L \& Rothbaum, B 2005, 'Cognitive behavioral therapy for public-speaking anxiety using virtual reality for exposure', Depression and Anxiety, vol. 22, no. 3, pp. 156-158.

Andersson, G \& Cuijpers, P 2009, 'Internet-based and other computerized psychological treatments for adult depression: a meta-analysis', Cognitive Behaviour Therapy, vol. 38, no. 4, pp. 196-205.

Andrews, DA \& Bonta, J 2010, 'Rehabilitating criminal justice policy and practice', Psychology, Public Policy, and Law, vol. 16, no. 1, pp. 39-55.

Annerstedt, C \& Lindgren, E-C 2014, 'Caring as an important foundation in coaching for social sustainability: a case study of a successful Swedish coach in high performance sport', Reflective Practice: International and Multidisciplinary Perspectives, vol. 15, no. 1, pp. 27-39.

Ansdell, G 1995, Music for life: aspects of creative music therapy with adult clients, Jessica Kingsley Publishers, London, UK. 
Anthony, W, Rogers, ES \& Farkas, M 2003, 'Research on evidence-based practices: future directions in an era of recovery', Community Mental Health Journal, vol. 39, no. 2, pp. 101114.

Apodaca, TR \& Miller, WR 2003, 'A meta-analysis of the effectiveness of bibliotherapy for alcohol problems', Journal of Clinical Psychology, vol. 59, pp. 289-304.

Armitage, S, Parkinson, M, Halligan, S, Reynolds, S 2020, 'Mothers' experiences of having an adolescent child with depression: an interpretative phenomenological analysis', Journal of Child and Family Studies, vol. 29, pp. 1617-1629.

Australian Bureau of Statistics 2020, General social survey: summary results, Australia, Australian Bureau of Statistics, viewed 8 December 2020, $<$ https://www.abs.gov.au/statistics/people/people-and-communities/general-social-surveysummary-results-australia/latest-release $>$.

Australian Centre for Arts and Health 2018, The art of good health and wellbeing, Australian Centre for Arts and Health, viewed 16 April 2020, <https://www.artsandhealth.org.au/app/uploads/2018/11/ACAH_2018Conference_A4Email2.pdf>.

Australian Government 2010, Social inclusion in Australia: how Australia is faring, Australian Social Inclusion Board, viewed 8 December 2020, <https://apo.org.au/sites/default/files/resource-files/2010-01/apo-nid20210.pdf>.

Aveling EL, Martin, G, Herbert, G \& Armstrong, N 2017, 'Optimising the community-based approach to healthcare improvement: comparative case studies of the clinical community model in practice', Social Science \& Medicine, vol. 173, pp. 96-103.

Ayyash-Abdo, H 2001, 'Childhood bereavement: what school psychologists need to know', School Psychology International, vol. 22, no. 4, pp. 417-433.

Azadbakht, E \& Englert, T 2018, 'Promoting student wellbeing through student success collection', in S McNichol \& L Brewster (eds), Bibliotherapy, Facet Publishing, London, UK, pp. 171-180.

Bailey, F 2018, 'Long-term impacts of bibliotherapy groups: reading and writing together', in S McNichol \& L Brewster (eds), Bibliotherapy, Facet Publishing, London, UK, pp. 93-104.

Bailey, RJ \& Ogles, BM 2019, 'Common factors as a therapeutic approach: what is required?', Practice Innovations, vol. 4, no. 4, pp. 241-254.

Bakhtin, M 1984, Problems of Dostoevsky's Poetics, University of Minnesota Press, Minnesota, USA.

Baldwin, M 1987, 'Interview with Carl Rogers on the use of the self in therapy', in M Baldwin and V Satir (eds), The use of self in therapy, Haworth Press, New York, USA, pp. 45-52.

Barclay, KH \& Whittington, P 1992, 'Night scares: a literature based approach for helping young children', Childhood Education, vol. 68, no. 3, pp. 149-154.

Barney, LJ, Griffiths, KM, Jorm, AF \& Christensen, H 2006, 'Stigma about depression and help-seeking intentions', Australian and New Zealand Journal of Psychiatry, vol. 40, no. 1, pp. 51-54.

Bassuk, EL \& Gerson, S 1978, 'Deinstitutionalization and mental health services', Scientific 
American, vol. 238, no. 2, pp. 46-53.

Batson, CD, Lishner, DA \& Stocks, EL 2015, 'The empathy-altruism hypothesis', in DA Schroeder \& WG Graziano (eds), The Oxford handbook of prosocial behaviour, Oxford University Press, New York, USA, pp. 259-281.

Baum, CM 2002, 'Creating partnerships: constructing our future', Australian Occupational Therapy Journal, vol. 49, no. 2, pp. 58-62.

Baumhover, LA \& McNicoll, L 2007, 'Providing a geriatric-friendly environment for the older surgical patient', Perioperative Nursing Clinics, vol. 2, no. 4, pp. 309-316.

Beinter, I, Jacobi, C \& Schmidt, UH 2014, 'Participation and outcome in manualized self-help for bulimia nervosa and binge eating disorder-a systematic review and metaregression analysis', Clinical Psychology Review, vol. 34, no. 2, pp. 158-176.

Benefield, N, Naylor, K \& Magee, F 2019, 'Reading in secure settings', in J Billington (ed.), Reading and Mental Health, Palgrave Macmillan, London, UK, pp. 419 -431.

Benne, KD, \& Sheats, P 1948, 'Functional roles of group members', Journal of Social Issues, vol. 4, no. 2, pp. 41-49.

Berg JS \& Moore, JL 1996, 'A case of "eating disorder NOS": aeromedical implications of DSM-IV diagnostic criteria', Aviation, Space, and Environmental Medicine, vol. 67, no. 2, pp. 157-160.

Berndtsson, I, Claesson, S, Friberg, F \& Öhlén, J 2007, 'Issues about thinking phenomenologically while doing phenomenology', Journal of Phenomenological Psychology, vol. 38 , no. 2, pp. 256-277.

Berns, GS, Blaine, K, Prietula, MJ \& Pye, BE 2013, 'Short- and long-term effects of a novel on connectivity in the brain', Brain Connectivity, vol. 3, no. 6, pp. 590-600.

Bevan, MT 2014, 'A method of phenomenological interviewing', Advancing Qualitative Methods, vol. 24, no. 1, pp. 136-144.

Beyond Blue 2015, Victoria's next 10-year mental health strategy-discussion paper, Beyond Blue, viewed 31 August 2020, <https://www.beyondblue.org.au/docs/default-source/policysubmissions/victoria's-next-10-year-mental-health-strategy_beyondbluesubmission.pdf?sfvrsn=e4aa49ea_2>.

Bi, J-W, Liu, Y, Fan, Z-P \& Zhang, J 2019, 'Wisdom of crowds: conducting importanceperformance analysis (IPA) through online reviews', Tour Management, vol. 70, pp. 460-478. Bien, TH, Miller, W \& Tonigan, J 1993, 'Brief interventions for alcohol problems: a review', Addiction, vol. 88, no. 3, pp. 315-316.

Billington, J 2011, 'Reading for life: prison reading groups in practice and theory', Critical Survey, vol. 23, no. 3, pp. 67-85.

Billington, J 2019, 'Introduction', in J Billington (ed.), Reading and Mental Health, Palgrave Macmillan, London, UK, pp. 1-11.

Billington, J, Dowrick, C, Homer, A, Robinson, J \& Williams, C, Liverpool Primary Care Trust \& The Reader Organisation 2010, 'An investigation into the therapeutic benefits of reading in relation to depression and well-being', The Liverpool Health Inequalities Research Institute, Liverpool, UK. 
Billington, J, Farrington, G, Lampropoulou, S, McDonnell, K, Jones, A, Ledson, J, Humphreys, A-L, Lingwood, J, Duirs, N, Holloway, C \& Smart, B 2016, 'A comparative study of cognitive of cognitive behavioural therapy and shared for chronic pain', Medical Humanities, vol. 43, no. 3, pp. 155-165.

Bird, K 2020, Container, Presencing Institute blog, 10 March, viewed 24 August 2020, $<$ https://medium.com/presencing-institute-blog/containers-458a26083f00>.

Books LLC (ed) 2010, Hospitals in Yorkshire: hospitals in North Yorkshire, hospitals in Sheffield, hospitals in South Yorkshire, hospitals in West Yorkshire, Books LLC, Tennessee, USA.

Bossers, A, Cook, J, Polatajko, H \& Laine, C 1997, 'Understanding the role-emerging fieldwork placement', Canadian Journal of Occupational Therapy, vol. 64, no. 1, pp. 70-81.

Botella, C, Gallego, MJ, Garcia-Palacios, A, Guillen, V, Baños, RM, Quero, S \& Alcañiz, M 2010, 'An internet-based self-help treatment for fear of public speaking: a controlled trial', Cyberpsychology, Behavior, and Social Networking, vol. 13, no. 4, pp. 407-421.

Bower, P, Kontopantelis, E, Sutton, A, Kendrick, T, Richards, DA, Gilbody, S, Knowles, S, Cuijpers, P, Andersson, G, Christensen, H, Meyer, B, Huibers, M, Smit, F, van Straten, A, Warmerdam, L, Barkham, M, Bilich, L, Lovell, K \& Tung-Hsueh Liu, E 2013, 'Influence of initial severity of depression on effectiveness of low intensity interventions: meta-analysis of individual patient data', British Medical Journal, pp. 1-11.

Bowman, D, Scogin, F \& Lyrene, B 1995, 'The efficacy of self-examination therapy and cognitive bibliotherapy in the treatment of mild to moderate depression', Psychotherapy Research, vol. 5, no. 2, pp. 131-140.

Bozarth, JD 2013, 'Unconditional positive regard', in M Cooper, M O'Hara, PF Schmid \& AC Bohart (eds), The handbook of person-centred psychotherapy and counselling, Palgrave Macmillan, London, UK, pp. 180-192.

Bradley, C \& Bosquet, C 1936, 'Uses of books for psychotherapy with children', American Journal of Orthopsychiatry, vol. 6, no. 1, pp. 23-31.

Brady, A 2018, 'Holding space: the art of being present with others', Chopra, 9 February, viewed 24 August 2020, <https://chopra.com/articles/holding-space-the-art-of-beingpresent-with-others $>$.

Branching Out 2015, What is reader development?, Branching Out, viewed 19 December 2015, <http://www.openingthebook.com/archive/branching-out/page2.asp?idno=519>.

Brewster, EA 2011, 'An investigation of experiences of reading for mental health and wellbeing and their relation to models of bibliotherapy', PhD thesis, University of Sheffield, UK, $<$ http://etheses.whiterose.ac.uk/2006/>.

Brewster, L 2008, 'Medicine for the soul: bibliotherapy', Australasian Public Libraries and Information Services, vol. 21, no. 3, pp. 115-119.

Brewster, L 2014, 'The public library as therapeutic landscape: a qualitative case study', Health \& place, vol. 26, pp. 94-99.

Brewster, L, Sen, B \& Cox, A 2012, 'Legitimising bibliotherapy: evidence-based discourses in healthcare', Journal of Documentation, vol. 68, no. 2, pp. 185-205. 
Brewster, L, Sen, B \& Cox, A 2013, 'Mind the gap: do librarians understand service user perspectives on bibliotherapy?', Library Trends, vol. 61, no. 3, pp. 569-586.

Briggs, CA \& Pehrsson, DE 2008, 'Use of bibliotherapy in the treatment of grief and loss: a guide to current counseling practices', Adultspan Journal, vol. 7, no. 1, pp. 32-42.

Brocki, JB \& Wearden, AJ 2006, 'A critical evaluation of the use of interpretative phenomenological analysis (IPA) in health psychology', Psychology and Health, vol. 21, no. 1, pp. 87-108.

Brodley, BT \& Schneider, C 2001, 'Unconditional positive regard as communicated through verbal behaviour in client-centred therapy', in J Bozarth \& P Wilkins (eds), Unconditional positive regard, PCCS Books, Ross-on-Wye, UK, pp. 5-18.

Brown, A 1986, Group work, 2nd edn, Gower Publishing, Brookfield, USA.

Brunero, S 2008, 'The effectiveness of clinical supervision in nursing: an evidence based literature review', Australian Journal of Advanced Nursing, vol. 25, no. 3, pp. 86-94.

Brunwasser, SM, Gillham, JE \& Kim, ES 2009, 'A meta-analytic review of the Penn resiliency program's effect on depressive symptoms', Journal of Consulting and Clinical Psychology, vol. 77 , no. 6 , pp. 1042-1054.

Bryan, A 1939a, 'The psychology of the reader', Library Journal, vol. 64, pp. 7-12.

Bryan, A 1939b, 'Can there be a science of bibliotherapy?', Library Journal, vol. 64, pp. 773777.

Burkeman, O 2015, Does creativity scare you?, The Guardian, 17 October, viewed 4 July 2020, <https://www.theguardian.com/lifeandstyle/2015/oct/16/creativity-frightening-dealwith-fear-oliver-burkeman>.

Burlingame, GM, McClendon, DT \& Yang, C 2018, 'Cohesion in group therapy: a metaanalysis', Psychotherapy, vol. 55, no. 4, pp. 384-398.

Caeiro, C, Cruz, EB \& Pereira, CM 2014, 'Arts, literature and reflective writing as educational strategies to promote narrative reasoning capabilities among physiotherapy students', Physiotherapy Theory and Practice, vol. 30, no. 8, pp. 572-580.

Caplan, A 2004, 'Empathic engagement with narrative fiction', The Journal of Aesthetics and Art Criticism, vol. 62, no. 2, pp. 141-152.

Cardemil, EV, Reivich, KJ \& Seligman, MEP 2002, 'The prevention of depressive symptoms in low-income minority middle school students', Prevention \& Treatment, vol. 5, no. 8, pp. 131.

Carlbring, P, Bergman Nordgren, L, Furmark, T \& Andersson, G 2009, 'Long-term outcome of internet-delivered cognitive-behavioural therapy for social phobia: a 30-month follow-up', Behaviour Research and Therapy, vol. 47, no. 10, pp. 848-850.

Carlbring, P, Furmark, T, Steczko, J, Ekselius, L \& Andersson, G 2006, 'An open study on internet-based bibliotherapy with minimal therapist contact via email for social phobia', Clinical Psychologist, vol. 10, no. 1, pp. 30-38.

Carlbring, P, Nilsson-Ihrfelt, E, Waara, J, Kollenstam, C, Buhrman, M, Kaldo, V, Söderberg, M, Ekselius, L \& Andersson, G 2005, 'Treatment of panic disorder: live therapy vs. self-help via internet', Behaviour Research and Therapy, vol. 43, pp. 1321-1333. 
Carlson, R 2001, 'Therapeutic use of story in therapy with children', Guidance \& Counseling, vol. 16, no. 3, pp. 92-99.

Carr, LT 1994, 'The strengths and weaknesses of quantitative and qualitative research: what method for nursing?' Journal of Advanced Nursing, vol. 20, pp. 716-721.

Carrington, $\mathrm{CH}$ 2006, 'Clinical depression in African American women: diagnoses, treatment, and research', Journal of Clinical Psychology, vol. 62, no. 7, pp. 779-791.

Carroll, M \& Garner, J 2017a, 'Reading in Australian prisons: a history of good intentions and unfulfilled potential', Charles Sturt University, viewed 28 December 2020, $<$ https://researchoutput.csu.edu.au/ws/portalfiles/portal/19680203/ANZHESprisongarner_ and_carroll.pdf $>$.

Carroll, M \& Garner, J 2017b, 'Civilising the uncivilised and morally corrupt: a depiction of reading in Australian penal settlements', abstract for Picturing the Reader, Liverpool Hope University, Liverpool, United Kingdom, 7 September, viewed 28 December 2020, < https://researchoutput.csu.edu.au/en/publications/civilising-the-uncivilised-and-morallycorrupt-a-depiction-of-rea>.

Carron, AV \& Spink, KS 1993, 'Team building in an exercise setting', The Sport Psychologist, vol. 7, no. 1, pp. 8-18.

Cather, C 2007, 'To every reader her book: creating bibliotherapy for women', MA Dissertation, University of Strathclyde, UK, <https://www.academia.edu/204128/To_Every_Reader_Her_Book_Creating_Bi bliotherapy_for_Women>.

Cavanagh, K, Strauss, C, Forder, L \& Jones, F 2014, 'Can mindfulness and acceptance be learnt by self-help?: a systematic review and meta-analysis of mindfulness and acceptancebased self-help interventions', Clinical Psychology Review, vol. 34, no. 2, pp. 118-129.

Centre for Research into Reading, Information and Linguistic Systems (CRILS) 2012, A literature-based intervention for older people living with dementia, University of Liverpool, Liverpool, viewed 12 June 2017, <http://www.merseycare.nhs.uk/Library/Learning/Library_Service/reading_groups/A\%20Lit erature-based\%20Intervention\%20for\%200lder\%20People\%20Living\%20with\%20 Dementia.pdf>.

Chadbourne, SP 1976, 'Bibliotherapy: an overview and the librarian's role', ERIC Document Reproduction Service No. ED 131 426, <https://files.eric.ed.gov/fulltext/ED131426.pdf>, pp. 1-42.

Chalder, T, Wallace, P \& Wessely, S 1997, 'Self-help treatment of chronic fatigue in the community: a randomised control trial', British Journal of Health Psychology, vol. 2, no. 3, pp. 189-197.

Chamberlain, D 2018, 'Developing a reading group service for an older adult functional psychiatric in-patient ward', in S McNichol \& L Brewster (eds), Bibliotherapy, Facet Publishing, London, UK, pp. 117-127.

Chamberlain, D, Heaps, D \& Robert, I 2008, 'Bibliotherapy and information prescriptions: a summary of the published evidence-base and recommendations from past and ongoing Books on Prescription projects', Journal of Psychiatric and Mental Health Nursing, vol. 15, 
no. 1 , pp. 24-36.

Changing Lives Through Literature 2003, Instructional materials, Board of Trustees of the University of Massachusetts, viewed 26 July 2020,

<http://cltl.umassd.edu/resourcesinstruct.cfm>.

Cherry, K 2019, Carl Rogers psychologist biography, Verywell Mind, viewed 8 October 2020, <https://www.verywellmind.com/carl-rogers-biography-1902-1987-2795542>.

Chow, CM, Ruhl, H \& Buhrmester, D 2013, 'The mediating role of interpersonal competence between adolescents' empathy and friendship quality: a dyadic approach', Journal of Adolescence, vol. 36, no. 1, pp. 191-200.

Christensen, H, Griffiths, KM \& Jorm, AF 2004, 'Delivering interventions for depression by using the internet: randomised controlled trial', BMJ, vol. 328, pp. 265-268.

Cimciolo, PJ 1965, 'Children's literature can effect coping behavior', Personnel and Guidance Journal, vol. 43, pp. 897-903.

City of Moonee Valley 2013, Public health and wellbeing plan 2013-17, Moonee Valley City Council, Moonee Ponds, Australia.

Clark, K, Weber, C \& McLaine, S 2019, 'Reading for dementia', in J Billington (ed.), Reading and Mental Health, Palgrave Macmillan, London, UK, pp. 91-110.

Clarke, G, Eubanks, D, Reid, E, Kelleher, C, O'Connor, E, DeBar, LL, Lynch, F, Nunley, S \& Gullion, C 2005, 'Overcoming depression on the internet (ODIN) (2): a randomized trial of a self-help depression skills program with reminders, Journal of Medical Internet Research, vol. 7, no. 2, pp. 2-12.

Cleeves, A 2020, Stories have always been healing, so I'm funding bibliotherapists, The Guardian, 2 September, viewed 2 September 2020, $<$ https://www.theguardian.com/books/2020/sep/02/stories-healing-fundingbibliotherapists-ann-cleeves>.

Coburn, C \& Edge, E 2007, 'Listening to each other: the heart of mediation and dialogue', Australasian Dispute Resolution Journal, vol. 18, no. 1, pp. 19-26.

Cockburn, K 2020, 'Crossing thresholds residential weekend, March 2021', Lapidus Scotland, viewed 26 July 2020, <https://www.lapidusscotland.co.uk/crossing-thresholds-residentialweekend-march-2021/?fbclid=IwAR1SYUv1fU03JLMNHRNaqyG581MhlJwSP5tBbrilAaWeXaBIDsHfLAd1XA>.

Collins, NL 1996, 'Working models of attachment: implications for exploration, emotion and behavior', Journal of Personality and Social Psychology, vol. 71, no. 4, pp. 810-832.

Corbin, J \& Strauss, A 1990, 'Grounded theory research: procedures, canons, and evaluative criteria, Qualitative Sociology, vol. 13, no. 1, pp. 3-21.

Corbin J \& Strauss AC 2014, Basics of qualitative research: techniques and procedures for developing grounded theory, 4th edn, Thousand Oaks, California, USA.

Corcoran, R \& Oatley, K 2019, 'Reading and psychology I. reading minds: fiction and its relation to the mental worlds of self and others', in J Billington (ed.), Reading and Mental Health, Palgrave Macmillan, London, pp. 331- 339.

Corey, G 1986, Theory and practice of counseling and psychotherapy, Brooks Cole 
Publishing, California, USA.

Corey, M, Corey, G \& Corey, C 2009, Groups process and practice, 8th edn, Brooks Cole Publishing, California, USA.

Coulshed, V \& Orme, J 2006, Social work practice: an introduction, 4th edn, Palgrave Macmillan, London, UK.

Coyle, W 1987, Libraries in prisons: a blending of institutions, Greenwood Press, Connecticut, USA.

Crenshaw, DA \& Cannelli, K 2020, 'Reflections on "stealth therapy" in therapeutic residential care', Residential Treatment for Children \& Youth, vol. 37, pp. 244-264.

Cresswell, JW \& Cresswell, JD 2018, Research design: qualitative, quantitative, and mixed methods approaches, 5th edn, Sage publications, USA.

Cronin, C \& Armour, KM 2013, 'Lived experience and community sport coaching: a phenomenological investigation', Sport, Education and Society, vol. 20, pp. 1-17.

Cronin-Davis, J, Butler, A \& Mayers, CA 2009, 'Occupational therapy and interpretative phenomenological analysis: comparable research companions?', British Journal of Occupational Therapy, vol. 72, no. 8, pp. 332-338.

Cronlund, KJ 2008, 'Analysis of positive psychology training at Geelong Grammar School', Masters thesis, University of Pennsylvania, USA, <https://repository.upenn.edu/mapp_capstone/27>.

CSIRO 2018, Future of health: shifting Australia's focus from illness treatment to health and wellbeing management, CSIRO Futures, viewed 28 July 2020, <https://www.csiro.au/en/Dobusiness/Futures/Reports/Future-of-Health>.

Cuijpers, P 1997, 'Bibliotherapy in unipolar depression: a meta-analysis', Journal of Behavior Therapy and Experimental Psychiatry, vol. 28, no. 2, pp. 139-147.

Cuijpers, P 1998, 'A psychoeducational approach to the treatment of depression: a metaanalysis of Lewinsohn's "coping with depression" course', Behavior Therapy, vol. 29, no. 3, pp. 521-533.

Cuijpers, P, de Beurs, DP, van Spijker, BAJ, Berking, M, Andersson, G \& Kerkhof, FM 2013, 'The effects of psychotherapy for adult depression on suicidality and hopelessness: a systematic review and meta-analysis', Journal of Affective Disorders, vol. 144, no. 3, pp. 183190.

Cuijpers, P, Donker, T, Johansson, R, Mohr, DC, van Straten, A \& Andersson, G 2011, 'Selfguided psychological treatment for depressive symptoms: a meta-analysis', PLOS One, vol. 6, no. 6 , pp. 1-7.

Cuijpers, P, Donker, T, van Straten, A, Li, J \& Andersson, G 2010a, 'Is guided self-help as effective as face-to-face psychotherapy for depression and anxiety disorders?: a systematic review and meta-analysis of comparative outcome studies', Psychological Medicine, vol. 40, pp. 1943-1957.

Cuijpers, P \& Schuurmans, J 2007, 'Self-help interventions for anxiety disorder: an overview', Current Psychiatry Reports, vol. 9, pp. 284-290.

Cuijpers, P, Smit, F, Bohlmeijer, ET, Hollon, SD \& Andersson, G, 2010b 'Is the efficacy of 
cognitive behaviour therapy and other psychological treatments for adult depression overestimated?: a meta-analytic study of publication bias', The British Journal of Psychiatry, vol. 196, no. 3, pp. 173-178.

Danaher, T \& Briod, M 2005, 'Phenomenological research with children', in S Greene \& D Hogan (eds), Researching children's experiences: methods and approaches, Sage, London, UK, pp. 217-235.

Davis J 2012, 'Trust and the risks of reading?', blog post, 18 February, viewed 20 March 2019, <http://readerjanedavis.blogspot.com.au/2012/02/trust-and-risks-of-reading.html>.

Davis, MH 1980, 'A multidimensional approach to individual differences in empathy', JSAS Catalog of Selected Documents in Psychology, vol. 10, pp. 85-99.

Davis, MH 1983, 'Measuring individual differences in empathy: evidence for a multidimensional approach', Journal of Personality and Social Psychology, vol. 44, pp. 113126.

Davis, N 2016, Dogs understand both words and intonation of human speech, The Guardian, 31 August, viewed 31 August 2016, <www.theguardian.com/science/2016/aug/30/dogsunderstand-both-words-and-intonation-of-human-speech>.

Davis, P, Corcoran, R, Rylance, R, Zeman, A, Kidd, D \& de Bezenac, C 2019, 'Reading: brain, mind and body', in J Billington (ed.), Reading and Mental Health, Palgrave Macmillan, London, UK, pp. 293-320.

Davis, P, Magee, F, Koleva, K, Tangeras, TM, Hill, E, Baker, H, \& Crane, L 2016, 'What literature can do: an investigation into the effectiveness of shared reading as a whole population health intervention, University of Liverpool, Liverpool, viewed 20 December 2020, <https://research.gold.ac.uk/id/eprint/18847/1/

What\%20Literature\%20Can\%20Do\%202016.pdf>.

de Gelder, B, Morris, JS \& Dolan, RJ 2005, 'Unconscious fear influences emotional awareness of faces and voices', Proceedings of the National Academy of Sciences of the United States of America, vol. 102, no. 51, pp. 18682-18687.

de Graaf, LE, Gerhards, SA, Arntz, A, Riper, H \& Metsemakers, JF 2009, 'Clinical effectiveness of online computerised cognitive-behavioural therapy without support for depression in primary care: randomised trial', The British Journal of Psychiatry, vol. 195, no. 1, pp. 73-80.

Dean, SG, Smith, JA \& Payne, S 2006, 'Low back pain: exploring the meaning of exercise management through interpretative phenomenological analysis (IPA)', in L Finlay \& C Ballinger (eds), Qualitative research for allied health professionals: challenging choices, Whurr Publishers Limited, Chichester, UK, pp. 139-155.

Difede, J \& Blanchard, EB 2005, 'A randomized controlled trial of an internet-based treatment for chronic headache', Behaviour Research and Therapy, vol. 43, no. 3, pp. 277292.

Difede, J, Hoffman, H \& Jaysinghe, N 2002, 'Multimedia reviews: innovative use of virtual reality technology in the treatment of PTSD in the aftermath of September 11', Psychservicesonline, vol. 53, no. 9, pp. 1083-1085.

DiGiulio, S 2018, Why 'getting lost in a book' is so good for you, according to science, NBC 
News BETTER by Today, 23 July, viewed 5 October 2020, <https://www.nbcnews.com/better/pop-culture/ why-getting-lost-book-so-good-youaccording-science-ncna893256>.

Djikic, M, Oatley, K, Zoeterman, S \& Peterson, JB 2009, 'On being moved by art: how reading fiction transforms the self', Creativity Research Journal, vol. 21, no. 1, pp. 24-29.

Dodell-Feder, D \& Tamir, DI 2018, 'Fiction reading has a small positive impact on social cognition: a meta-analysis', Journal of Experimental Psychology: General, vol. 147, no. 11, 1713-1727.

Dodge, R, Daly, A, Huyton, J \& Sanders, L 2012, 'The challenge of defining wellbeing', International Journal of Wellbeing, vol. 2, no. 3, 222-235.

Doel, M 2006, Using group work, Psychology Press, East Sussex, UK.

Doel, M \& Kelly, TB 2014, a-z of groups \& groupwork, Red Globe Press, London, UK.

Doel, M \& Sawdon, S 1999, The essential groupworker: teaching and learning creative groupwork, Jessica Kingsley Publishers, London, UK.

Doll, B \& Doll, C 1997, 'Bibliotherapy with young people: librarians and mental health professionals working together', Libraries Unlimited, Inc., Engelwood, New Jersey, USA.

Dowrick, C 2019,' Comfort in a whirlwind: literature and distress in general practice', in J Billington (ed.), Reading and Mental Health, Palgrave Macmillan, London, UK, pp. 15-30.

Dowrick, C, Billington, J, Robinson, J \& Hamer, A 2012, 'Get into Reading as an intervention for common mental health problems: exploring catalysts for change', Medical Humanities, vol. 38 , no. 1 , pp. 15-20.

Duarte, PS, Miyazaki, MC, Blay, SL \& Sesso, R 2009, 'Cognitive-behavioral group therapy is an effective treatment for major depression in hemodialysis patients', Kidney International, vol. 76, no. 4, pp. 414-421.

Duffy, J 2020, The healing power of books and libraries, The Guardian, 8 September, viewed 8 September 2020, <https://www.theguardian.com/books/2020/sep/07/the-healing-powerof-books-and-libraries>.

Eagleton, T 2003, After theory, Allen Lane/Penguin, London, UK.

Eatough V \& Smith JA 2008, 'Interpretative phenomenological analysis', in C Willing \& W Stainton-Rogers (eds), The Sage handbook of qualitative research in psychology, Sage, Los Angeles, USA, pp 179-194.

Ehlers, Al, Clarke, DM, Hackmann, A, McManus, F \& Fennell, M 2005, 'Cognitive therapy for post-traumatic stress disorder: development and evaluation', Behaviour Research and Therapy, vol. 43, no. 4, pp. 413-431.

Eliasa, E \& Iswantti, S 2014, 'Bibliotherapy with the career topic to increase the student's career motivation of guidance and counseling', Procedia-Social and Behavioral Sciences, vol. 114 , pp. 434-438.

Elkins, G, Fisher, W, Johnson, A 2010, 'Mind-body therapies in integrative oncology', Current Treatment Options in Oncology, vol. 11, pp. 128-140.

Ellingham, I 1999, 'Carl Rogers' 'congruence' as an organismic; not a Freudian concept', The 
Person-Centered Journal, vol. 6, no. 2, pp. 121-140.

Elliott, H, Ryan, J \& Hollway, W 2012, 'Research encounters, reflexivity and supervision', International Journal of Social Research Methodology, vol. 15, no. 5, pp. 433-444.

Ellis, C, McCann, E \& Dalsgård, AL 2019, 'Reading for depression/mental health', in J Billington (ed.), Reading and Mental Health, Palgrave Macmillan, London, UK, pp. 71-90.

Emerick, LL 1966, 'Bibliotherapy for stutterers: four case histories', Quarterly Journal of Speech, vol. 52, no. 1, pp. 74-79.

England NHS 2016, New care models: vanguards-developing a blueprint for the future of NHS and care services, NHS England, viewed 28 July 2017, <https://www.england.nhs.uk/wpcontent/uploads/2015/11/new_care_models.pdf>.

Estabrooks, PA, Harden, SM \& Burke, SM 2012, 'Group dynamics in physical activity promotion: what works?', Social and Personality Psychology Compass, vol. 6, no. 1, pp. 1840.

Fade, S 2004, 'Using interpretative phenomenological analysis for public health nutrition and dietetic research: a practical guide', Proceedings of the Nutrition Society, vol. 63, no. 4, pp. 647-653.

Fanner, D \& Urquhart, C 2008, 'Bibliotherapy for mental health service users part 1: a systematic review', Health Information and Libraries Journal, vol. 25, no. 4, pp. 237-252.

Farrington, G, Davis, P \& Billington, J 2012 'From sullen earth', The Reader Magazine, The Reader Organisation, UK, pp. 63-69.

Farrington, G, Davis, P \& Billington, J 2019, 'The Victorian novel: laying the foundations for 'bibliotherapy', in J Billington (ed.), Reading and Mental Health, Palgrave Macmillan, London, UK, pp. 47-68.

Fearnley, D \& Farrington, G 2019, 'Reading and psychiatric practices', in J Billington (ed.), Reading and Mental Health, Palgrave Macmillan, London, UK, pp. 323-329.

Finlay, L 2011, Phenomenology for therapists: researching the lived world, Wiley-Blackwell, West Sussex, UK.

Finlay, L \& Ballinger, C 2006, Qualitative research for allied health professionals: challenging choices, John Wiley \& Sons, West Sussex, UK.

Finlay, L \& Gough, B (eds) 2003, Reflexivity-a practical guide for researchers in health and social sciences, Blackwell, Oxford, UK.

Floyd, M 2003, 'Bibliotherapy as an adjunct to psychotherapy for depression in older adults', Journal of Clinical Psychology, vol. 59, no. 2, PP. 187-195.

Floyd, M, Rohen, N, Shackelford, JA 2006, 'Two-year follow-up of bibliotherapy and individual cognitive therapy for depressed older adults', Behavior Modification, vol. 30, no. 3, pp. 281-294.

Floyd, M, Scogin, F, McKendree-Smith, NL, Floyd, DL \& Rokke, PD 2004, 'Cognitive therapy for depression: a comparison of individual psychotherapy and bibliotherapy for depressed older adults', Behavior Modification, vol. 28, no. 2, pp. 297-318.

Ford, D, Tyson, CA, Howard, TC \& Harris III, JJ 2000, 'Multicultural literature and gifted black 
students: promoting self-understanding, awareness, and pride', Roeper Review, vol. 22, no. 4, pp. 235-240.

Forrest, MES 1998, 'Recent developments in reading therapy: a review of the literature', Health Libraries Review, vol. 15, pp. 157-164.

Fosha, D, Siegel, DJ \& Solomon MF 2009, 'Introduction', in D Fosha, DJ Siegel, \& MF Solomon (eds), The healing power of emotion: affective neuroscience, development \& clinical practice, Norton, New York, USA.

Fouracres, AJS \& Van Nieuwerburgh, C 2020, 'The lived experiences of self-identifying character strengths through coaching: an interpretative phenomenological analysis', International Journal of Evidence Based Coaching and Mentoring, vol. 18, no. 1, pp. 43-56.

Frasier, M \& McCannon, C 1981, 'Using bibliotherapy with gifted children', Gifted Children Quarterly, vol. 25, no. 2, pp. 81-85.

Frazer, CJ, Christensen, H \& Griffiths, KM 2005, 'Effectiveness of treatments for depression in older people', Medical Journal of Australia, vol. 182, no. 12, pp. 627-632.

Freeman-Greene, S 2011, Between the lines, The Age, Australia, 14 March, viewed 11 September 2018, <http://www.theage.com.au/national/between-the-lines-201103131bssj.html\#ixzz2gZ8dtnJD>.

Freire, ES, Koller, SH, Piason, A \& Silva, RB 2005, 'Person-centred therapy with impoverished, maltreated, and neglected children and adolescents in Brazil', Journal of Mental Health Counselling, vol. 27, no. 3, pp. 225-237.

Freire, P 2007, Pedagogy of the oppressed, Continuum, New York, USA.

Friedland, J, Polatajko, H, Gage, M 2001, 'Expanding the boundaries of occupational therapy practice through student fieldwork experiences: description of a provincially-funded community development project', Canadian Journal of Occupational Therapy, vol. 68, no. 5, 301-309.

Fritzler, BK, Hecker, JE \& Losee, MC 1997, 'Self-directed treatment with minimal therapist contact: preliminary findings for obsessive-compulsive disorder', Behaviour Research and Therapy, vol. 35, no. 7, pp. 627-631.

Frost, N 2011, Qualitative research methods in psychology: combining core approaches, Open University Press, Berkshire, UK.

Frude, N 2003, The Cardiff book prescription scheme, Wales Mental Health in Primary Care, viewed 31 December 2020, <http://www.wamhipc.org.uk/sites/default/files/bursariescardiff-prescription-scheme.pdf>.

Frude, N 2004, 'A book prescription scheme in primary care', Clinical Psychology, vol. 39, pp. 11-14.

Frude, N 2009, 'Book prescriptions: five years on', Healthcare Counselling and Psychotherapy Journal, vol. 5, no. 1, pp. 8-10.

Furmark, T, Carlbring, P, Hedman, E, Sonnenstein, A, Clevberger, P, Bohman, B, Eriksson, A, Hållén, A, Frykman, M, Holmström, A, Sparthan, E, Tillfors, M, Ihrfelt, EN, Spak, M, Eriksson, A, Ekselius, L \& Andersson, G 2009, 'Guided and unguided self-help for social anxiety disorder: randomised controlled trial', British Journal of Psychiatry, vol. 195, no. 5, pp. 440- 
447.

Furner, JM \& Duffy, ML 2002, 'Equity for all students in the new millennium disabling math anxiety', Intervention in School and Clinic, vol. 38, no. 2, pp. 67-74.

FutureLearn 2016, Literature and mental health: reading for wellbeing, FutureLearn, viewed 4 December 2016, <https://www.futurelearn.com/courses/literature>.

FutureLearn 2020, Improve your understanding of depression and anxiety and find out more about an effective and evidence-based treatment: CBT, FutureLearn, viewed 26 July 2020, $<$ https://www.futurelearn.com/courses/anxiety-depression-and-cbt>.

Gadamer, HG 1990, $2^{\text {nd }}$ edn, Truth and method, Crossroad, New York, USA.

Galinsky, AD, Maddux, WM, Gilin, D \& White, JB 2008, 'Why it pays to get inside the head of your opponent: the differential effects of perspective taking and empathy in strategic interactions', Association for Psychological Science, vol. 19, no. 4, pp. 378-384.

Galt JM, 1853, 'On the reading, recreation, and amusements of the insane', Journal of Psychological Medicine and Mental Pathology, vol. 6, no. 24, pp. 581-589.

Garner, J 2017, 'Australian prison libraries: a study of existing knowledge and recent findings', Journal of the Australian Library and Information Association, vol. 66, no. 4, pp. 331-343.

Garner, J 2020, “'Almost like freedom”: prison libraries and reading as facilitators of escape', The Library Quarterly, vol. 90, no. 1, pp. 5-19.

Garrubba, M \& Melder, A 2019, 'Re-imagining community healthcare services', Centre for Clinical Effectiveness, Monash Health, Melbourne, Australia.

Gill, MJ 2015, 'A phenomenology of feeling' in CEJ Härtel, WJ Zerbe \& NM Ashkanasy (eds), Research on emotions in organizations: new ways of studying emotions in organisations, Emerald Group, UK, pp. 29-50.

Gillon, E 2007, Person-centred counselling psychology: an introduction, SAGE, London, UK.

Giorgi, A 1994, 'A phenomenological perspective on certain qualitative research methods', Journal of Phenomenological Psychology, vol. 25, no. 2, pp. 190-220.

Glasziou, P, Bennett, J, Greenberg, P, Green, S, Gunn, J, Hoffman, T, Pirotta, M \& Usher, T 2013, 'Bibliotherapy for depression', Australian Family Physician, vol. 42, no. 4, pp. 199-200.

Glavin, CEY \& Montgomery, P 2017, 'Creative bibliotherapy for post-traumatic stress disorder (PTSD): a systematic review', Journal of Poetry Therapy, vol. 30, no. 2, pp. 95-107.

Goering, PN \& Streiner, DI 1996, 'Reconcilable differences: the marriage of qualitative and quantitative methods', Canadian Journal of Psychiatry, vol. 41, no. 8, pp. 491-497, in DL Streiner (ed.), A guide for the statistically perplexed: selected readings for clinical researchers, 2013, pp. 225-241, University of Toronto Press, Toronto, Canada.

Gold, J 1990, Read for your life: literature as a life support system, Fitzhenry \& Whiteside, Ontario, Canada.

Gold, J 2001, The story species, Fitzhenry \& Whiteside, Ontario, Canada.

Gordon, E \& Kenny, M 2018, 'Group work in psychiatric/mental health nursing: the case for psychoeducation as a means to therapeutic ends', in J Santos and J Cutcliffe (eds), 
European psychiatric/mental health nursing in the 21st century: a person-centred evidence-based approach, Springer International Publishing, New York, USA, pp. 269282.

Gould, RA, Clum, GA \& Shapiro, D 1993, 'The use of bibliotherapy in the treatment of panic: a preliminary investigation', Behavior Therapy, vol. 24, no. 2, pp. 241-252.

Grace, D \& Sen, B 2013, 'Community resilience and the role of the public library', Library Trends, vol. 61, no. 3, pp. 513-541.

Gray, E, Farrington, G \& Steenberg, M 2019, 'Reading and mental health', in J Billington (ed.), Reading and Mental Health, Palgrave Macmillan, London, UK, pp. 371-385.

Greasley, AE \& Prior HM 2013, 'Mixtapes and turntablism: DJs' perspectives on musical shape', Empirical Musicology Review, vol. 8, no. 1, pp. 23-43.

<https://emusicology.org/article/view/3921/3549>.

Greene, R 1994, 'The social work interview: legacy of Carl Rogers and Sigmund Freud', in R Greene (ed.), Human behaviour theory: a diversity framework, Routledge, New York, USA, pp. 245-291.

Gregory, R, Canning, S, Lee, T \& Wise, J 2004, 'Cognitive bibliotherapy for depression: a meta-analysis', Professional Psychology: Research and Practice, vol. 35, no. 2, pp. 275-280.

Gielgud, K, 2018, 'Bibliotherapy read aloud groups with native and non-native speakers', in S McNichol \& L Brewster (eds), Bibliotherapy, Facet Publishing, London, UK, pp. 163-170.

Gumbrecht, HU, 1992 Making sense in life and literature, Minnesota University Press, Minnesota, USA.

Gumbrecht, HU 2006, 'Aesthetic experience in everyday worlds: reclaiming an unredeemed utopian motif', New Literary History, vol. 37, no. 2, pp. 299-318.

Hallam, G 2014, Victorian public libraries: our future, our skills - research report, State Library Victoria, Melbourne, Australia.

Hargaden, H \& Sills, C 2002, Transactional analysis: a relational perspective, Routledge, London, UK.

Harris, SR, Kemmerling, RL \& North, MM 2002, 'Brief virtual reality therapy for public speaking anxiety', Cyberpsychology \& Behavior, vol. 5, no. 6, pp. 543-550.

Harrison, N, Jacobs, L \& Parke, A 2020, 'Understanding the lived experiences of transitioning adults with gender dysphoria in the United Kingdom: an interpretative phenomenological analysis', Journal of LGBT in Counseling, vol. 14, no. 1, pp. 38-55.

Haynes, A \& Haynes-Berry, M 1986, Bibliotherapy-the interactive process: a handbook, Westview Press, Colorado, USA.

Headey, BW \& Wearing, AJ 1991, 'Subjective well-being: a stocks and flows framework', in F Strack, M Argyle \& N Schwarz (eds), Subjective wellbeing-an interdisciplinary perspective, Pergamon Press, Oxford, UK, pp. 49-76.

Healthy Books n.d., 'Categories', viewed 2 December 2020, <http://www.healthybooks.org.uk/browse/>.

Hebert, TP \& Kent, R 2000, 'Nurturing social and emotional development in gifted teenagers 
through young adult Literature', Roeper Review, vol. 22, no. 3, pp. 167-171.

Hecker, JE, Losee, MC, Fritzler, BK \& Fink, CM 1996, 'Self-directed versus therapist-directed cognitive behavioural treatment for panic disorder', Journal of Anxiety Disorders, vol. 10, no. 2, pp. 253-265.

Hecker, JE, Losee, MC, Roberson-Nay, R \& Maki, K 2004, 'Mastery of your anxiety and panic and brief therapist contact in the treatment of panic disorder', Journal of Anxiety Disorders, vol. 18, pp. 111-126.

Hedman, E, Ljótsson, B, Kaldo, V, Hesser, H, Alaoui, S, Kraepelien, M, Andersson, E, Rück, C, Svanborg, C, Andersson, G \& Lindefors, N 2014, 'Effectiveness of internet-based cognitive behaviour therapy for depression in routine psychiatric care', Journal of Affective Disorders, vol. 155 , pp. 49-58.

Hefferon, K \& Gil-Rodriguez, E 2011, 'Interpretative phenomenological analysis', The Psychologist, vol. 24, no. 10, pp. 756-759.

Heidegger, M 1962, Being and time, SCM Press, London, UK.

Heidegger, M 1971, 'Building dwelling thinking', in M Heidegger (ed.), Poetry, language, thought, trans. A Hofstader, Harper Colophon Books, New York, pp. 143-161.

Hendricks, CG, Hendricks, JE \& Cochran, LL 1999, 'Using literacy conversations for healing: the significant conversationalists', American Reading Forum, viewed 14 April 2019, <https://18970341-7a2c-4cd7-a809-39ba885eda1d.filesusr.com/ugd/ c10ff9_1fa49c7721344c36b8e87f4cb0910792.pdf>.

Hennum, N 2014, 'Developing child-centered social policies: when professionalism takes over, Social Sciences, vol. 3, pp. 441-459.

Henricks, M 2001, 'An experiential version of unconditional positive regard', in J Bozarth \& $P$ Wilkins (eds), UPR: unconditional positive regard, PCCS Books, Ross-on-Wye, UK, pp. 126144.

Hepburn, S, Creane, C, Barnhofer, T, Duggan, DS, Fennell, MJV \& Williams, M 2009, 'Mindfulness-based cognitive therapy may reduce thought suppression in previously suicidal participants: findings from a preliminary study', British Journal of Clinical Psychology, vol. 48, pp. 209-215.

Herman, D 2006, 'Dialogue in discourse context: scenes of talk in fictional narrative', Narrative Inquiry, no. 16, vol. 1, pp. 75-88.

Hicks, D 2006, An audit of bibliotherapy/books on prescription activity in England, Arts Council England and Museums, Libraries and Archives Council, London, <https://tinyurl.com/y9gzvdyc>.

Hindustan Times 2019, Librarians facing new tasks say crisis isn't in the catalog, Associated Press, 10 August, viewed 26 March 2020, <https://www.hindustantimes.com/art-andculture/librarians-facing-new-tasks-say-crisis-isn-t-in-the-catalog/storyohoen6IIYOCWCMIEtHUkYK.html>.

Hoagland, J 1972, 'Bibliotherapy: aiding children in personality development', Elementary English, vol. 49, no. 3, pp. 390-391.

Hodge, S, Robinson, J \& Davis, P 2007, 'Reading between the lines: the experiences of taking 
part in a community reading project', Medical Humanities, vol. 33, pp. 100-104.

Hohne, K \& Wussow, H (eds), 1994, A dialogue of voices: feminist literary theory and Bakhtin, University of Minnesota Press, Minnesota, USA.

Howie, M 1983, 'Bibliotherapy in social work', The British Journal of Social Work, vol. 13, no. 3, pp. 287-319.

Hughes, DA 2009, Attachment-focused parenting: effective strategies to care for children, WW Norton \& Co, New York, USA.

Hughes, R \& Szczepek Reed, BS 2006, 'Factors affecting turn-taking behaviour: genre meets prosody', in R Hughes (ed.), Spoken English, TESOL and applied linguistics: challenges for theory and practice, Palgrave Macmillan, London, UK, pp. 126-140.

Husserl, E 1999, The idea of phenomenology, translated by Lee Hardy, Kluwer Academic Publishers, Amsterdam, Netherlands.

International Federation of Library Associations and Institutions (IFLA) 2000, Guidelines for libraries serving hospital patients and the elderly and disabled in long-term care facilities, IFLA Professional Reports, no. 61, viewed 15 September 2013, $<$ https://archive.ifla.org/VII/s9/nd1/iflapr-61e.pdf>.

Ireland, GO 1934, 'Bibliotherapy: use of books as form of treatment in neuropsychiatric hospital', Journal of Nervous \& Mental Disease, vol. 79, no. 2, p. 198.

Irwin, J, Waugh, F \& Bonner, M 2006, 'The inclusion of children and young people in research on domestic violence', Communities, Children and Families Australia, vol. 1, no. 1, pp. 17-23.

Issacs, W 1999, Dialogue: the art of thinking together, Currency Press, Sydney, Australia. Isaacs, W 2016, Listening at the heart of dialogue, A matter of spirit: a publication of the Intercommunity Peace \& Justice Center, no.110, viewed 17 February 2019, <http://www.ipjc.org/wp-content/uploads/2016/10/AMOSSpring2016.pdf>;

Iser, W 1974, The implied reader: patterns of communication in prose fiction from Bunyan to Beckett, John Hopkins University Press, Baltimore, USA.

Jack, SJ \& Ronan, KR 2008, 'Bibliotherapy: practice and research', School Psychology International, vol. 29, no. 2, pp. 161-182.

Jackson, M 2003, System thinking: creative holism for managers, John Wiley, West Sussex.

Jacobs, E, Masson, R, Harvill, R \& Schimmell, C 2012, Group counselling: strategies and skills, 7th edn, Brooks/Cole Cengage Learning, Belmont, California, USA.

Jamison, C \& Scogin, F 1995, 'The outcome of cognitive bibliotherapy with depressed adults', Journal of Consulting and Clinical Psychology, vol. 63, no. 4, pp. 644-650.

Jarjoura, GR \& Krumholz, ST 1998, 'Combining bibliotherapy and positive role modeling as an alternative to incarceration', Journal of Offender Rehabilitation, vol. 28, no 1/2, pp. 127-139.

Jeon, K-W 1992, 'Bibliotherapy for gifted children', Gifted Child Today, pp. 16-19.

John Hopkins Medicine 2020, Types of complementary and alternative medicine, John Hopkins Medicine, viewed 29 September 2020, <https://www.hopkinsmedicine.org/health/wellness-and-prevention/types-of- 
complementary-and-alternative-medicine>.

Jones, A, Ledson, L \& McDonnell, K 2019, 'Reading in a clinical context', in J Billington (ed.), Reading and Mental Health, Palgrave Macmillan, London, UK, pp. 432-441.

Jones, P 1944, 'Hospital libraries-today and tomorrow, Bulletin of the Medical Library Association, pp. 467-478.

Jorm, AF, Christensen, H, Griffiths, KM, Parslow, RA, Rodgers, B \& Blewitt, KA 2004, 'Effectiveness of complementary and self-help treatments for anxiety disorders', The Medical Journal of Australia, vol. 181, no. 7, pp. 29-S46.

Justice, T \& Jamieson, D 1999, The facilitator's fieldbook, American Management Association, New York, USA.

Kavanagh, DJ \& Proctor, DM 2011, 'The role of assisted self-help in services for alcoholrelated disorders', Addictive Behaviours, vol. 36, pp. 624-629.

Kayser, T 1990, Mining group gold, Serif Publishing, London, UK.

Kenwright, M 2010, 'Introducing and supporting written and internet-based guided CBT', in J Bennett-Levy, DA Richards, P Farrand, H Christensen, KM Griffiths, DJ Kavanagh, B Klein, MA Lau, J Proudfoot, L Ritterband, J White \& C Williams (eds), Oxford guide to low intensity CBT interventions, Oxford University Press, Oxford, pp. 105-111.

Kidd, DC and Castano, E 2013, 'Reading literary fiction improves theory of mind', Science, vol. 342 , no. 6156 , pp. 377-380.

King, N 1998, 'Template analysis', in G Symon \& C Cassell (eds), Qualitative methods and analysis in organizational research: a practical guide, Sage Publications, Thousand Oaks, California, USA, pp. 118-134.

King, N 2012, Template analysis, University of Huddersfield, viewed 2 October 2012, <http://hhs.hud.ac.uk/w2/research/template_analysis/>.

Kirkham, JA, Smith, JA \& Havsteen-Franklin, D 2015, 'Painting pain: an interpretative phenomenological analysis of representations of living with chronic pain', Health Psychology, vol. 34, no. 4, pp. 398-406.

Kirklees 2019, Bibliotherapy-words in mind, Kirklees Library and Information Centre, viewed 26 July 2020, <https://www.facebook.com/BibliotherapyKirklees/>.

Kirklees Council n.d, Well into words: video and training contact details, Kirklees Library and Information Centre, viewed 26 July 2020, <https://vimeo.com/wellintowords/about>.

Kiropoulos, LA, Klein, B, Austin, DW, Gilson, K, Pier, C, Mitchell, J \& Ciechomski, L 2008, 'Is internet-based CBT for panic disorder and agoraphobia as effective as face-to-face CBT?', Journal of Anxiety Disorders, vol. 22, pp. 1273-1284.

Kloep, M, Hendry, L \& Saunders, D 2009, 'A new perspective on human development', Conference of the International Journal of Arts and Sciences, vol. 1, no. 6, pp. 332-343.

Knewstubb, B 2016, 'The learning-teaching nexus: modelling the learning-teaching relationship in higher education', Studies in Higher Education, vol. 41, no. 3, pp. 525-540.

Koopman, EM 2011, 'Predictors of insight and catharsis among readers who use literature as a coping strategy', Scientific Study of Literature, vol. 1, no. 2, pp. 241-259. 
Koopman, EM 2013, 'The attraction of tragic narrative: catharsis and other motives', Scientific Study of Literature, vol. 3, no. 2, pp. 178-208.

Koopman, EM 2015, 'Empathic reactions after reading: the role of genre, personal factors, and affective responses', Poetics, vol. 50, pp. 62-79.

Kramer, PA 1999, 'Using literature to enhance inclusion', Contemporary Education, vol. 70, no. 2, pp. 34-37.

Kramer, PA \& Smith, GG 1998, 'Easing the pain of divorce through children's literature', Early Childhood Education Journal, vol. 26, no. 2, pp. 89-94.

Kraner-Tucci, R 2020, Gertrude \& Alice's bibliotherapy service will send you books to lift your mood, Broadsheet, 8 May, viewed 22 September 2020,

$<$ https://www.broadsheet.com.au/sydney/entertainment/article/gertrude-alicesbibliotherapy-service-send-books-lift-mood>.

Kretzmann, JP \& McKnight, JL 1993, Building communities from inside out: a path toward finding and mobilizing a community's assets, ACTA Publications, Chicago, USA.

Kristensen, LK 2018, “Peeling an onion": layering as a methodology to promote embodied perspectives in video analysis', Journal of Education and Pedagogy, vol. 3, no. 3, pp. 1-21.

Kristjánnsson, K 2012, 'Positive psychology and positive education: old wine in new bottles?', Educational Psychologist, vol. 47, no. 2, pp. 86-105.

Kuiken, D 2019, 'Reading and psychology II. Metaphoricity, inexpressible realisations and expressive enactment', in J Billington (ed.), Reading and Mental Health, Palgrave Macmillan, London, UK, pp. 345-357.

Kukenberger, MR \& D'Innocenzo, L 2019, 'The building blocks of shared leadership: the interactive effects of diversity types, team climate, and time', Personnel Psychology, vol. 73, no. 1 , pp. $125-150$.

Lack, C \& Bettencourt, B 1971, 'Agnews State Hospital Rehabilitation Services Patients' Library Bibliotherapy Project: Third Annual Report', ERIC Document Reproduction Service, $<$ https://files.eric.ed.gov/fulltext/ED088508.pdf>.

Laidlaw, K, Davidson, K, Toner, H, Jackson, G, Clark, S, Law, J, Howley, M, Bowie, G, Connery, $\mathrm{H} \&$ Cross, S 2008, 'A randomised controlled trial of cognitive behaviour therapy vs treatment as usual in the treatment of mild to moderate late life depression', International Journal of Geriatric Psychiatry, vol. 23, no. 8, pp. 843-50.

Langum, V 2004, Martial arts as stealth therapy, Chicago Tribune, 28 March, viewed 19 June 2020, <https://www.chicagotribune.com/news/ct-xpm-2004-03-28-0403280275story.html>.

Lankes, D 2019, Library as movement, Victoria Libraries 2019 Planning Summit, Kalorama, Victoria, Australia, viewed 21 July 2019, <https://davidlankes.org/library-as-movement/>. Lapidus International 2020, Lapidus International: where words and wellness meet, Lapidus International, viewed 24 September 2020, <https://www.lapidus.org.uk/>.

Lapidus Scotland 2020, Facilitators, Lapidus International, viewed 26 July 2020, <https://www.lapidusscotland.co.uk/>.

Larkin, M, Eatough, V \& Osborne, M 2011, 'Interpretative phenomenological analysis and 
embodied, active, situated cognition', Theory \& Psychology, vol. 21, no. 3, pp. 318-337.

Laverty, S 2003, 'Hermeneutic phenomenology and phenomenology: a comparison of historical and methodological considerations', International Journal of Qualitative Methods, vol. 2, no. 3, pp. 21-35.

Le Boutillier C, Leamy M, Bird VJ, Davidson L, Williams, J \& Slade, M 2011, 'What does recovery mean in practice? A qualitative analysis of international recovery-oriented practice guidance', Psychiatric Services, vol. 62, no. 12, pp. 1470-1476.

Leung, R, Flaherty, MG, Rudd, R \& Toumbourou, JW 2016, Are libraries effective settings for accessing health information? An evidence check rapid review, NSW Ministry of Health, viewed 4 October 2010, <https://www.saxinstitute.org.au/wp-content/uploads/Arelibraries-effective-settings-for-accessing-health-information.pdf>.

Levertov, D 2003, 'Witness' in PA Lacey (ed.), Selected poems, New Directions, New York, USA.

Levine, JM \& Moreland, RL (eds) 2006, Key readings in social psychology: small groups, Psychology Press, East Sussex, UK.

Lewis, C, Enciso, P \& Moje, EB 2009, 'Introduction: reframing sociocultural research on literacy', in C Lewis, P Enciso \& EB Moje (eds), Reframing sociocultural research on literacy: identity, agency, and power, Routledge, New York, USA, pp. 15-48.

Lewis, T, Amini, F \& Lannon, R 2000, A general theory of love, Vintage Books, New York, USA. Lichtenstein, AH, Berger, A \& Cheng, MJ 2017, 'Definitions of healing and healing interventions across different cultures', Annals of Palliative Medicine, vol. 6, no. 3, pp. 248252

Lidren, DM, Watkins, PL, Gould, RA, Clum, GA, Asterino, M \& Tulloch, HL 1994, 'A comparison of bibliotherapy and group therapy in the treatment of panic disorder', Journal of Consulting and Clinical Psychology, vol. 62, no. 4, pp. 865-869.

Lindsay, T \& Orton, S 2014, Groupwork practice in social work, 3rd edn, Sage, London, UK. Lippincott, J, Vedantham, A \& Duckett, K 2014, Libraries as enablers of pedagogical and curricular change, Educausereview, 27 October, viewed 4 October 2020, $<$ https://er.educause.edu/articles/2014/10/libraries-as-enablers-of-pedagogical-andcurricular-change>.

Lipsey, MW \& Cullen, FT 2007, 'The effectiveness of correctional rehabilitation: a review of systematic reviews', Annual Review of Law and Social Science, vol. 3, no. 1, pp. 297-320.

Lloyd, C, Bassett, H, King, R 2002, 'Mental health: how well are occupational therapists equipped for a changed practice environment?', Australian Occupational Therapy Journal, vol. 49, no. 3, pp. 163-66.

Longden, E, Davis, P, Billington, J, Lampropoulou, S, Farrington, G, Magee, F, Walsh, E \& Cororan, R 2015, 'Shared reading: assessing the intrinsic value of a literature-based health intervention', Medical Humanity, vol. 41, pp. 113-120.

Longden, E, Davis, P, Carroll, J \& Billington, J 2016, Read to care: an investigation into quality of life benefits of shared reading groups for people living with dementia, Centre for Research into Reading Literature and Society (CRILS), viewed 19 December 2020, 
$<$ https://issuu.com/emmawalsh89/docs/read-to-care>.

Lynch, L, Long, M \& Moorhead, A 2018, 'Young men, help-seeking, and mental health services: exploring barriers and solutions', American Journal of Men's Health, vol. 12, no. 1, pp. 138-49.

MacLeod, A 2019, 'Interpretative phenomenological analysis (IPA) as a tool for participatory research within critical autism studies: a systematic review', Research in Autism Spectrum Disorders, vol. 64, pp. 49-62.

Maibom, HL 2009, 'Feeling for others: empathy, sympathy, and morality', Inquiry, vol. 52, no. 5, pp. 483-499.

Maier, NRF 1967, 'Assets and liabilities in group problem solving: the need for an integrative function', Psychological Review, vol. 74, no. 4, pp. 239-249.

Manor, O 2000, Choosing a groupwork approach, Jessica Kingsley Publishers, London, UK.

Mar, RA 2011, 'The neural bases of social cognition and story comprehension', Annual Review of Psychology, vol. 62, pp. 103-36.

Mar, RA \& Oatley, K 2008, 'The function of fiction is the abstraction and simulation of social experience', Perspectives on Psychological Science, vol. 3, no. 3, pp 173-92.

Mar, RA, Oatley, K, Hirsh, J, dela Paz, J \& Peterson, JB 2006, 'Bookworms versus nerds: exposure to fiction versus non-fiction, divergent associations with social ability, and the simulation of fictional social worlds', Journal of Research in Personality, vol. 40, no. 5, pp. 694-712.

Mar RA, Oatley K \& Peterson, JB 2009, 'Exploring the link between reading fiction and empathy: ruling out individual differences and examining outcomes, Communications, vol. 34 , pp. 407-428.

Marks, IM, Kenwright, M, McDonough, M, Whittaker, M \& Mataix-Cols, D 2004, 'Saving clinicians' time by delegating routine aspects of therapy to a computer: a randomised controlled trial in phobia/panic disorder', Psychological Medicine, vol. 34, no. 1, pp. 9-18.

Martins, CD 2018, 'Bibliotherapy in Uruguay: a case study', in S McNichol \& L Brewster (eds), Bibliotherapy, Facet Publishing, London, UK, pp. 129-140.

Masaryk University, 2015, Introduction to bibliotherapy, Department of Psychology, Masaryk University, Brno, viewed 26 July 2020, <https://is.muni.cz/el/1421/jaro2015/PSA_051/ Bibliotherapy_workshop_syllabus.pdf $>$.

Mason, L 1998, 'Fieldwork education: collaborative group learning in community settings', Australian Occupational Therapy Journal, vol. 45, no. 4, pp. 124-30.

Mason, M 2010, 'Sample size and saturation in PhD studies using qualitative interviews', Forum: Qualitative Social Research, vol. 11, no. 3, art. 8.

Matcham, F, Rayner, L, Hutton, J, Monk, A \& Hotopf, M 2014, 'Self-help interventions for symptoms of depression, anxiety and psychological distress in patients with physical illnesses: a systematic review and meta-analysis', Clinical Psychology Review, vol. 34, no. 2, pp. 141-157.

Matthijs Bal, P \& Veltkamp, M 2013, 'How does fiction reading influence empathy? An experimental investigation on the role of emotional transportation, Fiction Reading and 
Empathy, vol. 8, no. 1, pp. 1-12.

McCarthy, H \& Thomas, G 2004, Home alone: combating isolation with older housebound people, Demos, London, UK.

McCown, D \& Billington, J 2017, 'Correspondence: sitting and reading as two routes to community', Journal of Contemplative Inquiry, vol. 4, no. 1, pp. 165-185.

McCoy, H \& McKay, C 2006, 'Preparing social workers to identify and integrate culturally affirming bibliotherapy into treatment', Social Work Education, vol. 25, no. 7, pp. 680-693.

McCulliss, D 2012, 'Bibliotherapy: historical and research perspectives', Journal of Poetry Therapy: The Interdisciplinary Journal of Practice, Theory, Research and Education, vol. 25, no. 1, pp. 23-38.

McCulliss, D \& Chamberlain, D 2013, 'Bibliotherapy for youth and adolescents-school-based application and research', Journal of Poetry Therapy: The Interdisciplinary Journal of Practice, Theory, Research and Education, vol. 26, no. 1, pp. 13-40.

McDaniel, WB 1956, 'Bibliotherapy-some historical and contemporary aspects', ALA Bulletin, vol. 50, pp. 584-589.

McDonnell, K \& Cook, H 2019, 'Reading and chronic pain', in J Billington (ed.), Reading and Mental Health, Palgrave Macmillan, London, UK, pp. 143-150.

McGrath, PJ, Humphreys P, Keene, D, Goodman, JT, Lascelles, MA, Cunningham, SJ \& Firestone, P 1992, 'The efficacy and efficiency of a self-administered treatment for adolescent migraine', Pain, vol. 49, no. 3, pp. 321-324.

McGregor, T 2020, Defining empathy skills in practice: Carl Rogers and unconditional regard, Owlcation, viewed 12 September 2020, <https://owlcation.com/social-sciences/Empathy-inpractice>.

McKendree-Smith, NL 1998, 'Cognitive and behavioral bibliotherapy for depression: an examination of efficacy and mediators and moderators of change', PhD thesis, University of Alabama, Tuscaloosa, USA.

McKnight, DM 2010, 'Overcoming "ecophobia": fostering environmental empathy through narrative in children's science literature', Frontiers in Ecology and the Environment, vol. 8, pp. e10-e15.

McLaine, S 2011, 'The Victorian Book Well program', Australasian Public Libraries and Information Services, vol. 24, no. 2, pp. 82-84.

McLaine, S 2012, 'Bibliotherapy: reading for wellbeing in old age', Alzheimer's Australia Dementia Forum, Melbourne, Australia, pp. 1-9.

McLaine, S 2019, 'Reading for wellbeing in old age', in J Billington (ed.), Reading and Mental Health, Palgrave Macmillan, London, pp. 101-110.

McLaine, S \& Mackenzie, E 2013, 'Books, mind \& wellbeing', Arts and Health Australia Conference 2013, Sydney, Australia.

McLaine, S \& McKenzie, E 2018, 'Reading groups for those at risk of homelessness' in S McNichol \& L Brewster (eds), Bibliotherapy, Facet Publishing, London, UK, pp. 105-115. McLeod, S 2014, Carl Rogers, Simply Psychology, viewed 15 September 2020, 
<https://www.simplypsychology.org/carl-rogers.html\#: :

text=Carl\%20Rogers\%20believed\%20that\%20for,behavior\%20(self\%2Dimage)>.

McLoughlin, CS 2009, 'Positive peer group interventions: an alternative to individualized interventions for promoting prosocial behaviour in potentially disaffected youth', Education \& Psychology, vol. 7, no. 3, pp. 1131-1156.

McMillen, PS 2006, 'A therapeutic collaboration: the bibliotherapy education project at Oregon State University', OLA Quarterly, vol. 12, no. 2, pp. 14-15.

McNay, A, Darby-Villis, C, Billington, J \& Walmsley, A 2019, 'Getting the inside out', in J Billington (ed.), Reading and Mental Health, Palgrave Macmillan, Switzerland, pp. 111-133.

McNichol, S 2018, 'Theories of bibliotherapy', in S McNichol \& L Brewster (eds), Bibliotherapy, Facet Publishing, London, UK, pp. 23-40.

McNichol, S \& Brewster, L 2018, Bibliotherapy, Facet Publishing, London, UK.

Melecio, N 2014, Bridging the gap between vision and reality: equipping ministry leaders to lead with passion, Lulu Press, North Carolina, USA.

Menninger, K 1930, The human mind, Alfred A. Knopf, New York, USA.

Menninger, WC 1937, 'Bibliotherapy', The Bulletin of the Menninger Clinic, vol. 1, no. 8, viewed 26 July 2020 ,

<https://www.proquest.com/publication/1818298?OpenUrlRefld=info:xri/sid:primo\&accou ntid=12372\#>.

Meyer, B, Berger, T, Caspar, F, Beevers, CG \& Andersson, G 2009, 'Effectiveness of a novel integrative online treatment for depression (deprexis): randomized controlled trial', Journal of Medical Internet Research, vol. 11, no. 2, pp. 1-18.

Michaels, S 2020, Books have the power to rehabilitate. But prisons are blocking access to them, MotherJones, viewed 15 July 2020, <https://www.motherjones.com/crimejustice/2019/11/prison-libraries-book-bans-california-sacramento-reading-rehabilitation/>.

Miles, M, Chapman, Y \& Francis, K 2015, 'Peeling the onion: understanding others' lived experience', Contemporary Nurse, vol. 50, no. 2-3, pp. 286-295.

Miller WR, Benefield, R \& Tonigan, JS 1993, 'Enhancing motivation for change in problem drinking: a controlled comparison of two therapist styles', Journal of Consulting and Clinical Psychology, vol. 61, no. 3, pp. 455-461.

Miller, WR \& Moyers, TB 2017, 'Motivational interviewing and the clinical science of Carl Rogers', Journal of Consulting and Clinical Psychology, vol. 85, no. 8, pp. 757-766.

Mimeault, V, \& Morin, CM 1999, 'Self-help treatment for insomnia: bibliotherapy with and without professional guidance', Journal of Consulting and Clinical Psychology, vol. 67, no. 4, pp. 511-519.

Mintz, LB, Balzer, AM, Zhao, X \& Bush, HE 2012, 'Bibliotherapy for low sexual desire: evidence for effectiveness', Journal of Counseling Psychology, vol. 59, no. 3, pp. 471-478.

Moldovan, R, Cobeanu, O \& David, D 2012, 'Cognitive bibliotherapy for mild depressive symptomatology: randomized clinical trial of efficacy and mechanisms of change', Clinical Psychology and Psychotherapy, vol. 20, no. 6, pp. 482-493. 
Mole, L, Kent, B, Hickson, M \& Abbott, R 2019, '"It's what you do that makes a difference" an interpretative phenomenological analysis of health care professionals and home care workers experiences of nutritional care for people living with dementia at home', BMC Geriatrics, vol. 19, no. 250, pp. 1-10.

Monroy-Fraustro, D, Maldonado-Castellanos, I, Aboites-Molina, M, Rodríguez, S, Sueiras P, Altamirano-Bustamante, NF, de Hoyos-Bermea, A \& Altamirano-Bustamante, MM 2021, 'Bibliotherapy as a non-pharmaceutical intervention to enhance mental health in response to the COVID-19 pandemic: a mixed-methods systematic review and bioethical metaanalysis. Front. Public Health 9:629872. doi: 10.3389/fpubh.2021.629872.

Moran, D \& Cohen, J 2012, The Husserl dictionary, Continuum International Group, London, UK.

Morawski, C \& Gilbert, J 2000, 'Interactive bibliotherapy as an innovative inservice practice: a focus on the inclusive setting', Reading Horizons, vol. 41, no. 1, pp. 47-64.

Morris, L 2016, Health happens in libraries part 1: public libraries promote health literacy, Public Libraries Online; viewed 28 July 2020, $<$ http://publiclibrariesonline.org/2016/05/health-happens-in-libraries-part-i-public-librariespromote-health-literacy/>.

Morrison B, 2008, The reading cure, The Guardian, 5 January, viewed 12 September 2013, <http://www.guardian.co.uk/books/2008/jan/05/fiction.scienceandnature>.

Moustakas, C 1994, Phenomenological research methods, Sage, Thousand Oaks, California, USA.

Mulholland, S \& Derdall, M 2005, 'A strategy for supervising occupational therapy students at community sites', Occupational Therapy International, vol. 12, no. 1, pp. 28-43.

National Health and Medical Research Council n.d., viewed 23 December 2013, $<$ http://www.nhmrc.gov.au/research/strategic-investment-mental-health-researchpriorities $>$.

National Institute for Health and Clinical Excellence n.d., para 9, London, UK, viewed 3 February 2010, <http://www.nice.org.uk/>.

Naveenan, RN \& Kumar, BR 2018, 'Impact of group dynamics on team', American International Journal of Social Science Research, vol. 2, no. 2, pp. 16-23.

Neenan, M \& Palmer, S (eds) 2012, Cognitive behavioural coaching in practice, Routledge, East Sussex, UK.

Neville, T 2012, Changing lives through literature: a sentencing option that works (part 2), Changing Lives Through Literature, viewed 6 March 2013, $<$ https://cltlblog.wordpress.com/2012/06/30/changing-lives-through-literature-asentencing-option-that-works-part-2/>.

Newman MG, Kenardy, J, Herman, S \& Taylor, CB 1997, 'Comparison of palmtop-computer assisted brief cognitive-behavioral treatment to cognitive-behavioral treatment for panic disorder', Journal of Consulting and Clinical Psychology, vol. 65, no. 1, pp. 178-183.

Newport, A, \& Clarke, C 2020, 'The experiences of people with severe mental health conditions participating in the occupation matters programme: an interpretative 
phenomenological analysis', British Journal of Occupational Therapy, pp. 1-11, viewed 22 August 2020, <file://E:/PhD_20082020/Pre\%20final\%20draft/Completed\%20chapters/ Ch\%203_Methodology\%20\&\%20Methods/Ch\%202\%20IPA\%20articles/Newport\%20\&\%20CI arke,\%202020.pdf>.

Nicholson, JI, Quinn, M \& Pearson, QM 2003, 'Helping children cope with fears: using children's literature in classroom guidance', Professional School Counseling, vol. 7, no. 1, pp. 15-19.

Norris, R 2020, Ready and waiting: what the volunteer sector can do for social prescribing in Liverpool, The Reader Organisation, UK, viewed 20 December 2020,

$<$ https://www.thereader.org.uk/ready-and-waiting/>.

Noruzi, A 2007, 'Webotherapy: reading web resources for problem solving', The Electronic Library, vol. 25, no. 6, pp. 741-756.

Nowak, A, Vallacher, RR \& Miller, ME 2003, 'Social influence and group dynamics', in T Millon \& MJ Lerner (eds), Handbook of psychology, vol. 5, John Wiley, New Jersey, USA, pp. 383-417.

Nowell, LS, Norris, JM, White, DE \& Moules, NJ 2017, 'Thematic analysis: striving to meet the trustworthiness criteria', International Journal of Qualitative Methods, vol. 16, no. 1, pp. 113.

Oatley, K 1998, 'Meeting of minds: dialogue, sympathy, and identification, in reading fiction', Poetics, vol. 26, pp. 439-454.

Oatley, K 2009, 'Communications to self and others: emotional experience and its skills', Emotion Review', vol. 1, no. 3, pp. 206-213.

Oately, K \& Djikic, M 2018, 'Psychology of narrative art', Review of General Psychology, vol. 22, no. 2, pp. 161-168.

Oatley, K \& Gholamain, M 1997, Emotions and identification: connections between readers and fiction', in M Hjort \& S Laver (eds), Emotion and the arts, Oxford University Press, New York, USA, pp. 263-281.

Oatley, K \& Kerr, A 1999, 'Memories prompted by emotions--emotions attached to memories: studies of depression and of reading fiction', Journal of the American Academy of Psychoanalysis, vol. 27, no. 4, pp. 657-670.

Oliver, M 1994, A poetry handbook: a prose guide to understanding and writing poetry, Houghton Mifflin Harcourt, New York, USA.

Opening the Book 2009, Why take a reader-centred approach?, Opening the Book, viewed 22 June 2009, <http://www.openingthebook.com/library-resources/readercentered/default.aspx>.

Optale, G, Marin, S, Pastore, M, Nasta, A \& Pianon, C 2003, 'Male sexual dysfunctions and multimedia immersion therapy (follow-up)', Cyberpsychology \& Behavior, vol. 6, no. 3, pp. 289-294.

Orrell, M, Yates, L, Leung, P, Kang, S, Hoare, Z, Whitaker, C, Burns, A, Knapp, M, Leroi, I, Moniz-Cook, E, Pearson, S, Simpson, S, Spector, A, Roberts, S, Russell, I, de Waal, H, Woods, RT \& Orgeta, V 2017, 'The impact of individual cognitive stimulation therapy (iCST) 
on cognition, quality of life, caregiver health, and family relationships in dementia: a randomised controlled trial', Aging \& Mental Health, vol. 14, no. 3, pp. 1-22.

Overton, A, Clark, M \& Thomas, Y 2009, 'A review of non-traditional occupational therapy practice placement education: a focus on role-emerging and project placements', British Journal of Occupational Therapy, vol. 72, no. 7, pp. 294-301.

Organisation for Economic Co-operation and Development 2020, Measuring well-being and progress, Organisation for Economic Co-operation and Development Better Life Initiative, viewed 8 December 2020, < https://www.oecd.org/sdd/OECD-Better-Life-Initiative.pdf>.

Panella, NM 1996, 'The patients' library movement: an overview of early efforts in the United States to establish organized libraries for hospital patients', Bulletin of the Medical Library Association, vol. 84, no. 1, pp. 52-62.

Panksepp, J 2008, 'Cognitive conceptualism-where have all the affects gone? Additional corrections for Barrett et al. (2007)', Perspectives in Psychological Science, vol. 3, no. 4, pp. 305-308.

Paparoussi, M, Andreou, E \& Gkouni, V 2011, 'Approaching children's fears through bibliotherapy: a classroom-based intervention. part I: community-building and student learning', in J Hagen \& AT Kisubi (eds) Best Practices in Human Services: A Global Perspective, Council for Standards in Human Service Education (CSHSE), Alexandria, Virginia, USA, pp. 284300.

Pardeck, J 1990a, 'Bibliotherapy with abused children', Families in Society: The Journal of Contemporary Human Services, vol. 71, no. 4, pp. 229-235.

Pardeck, J 1990b, 'Using bibliotherapy in clinical practice with children', Psychological Reports, vol. 67, pp. 1043-1049.

Pardeck, J 1994, 'Using literature to help adolescents cope with problems', Adolescence, vol. 29, no. 114, pp. 421-428.

Pardeck, JT 1991a, 'Using books to prevent and treat adolescent chemical dependency', Adolescence, vol. 26, no. 101, pp. 201-208.

Pardeck, JT 1991b, 'Self-help books and clinical intervention', Journal of Instructional Psychology, vol. 18, no. 4, pp. 270-273.

Pardeck, JT 1993, 'Literature and adoptive children with disabilities', Early Child Development and Care, vol. 91, no. 1, pp. 33-39.

Pardeck, JT 1998, Using books in clinical social work practice: a guide to bibliotherapy, Haworth Press, New York, USA.

Pardeck JT 2006, Children's rights: policy and practice, $2^{\text {nd }}$ edn, Haworth Press, New York, USA.

Pardeck JT \& Markward, MJ 1995, 'Bibliotherapy: using books to help children deal with problems', Early Child Development and Care, vol. 106, pp. 75-90.

Pardeck, J \& Pardeck, J 1984, Young people with problems: a guide to bibliotherapy, Greenwood Press, Westport, Connecticut, USA.

Pardeck, J \& Pardeck, J 1985, 'Bibliotherapy using a new-Freudian approach with children of divorced parents', The School Counselor, vol. 32, pp. 313-318. 
Pardeck, J \& Pardeck, J 1986, Books for early childhood: a developmental perspective, Greenwood Press, Westport, Connecticut, USA.

Pardeck, JT \& Pardeck, JA 1998, Children in foster care and adoption: a guide to bibliotherapy, Greenwood Press, Westport, Connecticut, USA.

Pardini, J, Scogin, F, Schriver, J, Domino, M \& Wilson, D 2014, 'Efficacy and process of cognitive bibliotherapy for the treatment of depression in jail and prison inmates', Psychological Services, vol. 11, no. 2, pp. 141-152.

Park, RE \& Burgess, EW 1929, Introduction to the science of sociology, University of Chicago Press, $2^{\text {nd }}$ edn, viewed 3 October 2020, <http://www.gutenberg.org/ebooks/28496>.

Patel, V 1998, 'Understanding the integration of alternative modalities into an emerging healthcare model in the United States', In JM Humber \& RF Almeder (eds), Alternative Medicines and Ethics, Springer, New York, USA, pp. 43-96.

Patton, MJ 1991, 'Qualitative research on college students: philosophical and methodological comparisons with the quantitative approach', Journal of College Student Development, vol. 32, no. 5, pp. 389-396.

Pearl, R 2017, 11 things that will help you hold space for someone, GoodTherapy, 23 May, viewed 24 August 2020, <https://www.goodtherapy.org/blog/11-things-that-willhelp-you-hold-space-for-someone-0523175>.

Pecheur, DR \& Edwards, KJ 1984, 'A comparison of secular and religious versions of cognitive therapy with depressed Christian college students', Journal of Psychology and Theology, vol. 12, no. 1, 45-54.

Pehrsson, DE \& McMillen, PS 2004, 'Competent counselor practice for use of bibliotherapy', The Counselor, vol. 15, no. 6, pp. 1-7.

Pehrsson, DE \& McMillen, PS 2005, 'A bibliotherapy evaluation tool: grounding counselors in the therapeutic use of literature', The Arts in Psychotherapy, vol. 32, no. 1, pp. 47-59.

Pehrsson, DE \& McMillen, PS 2010, 'A national survey of bibliotherapy preparation and practices of professional counselors', Journal of Creativity in Mental Health, vol. 5, no. 4, pp. 412-425.

Peterson-Delaney, S 1938, 'The place of bibliotherapy in a hospital', Library Journal, vol. 63, pp. 305-308.

Pettersson, C 2018, 'Psychological well-being, improved self-confidence, and social capacity: bibliotherapy from a user perspective', Journal of Poetry Therapy, vol. 31, no. 2, pp. 124 134.

Phillips A \& Davis P 2019, 'Reading and Psychoanalysis', in J Billington (ed.), Reading and Mental Health, Palgrave Macmillan, London, UK, pp. 359-370.

Phillips, J 2001, Groupwork in social care, Jessica Kingsley Publishers, London, UK.

Pienaar, L \& Reynolds, F 2015, “'A respite thing': a qualitative study of a creative arts leisure programme for family caregivers of people with dementia', Health Psychology Open, vol. 2, no. 1, pp. 1-11. 
Pierce, M 2016, 3 core conditions for therapeutic change, True Self Counselling, viewed 9 October 2020, <https://trueselfcounseling.com/2016/02/20/3-core-conditions-fortherapeutic-change/>.

Pietkiewicz, I \& Smith, JA 2014, 'A practical guide to using Interpretative phenomenological analysis in qualitative research physiology', Czasopismo Psychologiczne-Psychological Journal, vol. 20, pp. 7-14.

Pino, MC \& Mazza, M 2016, 'The use of "literary fiction" to promote mentalizing ability', PLOS One, vol. 11, no. 8, pp. 1-14.

Plett, H 2015, 'What it means to "hold space" for people, plus eight tips to do it well', Heather Plett, viewed 9 October 2020, < https://heatherplett.com/2015/03/hold-space/>. Polkinghorne, DE 1989, 'Phenomenological research methods', in RS Valle \& S Halling (eds), Existential phenomenological perspectives in psychology, Springer, Boston, USA, pp. 41-60.

Pomeroy, E 1937, 'Bibliotherapy-a study in results of hospital library service', Medical Bulletin of the Veterans Administration, vol. 13, no. 4, pp. 360-364.

Porges, SW 2009, 'Reciprocal influences between body and brain in the perception and expression of affect', in D Fosha, DJ Siegel, \& MF Solomon (eds), The healing power of emotion: affective neuroscience, development \& clinical practice, Norton, New York, USA, pp. 27-54.

Preston-Shoot, M 2007, Effective Groupwork, 2nd edn, Palgrave Macmillan, London, UK.

Priest, RG, Hawley, CJ, Kibel, D, Turian, T, Montgomery, SA, Patel, AG, Smeyatsky, N \& Steinert, J 1996, 'Recovery from depressive illness does fit an exponential model', Journal of Clinical Psychopharmacology, vol. 16, no. 6, pp. 420-424.

Priestley, P \& Vanstone, M 2010, Offenders or citizens?: readings in rehabilitation, Willan, Cullompton, Devon, UK.

Probst, B \& Berenson, L 2014, 'The double arrow: how qualitative social work researchers use reflexivity', Qualitative Social Work, vol. 13, no. 6, pp. 813-827.

Psychotherapy and Counselling Federation of Australia (PACFA) n.d., 'What is therapy?', PACA, viewed 30 October 2020, <https://www.pacfa.org.au/community-resources/what-istherapy/>.

Purton, C 1998, 'Unconditional positive regard and its spiritual implications' in B Thorne \& E Lambers (eds), Person-centred therapy: a European perspective, Sage, London, UK, pp. 2337.

Ramon, S, Healy, B \& Renouf, N 2007, 'Recovery from mental illness as an emergent concept and practice in Australia and the UK', International Journal of Social Psychiatry', vol. 53, no. 2, pp. 108-122.

Ramsey, K 2019, 'Practising congruence and the art of 'being real', The Achologist, viewed 9 October 2020, <https://medium.com/achology/practising-congruence-and-the-art-of-beingreal-f597db16cf09>.

Rappaport, J 1995, 'Empowerment meets narrative: listening to stories and creating settings', American Journal of Community Psychology, vol. 23, no. 5, pp. 795-807. 
Rashid, T 2009, 'Positive interventions in clinical practice', Journal of Clinical Psychology, vol. 65 , no. 5, pp. 461-466.

Ratcliffe, R 2012, 'Phenomenology as a form of empathy, Inquiry, vol. 55, no. 5, 473-495.

Rather, BC 1995, 'Alcoholics anonymous and rational recovery: readability of the 'big book' vs the small book', Perceptual and Motor Skills, vol. 81, no. 3 (part 2), pp. 1313-1314.

Regan, M, Elliott, I \& Goldie, I 2016, Better mental health for all: a public health approach to mental health improvement, Faculty of Public Health, and Mental Health Foundation, London, UK, viewed 21 November 2018, <https://www.mentalhealth.org.uk/sites/default/files/Better\%20MH\%20for\%20all\%20web. pdf>.

Reid, K, Flowers, P \& Larkin, M 2005, 'Exploring the lived experience', The Psychologist, vol. 18 , no. 1 , pp. 20-23.

Reynolds, S, Welch, B \& Carroll, M 2012, 'Passionate practitioners: engaging not just the head but also the heart', Education for Information, vol. 29, no. 3-4, pp. 243-251.

Rich, A \& Bernstein, JE 1975, 'The picture book image of entering school', National Council of Teachers of English, vol. 52, no. 7, pp. 978-982.

Richards, JC \& Alvarenga, ME 2002, 'Extension and replication of an internet-based treatment program for panic disorder', Cognitive Behaviour Therapy, vol. 31, no. 1, pp. 4147.

Richardson, R, Richards, D \& Barkham, M 2008, 'Self-help books for people with depression: a scoping review', Journal of Mental Health, vol. 17, no. 5, pp. 543-552.

Riordan, RJ, Mullis, F \& Nuchow, L 1996, 'Organizing for bibliotherapy: the science in the art', Individual Psychology: The Journal of Adlerian Theory, Research and Practice, vol. 52, no. 2 , pp. $169-180$.

Riva, G, Bacchetta, M, Cesa, MS, Conti, MS \& Molinari, E 2003, 'Six-month follow-up of inpatient experiential cognitive therapy for binge eating disorders', Cyberpsychology \& Behavior, vol. 6, no. 3, pp. 251-258.

Roberts, R 2013, 'Museums as sites of "being in conversation": a hermeneutic phenomenological study', PhD thesis, Antioch University, Seattle, USA.

Robinson, J \& Billington, J 2013, An evaluation of a pilot study of a literature-based intervention with women in prison, Centre for Research into Reading, Information and Linguistic Systems, University of Liverpool, UK, viewed 16 July 2014, <http://www.thereader.org.uk/media/73499/CRILS_Short_Report_web.pdf>.

Rockne Corrigan, D 2020, What happens when a library becomes a refuge for the homeless, TVO, 10 March, viewed 13 September 2020, <https://www.tvo.org/article/what-happenswhen-a-library-becomes-a-refuge-for-the-homeless>.

Rogers, C 1951, Client-centered therapy: its current practice, implications and theory, Constable, London, UK.

Rogers, C 1957, 'The necessary and sufficient conditions of therapeutic personality change', The Journal of Consulting Psychology, vol. 21, no. 2, pp. 95-103.

Rogers, C 1959, 'A theory of therapy, personality and interpersonal relationships as 
developed in the client-centered framework', in S. Koch (ed.), Psychology: a study of a science, study 1, vol. 3: formulations of the person and the social context, McGraw Hill, New York, USA, pp. 184-256.

Rogers, C 1971, 'Carl Rogers describes his way of facilitating encounter groups', The American Journal of Nursing, vol. 71, no. 2, pp. 275-279.

Rogers, C 1980, A way of being, Houghton Mifflin, Boston, USA.

Rogers, C n.d., Experiences in communication, ListeningWay, viewed 6 October 2020, <http://www.listeningway.com/rogers2-eng.html>.

Rogers, CR, 1961, On becoming a person: a psychotherapists view of psychotherapy, Houghton Mifflin, Boston, USA.

Roger, CR 1987, 'Rogers, Kohut, and Erickson: a personal perspective on some similarities and differences', in JK Zeig (ed.), The evolution of psychotherapy, Brunner/Mazel, New York, USA, pp. 179-187.

Rogers, CR \& Farson, RE 1987, 'Active listening', in RG Newman, MA Danzinger \& M Cohen (eds), Communicating in Business Today, DC Heath, Massachusetts, USA, pp. 1-5.

Rohen, N 2002, 'Analysis of efficacy and mediators of outcome in minimal contact cognitive bibliotherapy used in the treatment of depressive symptoms', PhD thesis, University of Alabama, Tuscaloosa, USA.

Rosenblatt, LM 1938, Literature as exploration, Appleton-Century, New York, USA.

Rosenblatt, LM 1969, 'Towards a transactional theory of reading', Journal of Reading Behavior, vol. 1, no. 1, pp. 31-49.

Rosenblatt, LM 1978, The reader, the text, the poem: the transactional theory of the literary work, Southern Illinois University Press, Carbondale, Illinois, USA.

Rosenblatt, LM 1981, 'On the aesthetic as the basic model of the reading process', Bucknell Review, vol. 26, no. 1, pp. 17-32.

Rosenblatt, LM 1985, 'Transaction versus interaction: a terminological rescue operation', Research in the Teaching of English, vol. 19, pp. 96-107.

Rothbaum, BO, Hodges, L, Ready, D, Grapp, K \& Alarcon, R 2001, 'Virtual reality exposure therapy for Vietnam veterans with posttraumatic stress disorder', Journal of Clinical Psychiatry, vol. 62, no. 8, pp. 617-622.

Rubin, RJ 1978a, Bibliotherapy sourcebook, Oryx Press, Phoenix, Arizona, USA.

Rubin, RJ 1978b, Using bibliotherapy: a guide to theory and practice, Oryx Press, Phoenix, Arizona, USA.

Rubin, RJ 1979, 'Use of bibliotherapy in response to the 1970s', Library Trends vol. 28, no. 2, pp. 239-252.

Runyan, WM 1983, 'Idiographic goals and methods in the study of lives', Journal of Personality', vol. 51, no. 3, pp. 413-437.

Russell, D \& Shrodes, C 1950a, 'Contributions of research in bibliotherapy to the languagearts program. I', School Review, vol. 58, no. 7, pp. 335-342. 
Russell, D \& Shrodes, C 1950b, 'Contributions of research in bibliotherapy to the languagearts program. II', School Review, vol. 58, pp. 411-420.

Salkovskis, P, Rimes, K, Stephenson, D, Sack, G \& Scott, J 2006, 'A randomised controlled trial of the use of self-help materials in addition to standard general practice treatment of depression compared to standard treatment alone', Psychological Medicine, vol. 36, no. 3, pp. 325-333.

Salup, BJ \& Salup, A 1981, 'Bibliotherapy: an historical overview', ERIC Document Reproduction Service, <https://eric.ed.gov/?id=ED200896>.

Sandelowski, M 1995, 'Sample size in qualitative research', Research in Nursing and Health, vol. 18 , no. 2, pp. 179-183.

Sandelowski, M 2006, 'Critical appraisal of rigor in interpretive phenomenological nursing research', Journal of Advanced Nursing, vol. 55, no. 5, pp. 643-645.

Scharmer, CO 2009, Theory U: leading from the future as it emerges, Berrett-Koehler Publishers, Inc., Oakland, California, USA.

Schlenther, E 1999, 'Using reading therapy with children', Health Libraries Review, vol. 16, pp. 29-37.

Schneider, RH, Alexander, CN, Staggers F, Rainforth, M, Salerno, JW, Hartz, A, Arndt, S, Barnes, VA \& Nidich, SI 2005, 'Long-term effects of stress reduction on mortality in persons $>$ or $=55$ years of age with systemic hypertension', American Journal of Cardiology, vol. 95, no. 9, pp. 1060-1064.

Schutt, RK, Deng, X \& Stoehr, T 2013, 'Using bibliotherapy to enhance probation and reduce recidivism', Journal of Offender Rehabilitation, vol. 52, no. 3, pp. 181-197.

Sclabassi, S 1973, 'Literature as a therapeutic tool: a review of the literature on bibliotherapy', American Journal of Psychotherapy, vol. 27, no. 1, pp. 70-77.

Seligman, MEP, Randal, ME, Gillham, J, Reivich, K \& Linkins, M 2009, 'Positive education: positive psychology and classroom intervention', Oxford Review of Education, vol. 58, no. 3, pp. 293-311.

Senge, P, Scharmer, O, Jaworski J, \& Flowers, BS 2004, Presence: human purpose and the field of the future, The Society for Organizational Learning, Cambridge, Massachusetts, USA.

Shadish, WR \& Sweeney, RB 1991, 'Mediators and moderators in meta-analysis: there's a reason we don't let dodo birds tell us which psychotherapies should have prizes', Journal of Consulting and Clinical Psychology, vol. 59, no. 6, pp. 883-893.

Shahzad, S, Begum, N \& Malik, S 2014, 'Multi-dimensional perceived social support as determinant of wellbeing in people with substance use disorder', International Journal of Prevention and Treatment of Substance Use Disorders, pp. 63-70.

Shakespeare, W [159-?], Titus Andronicus, viewed 19 July 2020,

$<$ http://shakespeare.mit.edu/titus/titus.4.1.html>.

Sharp DM, Power KG \& Swanson V 2000, 'Reducing therapist contact in cognitive behaviour therapy for panic disorder and agoraphobia in primary care: global measures of outcome in a randomised controlled trial', British Journal of General Practice, vol. 50, no. 461, pp. 963-968. 
Shechtman, Z \& Nir-Shfrir, R 2008, 'The effect of affective bibliotherapy on clients' functioning in group therapy', International Journal of Group Psychotherapy, vol. 58, no. 1, pp. 103-117.

Shrodes, C 1949, 'Bibliotherapy: a theoretical and clinical-experimental study', PhD thesis, University of California, Berkeley, California, USA.

Sibbet, D 2002, Principles of facilitation: the purpose and potential of leading group process, Grove Consultants International, San Francisco, USA.

Slade, M 2009, '100 ways to support recovery: a guide for mental health professionals', Rethink Recovery Series, vol. 1, viewed 22 June 2012, <http://deskuul.nl/afbeeldingen/2014/12/100_ways_to_support_recovery.pdf>.

Slade, M 2010, 'Mental illness and well-being: the central importance of positive psychology and recovery approaches', BMC Health Services Research, vol. 10, no. 26, pp. 1-14.

Smith, JA 1996a, 'Beyond the divide between cognition and discourse: using interpretative phenomenological analysis in health psychology', Psychology and health, vol. 11, no. 2, pp. 261-271.

Smith, JA 1996b, 'Qualitative methodology: analysing participants' perspectives', Current Opinion in Psychiatry, vol. 9, pp. 417-421.

Smith, JA 2007, 'Hermeneutics, human sciences and health: linking theory and practice', International Journal of Qualitative Studies on Health and Well-being, vol. 2, no. 1, pp. 3-11.

Smith, JA 2009, Interpretative phenomenological analysis: theory, method and research, Sage, London, UK.

Smith, JA 2011a, 'Evaluating the contribution of interpretative phenomenological analysis', Health Psychology Review, vol. 5, no. 1, pp. 9-27.

Smith JA 2011b, 'Evaluating the contribution of interpretative phenomenological analysis: a reply to the commentaries and further development of criteria', Health Psychology Review, vol. 5, no. 1, pp. 55-61.

Smith, JA 2011c "We could be diving for pearls": the value of the gem in experimental qualitative psychology', Qualitative Methods in Psychology Bulletin, vol. 12, pp. 6-15.

Smith, JA, Flowers, P \& Larkin, M 2009, Interpretative Phenomenological Analysis: theory, method and research, Sage, London, UK.

Smith, JA, Jarman, M \& Osborn, M 1999, 'Doing interpretative phenomenological analysis', in M Murray \& K Chamberlain (eds), Qualitative health psychology: theories and methods, Sage, London, UK, pp. 218-241.

Smith, JA \& Osborn, M 2003, Interpretative phenomenological analysis, in JA Smith (ed.), Qualitative psychology: a practical guide to research methods, Sage, London, UK, pp. 51-80.

Smith, JA \& Osborn, M 2007, 'Interpretative phenomenological analysis as a useful methodology for research on the lived experience of pain', British Journal of Pain, vol. 9, no. 1, pp. 41-42.

Smith, JA \& Osborn, M 2007, 'Pain as an assault on the self: an interpretive phenomenological analysis of the psychological impact of chronic back pain', Psychology and Health, vol. 22, no. 5, pp. 517-534. 
Smith, K 2013, Reverie and its afterglow, The Sydney Morning Herald, 8 July, viewed 27 November 2020, <https://www.smh.com.au/education/reverie-and-its-afterglow20130705-2pfxb.html>.

Smith, NM, Floyd, MR, Scogin, F \& Jamison, CS 1997, 'Three-year follow-up of bibliotherapy for depression', Journal of Consulting Clinical Psychology, vol. 65, no. 2, pp. 324-327.

Smith, R, Alkozei, A, Bao, J, Smith, C, Lane, RD \& Kilgore, RDS 2017, 'Resting state functional connectivity correlates of emotional awareness', Neurolmage, vol. 159, no. 1, pp. 99-106.

Solli, HP \& Rolvsjord, R 2014, “"The opposite of treatment": a qualitative study of how patients diagnosed with psychosis experience music therapy', Nordic Journal of Music Therapy, vol. 21, no. 1, pp. 67-92.

Southcott, J \& Joseph, D 2014 'Singing in La Voce Della Luna Italian women's choir in Melbourne, Australia', International Journal of Music Education, vol. 33, no. 1, pp. 91-102.

Spanos Dunfey, T 2019, What is social change and why should we care?, Southern New Hampshire University, USA, viewed 30 October 2020, < https://www.snhu.edu/aboutus/newsroom/2017/11/what-is-socialchange\#: :text=Social\%20change\%20is\%20way\%20human,a\%20profound\%20impact\%20of \%20society.\&text=Relationships\%20have\%20changed\%2C\%20institutions\%20have,That's\%2 Opretty\%20heady\%20stuff>.

Spielmans, GI, Pasek, LF \& McFall, JP 2007, 'What are the active ingredients in cognitive and behavioral psychotherapy for anxious and depressed children? A meta-analytic review', Clinical Psychology Review, vol. 27, pp. 642-654.

Stanley, M \& Nayar, S 2014, 'Deepening understandings', in S Nayar \& M Stanley (eds), Qualitative research methodologies for occupational science and therapy, Routledge, New York, USA, pp. 8-20.

State Library Victoria 2011, Dollars, sense and public libraries: technical report, State Library Victoria, viewed 31 December 2020, $<$ https://www.libraries.vic.gov.au/downloads/Dollars_Sense_and_Public_Libraries/2011032 2_sl_techrep_full_final.pdf>.

State Library Victoria, Public Libraries Victoria Network \& Chasing Sunrises, 2013, The Victorian public libraries 2030: strategic framework, State Library Victoria, viewed 31 December 2020, <https://apo.org.au/sites/default/files/resource-files/2013-06/aponid34720.pdf>.

State Library Victoria 2020a, Bibliotherapy for kids with State Library Victoria, State Library Victoria, viewed 27 July 2020, <https://www.slv.vic.gov.au/whats-on/bibliotherapy-kids>.

State Library Victoria, 2020b, Bibliotherapy with State Library Victoria, State Library Victoria, viewed 27 July 2020, <https://www.slv.vic.gov.au/bibliotherapy>.

Steenberg, M, Christiansen, C \& Ladegaard, N 2019, 'Time to read-a mixed method study of mental health effects of shared reading' in J Billington (ed.), Reading and Mental Health, Palgrave Macmillan, London, UK, pp. 272-280.

Stern, DB 1994, 'Empathy is interpretation (and who ever said it wasn't?)', Psychoanalytic Dialogues, vol. 4, no. 3, pp. 441-471. 
Stevens, G, Seid, M, Mistry, R \& Halfon, N 2006, 'Disparities in primary care for vulnerable children: the influence of multiple risk factors', Health services research, vol. 41, no. 2, pp. 507-31.

Stoehr, T 2016, Changing lives through literature, Routledge, New York, USA.

Straus, D 2002, How to make collaboration work: powerful ways to build consensus, solve problems, and make decisions, Berrett-Koehler Publishers, California, USA.

Ström, L, Pettersson, R \& Andersson, G 2000, 'A controlled trial of self-help treatment of recurrent headache conducted via the internet', Journal of Consulting and Clinical Psychology, vol. 68, no. 4, pp. 722-727.

Ström, L, Pettersson, R \& Andersson, G 2004, 'Internet-based treatment for insomnia: a controlled evaluation, Journal of Consulting and Clinical Psychology, vol. 72, no 1, pp. 113120.

Sturm, BW 2003, 'Reader's advisory and bibliotherapy: helping or healing?', Journal of Educational Media \& Library Sciences, vol. 41, no.2, pp. 171-79.

Suddaby, R 2006, 'From the editors: what grounded theory is not', Academy of Management Journal, vol. 49, no. 4, pp. 633-642.

Sullivan, AK \& Strang, HR 2002/2003, 'Bibliotherapy in the classroom: using literature to promote the development of emotional intelligence', Childhood Education, Winter 2002/2003, vol. 79, no. 3, pp. 74-80.

Sweeny, S \& O'Connell, R 2015, 'Puts the magic back into life: fathers' experience of planned home birth', Women and Birth, vol. 28, pp. 148-153.

Tawell, A, Thompson, I, Daniels, H, Elliott, V, Dingwall, N, Rubtsova, O \& Munk, K 2015, Being other: the effectiveness of arts based approaches in engaging with disaffected young people, University of Oxford, Department of Education, Oxford, UK.

Taylor, C 1971, 'Interpretation and the sciences of man', The Review of Metaphysics, vol. 25, no. 1 , pp. 3-51.

Tews, RM 1962, 'Introduction', Library Trends, vol. 11, no. 2, pp. 97-105.

The Australian, New Zealand and Asian Creative Arts Therapy Association, n.d. viewed 24 January 2013, < https://www.anzacata.org/>.

The Dax Centre 2015, Reverie, Sane Australia, viewed 27 November 2020, <https://www.daxcentre.org/portfolio/reverie/>.

The Network 2016, Words work well Scotland bibliotherapy toolkit, Lapidus Scotland and NHS Education for Scotland, viewed 11 April 2020, <https://www.seapn.org.uk/post/wordswork-well-scotland-bibliotherapy-toolkit>.

The Reader Organisation 2012, Upcoming open Read to Lead courses, The Reader Organisation, UK, viewed 26 July 2020, <https://www.thereader.org.uk/upcoming-openread-to-lead-courses/>.

The Reader Organisation 2020a, Join our online events, The Reader Organisation, UK, viewed 27 July 2020, <https://www.thereader.org.uk/get-involved/the-reader-at-home/>. 
The Reader Organisation 2020b, Ready and waiting: what the voluntary sector can do for social prescribing in Liverpool, The Reader Organisation, UK, viewed 20 December 2020, $<$ https://www.thereader.org.uk/wp-content/uploads/2020/11/SLC-Project-Report-2020F.pdf>.

The Reader Organisation 2021, What we do: the Reader brings people together and books to life, The Reader Organisation, UK, viewed 9 January 2021, <https://www.thereader.org.uk/what-we-do/>.

The School of Life n.d., Bibliotherapy, The School of Life, viewed 24 August 2017, $<$ https://www.theschooloflife.com/shop/bibliotherapy/>.

Thomashoff, H-O, Kopytin, A \& Sukhanova, E 2009, 'How to overcome psychiatric stigma through art', Advances in Psychiatry, vol. 3, pp. 223-233.

Tietjen, MC 1980, 'Medicine for the soul', ERIC Document Reproduction Service, Document number ED200232, viewed 5 January 2021,

$<$ https://eric.ed.gov/?q=Tietjen\%2c+MC+1980\%2c+\%e2\%80\%98Medicine+for+the+soul\%e2 \%80\%99\&id=ED200232>.

Tillfors, M, Carlbring, P, Furmark, T, Lewenhaupt, S, Spak, M, Eriksson, A, Westling, BE \& Andersson, G 2008, 'Treating university students with social phobia and public speaking fears: internet delivered self-help with or without live group exposure sessions', Depression and Anxiety, vol. 25, pp. 708-717.

Todorova, I 2011, 'Explorations with interpretative phenomenological analysis in different socio-cultural contexts', Health Psychology Review, vol. 5, no. 1, pp. 34-38.

Tolin, DF, Hannan, S, Maltby, N, Diefenbach, G. J, Worhunsky, P \& Brady, RE 2007, 'A randomized controlled trial of self-directed versus therapist-directed cognitive-behavioral therapy for obsessive-compulsive disorder patients with prior medication trials', Behavior Therapy, vol. 38, no. 2, pp. 179-191.

Tomkins, L \& Eatough, V 2010, 'Reflecting on the use of IPA with focus groups: pitfalls and potentials', Qualitative Research in Psychology, vol. 7, no. 3, pp. 244-262.

Topsfield, J 2019, New chapter for the homeless as City Library hires social worker, The Age, Melbourne, Victoria, 28 August, viewed 23 August 2020,

$<$ https://www.theage.com.au/national/victoria/new-chapter-for-the-homeless-as-citylibrary-hires-social-worker-20190828-p52lp3.html>.

Toseland, R 2017, 'Group dynamics' in C Garvin, LM Gutiérrez \& MJ Galinsky (eds), Handbook of social work with groups, The Guilford Press, New York, USA, pp. 9-27.

Toseland, RW, Jones, LV \& Gellis, ZD 2004, 'Group dynamics', in CD Garvin, LM Gutiérrez, \& MJ Galinsky (eds), Handbook of social work with groups, The Guilford Press, New York, USA, pp. 13-31.

Toseland, RW \& Rivas, RF 2005, 'Understanding group dynamics' in RW Toseland \& RF Rivas (eds), An introduction to group work practice, Pearson, Boston, Massachusetts, USA, pp. 6491.

Treasure, J, Schmidt, U, Troop, N, Tiller, J, Todd, G \& Turnbull, S 1996, 'Sequential treatment for bulimia nervosa incorporating a self-care manual', The British Journal of Psychiatry, vol. 168, no. 1, pp. 94-98. 
Trevarthen, C 2009, 'The functions of emotion in infancy: the regulation and communication of rhythm, sympathy, and meaning in human development', in D Fosha, DJ Siegel, MF Solomon (eds), The healing power of emotion: affective neuroscience, development \& clinical practice', W.W. Norton, New York, USA, pp. 55-85.

Troop, NA, Schmidt, MRC, Treasure, JL 1995, 'Feelings and fantasy in eating disorders: a factor analysis of the Toronto alexithymia scale', Eating Disorders, vol. 18, no. 2, pp. 151157.

Tu, W 1999, 'Using literature to help children cope with problems', ERIC Document Reproduction Service, <https://files.eric.ed.gov/fulltext/ED436008.pdf>.

Tudor, K 2011, 'Understanding empathy', Transactional Analysis Journal, vol. 41, no. 1, pp. 39-57.

Tukhareli, N 2011, 'Bibliotherapy in a library setting: reaching out to vulnerable youth', The Canadian Journal of Library and Information Practice and Research, vol. 6, no. 1, pp. 1-18.

Tukhareli, N 2014, Using bibliotherapy to promote consumer health information in a library setting, Conference paper, viewed 30 September 2014,

<https://www.researchgate.net/publication/274958711_Using_bibliotherapy_to_promote_ consumer_health_information_in_a_library_setting>.

Tukhareli, N 2018, 'Read to connect: reading to combat loneliness and promote resilience' in S McNichol \& L Brewster (eds), Bibliotherapy, Facet Publishing, London, UK, pp. 77-92.

Vallani, D, Riva, F \& Riva, G 2007, 'New technologies for relaxation: the role of presence', International Journal of Stress Management, vol. 14, no. 3, pp. 260-274.

Van Lankveld, JDM 1998, 'Bibliotherapy in the treatment of sexual dysfunctions: a metaanalysis', Journal of Consulting and Clinical Psychology, vol. 66, no. 4, 702-708.

Van Manen, M 1990, Researching lived experience: human science for an action sensitive pedagogy, SUNY Press, New York, USA.

Vannicelli, M 2001, 'Moderation training for problem drinkers: treatment techniques and clinical considerations', Cognitive and Behavioral Practice, vol. 8, no. 1, pp. 53-61.

Vasileiou, K, Barnett, J, Thorpe, S, \& Young, T 2018, 'Characterising and justifying sample size sufficiency in interview-based studies: systematic analysis of qualitative health research over a 15-year period', BMC Medical Research Methodology, vol. 18, no. 1, pp. 1-18.

Vernberg, D \& Schuh, MJ 2002, 'Internet bibliotherapy: a narrative analysis of a reading simulated support group', Journal of Social Work in Disability \& Rehabilitation, vol. 1, no. 1, pp. 81-97.

VicHealth 2010, 'Building health through arts and new media', VicHealth action plan 201013, viewed 29 January 2018, <https://www.vichealth.vic.gov.au/media-andresources/publications/building-health-through-arts-and-new-medią>.

Victoria Government 2015, Victorian public health and wellbeing plan 2015-2019, viewed 16 July 2016, <https://www2.health.vic.gov.au/Api/downloadmedia/\%7BB5380E79-EF3F4DFD-B16F-3CAA2AD640E8\%7D>. 
Victoria Government 2019, Victorian public health and wellbeing plan 2019-2023, viewed 28 December 2020, <https://www2.health.vic.gov.au/about/publications/ policiesandguidelines/victorian-public-health-wellbeing-plan-2019-2023>.

Volpe, U, Torre, F, De Santis, V, Perris, F \& Catapano, F 2013, 'Reading group rehabilitation for patients with psychosis: a randomized controlled study', Clinical Psychology and Psychotherapy, vol. 22, no. 1, pp. 15-21.

Wagstaff, C, Jeong, H, Nolan, M, Wilson, T, Tweedlie, J, Phillips, E, Senu, H \& Holland, H 2014, 'The accordion and the deep bowl of spaghetti: eight researchers' experiences of using IPA as a methodology', The Qualitative Report, vol. 19, no. 24, pp. 1-15.

Wainer, J \& Chester, J 2000, 'Rural mental health: neither romanticism nor despair', Australian Journal of Rural Health, vol. 8, pp. 141-147.

Waite, P, McManus \& Shafran, R 2012, 'Cognitive behaviour therapy for low self-esteem: a preliminary randomized controlled trial in a primary care setting', Journal of Behaviour Therapy and Experimental Psychiatry, vol. 43, no. 4, pp. 1049-1057.

Walter, IR 2016, Therapist integrity: how to hold space and hope for therapy clients, Family Therapy Basics, 20 December, viewed 23 August 2020, $<$ https://familytherapybasics.com/blog/2016/12/19/therapist-integrity-how-to-hold-spaceand-hope-for-your-therapy-clients>.

Walworth, RM 2018a, 'Adapting the Books on Prescription model for people living with dementia and their carers', in S McNichol \& L Brewster (eds), Bibliotherapy, Facet Publishing, London, UK, pp. 141-152.

Walworth, RM 2018b, 'Engaging young people in bibliotherapy and reading for wellbeing', in S McNichol \& L Brewster (eds), Bibliotherapy, Facet Publishing, London, UK, pp. 143-162.

Ward, D \& Mullender, A 1991, 'Empowerment and oppression: an indissoluble pairing for contemporary social work', Critical Social Policy, vol. 11, no. 32, pp. 21-30.

Ward, RL \& Miller, PK 2013, 'Depression, physical activity and mental health: an interpretative phenomenological analysis of general practitioners' experiences of exercise referral schemes in the North West', Cumbria Partnership Journal of Research Practice and Learning, vol. 3, no. 1, pp. 13-19.

Watzlawick, P, Bavelas, JB \& Jackson, DD 2011, Pragmatics of human connection: a study of interaction patterns, pathologies and paradoxes, Norton, New York, USA.

Waxman, L, Clemons, S, Banning, J \& McKelfresh, D 2007, 'The library as place: providing students with opportunities for socialization, relaxation, and restoration', New Library World, vol. 108, no. 9/10, pp. 424-434.

Weimerskirch, PJ 1965, 'Benjamin Rush and John Minson Galt II: pioneers of bibliotherapy in America', Bulletin of the Medical Library Association, vol. 53, no. 4, pp. 510-526.

Wennerstrom, A 2001, The music of everyday speech: prosody and discourse analysis, Oxford University Press, New York, USA.

Whyte, D 2014, Consolations: the solace, nourishment and underlying meaning of everyday words, Many Rivers Press, Langley, Washington, US. 
Whyte, D 2017, A lyrical bridge between past, present and future, TED2017, viewed 22 August 2020, <https://www.ted.com/talks/

david_whyte_a_lyrical_bridge_between_past_present_and_future?language $=e n>$.

Wilkins, P 2000, 'Unconditional positive regard reconsidered', British Journal of Guidance \& Counselling, vol. 28, no. 1, pp. 23-36.

Williams, C, Wilson, P, Morrison, J, McMahon, A, Walker, A, Lesley, A, McConnachie, A, McNeill, Y \& Tansey, L 2013, 'Guided self-help cognitive behavioural therapy for depression in primary care: a randomised controlled trial.' PLOS ONE, vol. 8, no. 1, pp. 1-7.

Willig, C 2001, Introducing qualitative research in psychology, Open University Press, Berkshire, UK.

Wilson, A 2014, 'Being a practitioner: an application of Heidegger's phenomenology', Nurse Researcher, vol. 21, no. 6, pp. 28-33.

Wilson, S \& Thornton, S 2007/08, 'The factor that makes us more effective teachers: two preservice primary teachers' experience of bibliotherapy', Mathematics Teachers Education \& Development, vol. 9, pp. 21-35.

Winnicott, DW 2005, Playing and reality, Routledge, Abingdon, Oxonbury, UK.

Witty, PA 1964, 'Meeting development needs through reading', Education, vol. 84, pp. 451457.

Wollersheim, JP \& Wilson, GL 1991, 'Group treatment of unipolar depression: a comparison of coping, supportive, bibliotherapy, and delayed treatment groups', Professional Psychology: Research and Practice, vol. 22, no. 6, 496-502.

Wood, A 2005, 'Student practice contexts: changing face, changing place', British Journal of Occupational Therapy, vol. 68, no. 8, pp. 375-378.

Wood, AM \& Tarrier, N 2010, 'Positive clinical psychology: a new visions and strategy for integrated research and practice', Clinical Psychology Review, vol. 30, no. 7, pp. 819-829.

Woods S, Finnis, A, Khan, H \& Ejbye, J 2016, At the heart of health: realising the value of people and communities, Realising the Value, viewed 28 July 2020, $<$ https://media.nesta.org.uk/documents/at_the_heart_of_health__realising_the_value_of_people_and_communities.pdf $>$.

Wootton, BM, Dear, BF, Johnston, L, Terides, MD \& Titov, N 2013, 'Remote treatment of obsessive-compulsive disorder: a randomized controlled trial', Journal of ObsessiveCompulsive and Related Disorders, vol. 2, no. 4, pp. 375-384.

Wootton, BM, Titov, N, Dear, BF, Spence, J, Andrews, G \& Johnston, L 2011, 'An internet administered treatment program for obsessive-compulsive disorder: a feasibility study', Journal of Anxiety Disorders, vol. 25, no. 8, pp. 1102-1107.

World Health Organization 1946, Constitution, World Health Organization, viewed 26 September 2012, <https://www.who.int/about/who-we-are/constitution>.

World Health Organization 2017, Human Rights Day 2017, World Health Organization viewed 10 July 2020, <https://www.who.int/mediacentre/news/statements/ fundamental-human-right/en/>. 
Zaccaria, JS \& Moses, HA 1968, Facilitating human development through reading: the use of bibliotherapy in teaching and counselling, Stripes Publishing Company, London, UK.

Zamawe, FC 2015, 'The implication of using NVivo software in qualitative data analysis:

evidence-based reflections', Malawi Medical Journal, vol. 27, no. 1, pp. 13-15.

Zettervall, S n.d., Whole person librarianship, Whole Person Librarianship, viewed 29 August 2020, <https://wholepersonlibrarianship.com/about-2/>.

Zhong, C-B \& Leonardelli, GJ 2008, 'Cold and lonely: does social exclusion literally feel cold?', Psychological Science, vol. 19, no. 9, pp. 838-842. 


\section{Appendix One: Ethics approval}

As discussed in Chapter 3.2.2: Ethics, the below document provides the approval from the Business College Human Ethics Advisory Network (BCHEAN) on 22 August 2013.

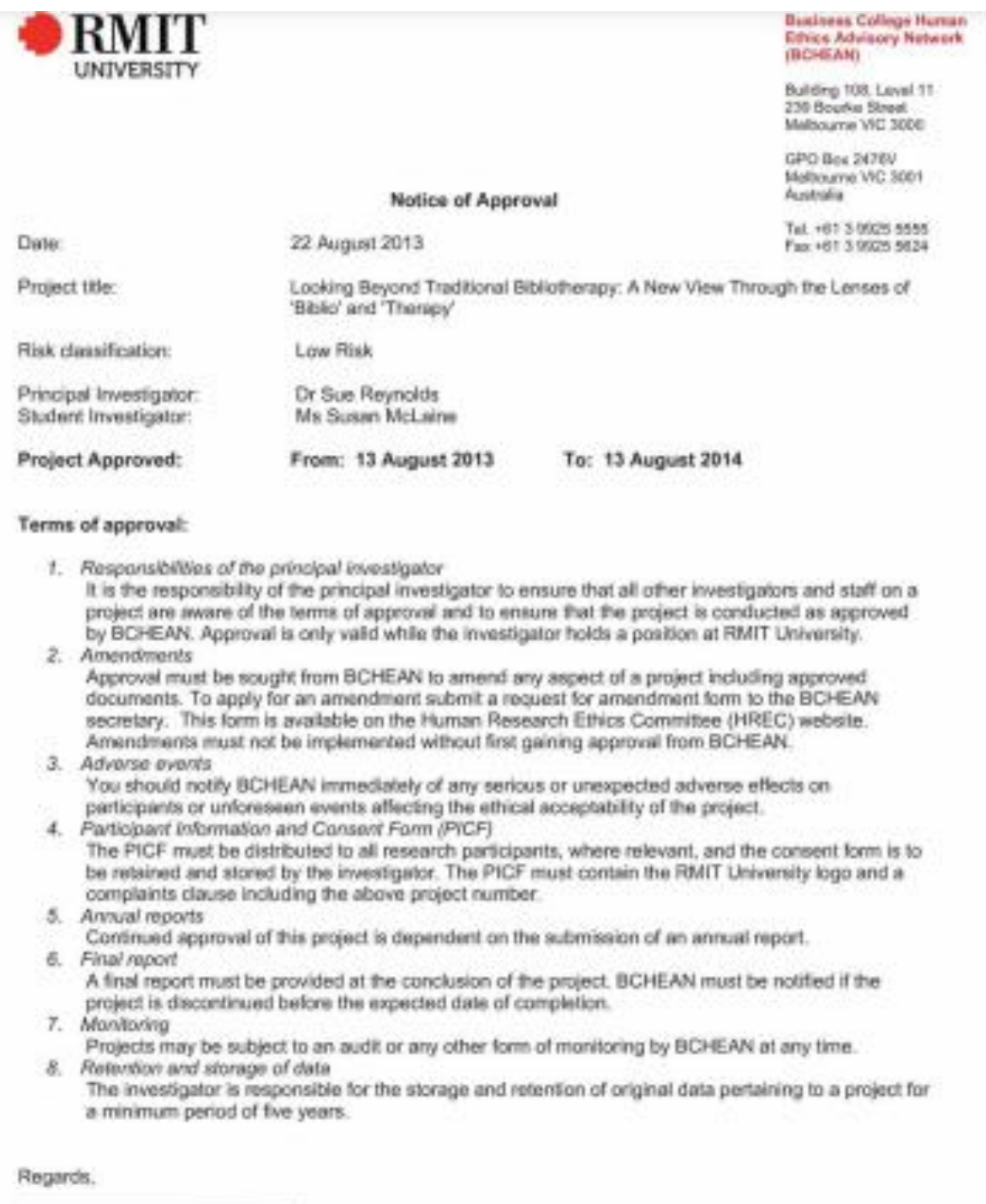

Protessor Rostyn Russel

Chsmerson
FMIT GCHEAN 


\section{Appendix Two: Interview questions}

As discussed in Chapter 3.2.3: Interview question development, the below table provides a full list of interview questions.

\begin{tabular}{|c|c|}
\hline No & Question \\
\hline & BACKGROUND TO THE TRAINING \\
\hline 1 & $\begin{array}{l}\text { What were you looking for when you decided to take part in the training? } \\
\text { To what extent were your expectations met? } \\
\text { Probe question: } \\
\text { How do you view the training now? Did it prepare you to do what you wanted } \\
\text { to do by taking the training? } \\
\text { It would be interesting to explore what has informed these changes over } \\
\text { time. l'd like to come back to that a little later. }\end{array}$ \\
\hline 2 & $\begin{array}{l}\text { If somebody asked you - someone who didn't know anything about it - asked } \\
\text { you 'what is bibliotherapy' how would you describe it? } \\
\text { Probe question: } \\
\text { Was that your understanding of bibliotherapy prior to doing the 'Read to } \\
\text { Lead' training? } \\
\text { Did the 'Read to Lead' training provide the theories underpinning the } \\
\text { therapeutic context and why/how it achieves therapeutic benefits? }\end{array}$ \\
\hline & NOW WE ARE GOING TO TALK A BIT ABOUT YOUR BACKGROUND \\
\hline 3 & $\begin{array}{l}\text { How did the training relate to your work as a ...? } \\
\text { Probe question: } \\
\text { Did you see this as an extension of your work as a ...? }\end{array}$ \\
\hline 4 & $\begin{array}{l}\text { What are the professional and personal characteristics you believe you bring } \\
\text { to bibliotherapy? } \\
\text { Probe questions: } \\
\text { What are your professional qualifications? } \\
\text { Had you had past personal or professional experience with people } \\
\text { experiencing mental illness? } \\
\text { If yes, How do you feel your previous experience informed the way you } \\
\text { responded to the 'Read to Lead' training? } \\
\text { If no, Did the training prepare you, and assist you to feel confident, to deliver } \\
\text { sessions to group members experiencing mental illness? } \\
\text { If no, what did you feel you needed? } \\
\text { If yes, what did the training include that supported you to prepare to assist } \\
\text { people with mental illness? } \\
\text { Have you since the training experienced working with group members } \\
\text { experiencing mental illness? } \\
\text { Has the way you deliver a session changed from this experience? Can you }\end{array}$ \\
\hline
\end{tabular}




\begin{tabular}{|c|c|}
\hline & describe that to me? \\
\hline & THE TRAINING EXPERIENCE \\
\hline 5 & $\begin{array}{l}\text { Texts: } \\
\text { Tell me how the training provided you with suitable texts to use in } \\
\text { bibliotherapy groups. } \\
\text { Probe questions: } \\
\text { Do you tend to use texts you are familiar with when facilitating sessions? } \\
\text { What do you look for in a text to add it to those used in your sessions? } \\
\text { Do factors change for selecting texts to use for different groups? What } \\
\text { determines which texts you use with different groups in different settings? } \\
\text { What makes a text good or bad to work with? }\end{array}$ \\
\hline 6 & $\begin{array}{l}\text { Using a text: } \\
\text { The GIR model is based on group members sharing the reading with many } \\
\text { pauses for discussion throughout the story. Can you tell me about your } \\
\text { experience with this model? } \\
\text { Tell me about the process involved to prepare any text for use in a session. } \\
\text { Probe questions: } \\
\text { Do you prepare open ended questions about the text or do you let the } \\
\text { discussion develop holistically? } \\
\text { If yes - can you give me an example? } \\
\text { Has the way you prepare a text changed over time? Can you describe that to } \\
\text { me? } \\
\text { Has the way you direct and shape how the discussion occurs changed over } \\
\text { time? Can you describe that to me? }\end{array}$ \\
\hline 7 & $\begin{array}{l}\text { Reading aloud: } \\
\text { What was your experience of reading aloud before starting to facilitate } \\
\text { sessions? } \\
\text { Probe questions: } \\
\text { Did you feel that you needed to practice reading aloud before starting to } \\
\text { facilitate sessions? Can you elaborate on your response? } \\
\text { One of the aims of the 'Read to Lead' training was to provide 'in depth } \\
\text { intensive practice' in reading methods of GIR. Can you tell me how this } \\
\text { supported your development in reading aloud? }\end{array}$ \\
\hline 8 & $\begin{array}{l}\text { Facilitation tools: } \\
\text { Another aim of the 'Read to Lead' training was to provide you with 'practical } \\
\text { tools' to run groups. What 'practical tools' did the training provide you with? } \\
\text { What practical skills do you believe are important for facilitators of } \\
\text { bibliotherapy groups? } \\
\text { As facilitator of the group, you have certain status, authority and } \\
\text { responsibility for the conduct of the session. This gives you power to direct } \\
\text { and shape how the discussion occurs. How comfortable do you feel holding }\end{array}$ \\
\hline
\end{tabular}




\begin{tabular}{|c|c|}
\hline & $\begin{array}{l}\text { this position? } \\
\text { What other skills in this position of conducting sessions do you bring to } \\
\text { bibliotherapy groups? }\end{array}$ \\
\hline \multirow[t]{2}{*}{9} & $\begin{array}{l}\text { We've spoken about you 'reading aloud'. I'm interested in some other ways } \\
\text { you help group members engage with literature. Can you describe any? } \\
\text { Probe questions: } \\
\text { What differences do you see between reminiscing and reflection? } \\
\text { Can you tell me how these are part of your bibliotherapy sessions? } \\
\text { What makes the session special? } \\
\text { Can you tell me about one of your best sessions? } \\
\text { What about a session that didn't go so well? } \\
\text { How do you deal with such a challenge? } \\
\text { What sort of other issues have you had to deal with? }\end{array}$ \\
\hline & READING IN DIFFERENT THERAPEUTIC SETTINGS \\
\hline \multirow[t]{2}{*}{10} & $\begin{array}{l}\text { Since the training have you delivered a program? } \\
\text { If yes, what types of groups have you delivered the program to? } \\
\text { When did you last deliver the program? } \\
\text { Probe questions: } \\
\text { Which sorts of settings appeal to you to work with the most? Why? } \\
\text { Which sorts of settings do you feel least drawn to work with? Why? } \\
\text { What is most challenging about this setting? } \\
\text { What might assist you to feel better prepared to deal with groups in this } \\
\text { setting? }\end{array}$ \\
\hline & THE EFFECTS OF THE TRAINING \\
\hline 11 & $\begin{array}{l}\text { I'd like to find out how effective the 'Read to Lead' training was for preparing } \\
\text { you to deliver bibliotherapy sessions: } \\
\text { What was particularly useful in the training? } \\
\text { Were there any areas of content within the training you would like to have } \\
\text { had more guidance or time spent on? } \\
\text { Were there any areas of training content you felt were not helpful and could } \\
\text { be left out of the training? } \\
\text { Is there anything else you would have liked added to the training? } \\
\text { With your experience since, do you have any suggestions how this could be } \\
\text { done? }\end{array}$ \\
\hline 12 & $\begin{array}{l}\text { What are your main goals in facilitating bibliotherapy sessions? } \\
\text { What professional development do you believe might support you to achieve } \\
\text { this in your role as a facilitator of a bibliotherapy group? }\end{array}$ \\
\hline
\end{tabular}




\section{Appendix Three: Sample of transcription}

As discussed in Chapter 3.2.4: Data recording and storage, the below provides a transcription sample as provided by the transcription service (manually produced).

Q: How did you find your training related to your work?

R: I have a community liaison and marketing role and one of the focuses of that particular role was to try and explore how we could make contact with or offer something to people who we didn't consider generally to be regular users or client groups and certainly people with mental health issues was one of those identified groups where we know that they come into the library space and use a variety of different services there on occasions but as far as looking at it from a literature point of view, wasn't something that we'd ever been able to manage to do.

So the opportunity to be able to present a kind of package to the community mental health team and say look, I've learnt all about this, be able to explain what had happened at the training in the State Library, so do you have anybody who you think that might be of interest to was really good. It actually worked very well because of the structure of it. Also having been auspiced by the State Library did help.

It actually was a more - whenever you're working in any of those environments you have to convince somebody in a management role that what you're doing is viable and valid. Having had that facilitator training down there and being able to explain clearly what the idea, having it all sitting there with a name to it made it a lot easier for me to start the program up with the mental health team as partner.

Q: What are the professional and personal characteristics you believe you bring to bibliotherapy?

R: Professionally I've had a real great interest in literature. I have - I read everything: non-fiction, fiction, classics, chip packets, anything. So because I have a fairly eclectic taste in literature I didn't find selecting things, which were probably outside what you'd usually be giving people in a reader advisory situation difficult. Personally I'm not sort of nervous around people who have got mental health issues. So the idea of being in an environment where people were a little bit unstable didn't trouble me too much.

I know that we had some of our other staff sit in on the sessions, on occasions, and they were really quite uncomfortable because they were nervous about how the dynamics of the group could go and how they can change. I don't find that too challenging. I also have a fair deal of confidence in the professionals who I was working with as well. So I was able to sit back when things weren't within my sphere of control and quite happily let someone else take over without feeling too pressured to get involved. So yeah, that would be about it.

Q: Had you had any past personal or professional experience with people experiencing mental illness?

R: Yeah, but quite a way back. I nursed when I first left school and did a psych component with that, but that was back in the '70s so it's a fair time ago. I suppose I've also had a lot to do with hospitality. I barmaided and worked in those kind of environments for decades. So you get to see a lot of people who 
are not necessarily floating along on an even keel. So yeah, the whole idea of being around people with a variety of mental health issues was something l've been peripherally involved with through some of my other work and had had some training when I first left school.

Q: Do you think the training prepared you and assisted you to feel confident further than that with working with groups with mental illness?

R: I'm not sure that it did. The idea of the reading style certainly was something I wouldn't have figured out on my own. The slow, measured way of adapting my speech patterns to make it easier for somebody who, perhaps, is struggling to understand, that was useful. The rest of it was probably not anything startling or new to me.

Q: When you say matching your speech patterns to the group, can you explain that a little more?

R: The idea of slowing down and creating pauses or empty spaces in the delivery was - I couldn't quite see why you would do that but when I actually started doing it in a group I found that given enough time there was quite often responses, which wouldn't have come out if I had just kept reading. That said, on occasions it's quite obvious that people are just enjoying the flow of language rather than wanting to comment on it. That, perhaps, would be obvious in the difference between perhaps, reading a poem where you may stop at the end of a stanza and perhaps will repeat the entire piece at the end of the you know, you read it through and then after people would like to read it again.

Or I've discovered sometimes I will read it through and then somebody else will want to read it again if I'm working with a group that's fairly high functioning. That delivery pattern changes when you read some prose. For example, there's a piece that we've read called The Wasteland by Frank Dalby Davison. That has been - it's a beautiful flowing piece of literature and people don't like you to stop because it has its own rhythm and tempo that goes through it. It's quite a lengthy piece. So, depending on how what you're reading, that concept of slowing down, making it quite - focussing on the actual words rather than the melody, if that makes any sense.

Q: Would you say the way you deliver a session has changed from your experiences?

R: Yes. Yes, there's a couple of different reasons for that. We've had a group of clients who have been ongoing now, I think we're into our third year, possibly coming into our fourth year with them and they've got to know us quite well. I say - I'm talking about myself if I've got the opportunity and the mental health team who have been working with delivering the program in three of our branches, and you learn when you walk into a room perhaps to go okay today we're probably better off just reading pieces out of the newspaper or today we'll read something a little bit heavier.

You get to know the clients quite well and while we do set what we read, to a point - we sort of try to avoid things about domestic violence, dead children, sick animals are a bit problematic as well - sometimes there is a request of kind of like an interest in those sorts of topics but you must let the group drive it. So there's a lot of - it hasn't - I went in thinking that it was quite a serious thing that I was doing and that has changed over the course of my experience with it 
but this is a particularly high functioning group of individuals as well, rather than people who are perhaps in a bit more trouble with their mental health. 


\section{Appendix Four: Training manual contents}

The Reader Organisation's training for Get Into Reading is entitled 'Read to Lead' in the UK but was rebranded as the 'Book Well' program in Australia and is referred to as 'Book Well' training in this study. The 41 page training manual (2010, unpublished) for the 'Book Well' training comprised mostly photos, case studies and reading suggestions but also addressed practicalities of delivering the Get Into Reading program and the different settings in which it was delivered in the UK. The contents listing is as follows:

- What is Get Into Reading? (pp. 4-5)

- Read to Lead Aims and Objectives (p. 6)

- The Roots of The Reader Organisation (p. 7)

- Maximum Pleasure, Minimum Stress: Case Study (p. 8)

- Reading Aloud (p. 10)

- Choosing Materials (p. 11)

- What Makes a Get Into Reading Text? (p. 11)

- Starter Pack: Thirteen Sessions (pp. 12-14)

- Facilitation Skills (p. 15)

- Preparing a Text (p. 15)

- Reading "Markheim" by Robert Louis Stevenson (pp. 16-17)

- Reading "Beyond Decoration" by P J Kavanagh (pp. 18-20)

- Community and Support at Together Women: Case Study (p. 21)

- Reading in Acute Mental Health Settings (pp. 23-24)

- Reading with People with Dementia (pp. 25-26)

- Reading with Older People: Case Study (p. 27)

- $\quad$ Reading with Young People (pp. 28-31)

- $\quad$ Reading with Young People: Case Studies (p. 32)

- Reading with People from Racial Minority Backgrounds (pp. 33-35)

- Reading Shakespeare (p. 36)

- Jelly and Ice-Cream: Case Study (p. 37)

- Cascading Training: Positioning Statement (pp. 39-40)

- Keep in touch (p. 41) 


\section{Appendix Five: Coding framework}

As discussed in Chapter 3.2.5.1: coding and theme development process, the below table provides the coding framework used in this study.

\section{Biblio}

1.1.1 Did they find and use the suggested texts?

1.1.2 Did the suggested texts engage their groups?

1.1.3 What were they looking for when selecting texts of their own?

1.1.4 Why?

1.1.5 Call for more biblio knowledge

\section{Therapy}

1.2.1 Preparing a text

1.2.2 Preparing questions

1.2.3 Interaction

1.2.4 Developing discussion

1.2.5 Asking questions

1.2.6 Pausing and silences

1.2.7 Deeper level of engagement

1.2.8 Call for more therapy knowledge

1.2.9 Lack of confidence within a therapeutic context

\section{Delivery}

2.1 Audiences

2.1.1 Group members

2.1.2 UK / AUS context

2.2 Model

2.3 Shared reading

2.4 Pausing

2.5 Dividing points

2.6 Stopping points

2.7 Reading aloud

\section{Wellbeing}

3.1 Social connection

3.2 Community

3.3 Support networks

3.4 Being read to

3.5 Relaxing 


\subsection{Conversation}

3.7 Stimulation

3.8 Positive group member interactions

3.9 Opportunity to talk about things that are hard to talk about

\section{Facilitator}

4.1 Attributes

4.2 Skills needed

4.3 Leading a group

4.4 Understanding yourself

4.5 Coping with silence

4.6 Yourself as a listener

4.7 Personal skills that support facilitation

4.8 Previous experience

4.8.1 Mental Health

4.8.2 Teaching

4.8.3 Librarian

4.9 Partnership development skills

\section{Other data collected:}

- Research participants' definition of bibliotherapy

- Research participants' reasons for undertaking the training

- Research participants' goals for undertaking the training

- Research participants' organisation's goal of having a staff member undertake the training 